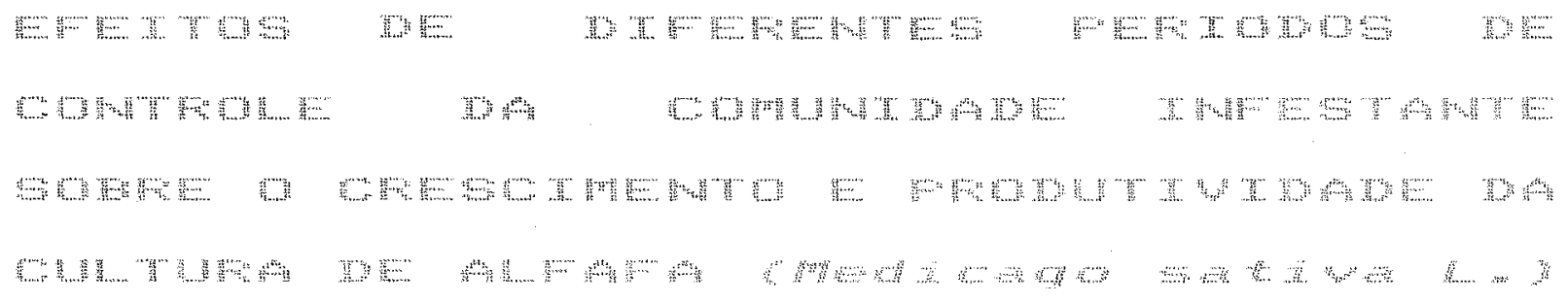

\title{
ROEINSON OSTPE
}

\author{
Wh

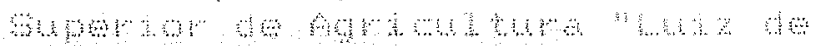

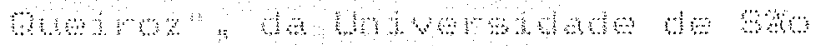

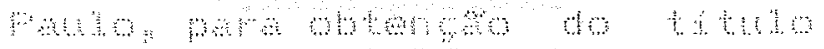

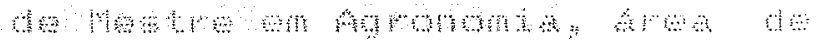

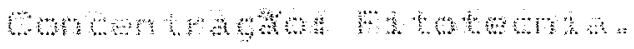

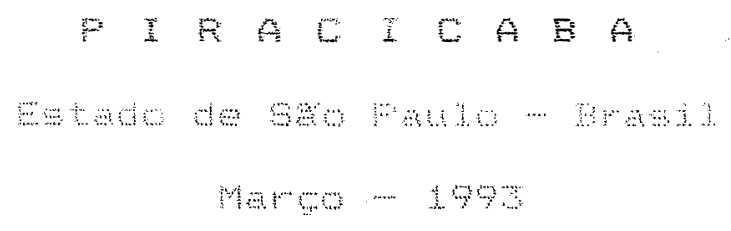


Ficha catalográfica preparada pela Seção de Livros da Divisão de Biblioteca e Documentação - PCLQ/USP

Osipe, Robinson

$082 \mathrm{e} \quad$ Efeitos de diferentes períodos de controle da comuninidade infestante sobre o crescimento e produtividade da cultura de alfafa (Medicago sativa L.). Piracicaba, 1993. $115 \mathrm{p}$.

Diss. (Mestre) - ESALQ

Bibliografia.

1. Alfafa - Planta daninha - Controle. 2. Planta daninha em Alfafa - Controle. I. Escola Superior de Agricultura Luiz de Queiroz, Piracicaba.

DDD 633.31 


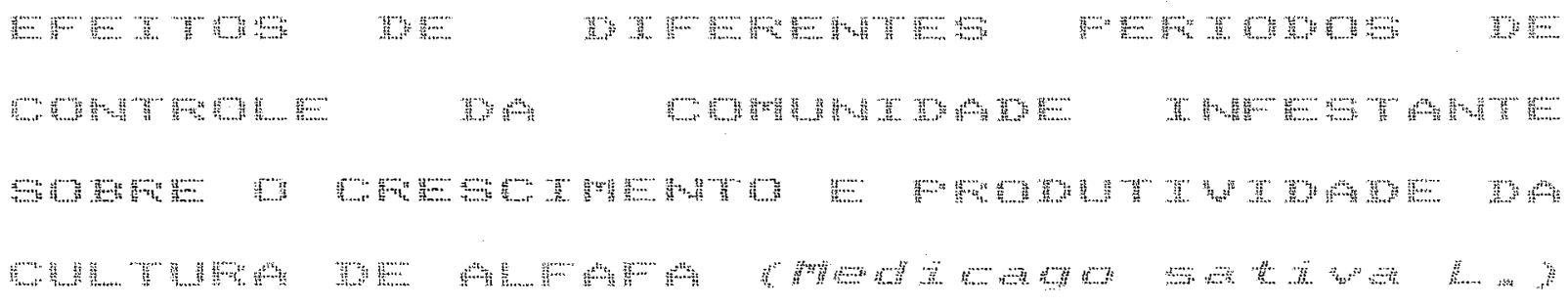

ROBINSON OSIPE

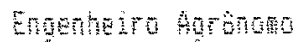

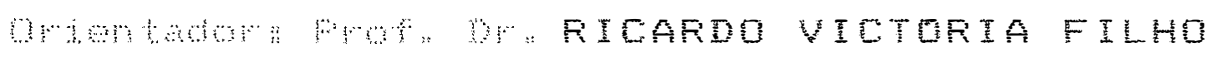

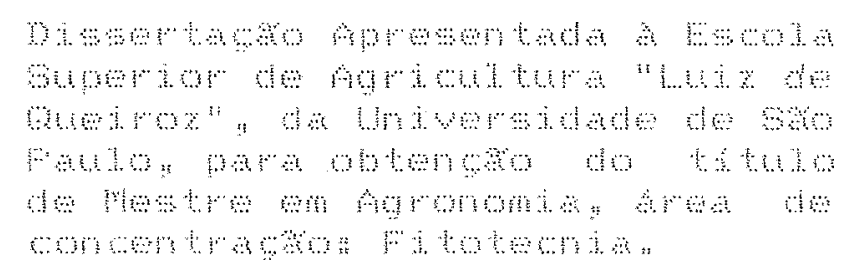

FIPAD兵

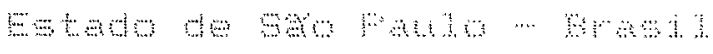

Mastor $19 \%$ 


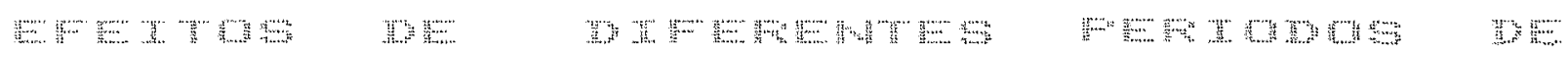

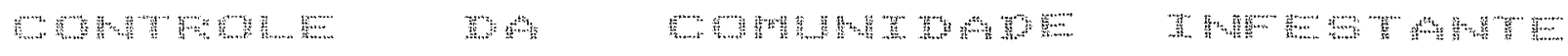

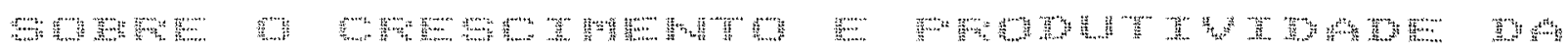
man

\section{ROBUTSUN OSTFE}

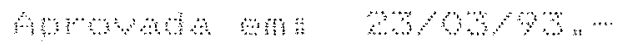

Hmand

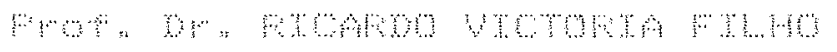

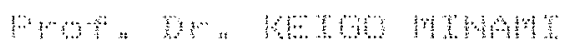

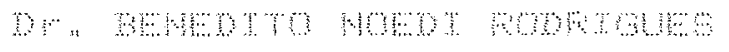

man

mon

Him

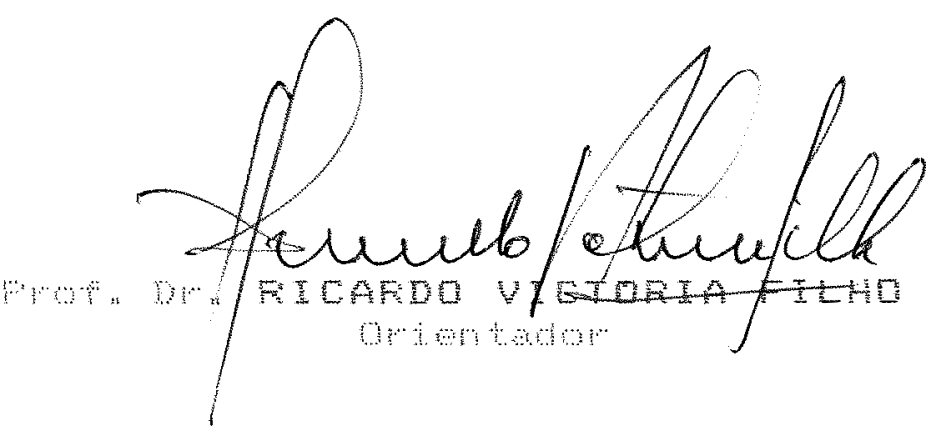


mon mas mas

FEDRO DPVA:

m.wmon

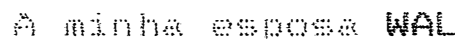

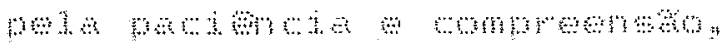

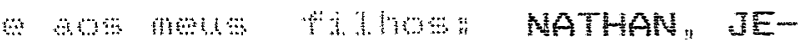
THFD: VINIS $\%$ FETFUS: WH म, का: 


\section{AGRADEC MENTOS}

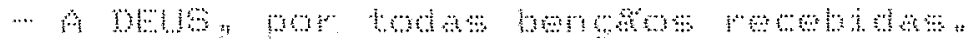

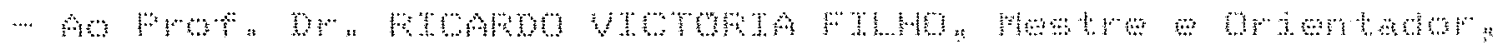
pelo

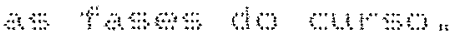

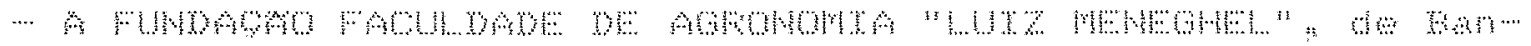

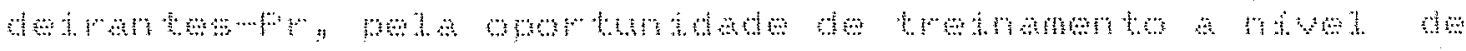

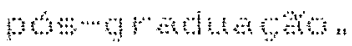

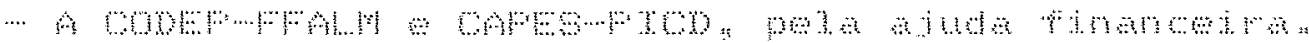

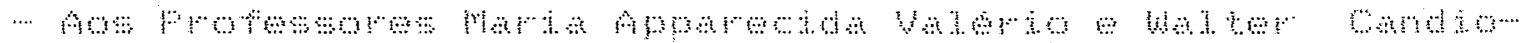

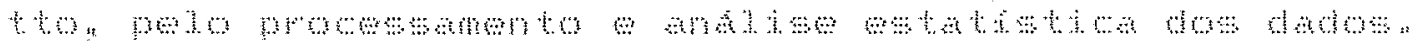

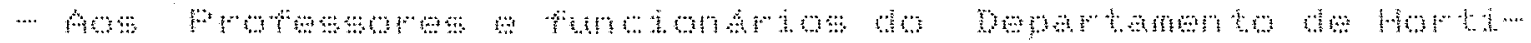

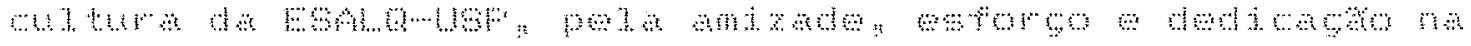

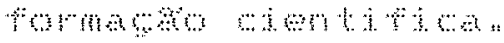

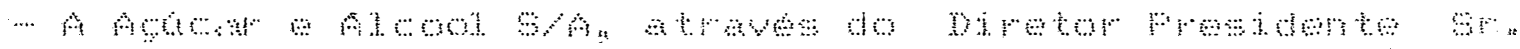

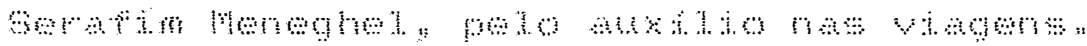

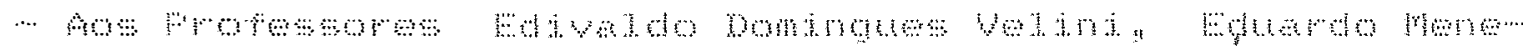

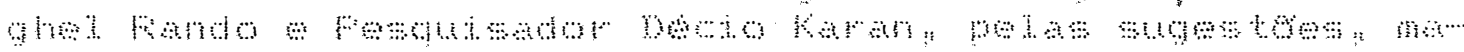
nम

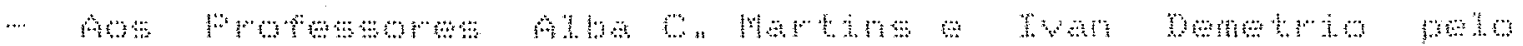

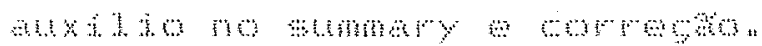

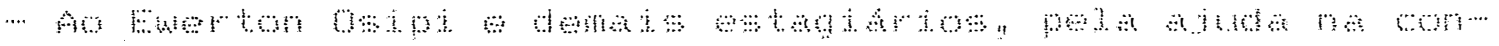

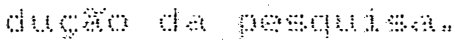

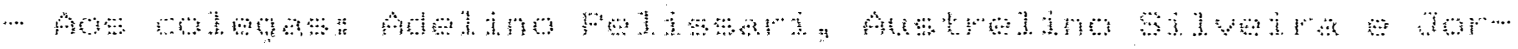

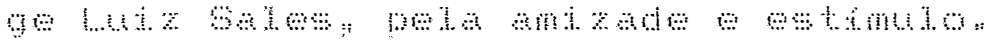

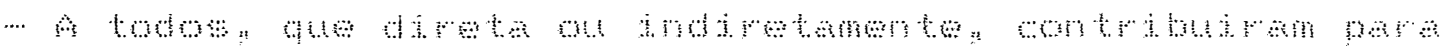

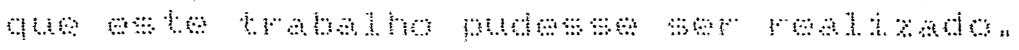




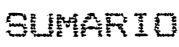

Hima

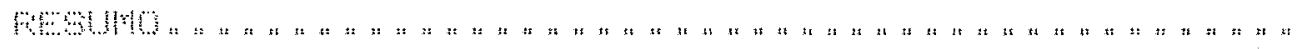

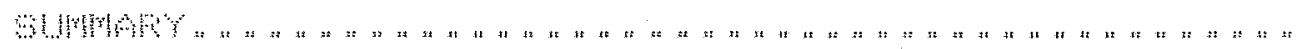

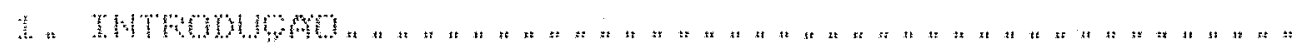

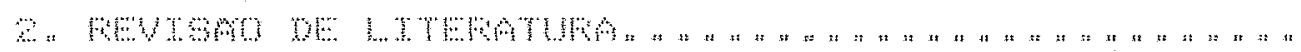

2.

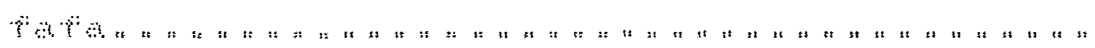

n-

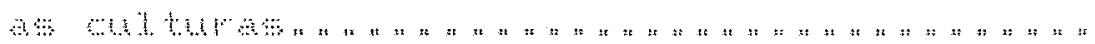

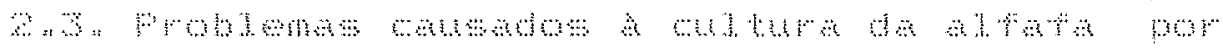

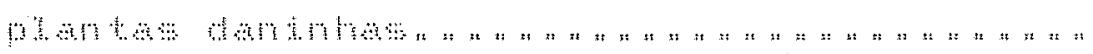

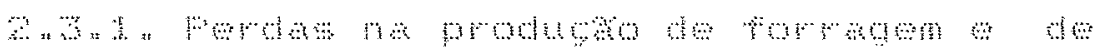

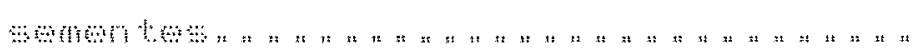

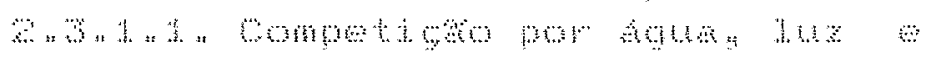

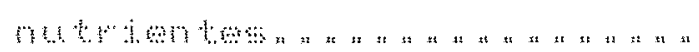

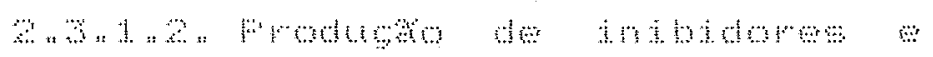

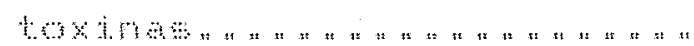

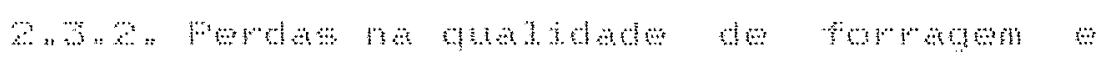
:

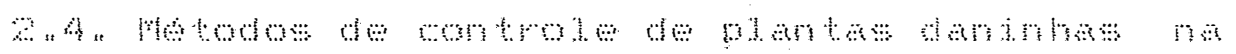
मे 
2. a

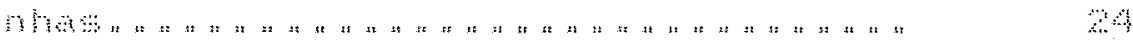

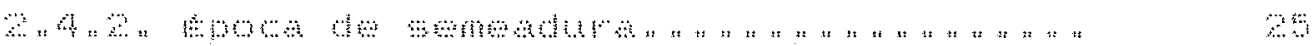

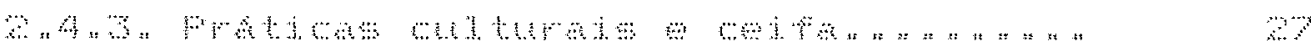

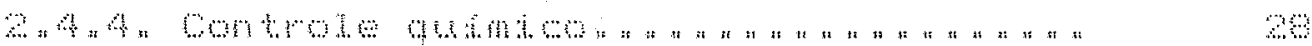

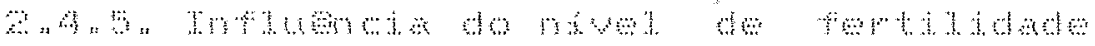

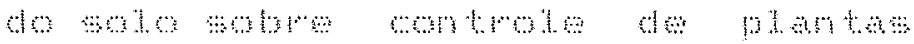
denthom

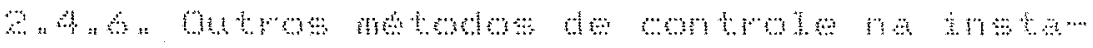

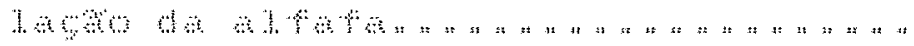

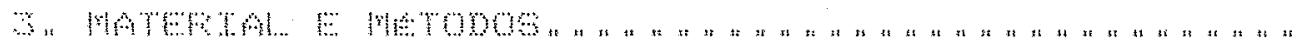

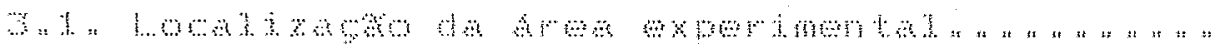

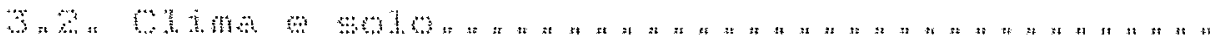

צ

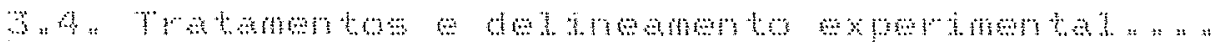

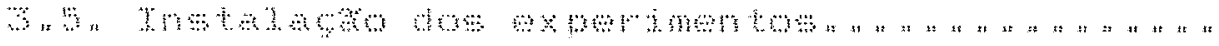

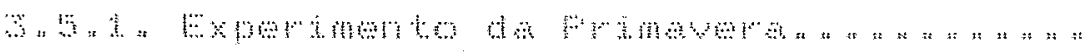

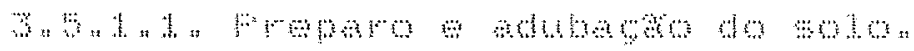

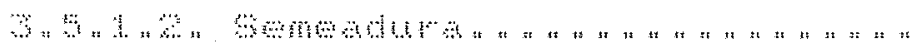

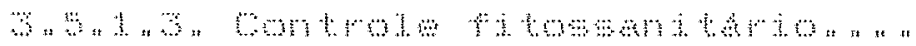

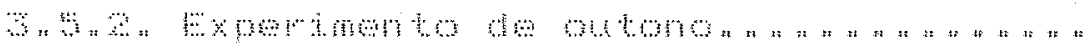

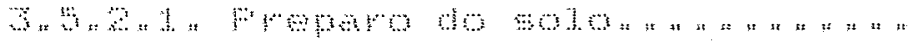

अ

अ

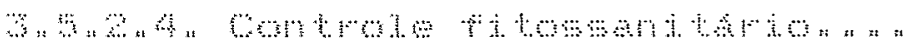




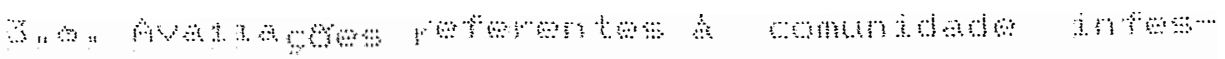

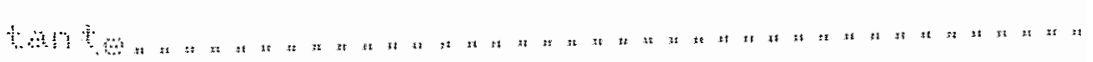

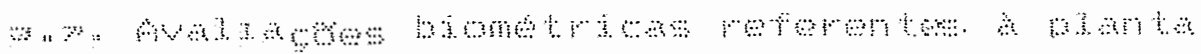

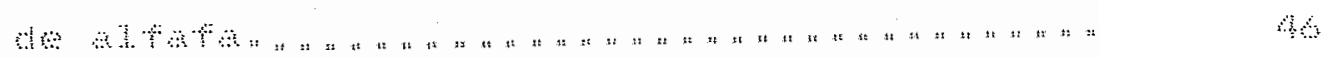

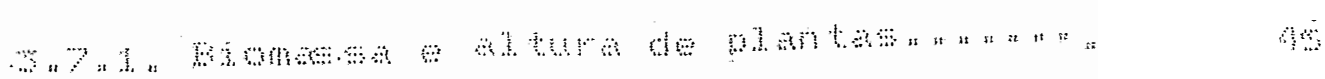

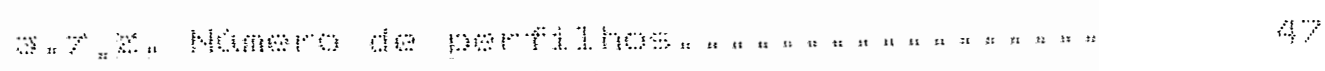

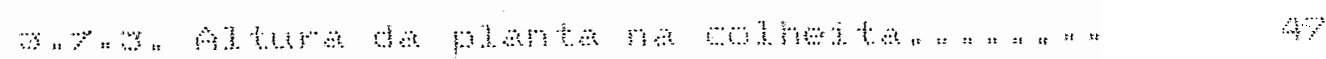

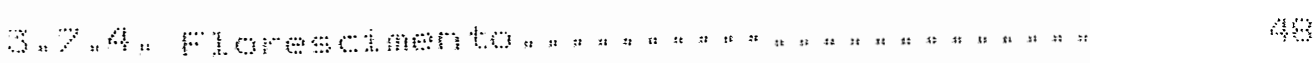

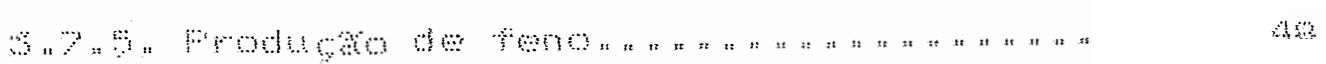

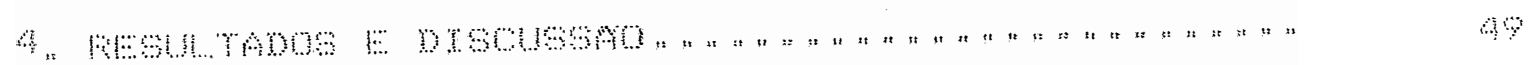

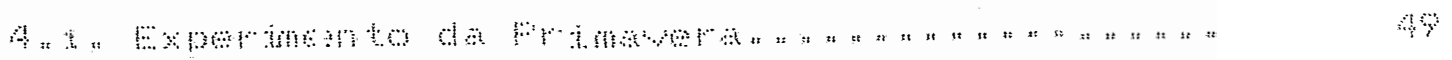

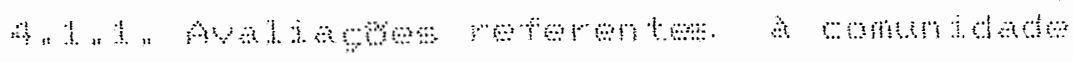

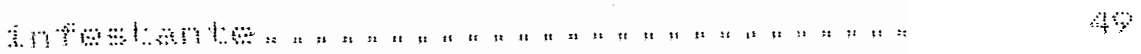

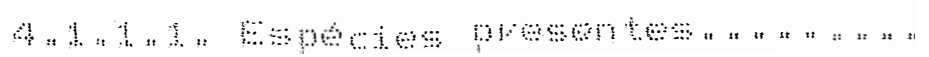

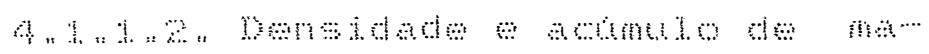

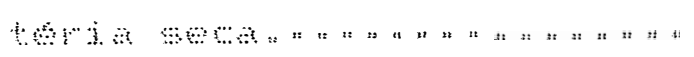

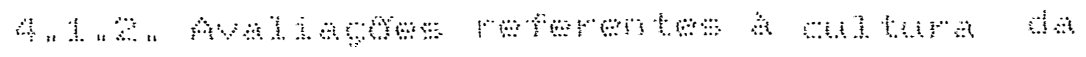

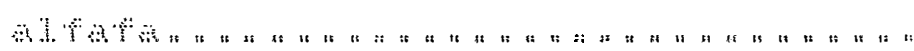

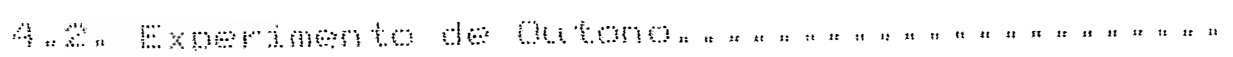

4 „2 "

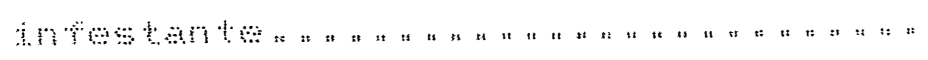

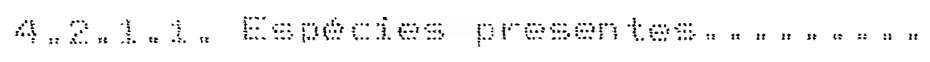

4 н

4. 
y i i

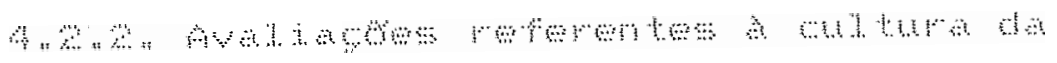

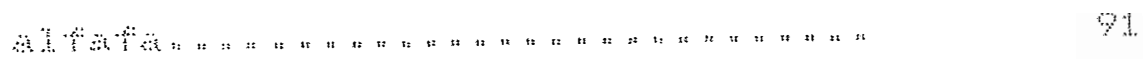

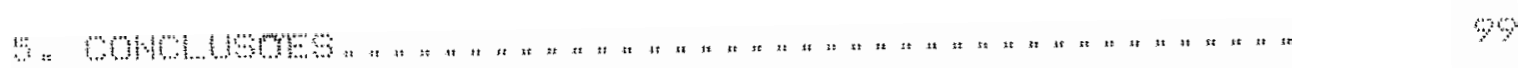

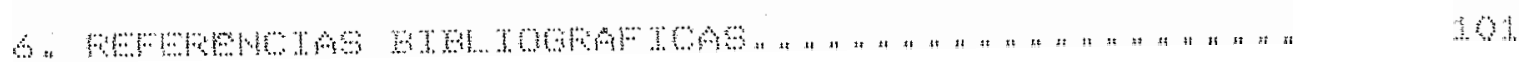




\title{
EFETTOS DE DIFEFEMTES FERIUDOS DE CONTFULE DA COMLNIDADE INFESTANTE SUBRE O CRESCIMENTE E FRODUTIVTDADE DA
}

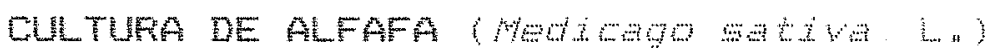

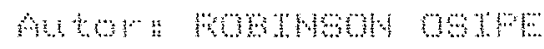

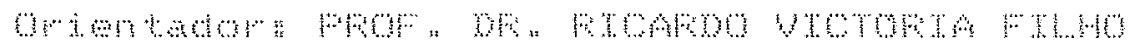

\section{FESUNO}

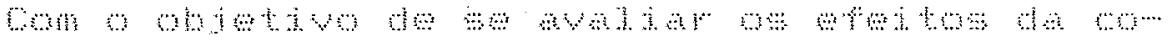

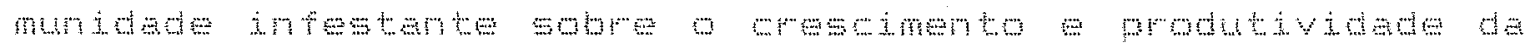

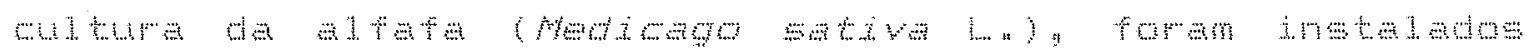

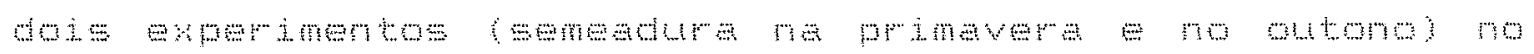

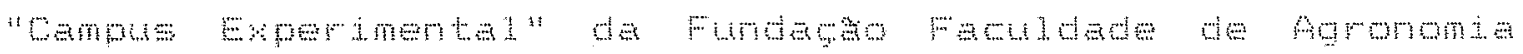

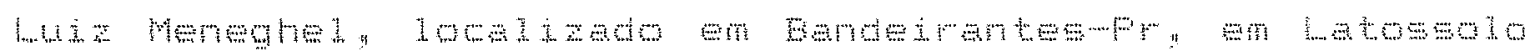
Hen

का then

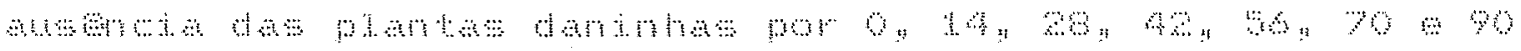

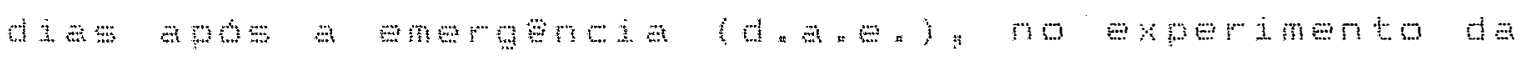

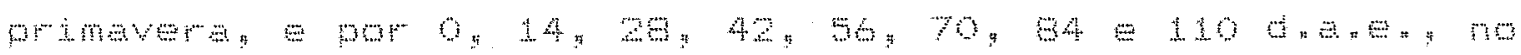

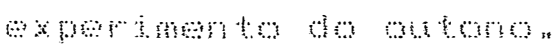

on 


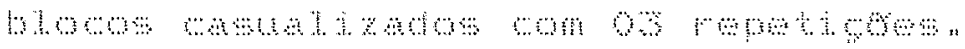

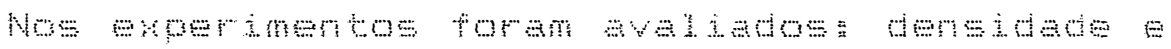
anmulo de mothin

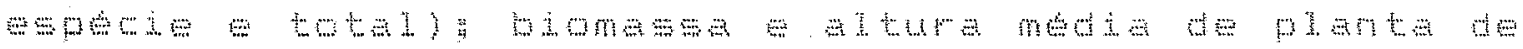

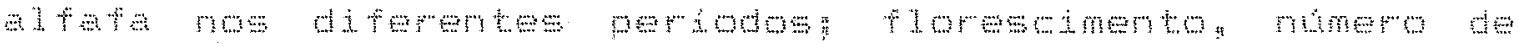

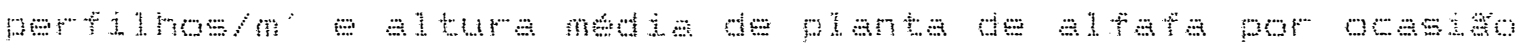

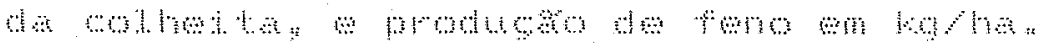

Nas -

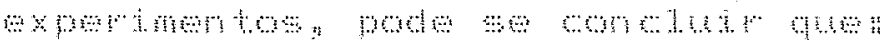

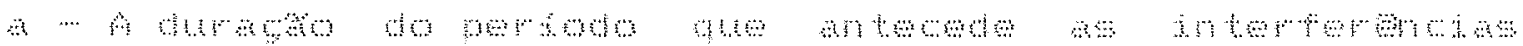

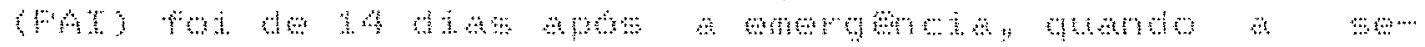

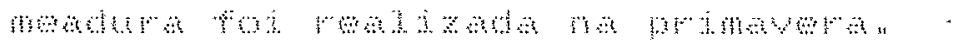

W ... क का

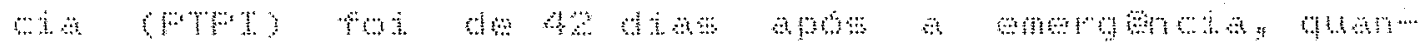

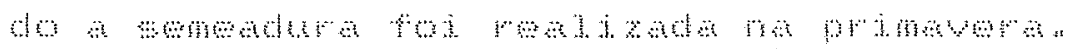

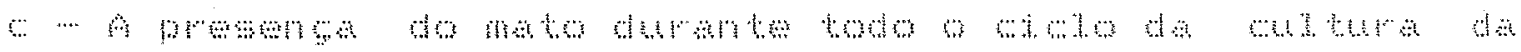

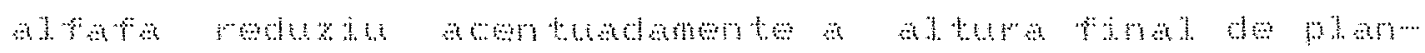

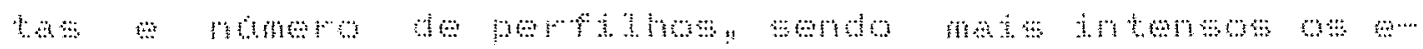

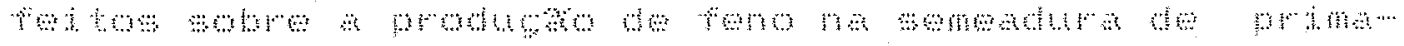
ग)

कнष m 


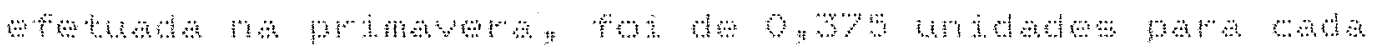

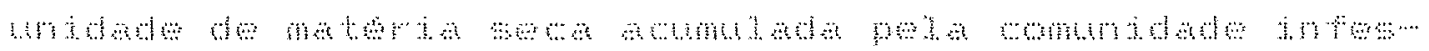
B.

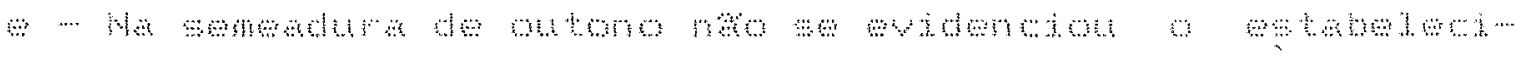

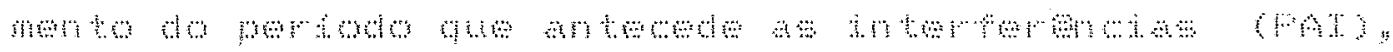

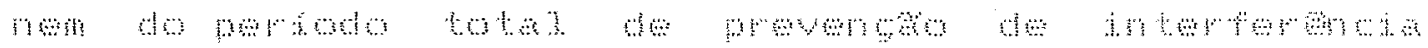
(w) ?

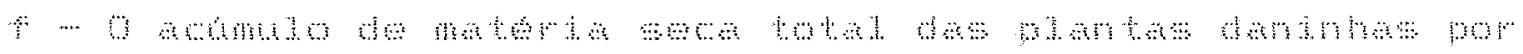

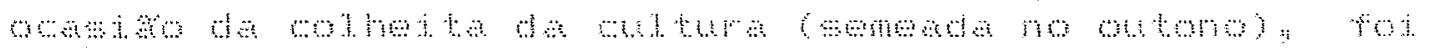
mand

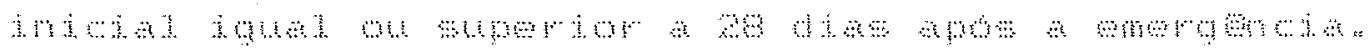




\section{EFFECTS OF OIFFEFENTS FEFIIDS OF \\ CONTFOL OF THE WEED COMUUNTYY \\ UFON THE GFOHTH AND YIELD OF ALFALFA}

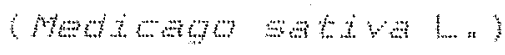

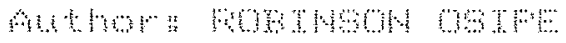

Adथ

\section{SUNAFY}

"म tow Furm,

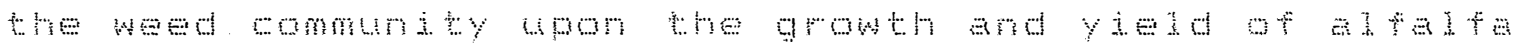

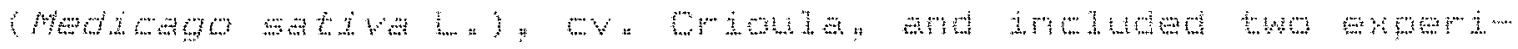
пюr atromm, The

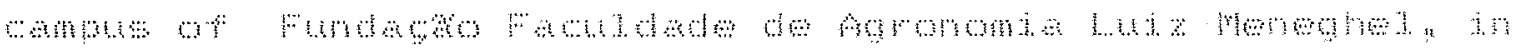
औym

M 8 का

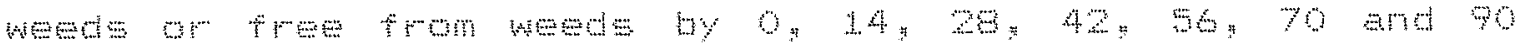

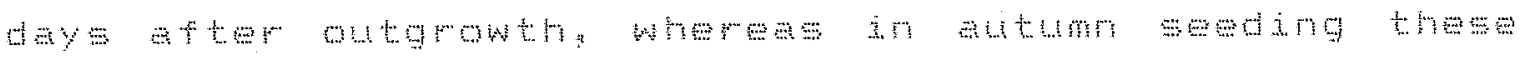

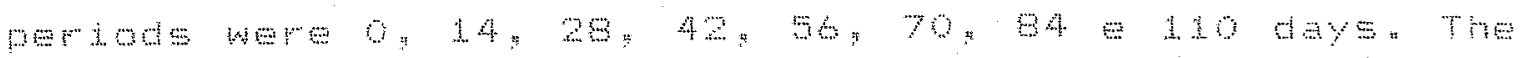

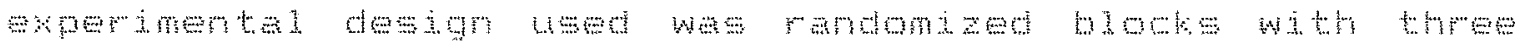

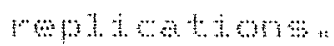




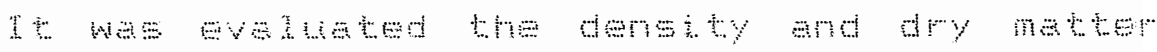

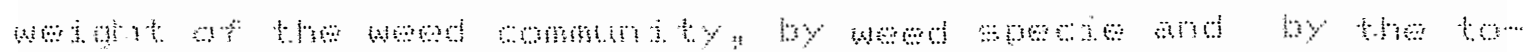

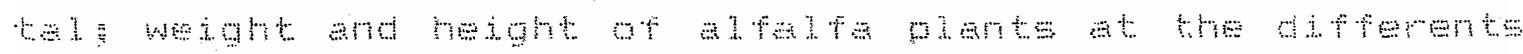

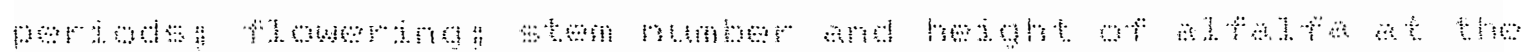

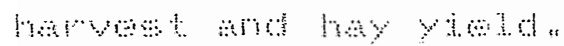

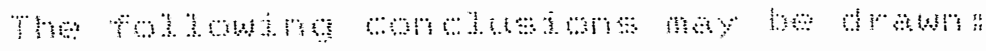

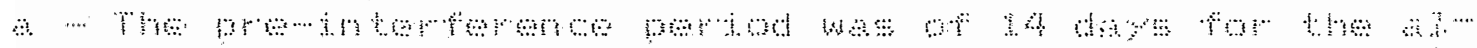

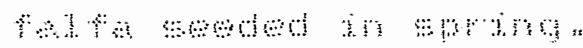

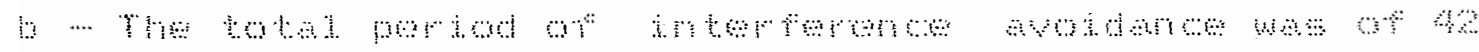

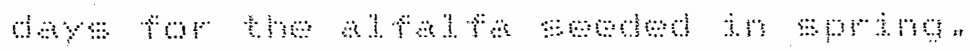

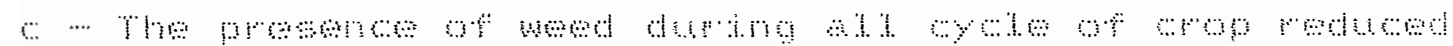

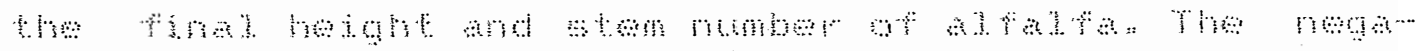

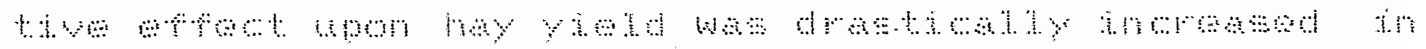

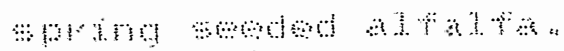

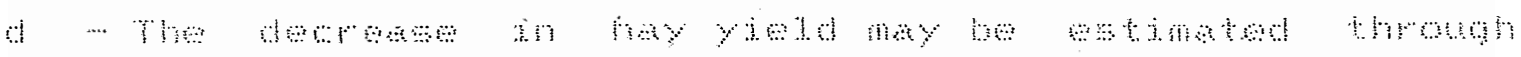

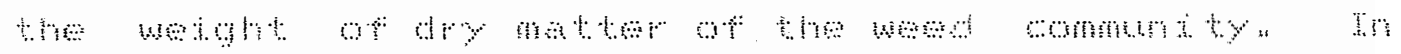
m

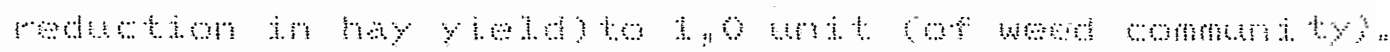
a - I

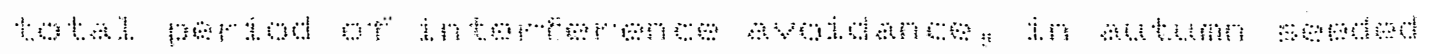
a.

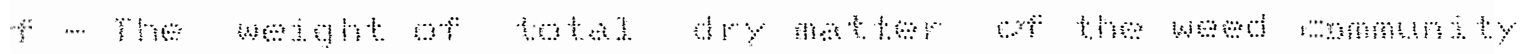

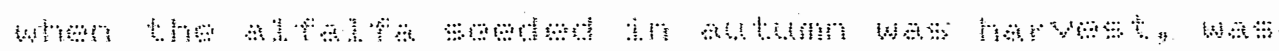

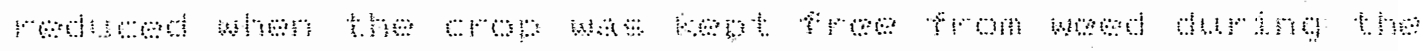
н. 


\section{I: MTRODLCFO}

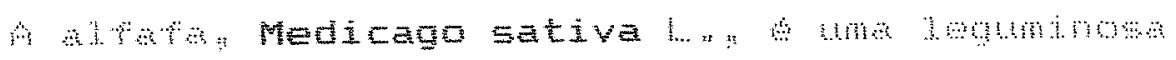

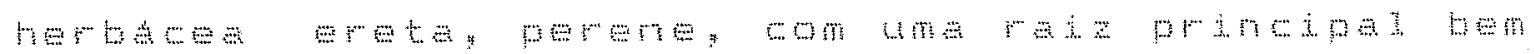
de

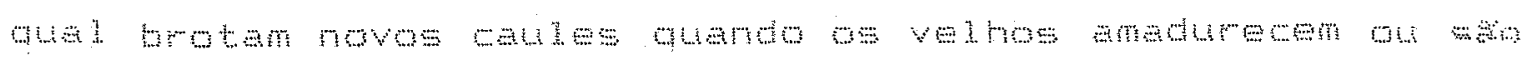
with

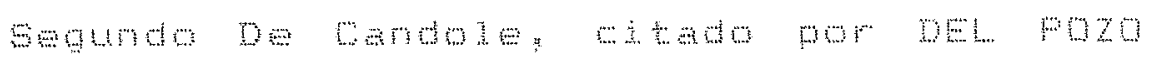

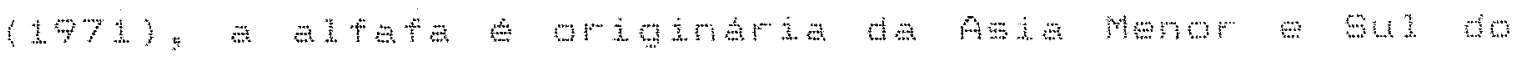

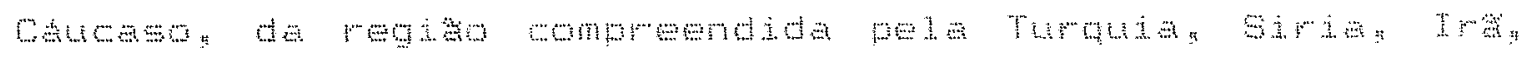

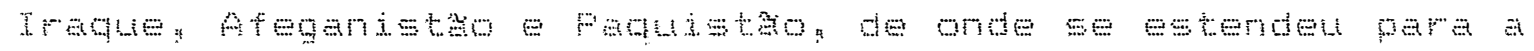

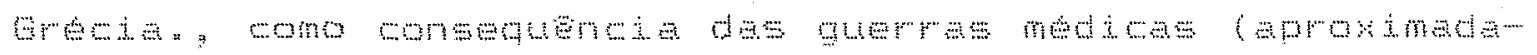

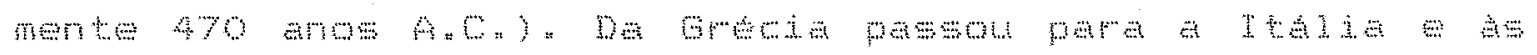

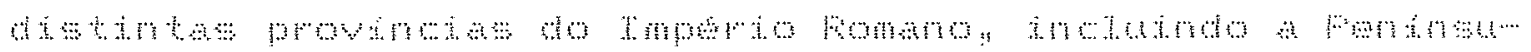

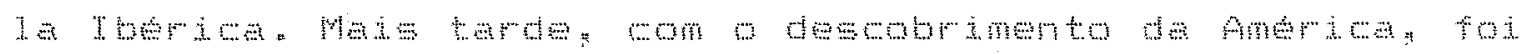

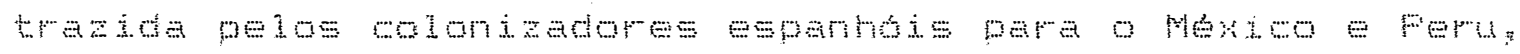

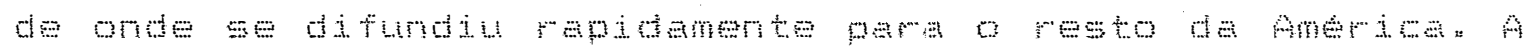

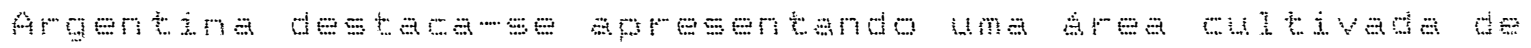




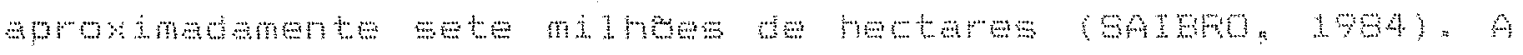

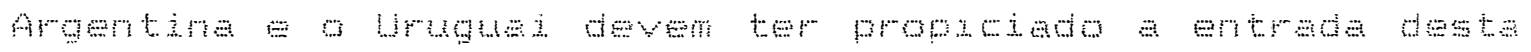

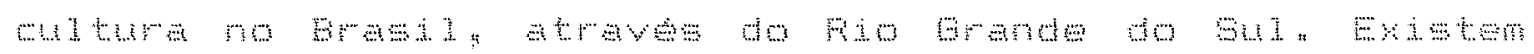
w

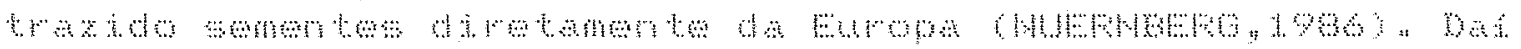
d

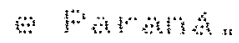

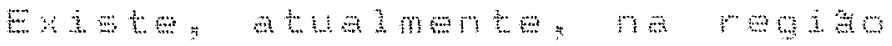
to

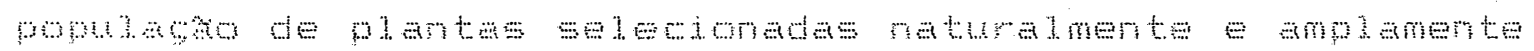

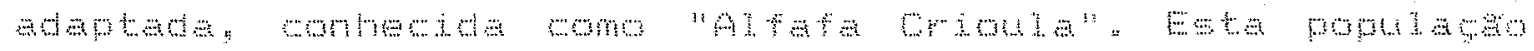

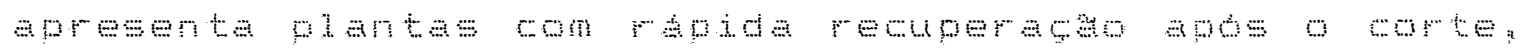

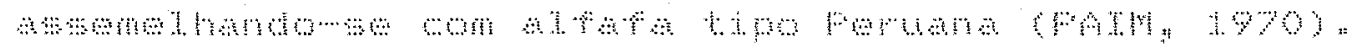

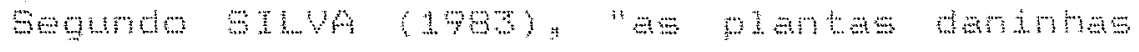

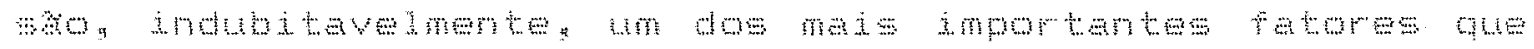

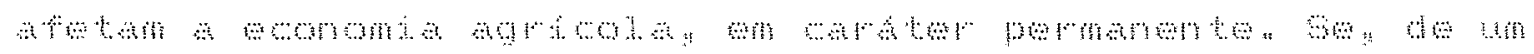
1

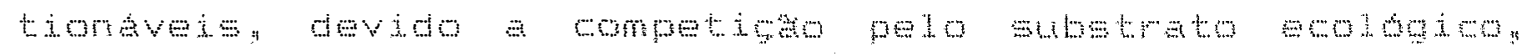

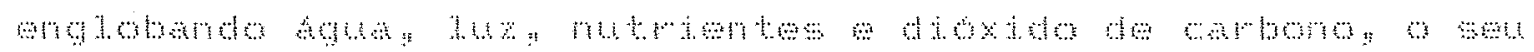

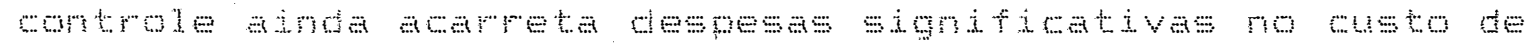

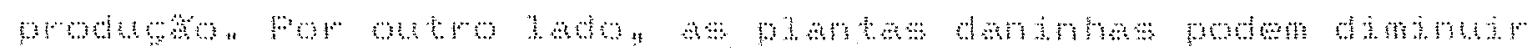

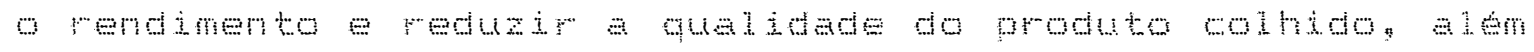

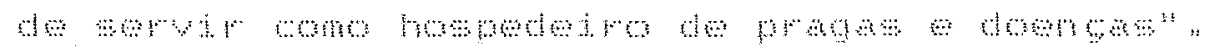

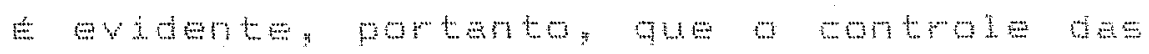

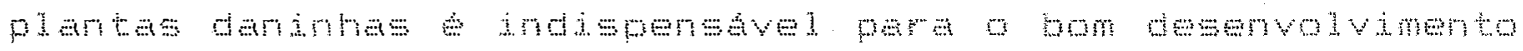

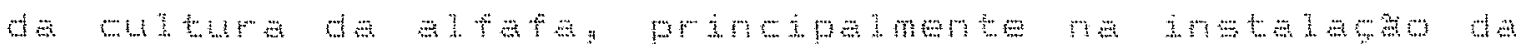




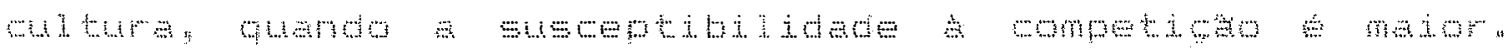

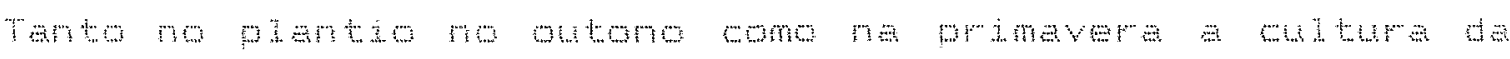

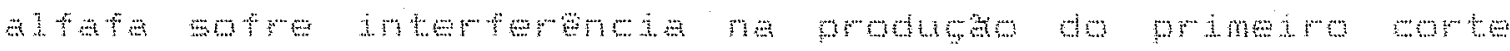

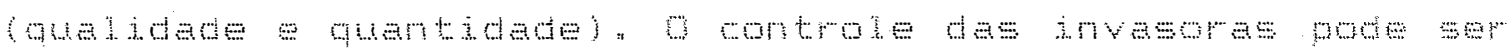

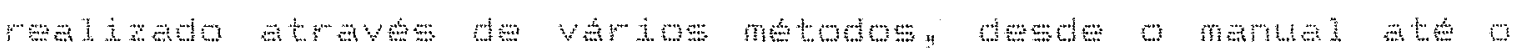

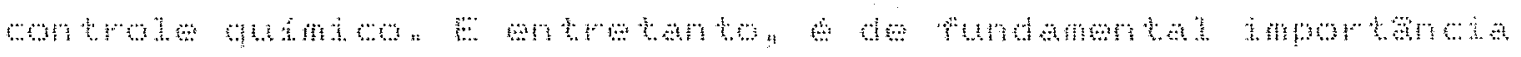
o monemento do periodo no qual a sua mosenga nas

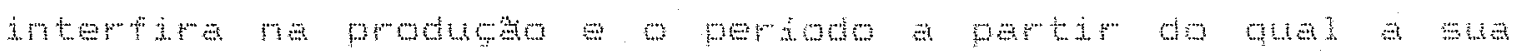

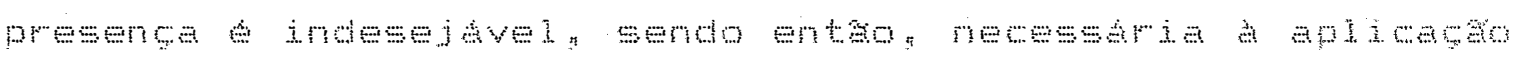

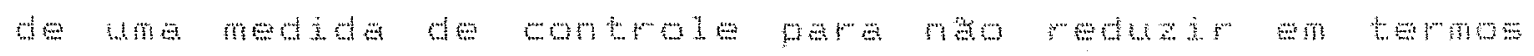

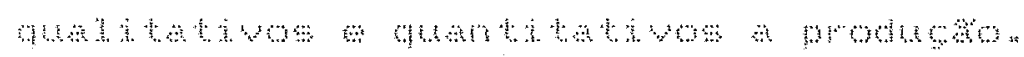

Frmin (1907) womente me na frea de emo

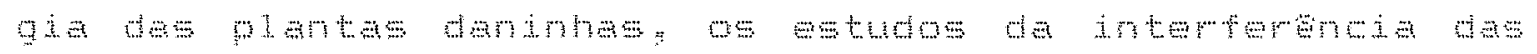
commidades intestantes sobm as cutrmas amicolas sempre

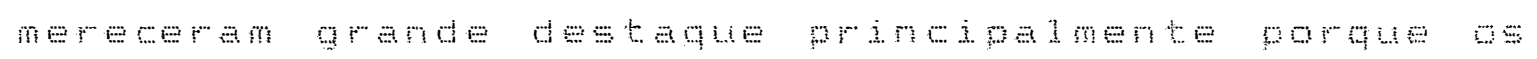
ment rem का manom a

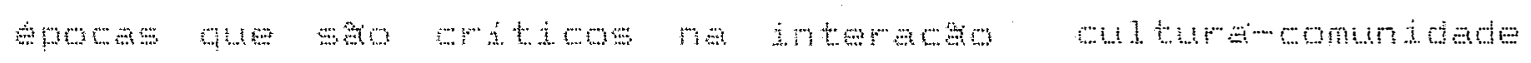

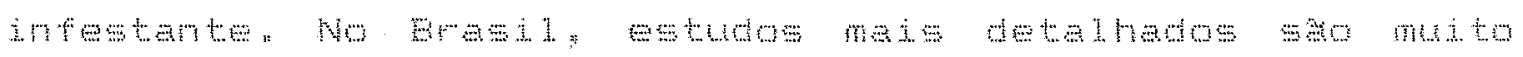

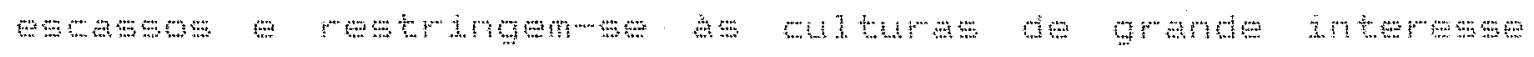

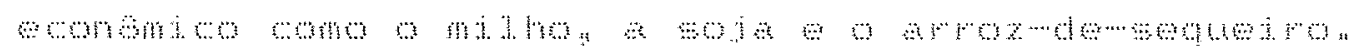

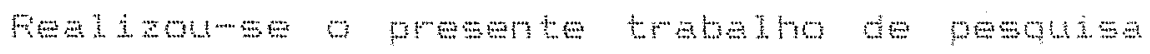

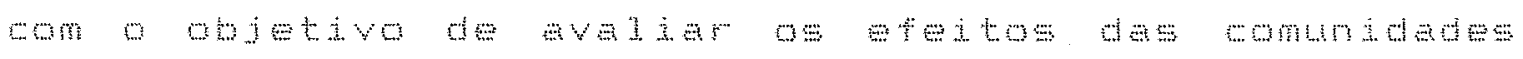

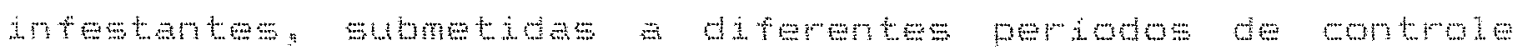

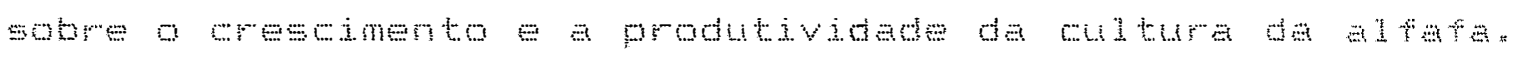

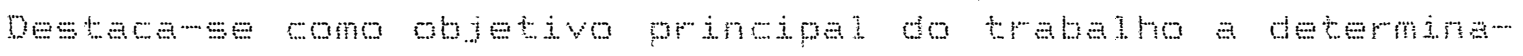




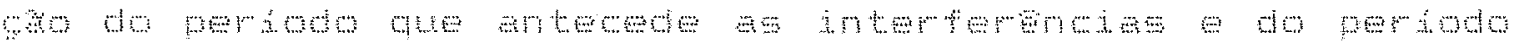

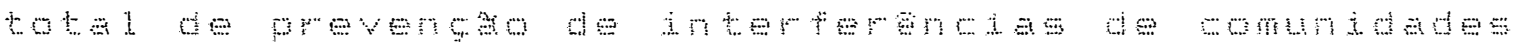
1.

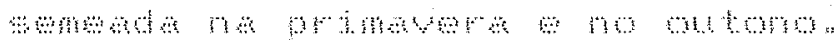




\title{
2. FEVISHO DE LITERATURA
}

\subsection{Consideragoes gerais sobre a cultura da altata}

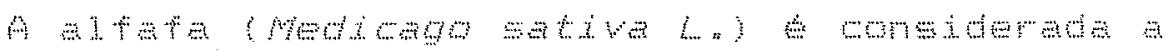

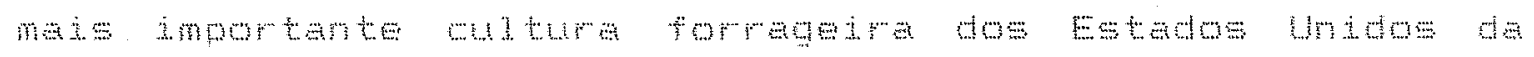

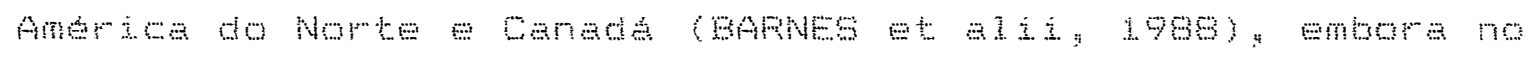

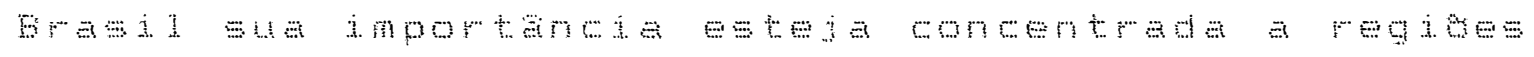

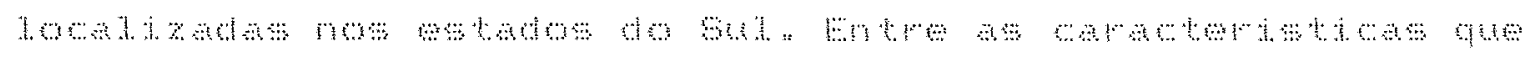

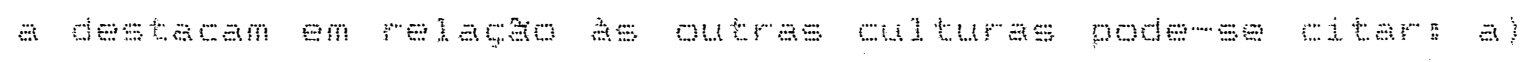

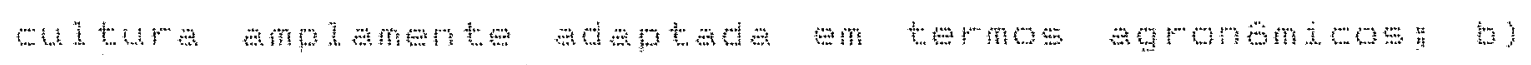

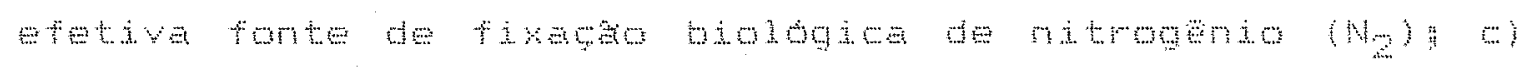

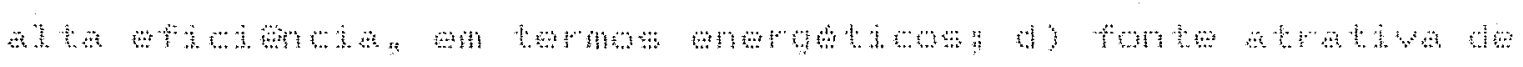

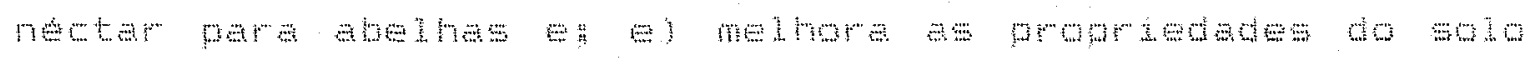

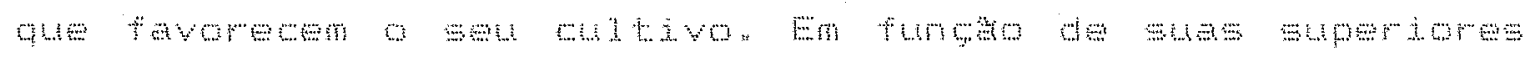

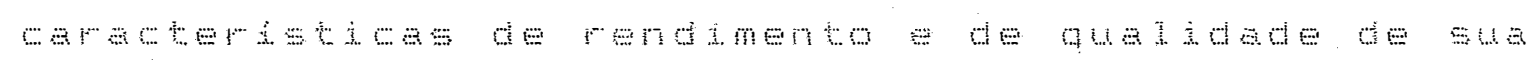

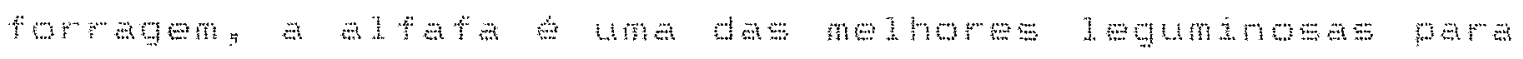

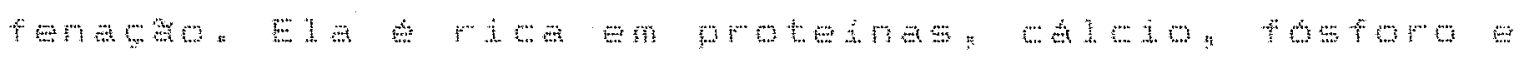

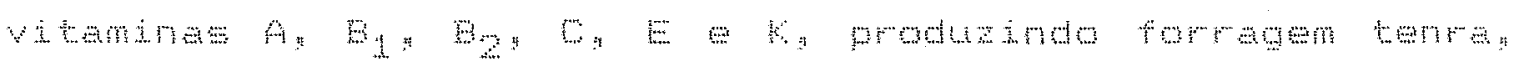

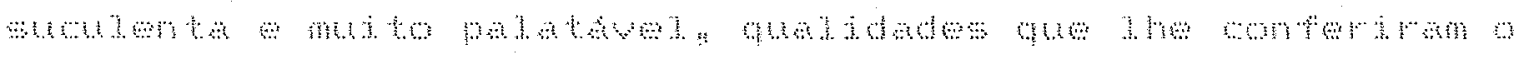

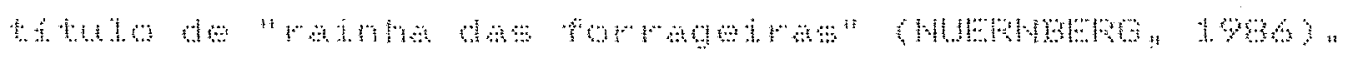




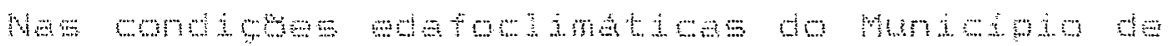

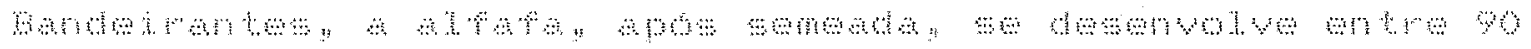

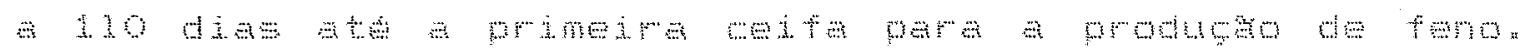

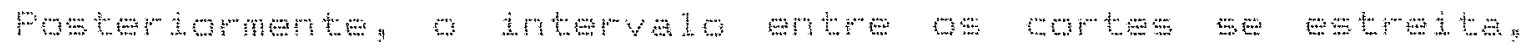

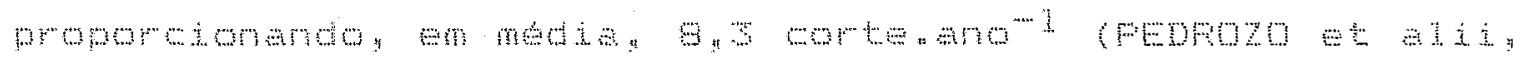

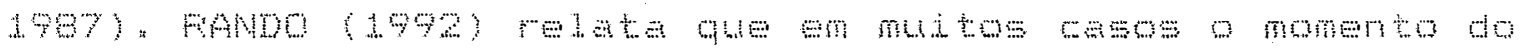

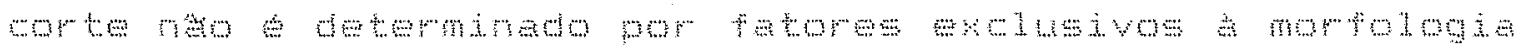

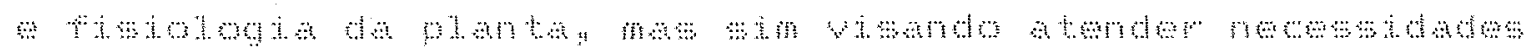

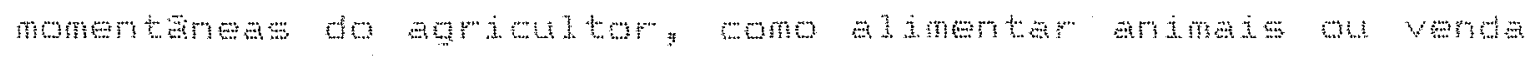

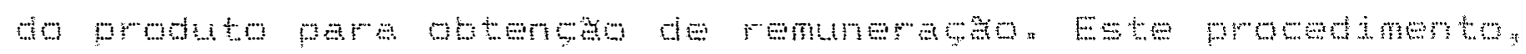

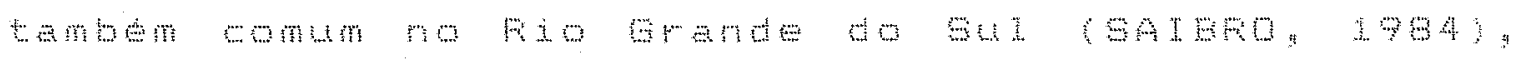

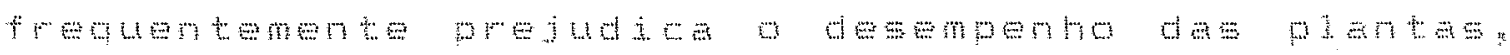

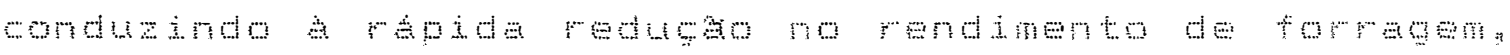

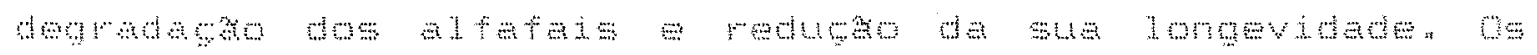

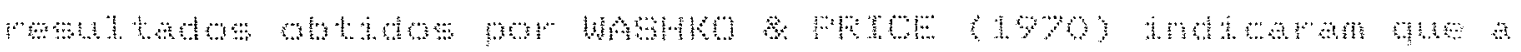

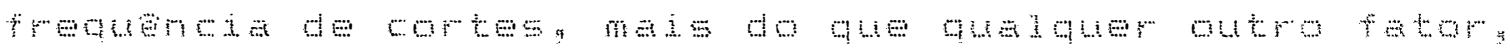
dm

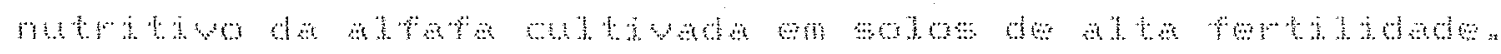

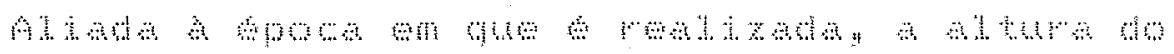

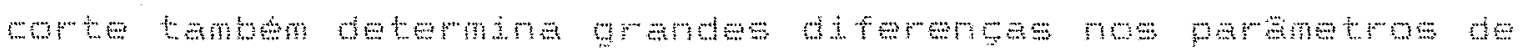

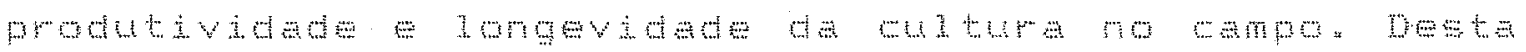

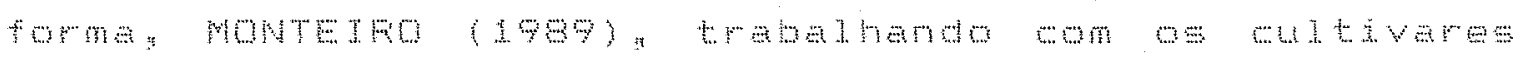

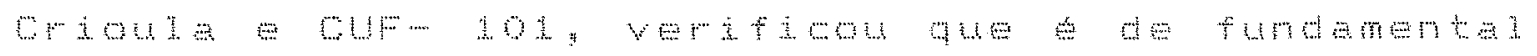
mpm

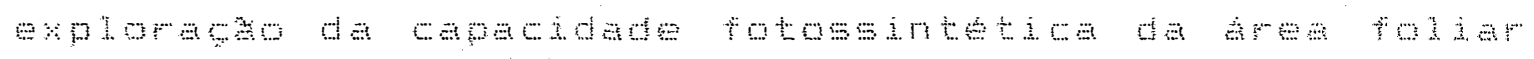

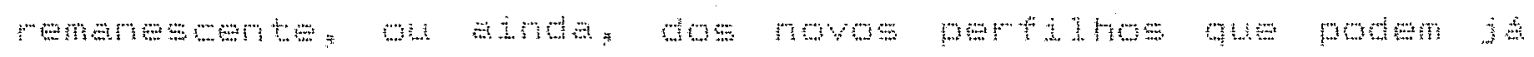




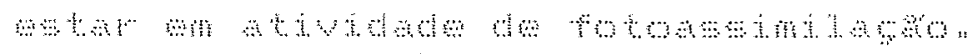

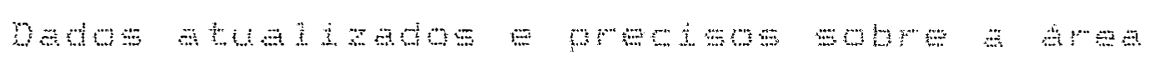

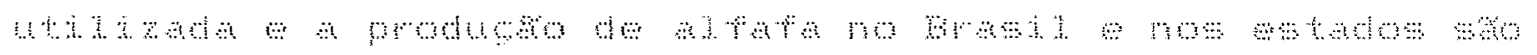

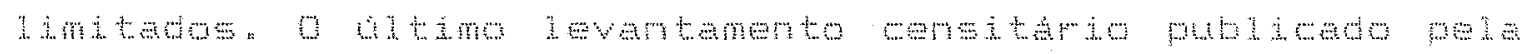

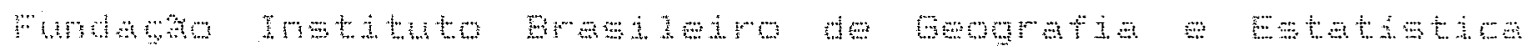

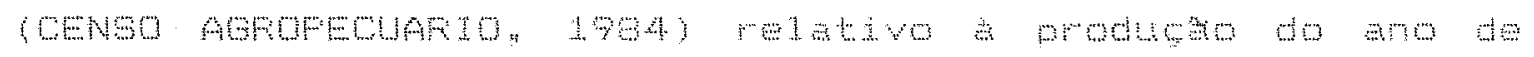

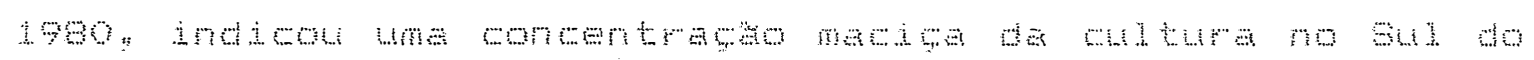

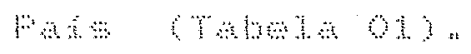

मnक

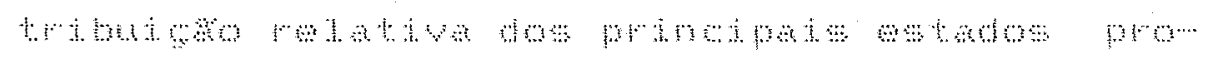

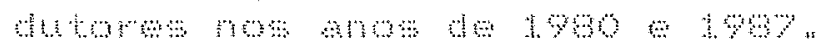

\begin{tabular}{|c|c|c|c|c|}
\hline \multirow{2}{*}{ Esatos } & \multicolumn{2}{|c|}{$1980^{1}$} & \multicolumn{2}{|c|}{$198 \%$} \\
\hline & rodusto & Contribusa & modusto & contribusto \\
\hline & $-\cdots \cdot \tan \cdots \cdots \cdots$ & $\ldots, \ldots \ldots \ldots \ldots$ & $\cdots \cdots+\tan \cdots \cdots \cdots$ & 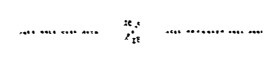 \\
\hline Fio orande do su & $n_{n}, 4 \Delta \mathrm{B}$ & 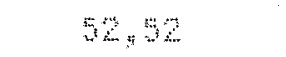 & $56=39$ & 67.66 \\
\hline marana & $3.40 \mathrm{~g}$ & 31,34 & $12=86$ & 1341 \\
\hline Santat catarine & 2,77 & 6,47 & $12=7 \%$ & 15,3 \\
\hline sas fato & 2.86 & 6,0 & 1,330 & $\$ 60$ \\
\hline Mines Gerais & 874 & 20 & a & $y_{0}$ \\
\hline ceara & 347 & 0,1 & $\ldots$ & $\ldots$ \\
\hline Do de and an & 319 & 0,74 & $\ldots$ & $\ldots$ \\
\hline mutros & 26 & 0,08 & 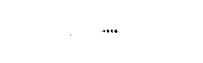 & $\cdots$ \\
\hline Total & 42,777 & 100,00 & 83.95 & 100,00 \\
\hline \multicolumn{5}{|c|}{ 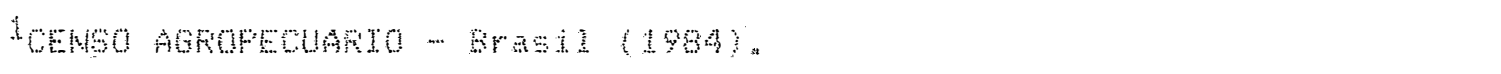 } \\
\hline 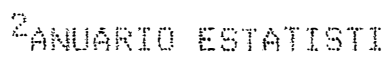 & no mest & $89 ?$ & & \\
\hline
\end{tabular}




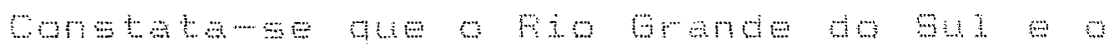

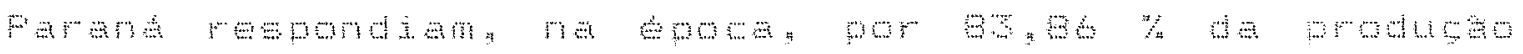

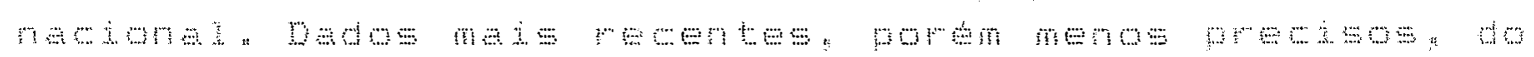

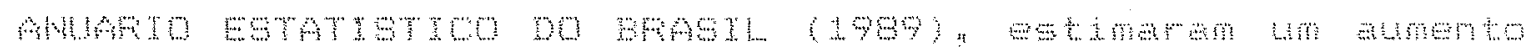
굴

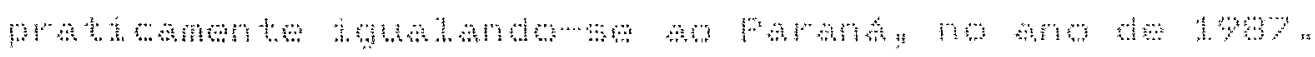

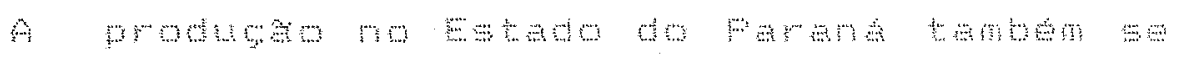

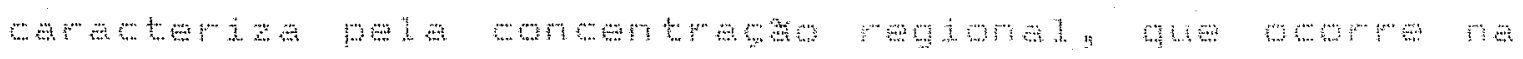

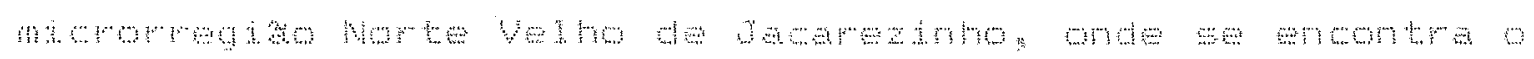

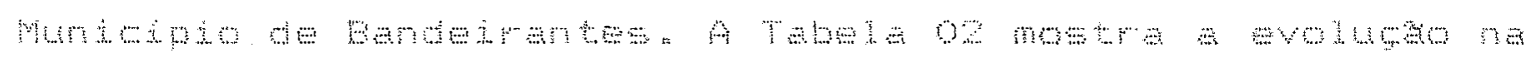
mWm

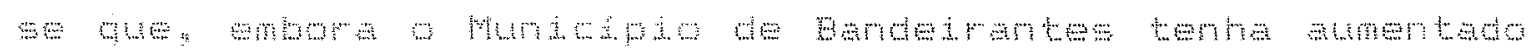

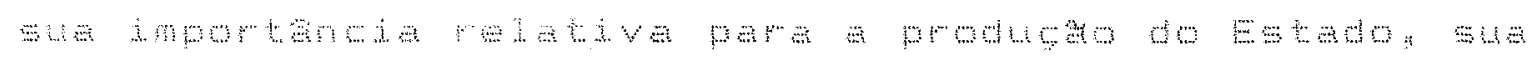

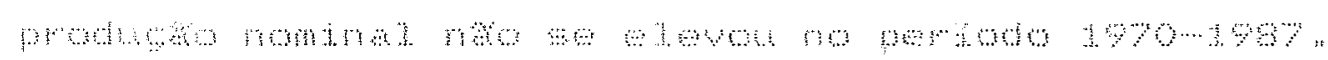

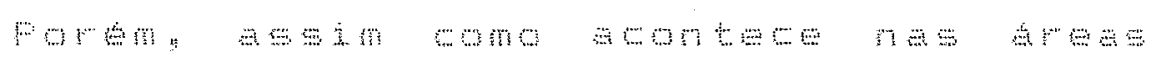

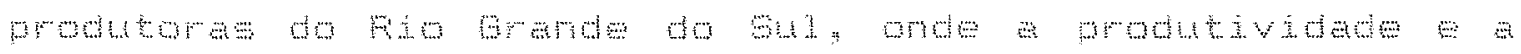
m

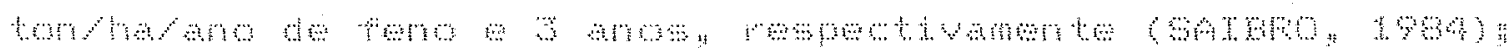
en mom

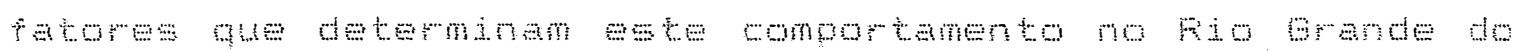

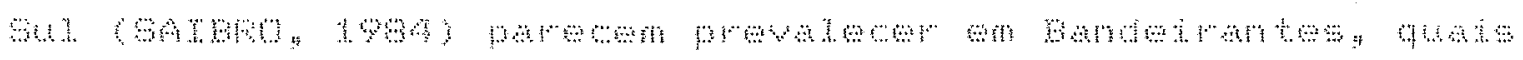
sw

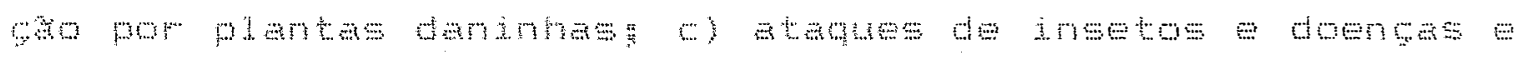

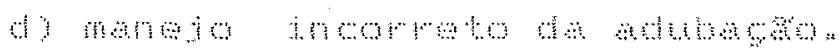


Taben क

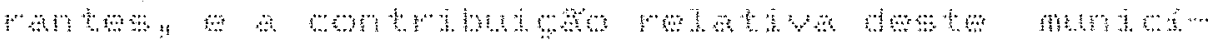

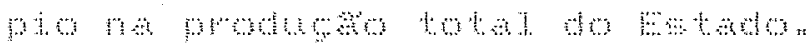

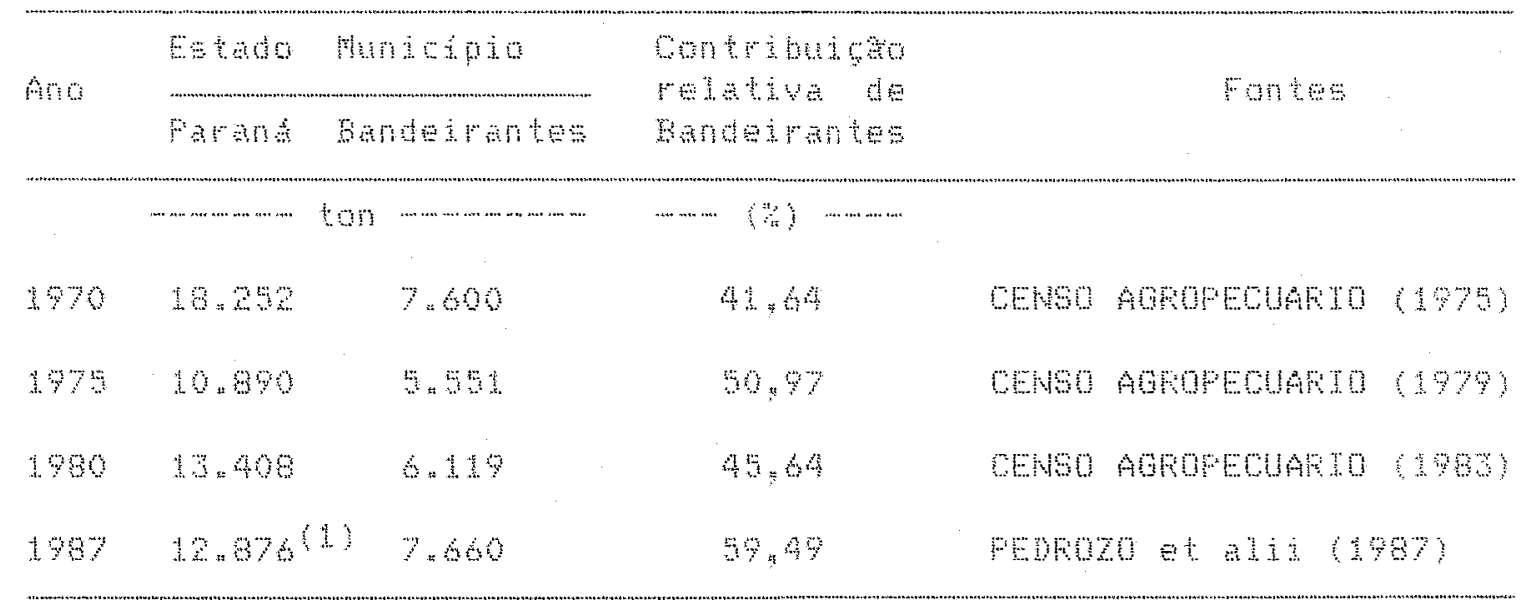

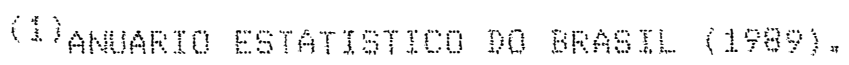

\section{$2=2$. Interterencia das plantas daninhas sobre as culturas}

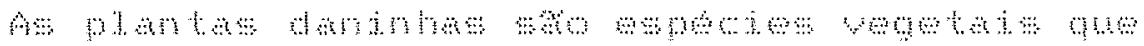

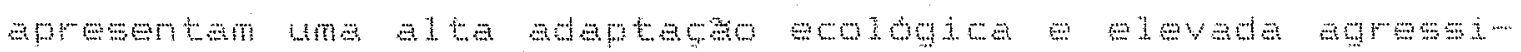

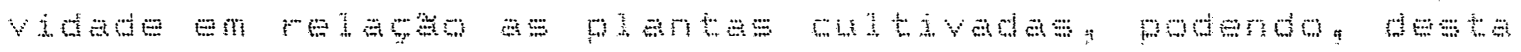

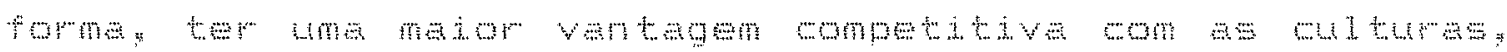

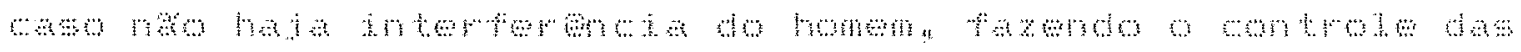

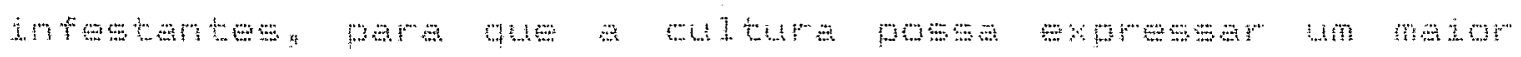
mathens.

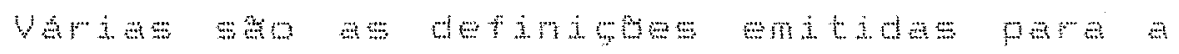

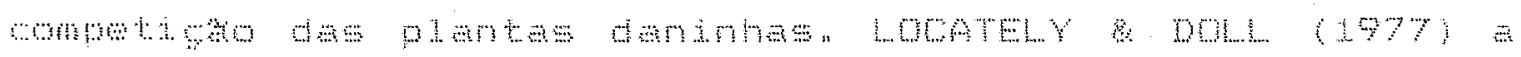

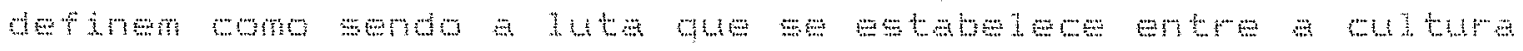


a

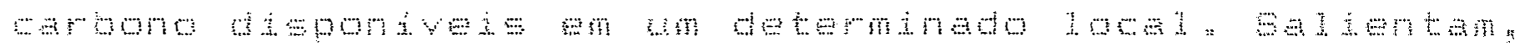

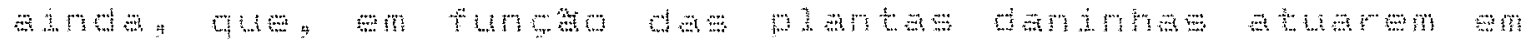

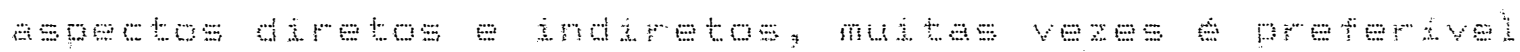
Fн

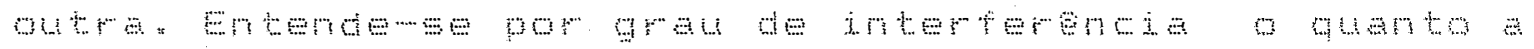
wकm

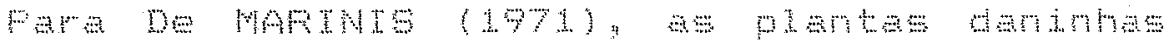

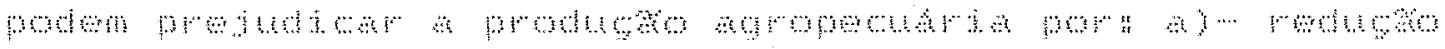

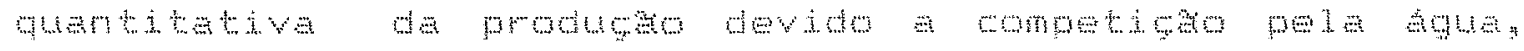

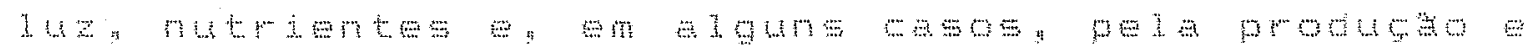
A

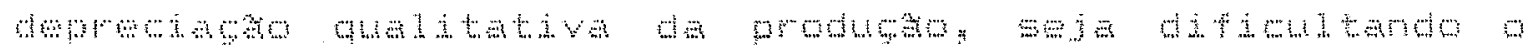

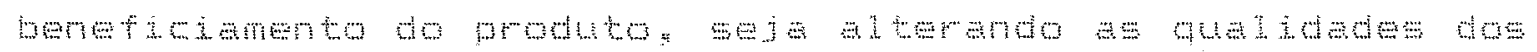

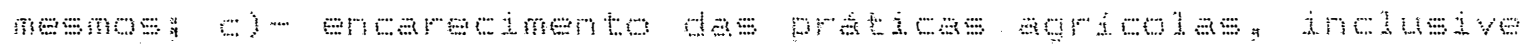

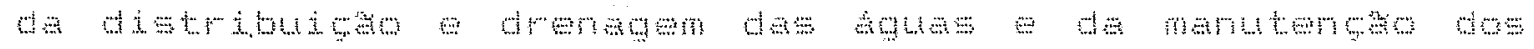
mantmog d)

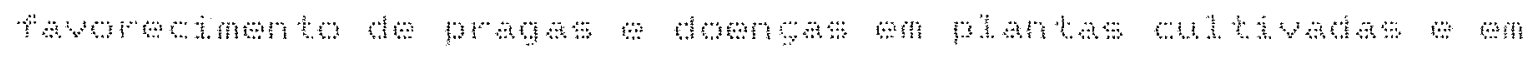

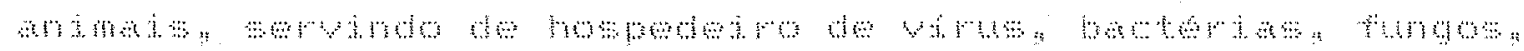
пен

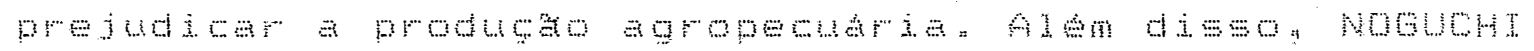

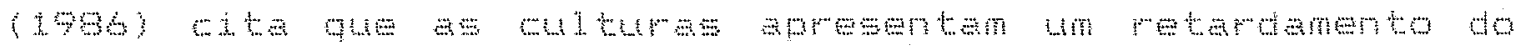

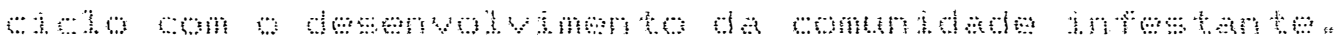

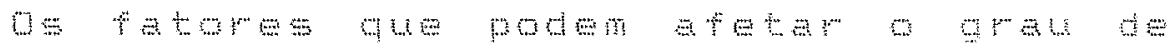

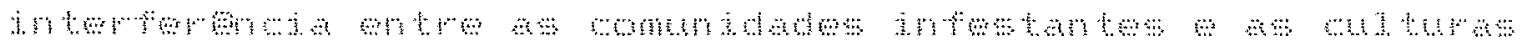

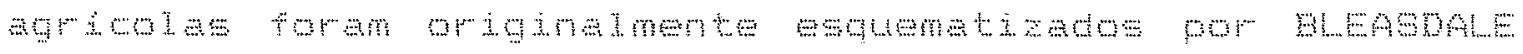




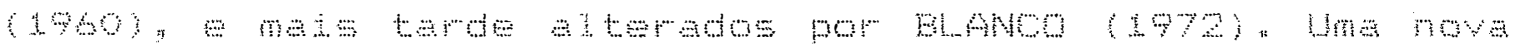

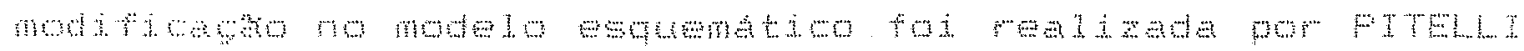

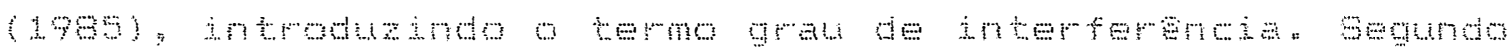

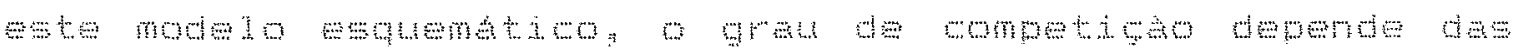

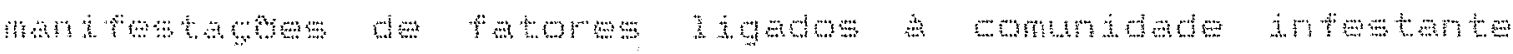

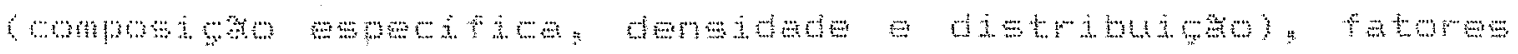

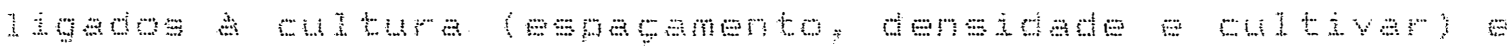

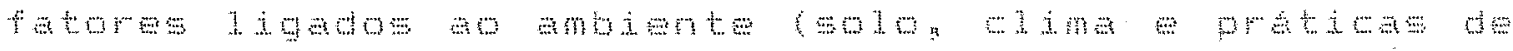

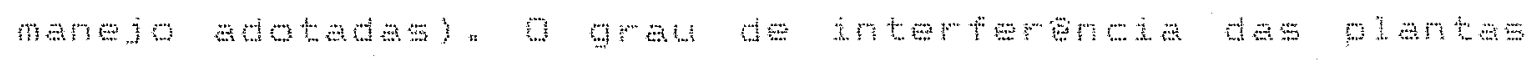
dannhe

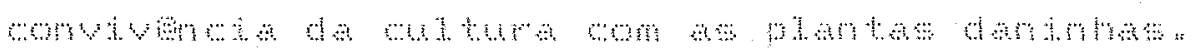

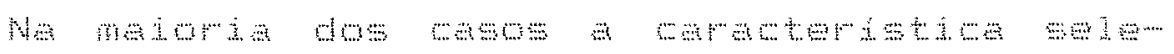

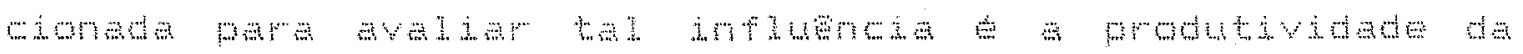

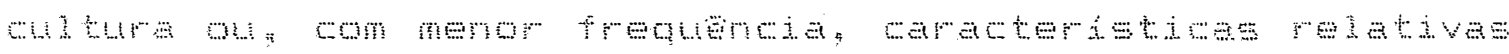

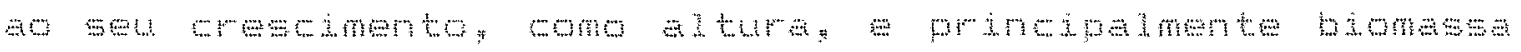

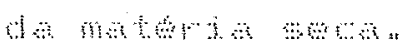

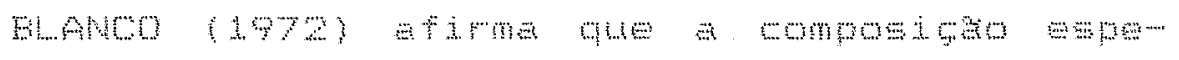

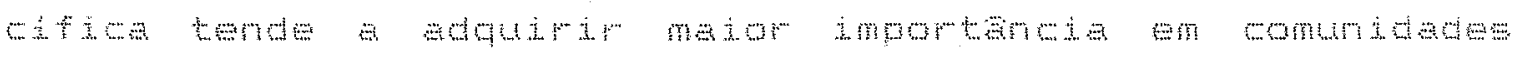

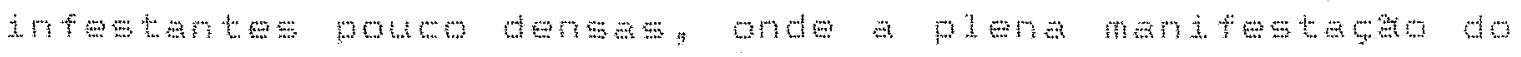

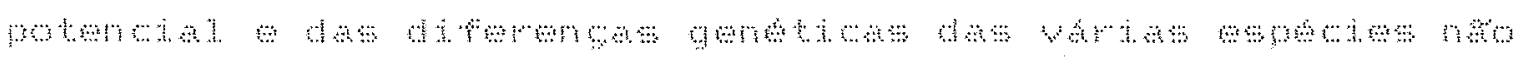

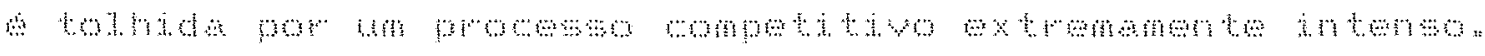

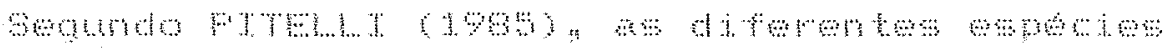

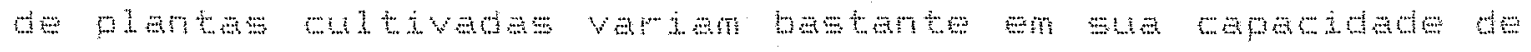

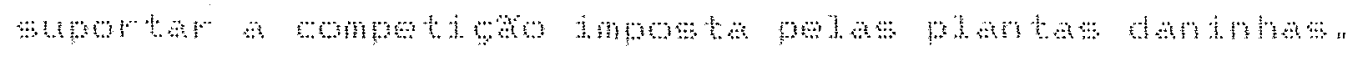

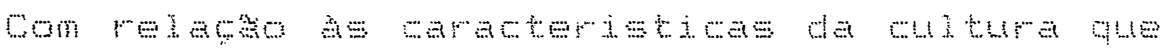

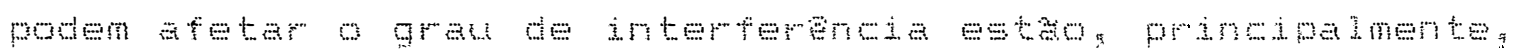




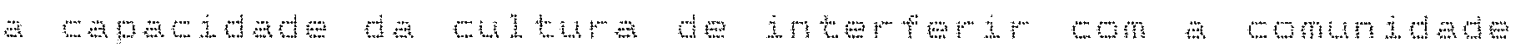
intestante n

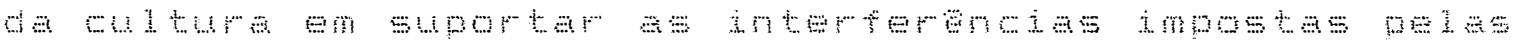

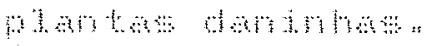

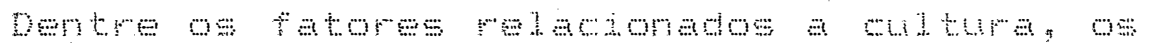

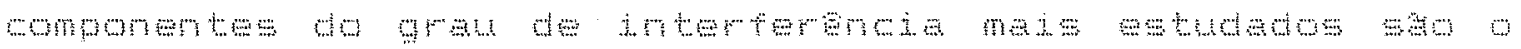

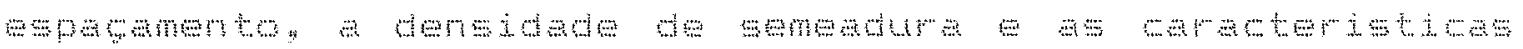
do watram

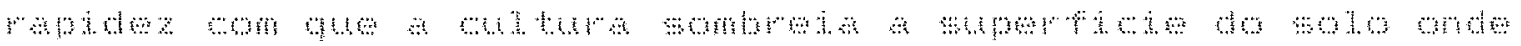

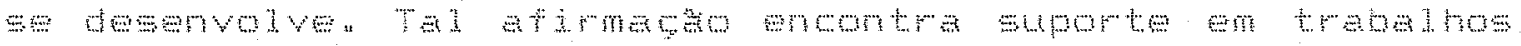

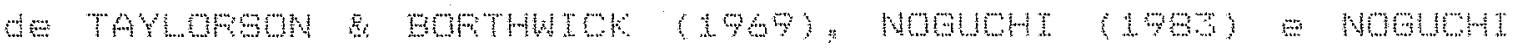
$\log 3$

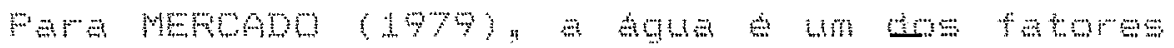
m+

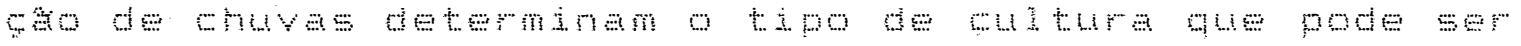

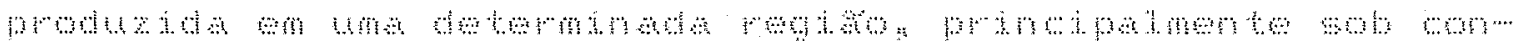
A

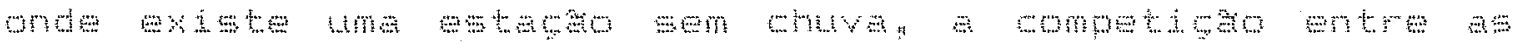

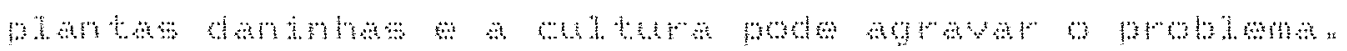

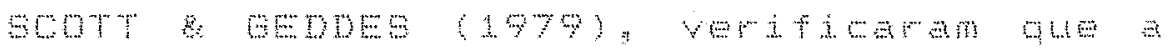

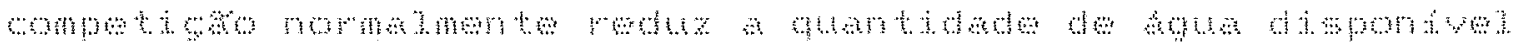

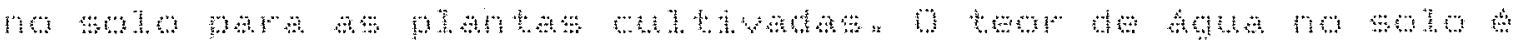
Thommlan w

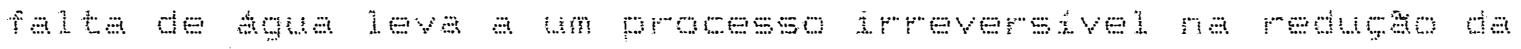
mon

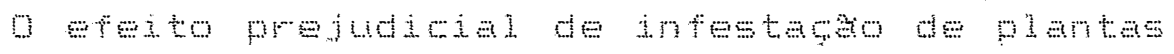




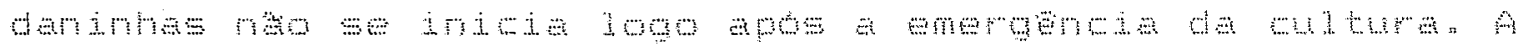

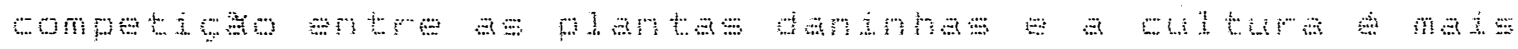

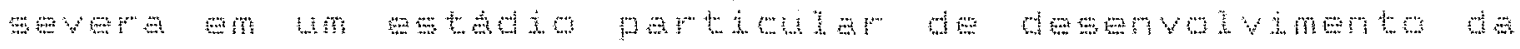

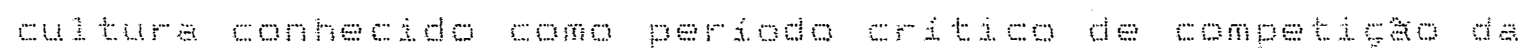

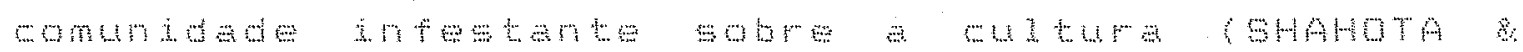

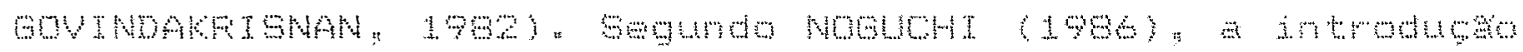

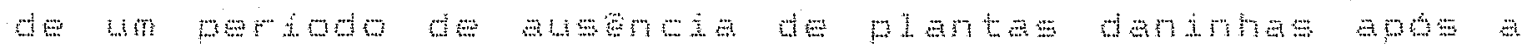

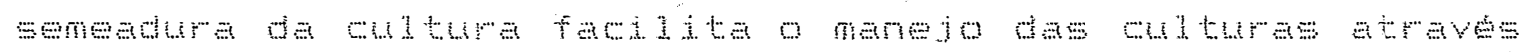

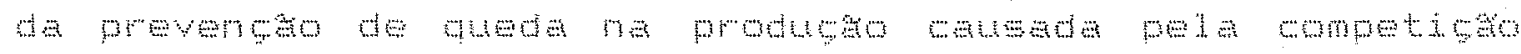

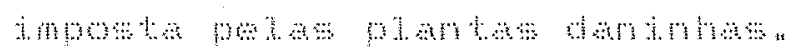

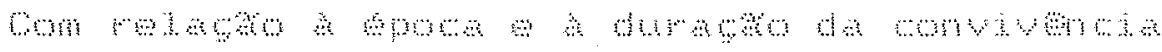

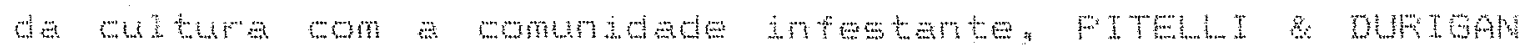

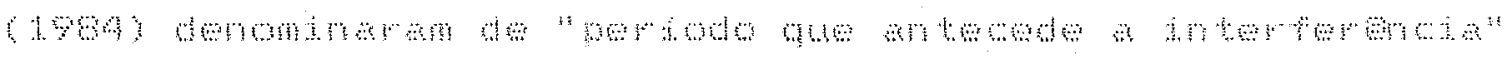

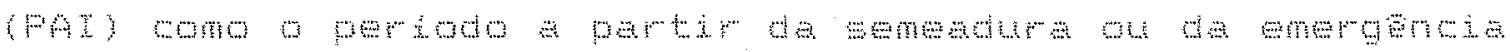

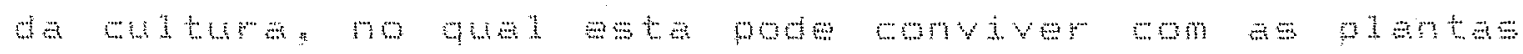

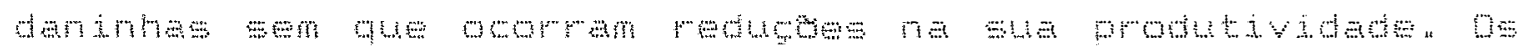

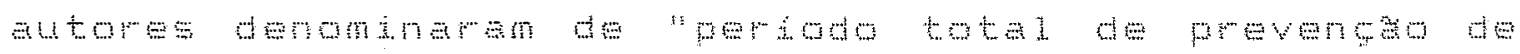

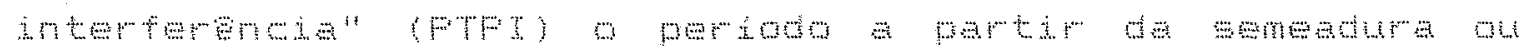

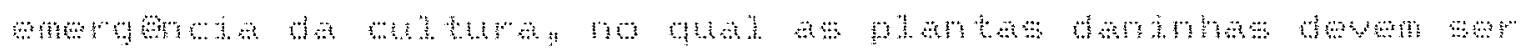

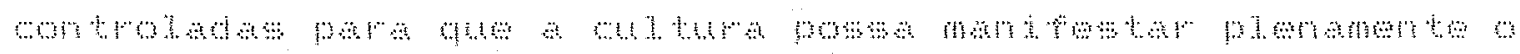

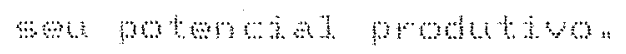

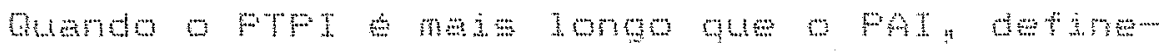

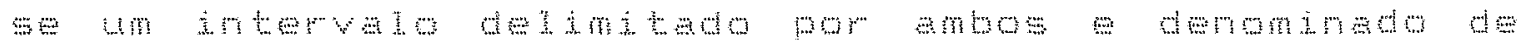

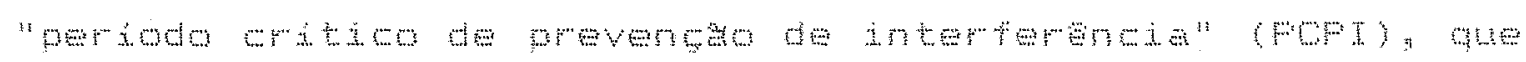

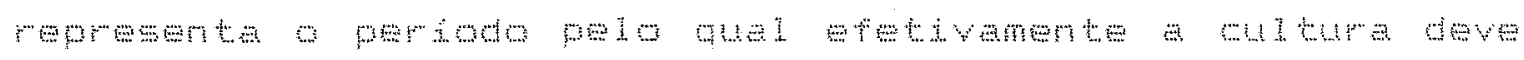

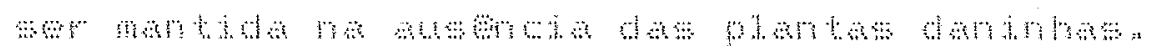




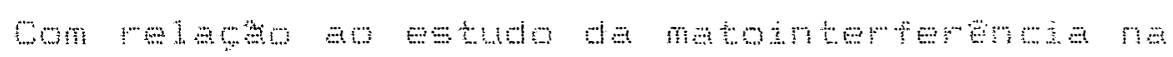

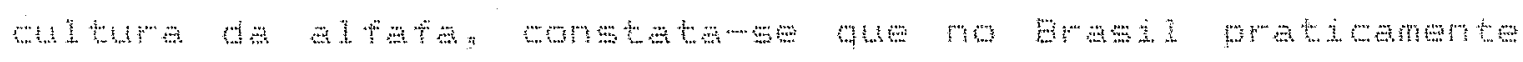

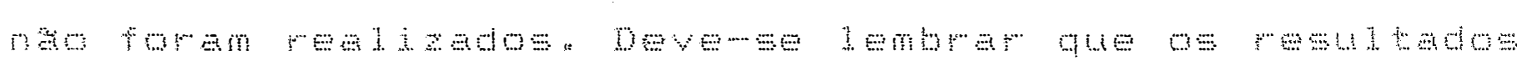

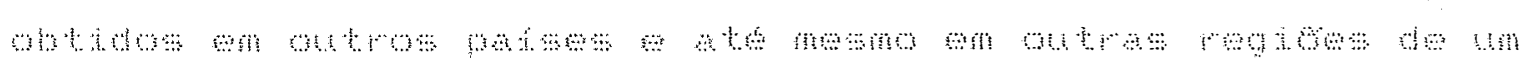

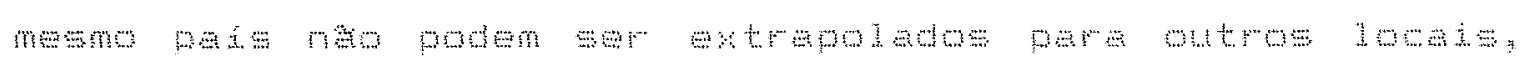

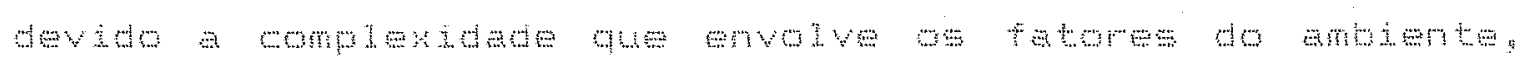

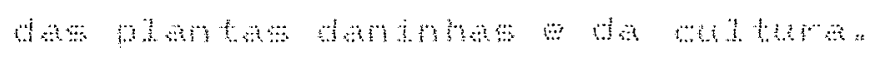

\subsection{Frobiemas causados a cultura da afafa por plantas daninhas}

2.3.1. Ferdas na produca de forragen e de sementes

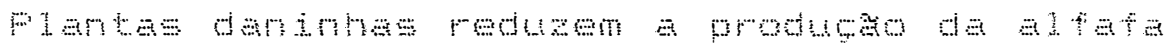

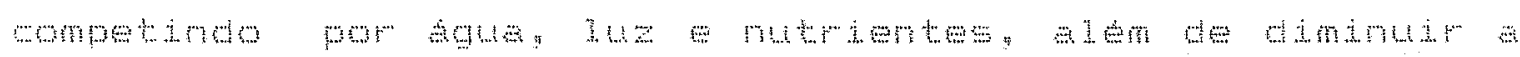

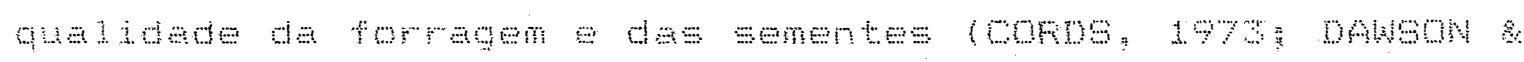

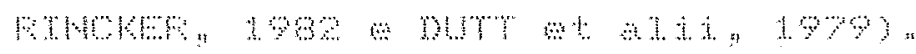

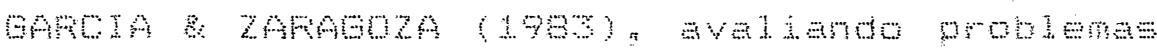

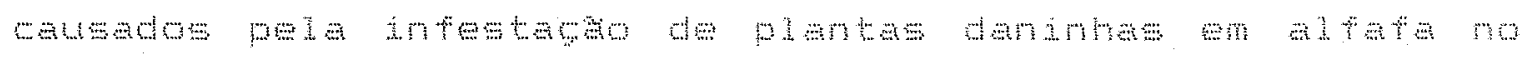

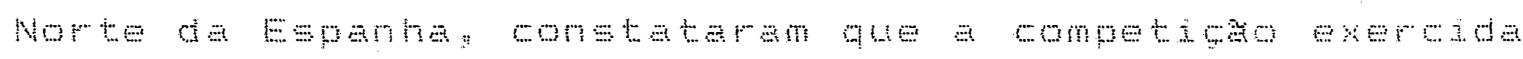

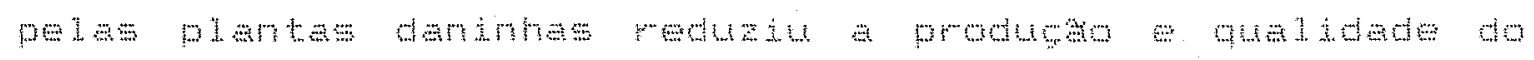

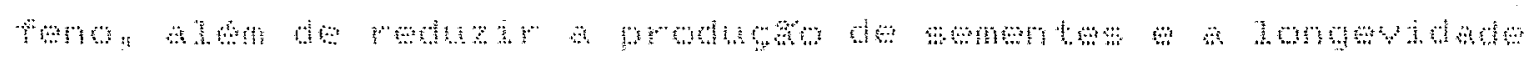




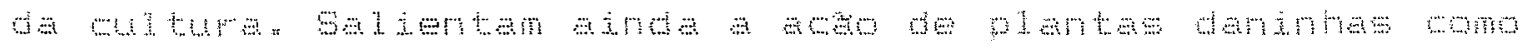

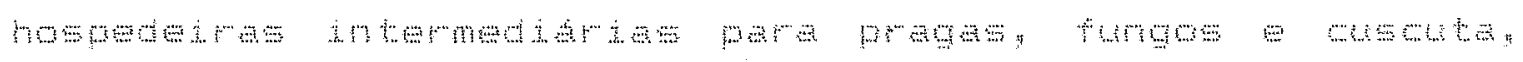

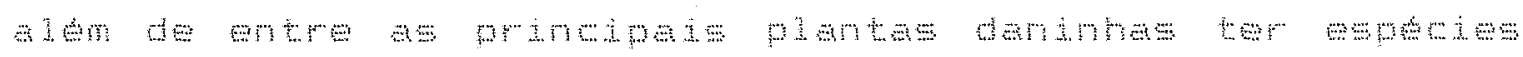

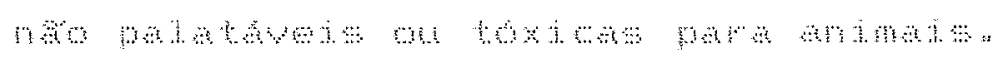

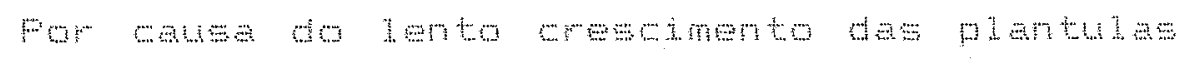

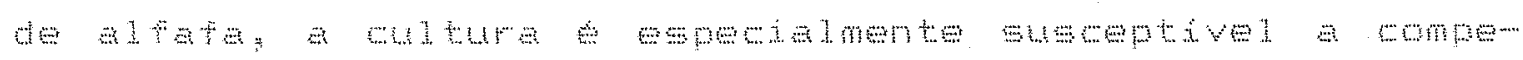

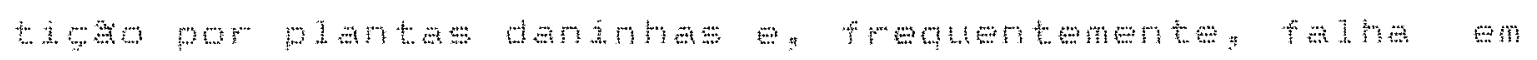

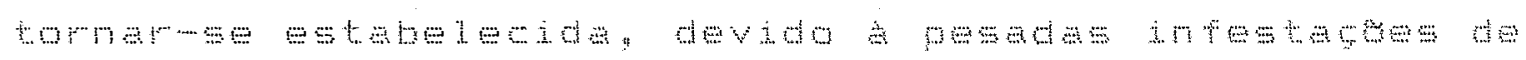

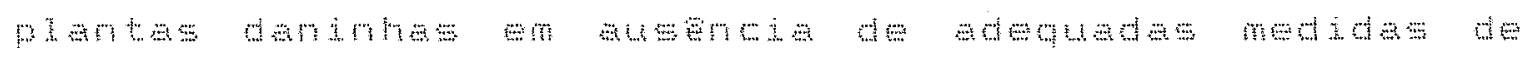

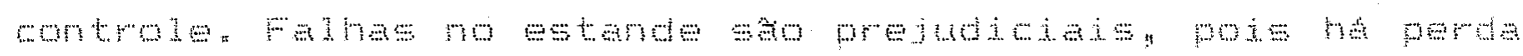
nж

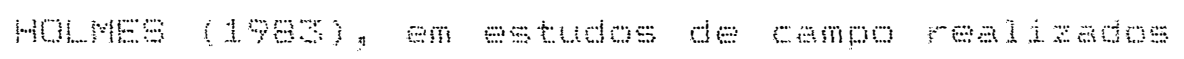

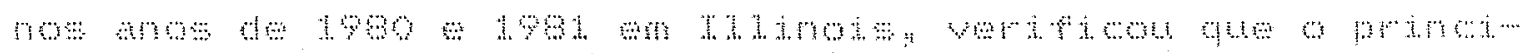

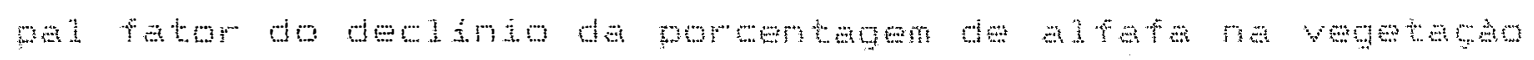

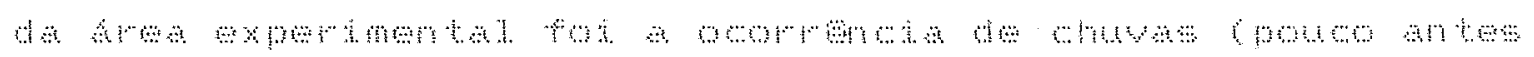

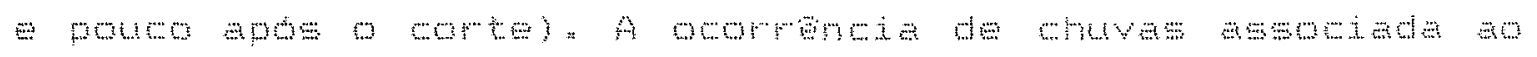

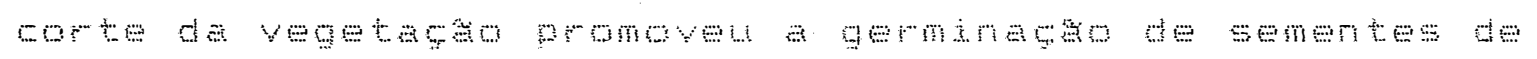

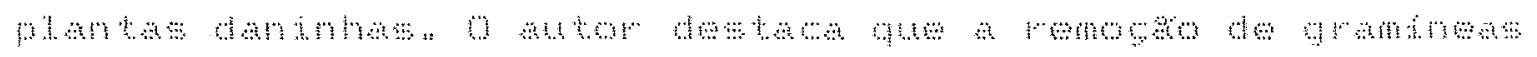

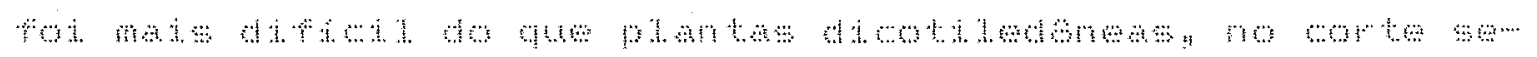

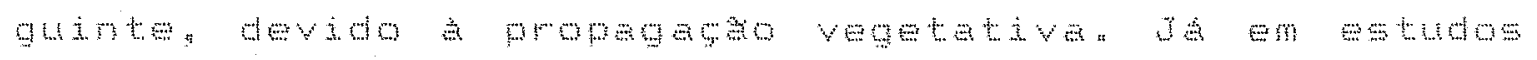

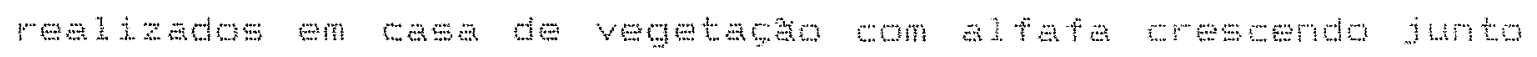

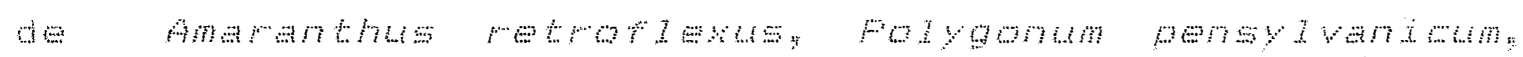

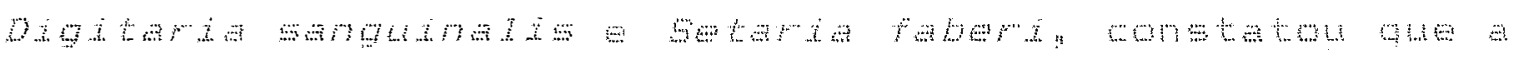

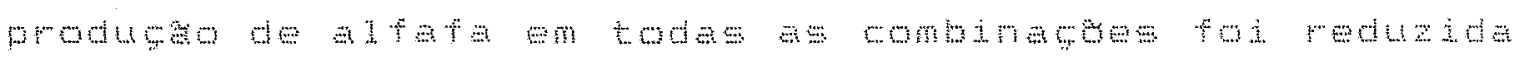

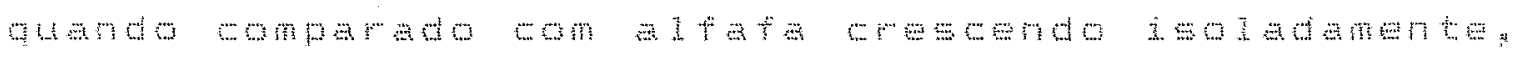

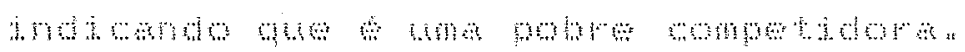


m

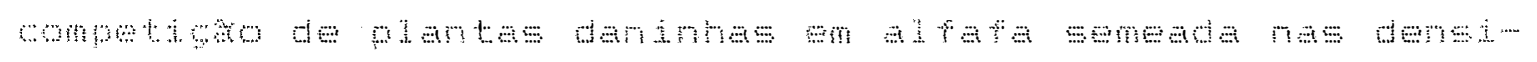

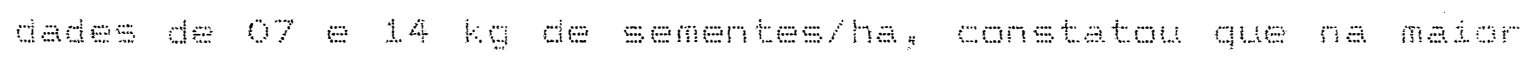

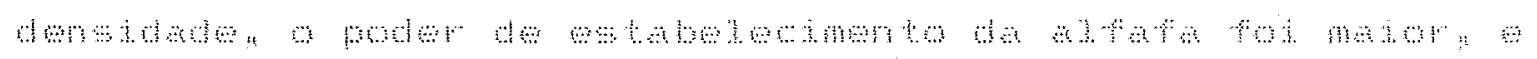

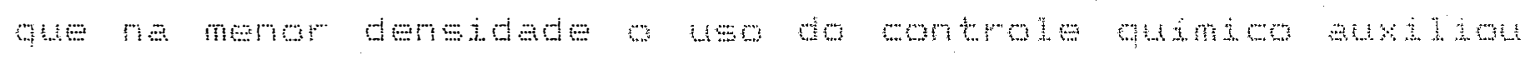
mato mo

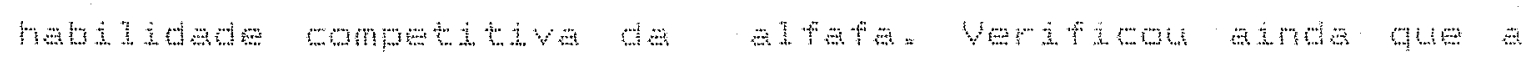

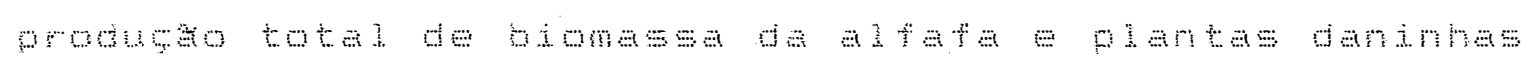

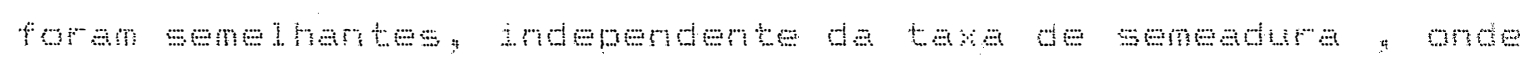

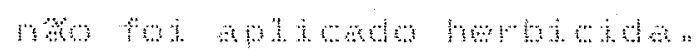

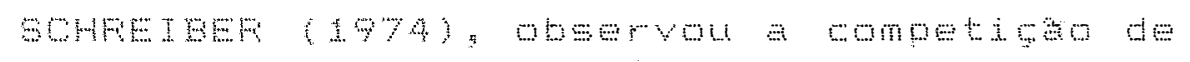

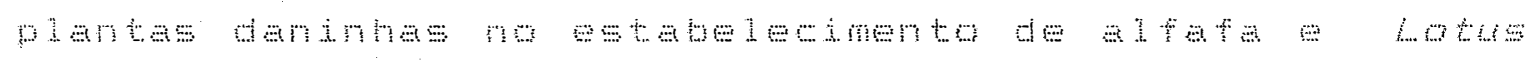

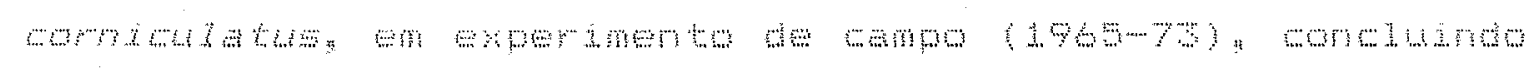

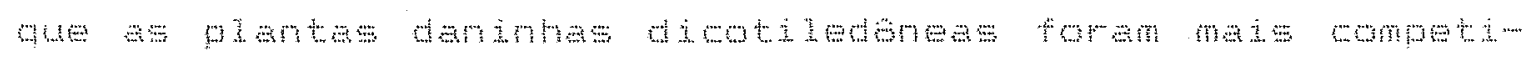

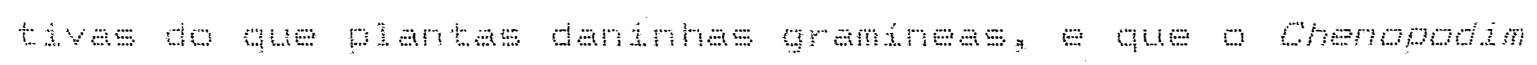

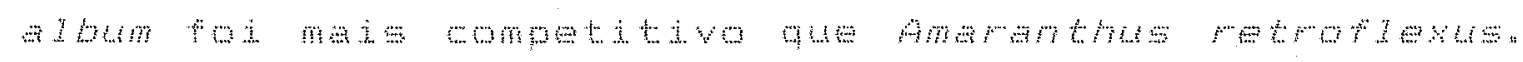

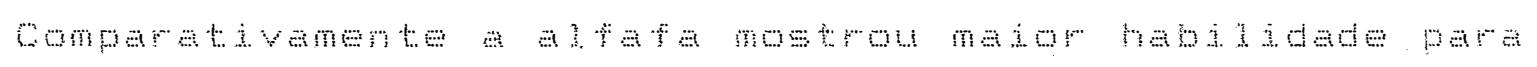
momplo

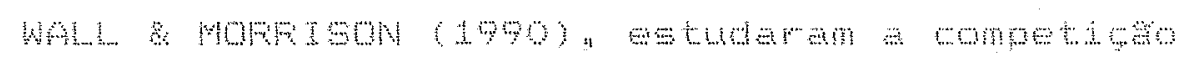
m

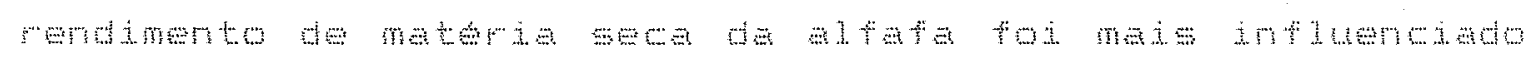
क्

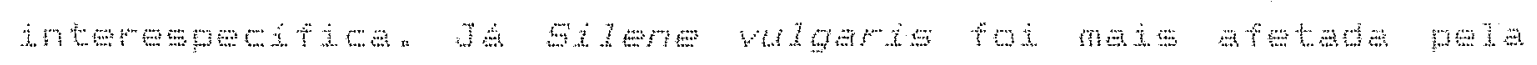

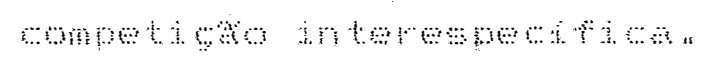

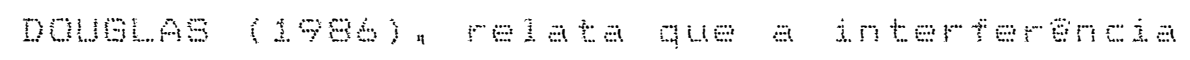

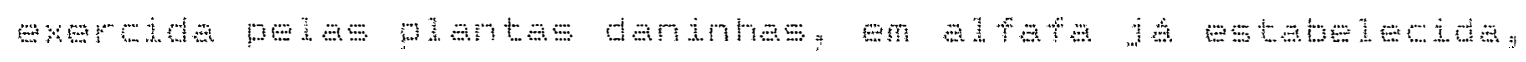




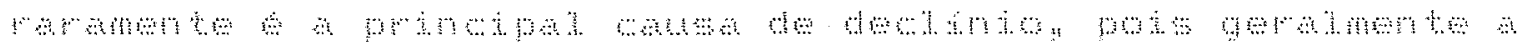

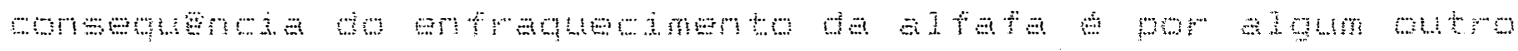

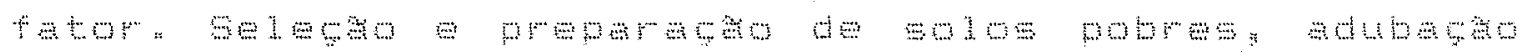
1. mon

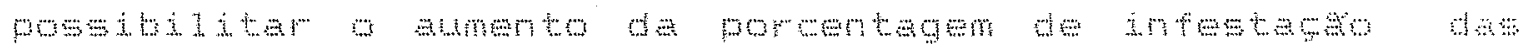

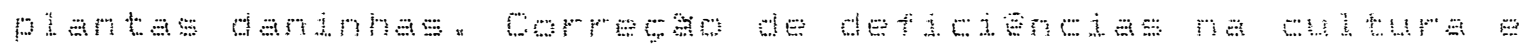

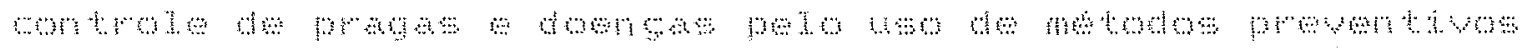

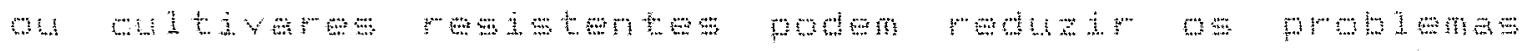

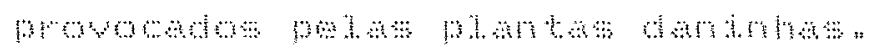

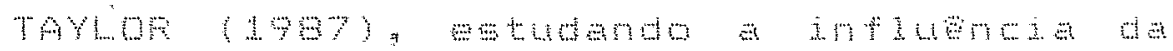

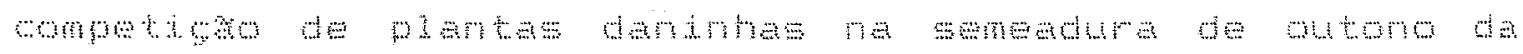
a

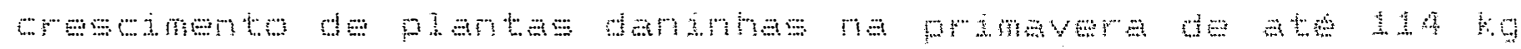

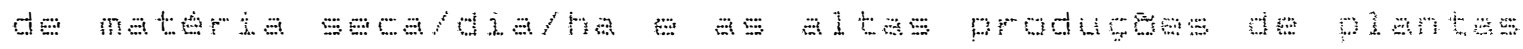

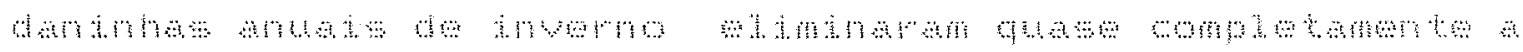

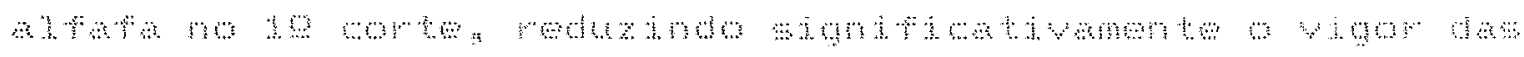

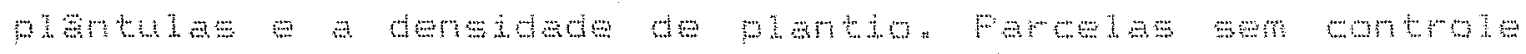

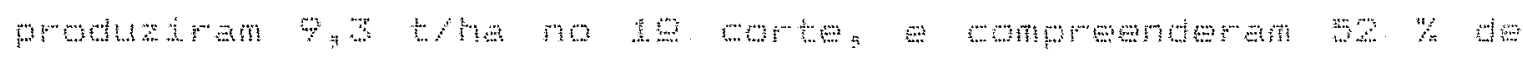

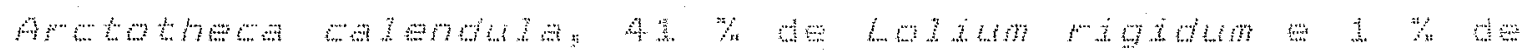

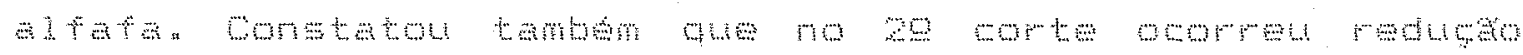

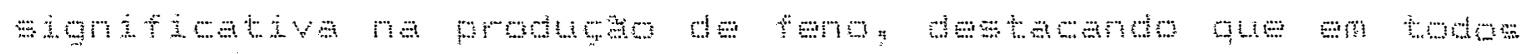

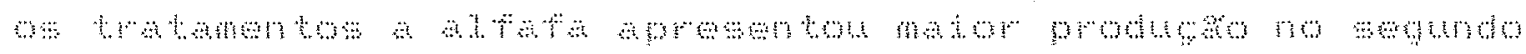

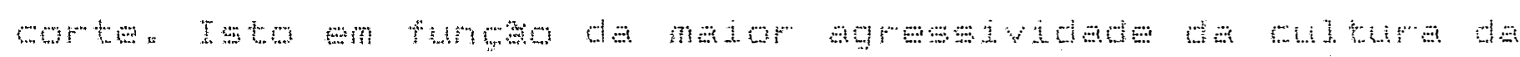

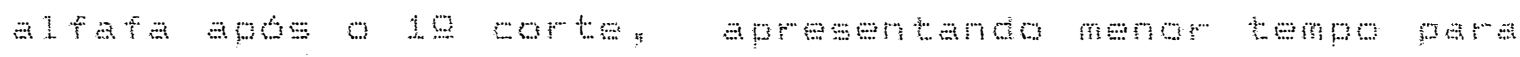
wrom 


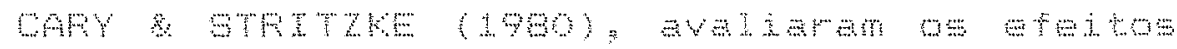

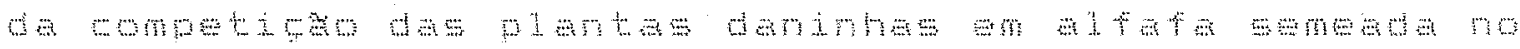

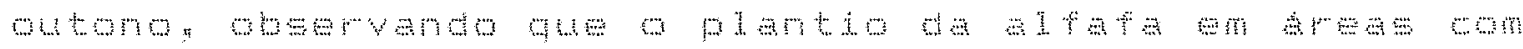

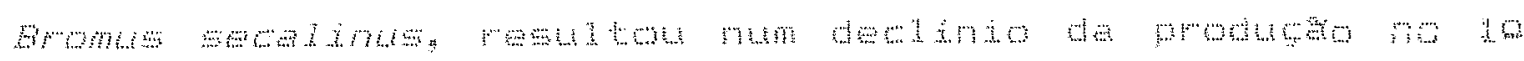

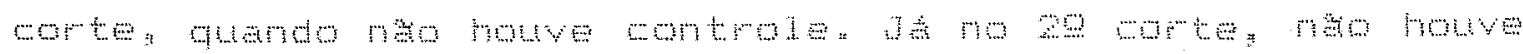

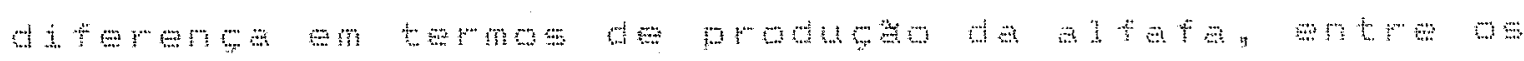

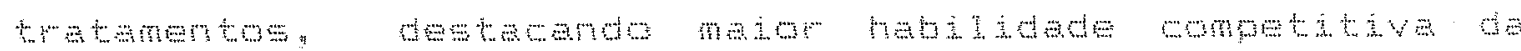

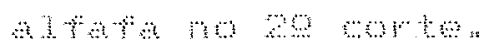

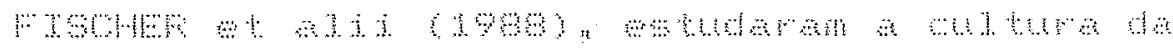

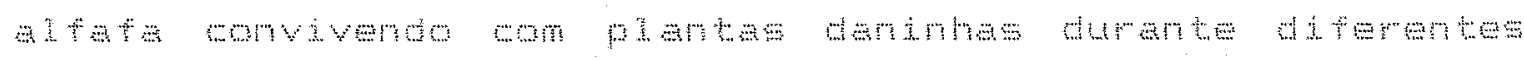

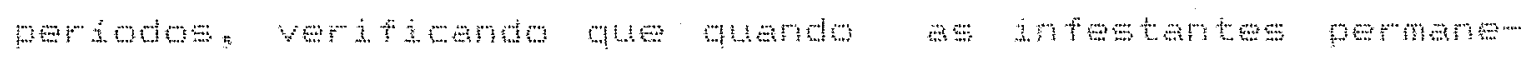

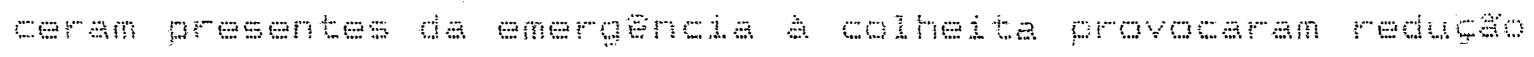

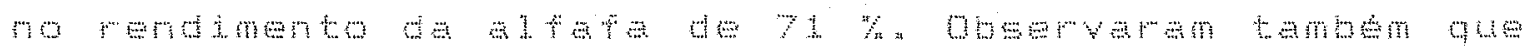

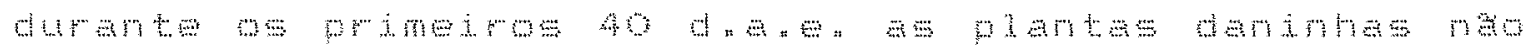
का

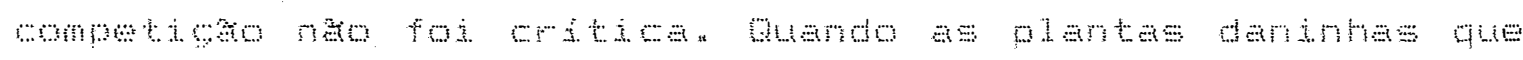

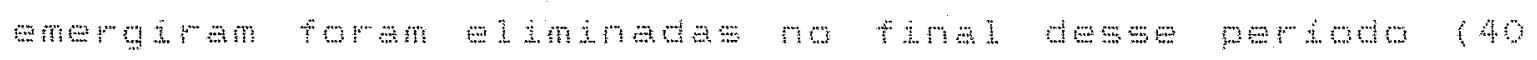

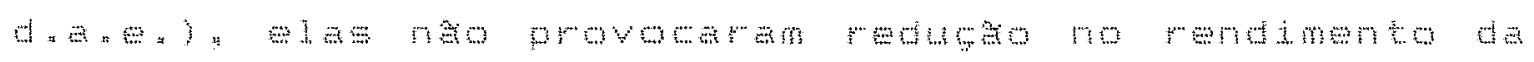
an

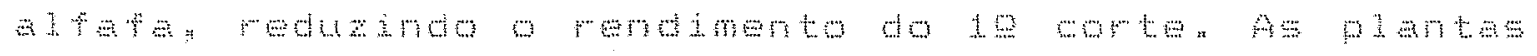

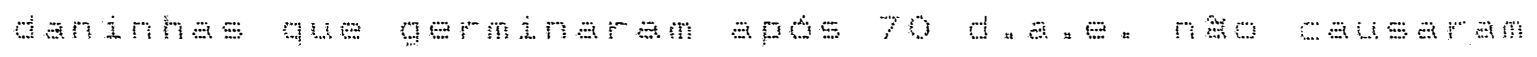

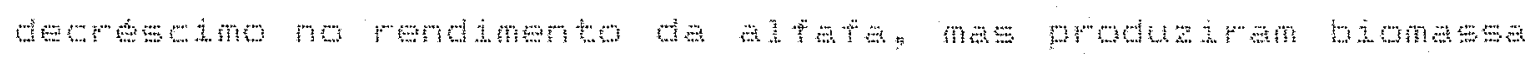

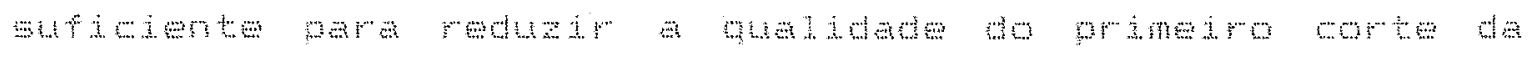

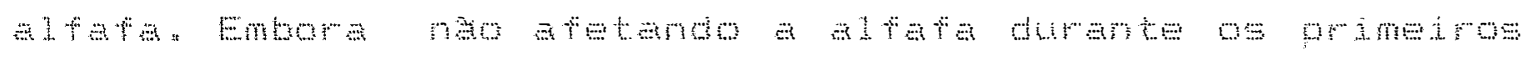

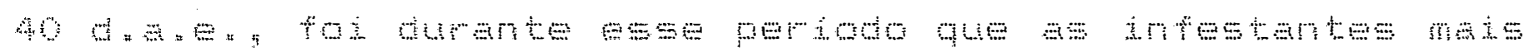




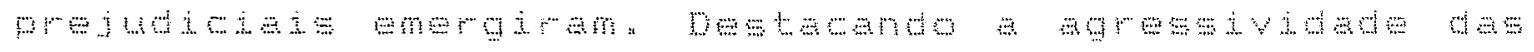

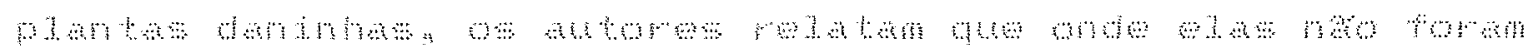

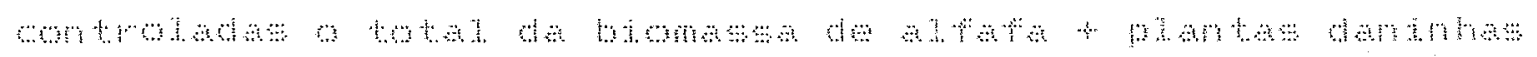

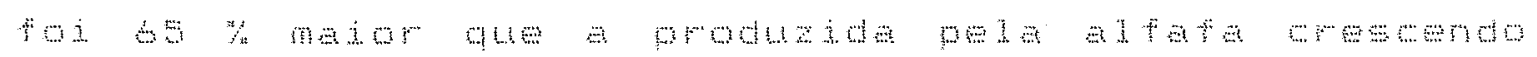

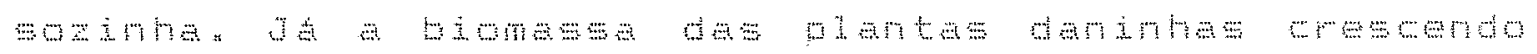

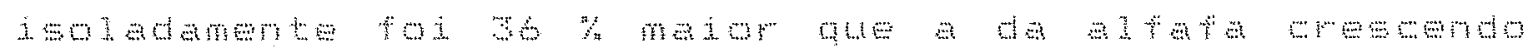
man⿴囗十

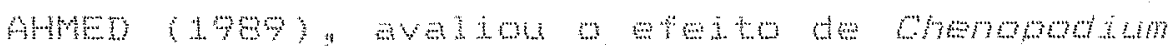

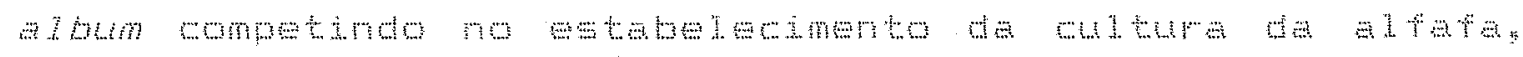

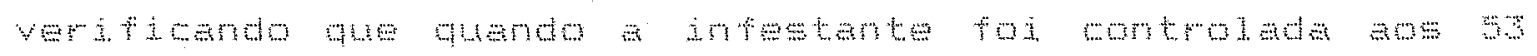

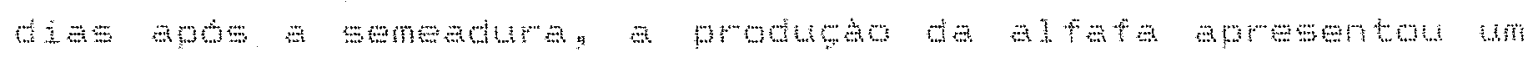

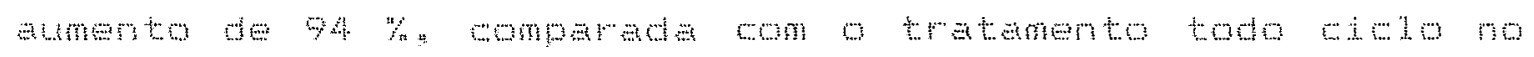
mato:

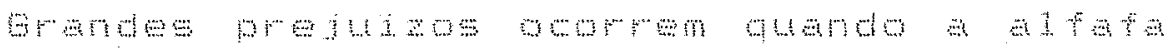

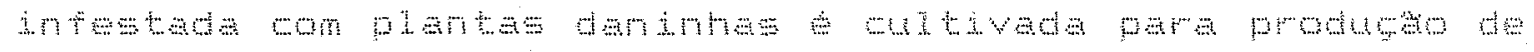

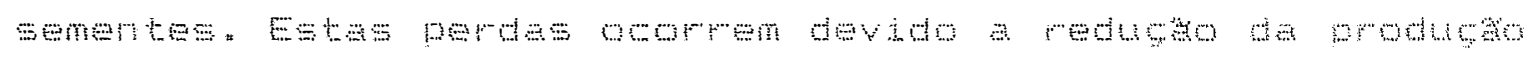

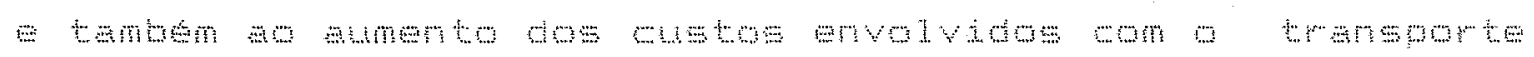

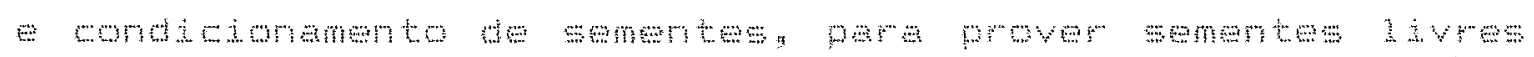

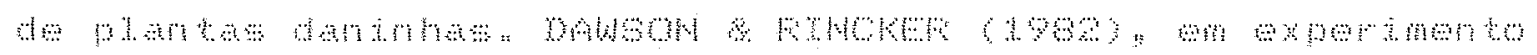

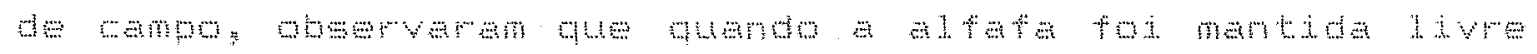

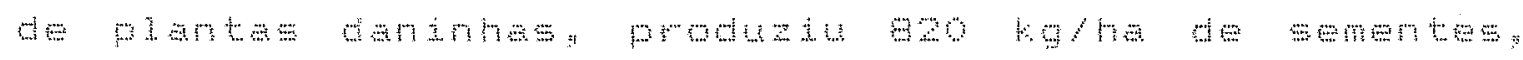

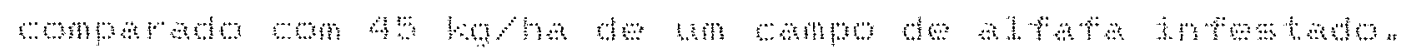

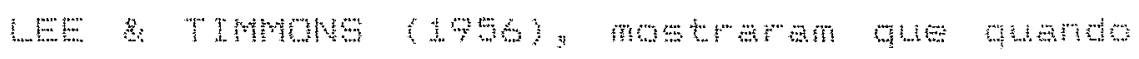

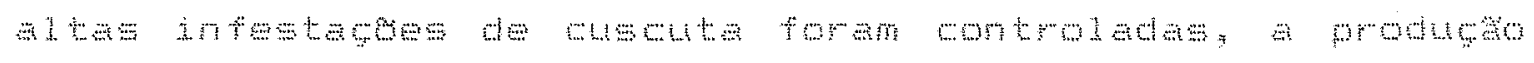

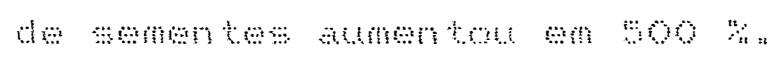




\subsubsection{Froduga de initidores E topinas}

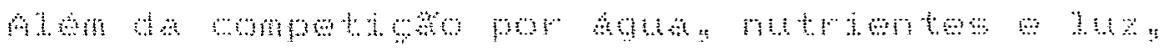

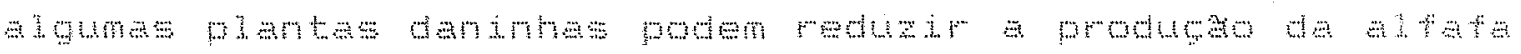

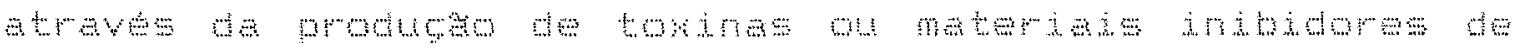

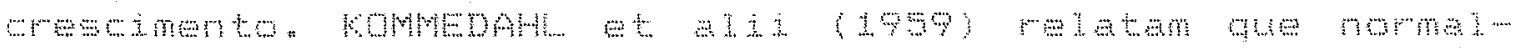

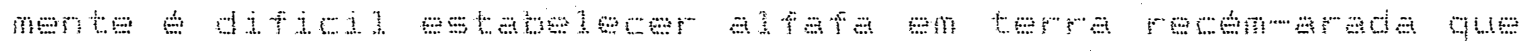

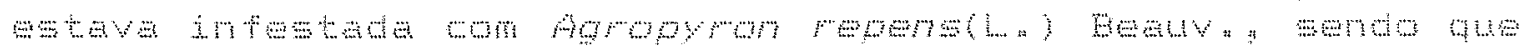

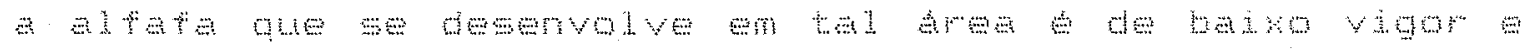

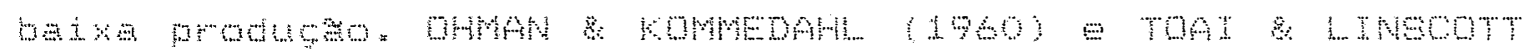

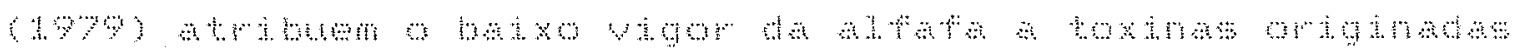

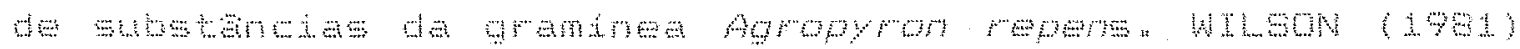

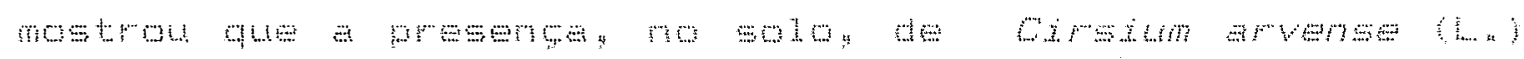

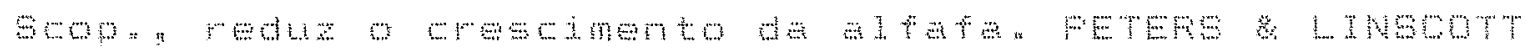

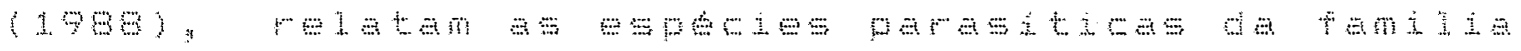

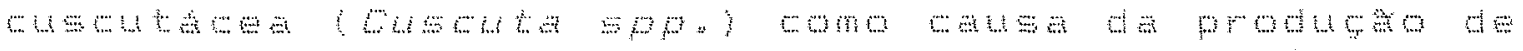

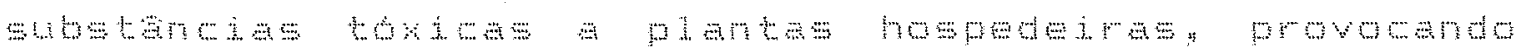

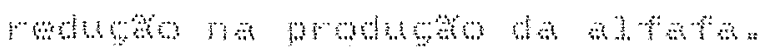

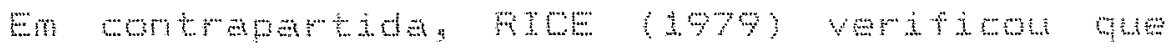

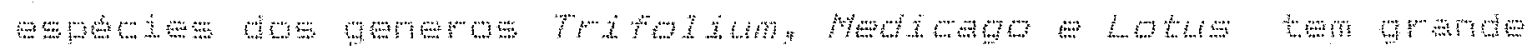

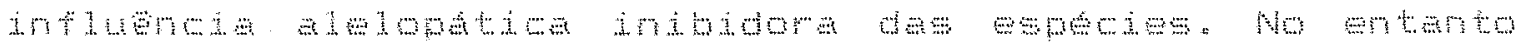

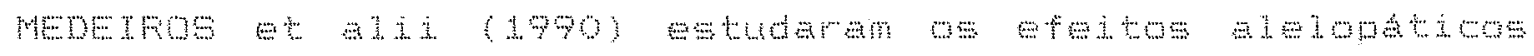

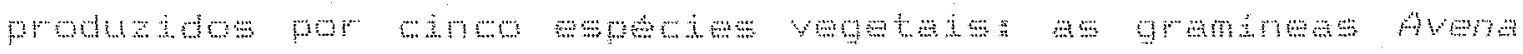

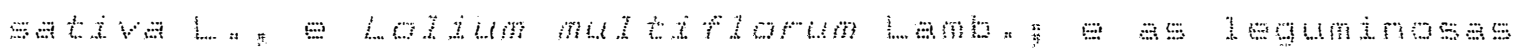

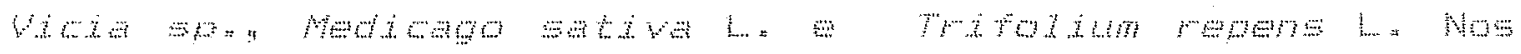




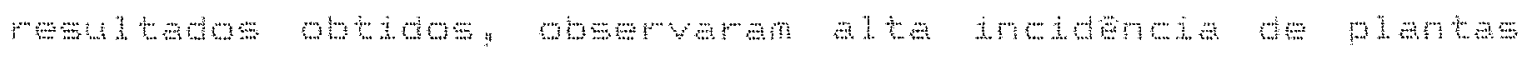

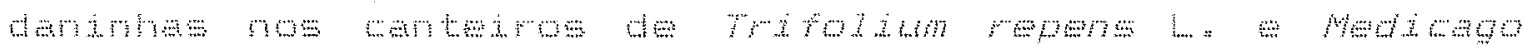
sajya L

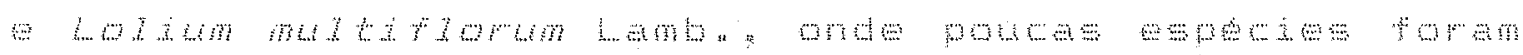
montm

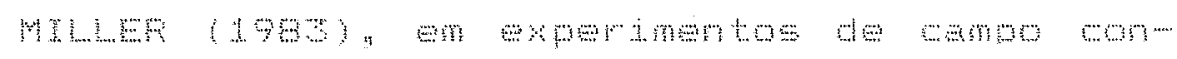

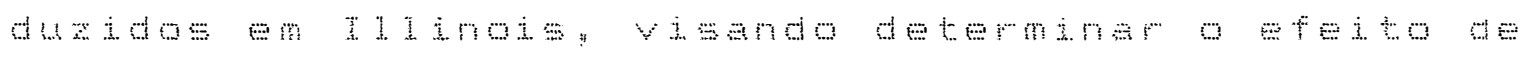

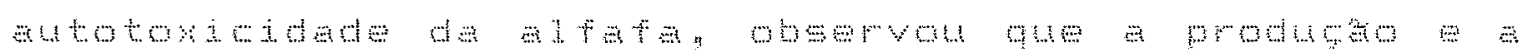

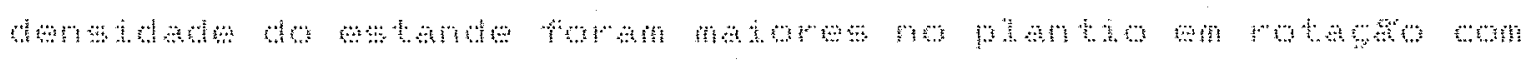

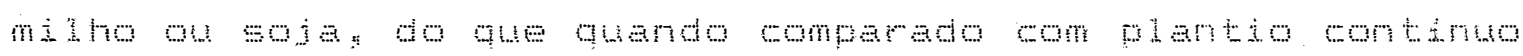

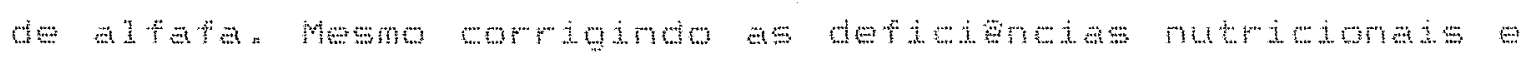
protegendo as antus es atome de rungos a meroume

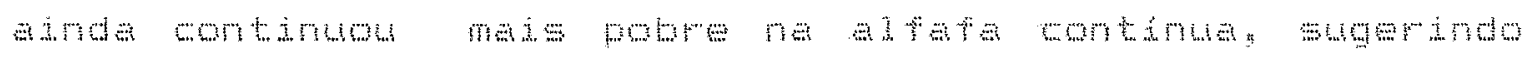

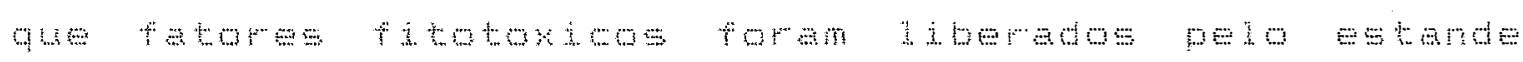

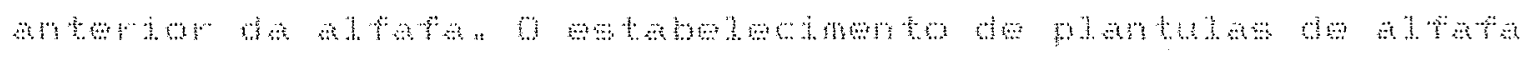

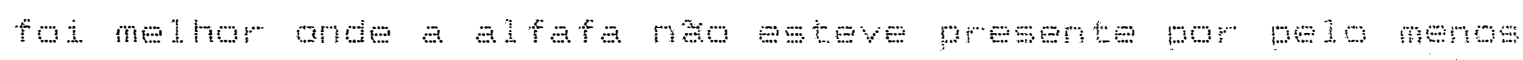

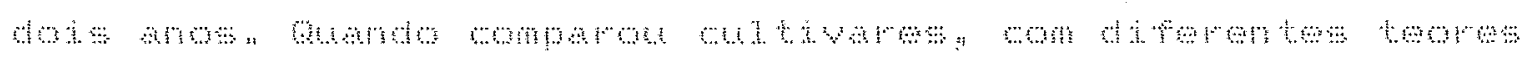

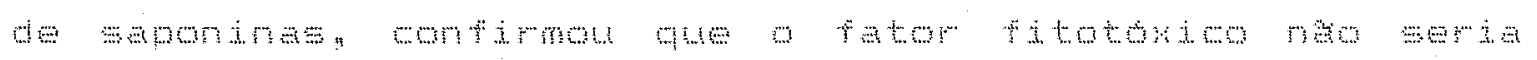
s.t.

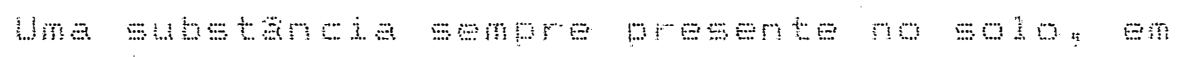
a

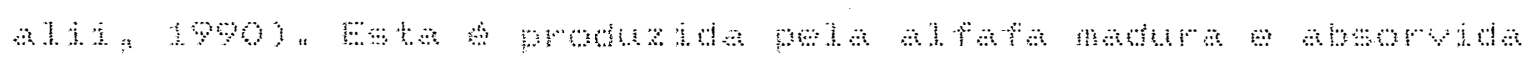

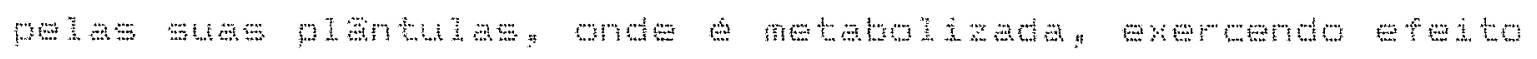

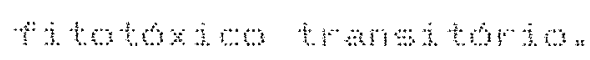




\title{
2.s.2. Ferdas na qual idade da formgen e senentes
}

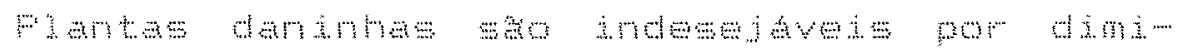

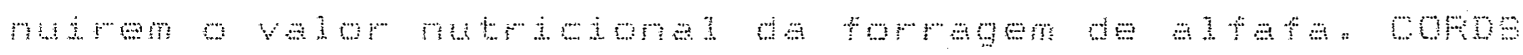

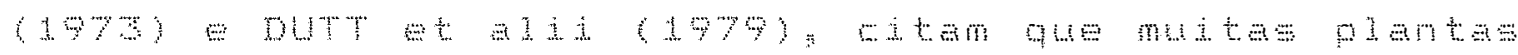

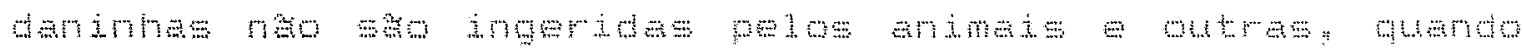
1. A

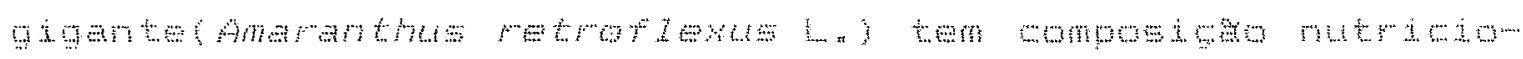

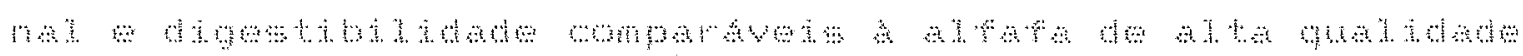

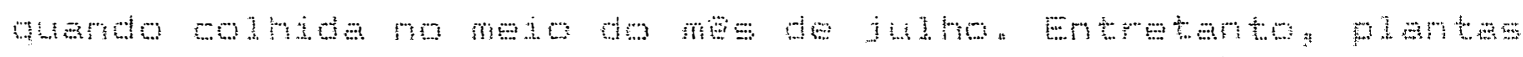

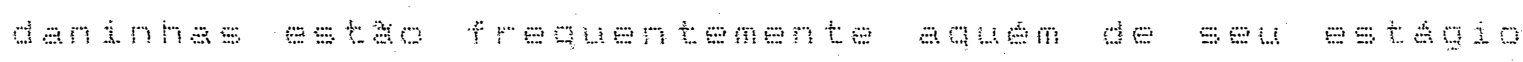

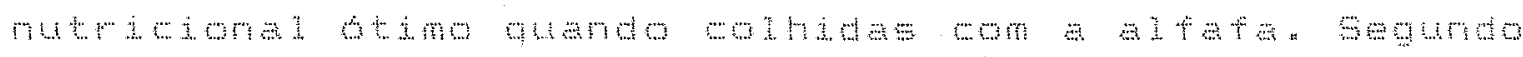

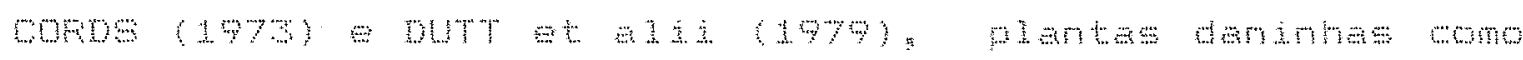

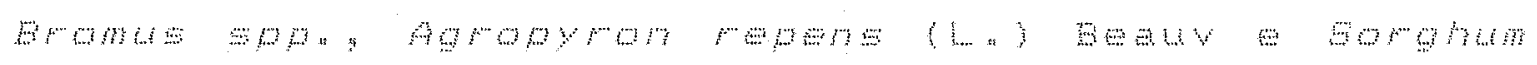

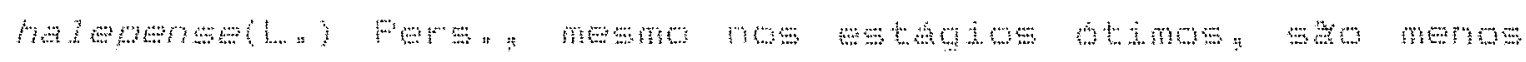

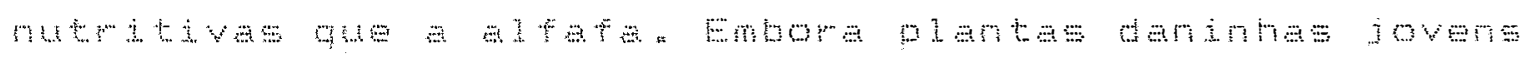

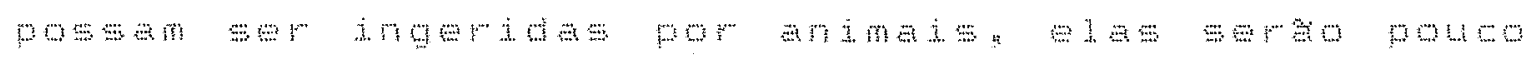

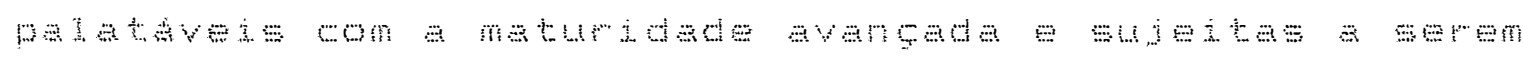

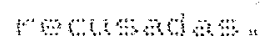

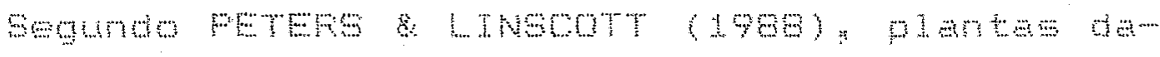

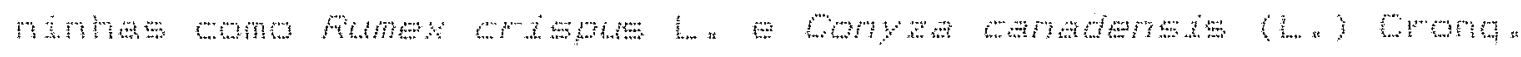

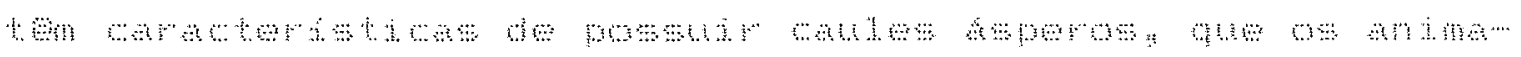

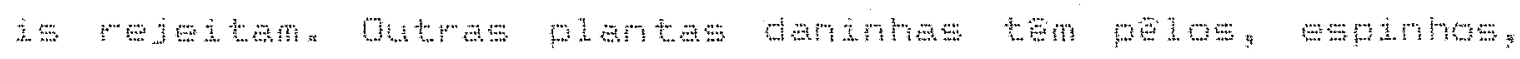

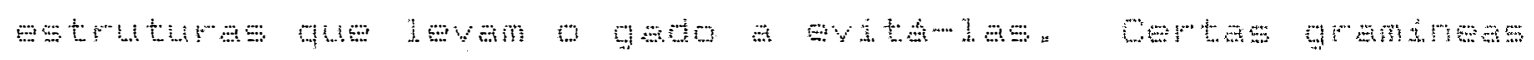

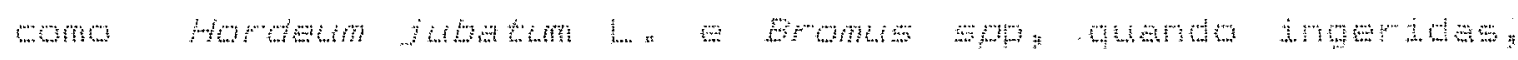




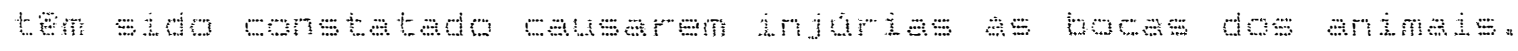

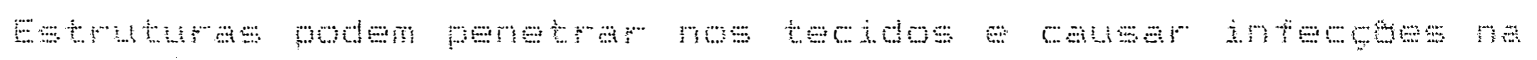

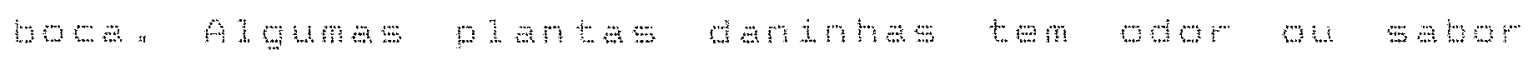
1 пе

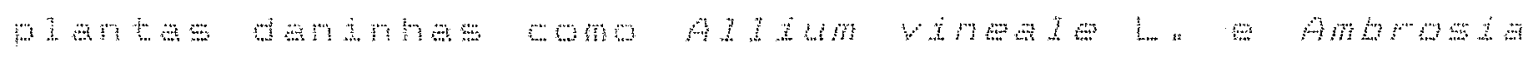

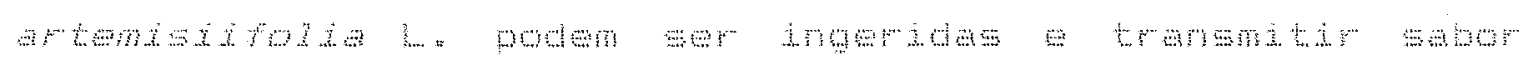

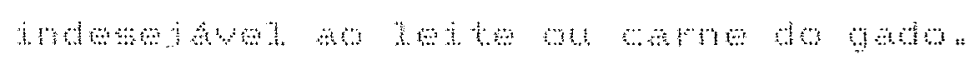

Va womb op

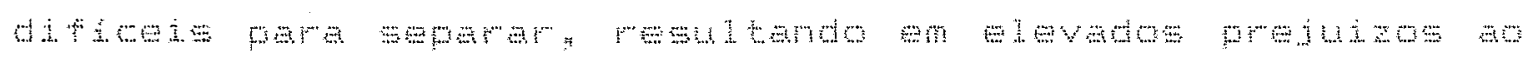

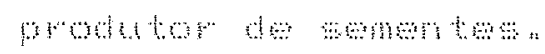

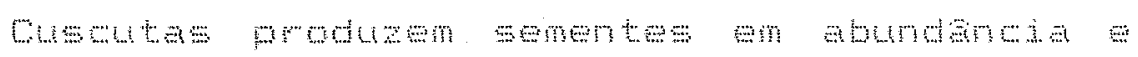

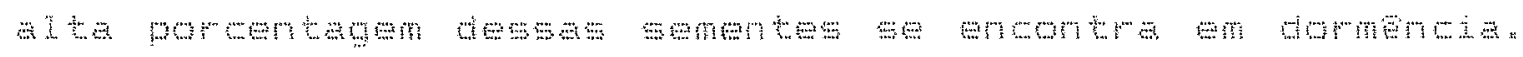

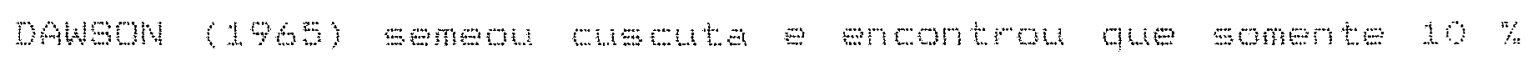

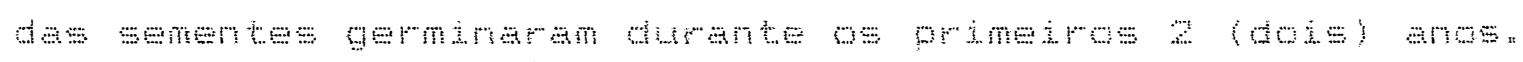

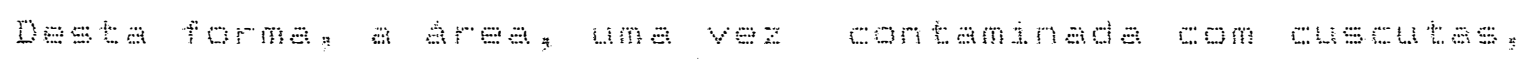

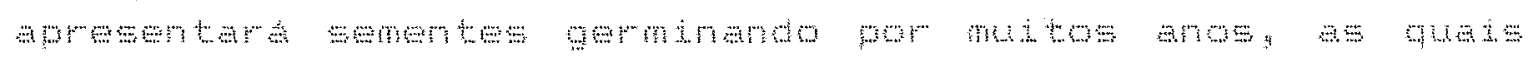

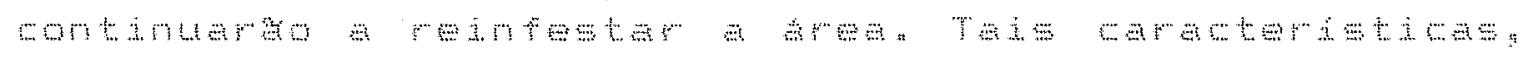

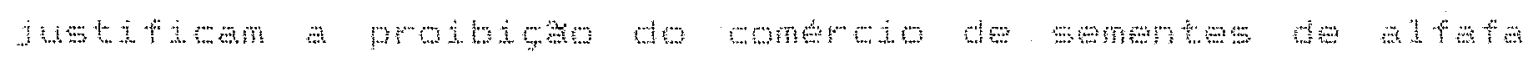

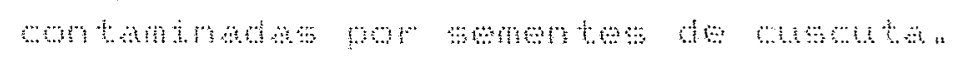

momos

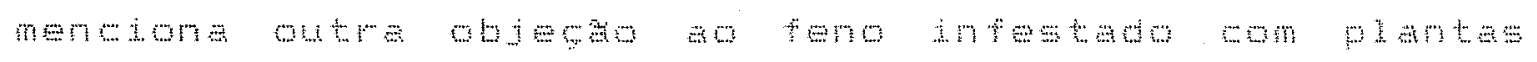

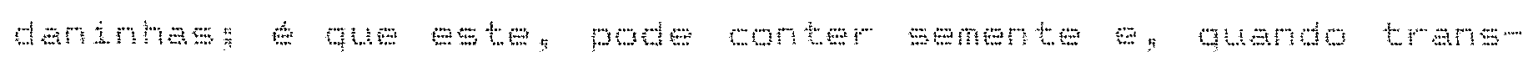

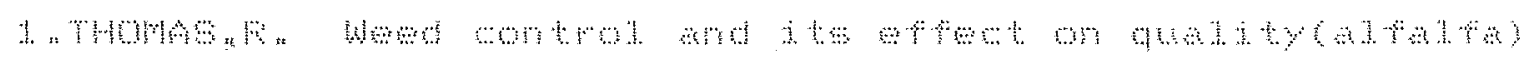

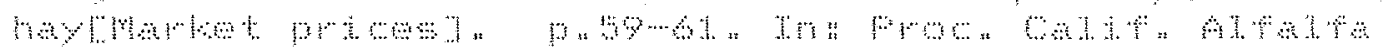

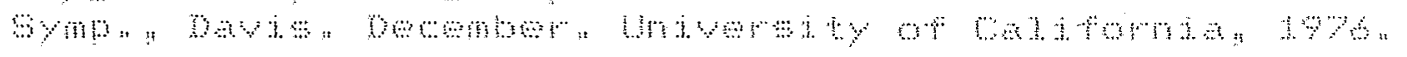




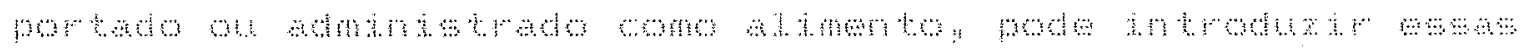

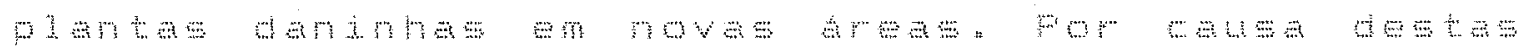

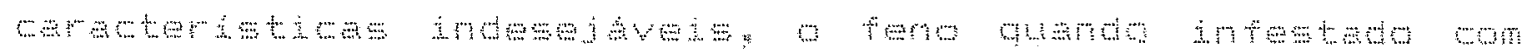

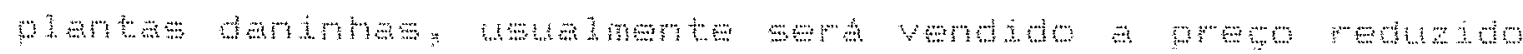

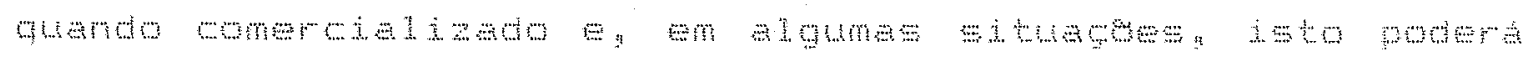

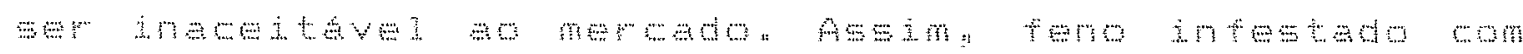

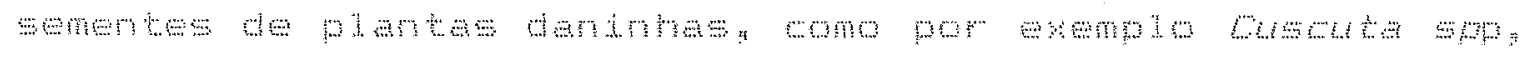

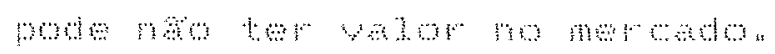

\title{
2.4. Metodos de controle de piantas danintas na 1 instala-

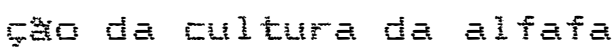

\section{4 $=1$ Controle preventivo de piantas darinhas}

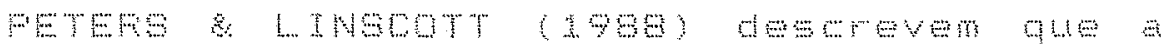

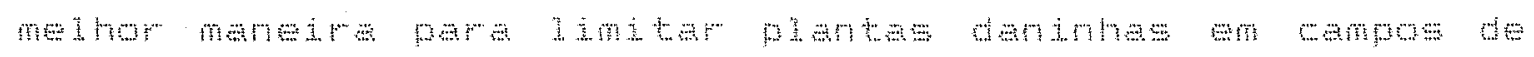

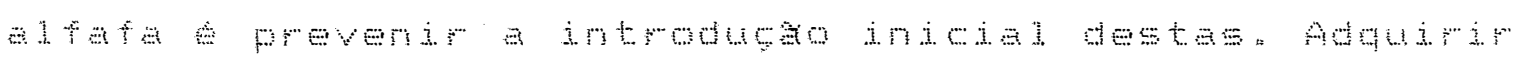

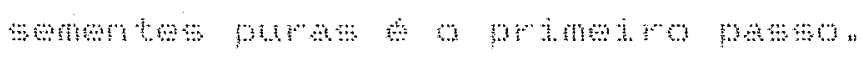

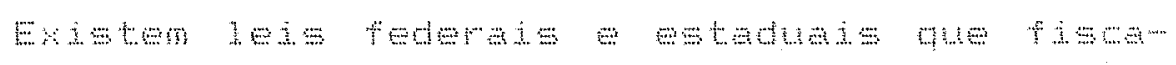

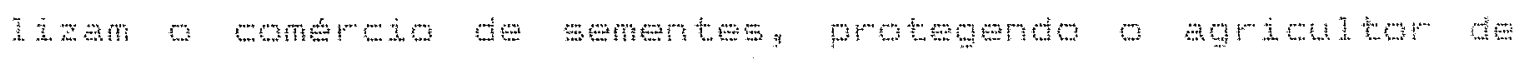

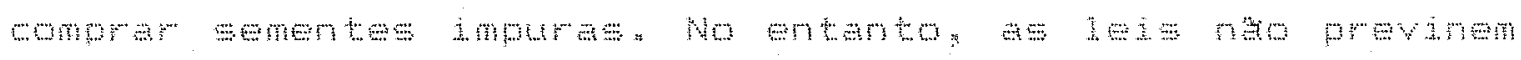

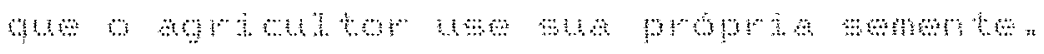




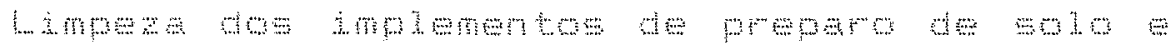

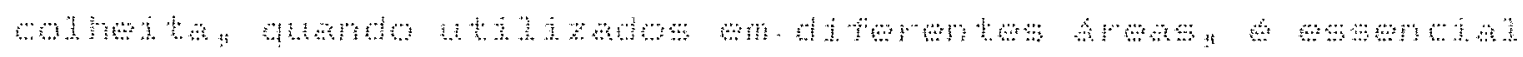

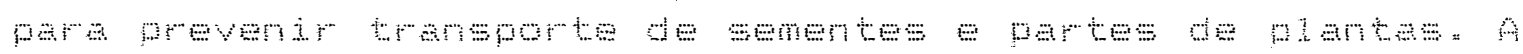

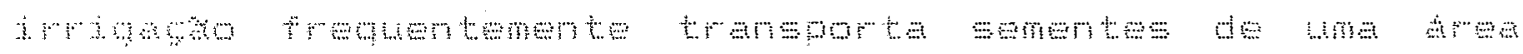

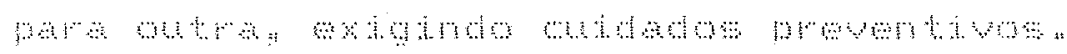

\section{4 .2 Epora de semeadura}

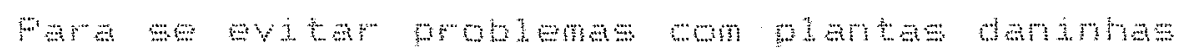

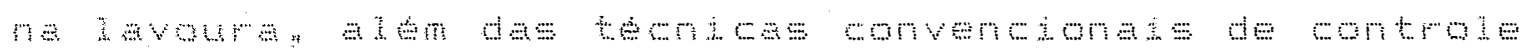

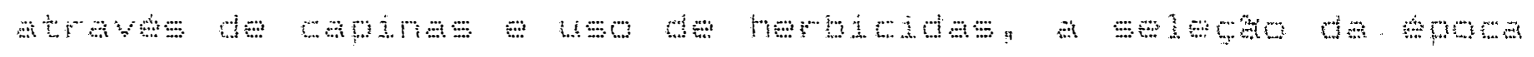

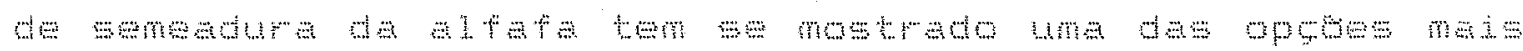

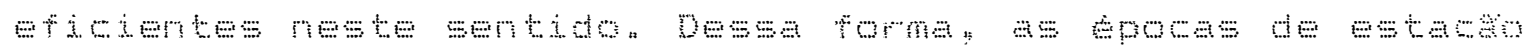

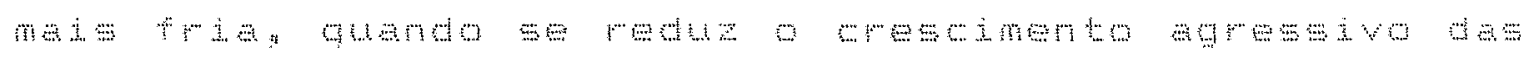

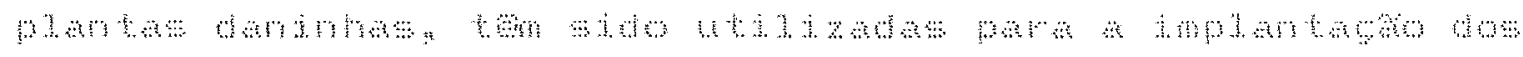

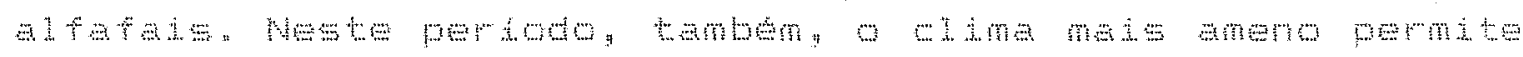

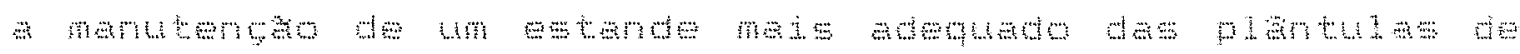
a

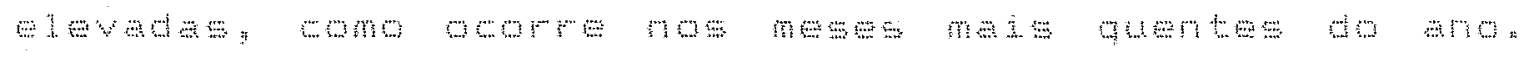

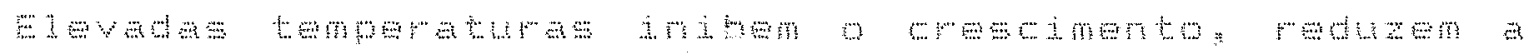

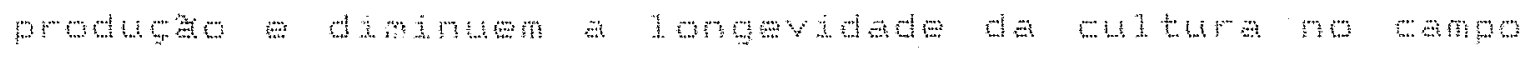

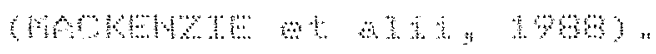

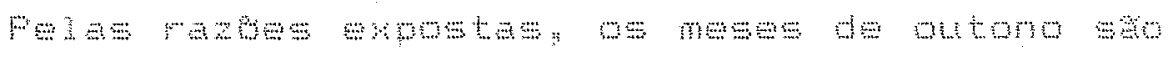

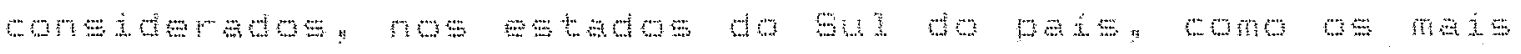

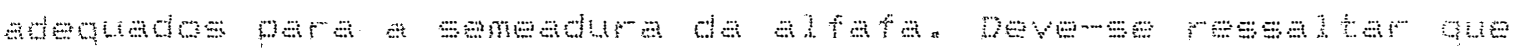
mesa 
r mpman सेक

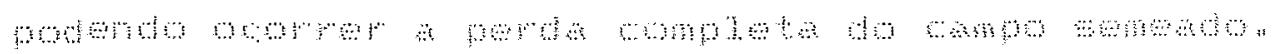

Ed a

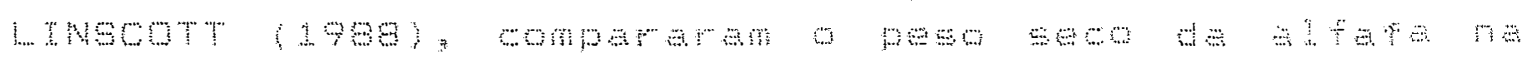
vimina smo mон

momm at and ( म.

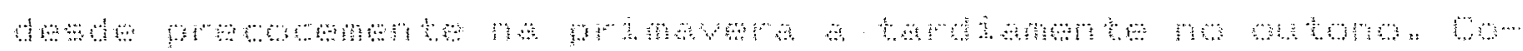

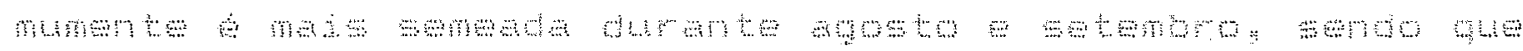

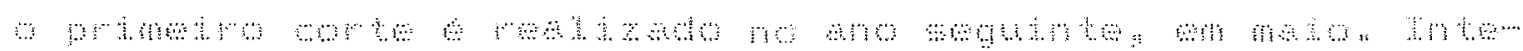

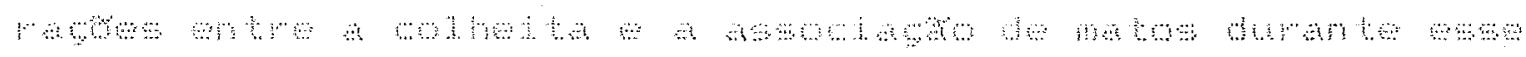
men

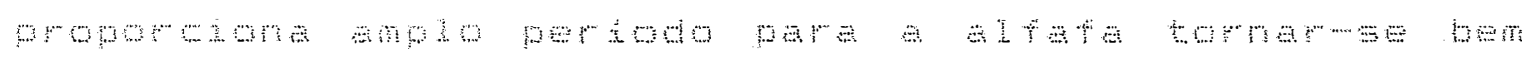
mane

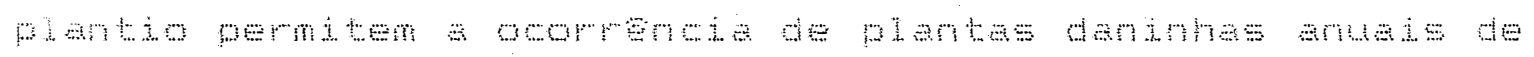

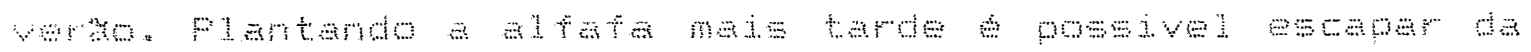

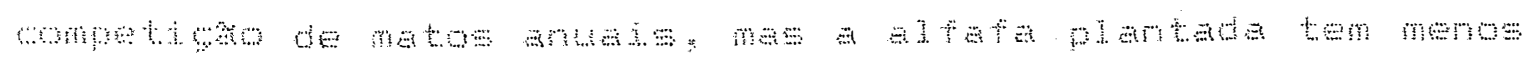

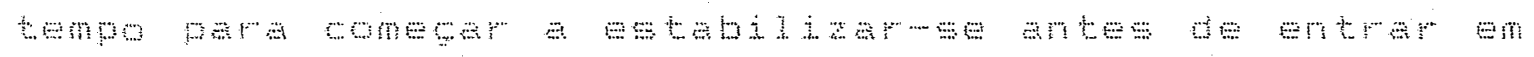

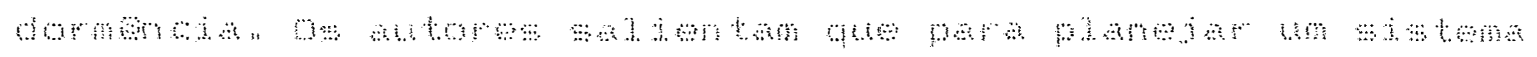

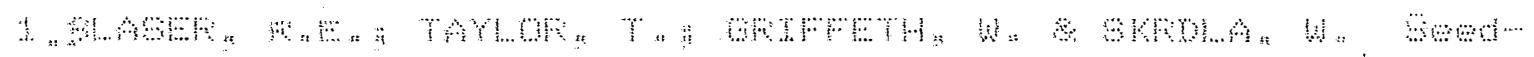

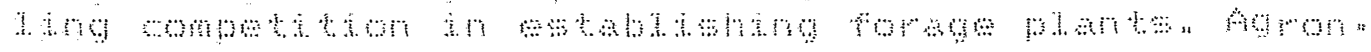

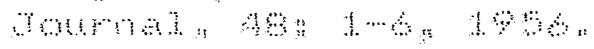




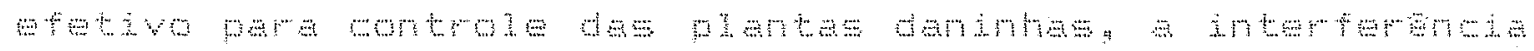

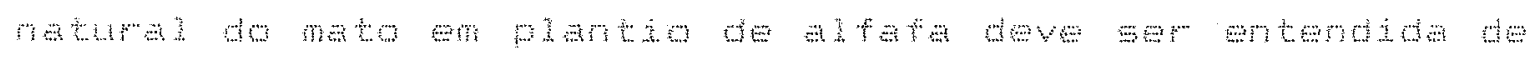

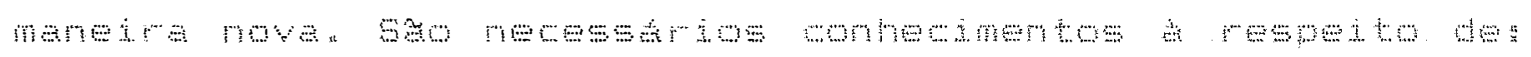

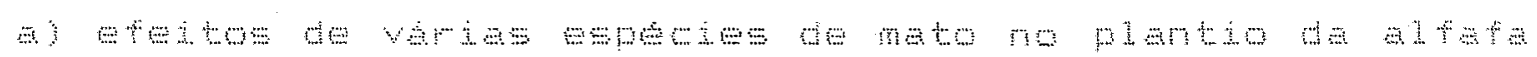

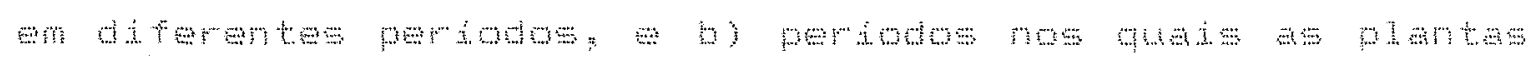

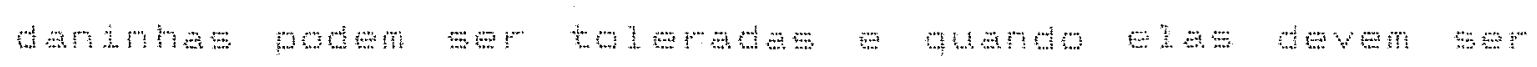

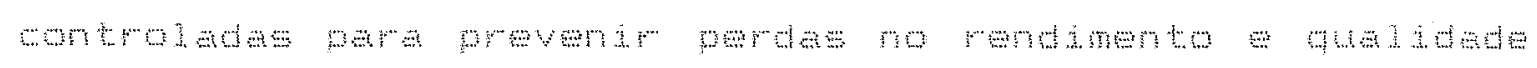
an mo whon

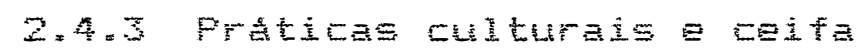

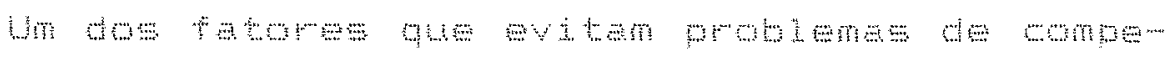

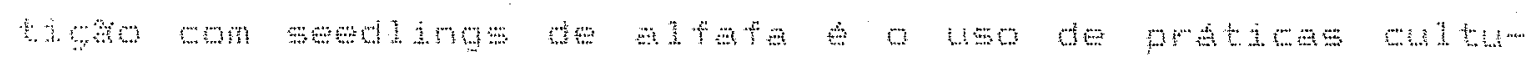

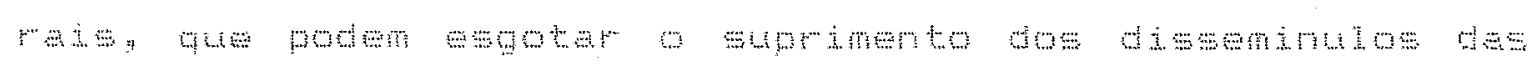

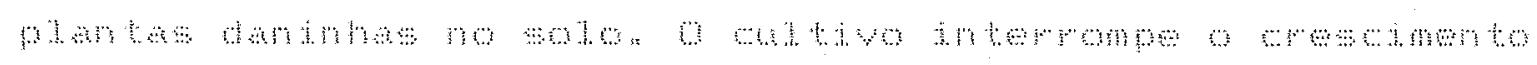

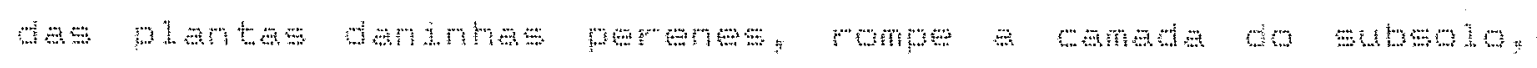

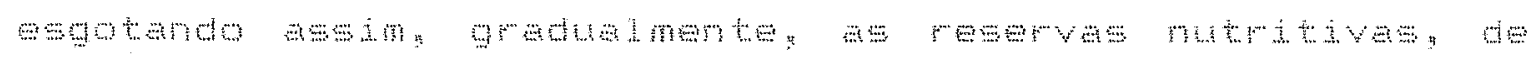

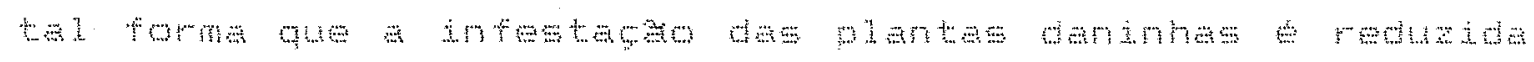
act intmin
\end{abstract}

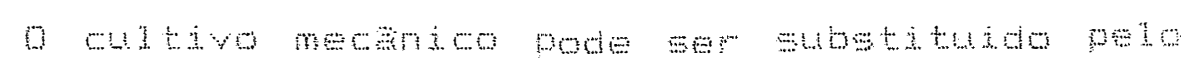

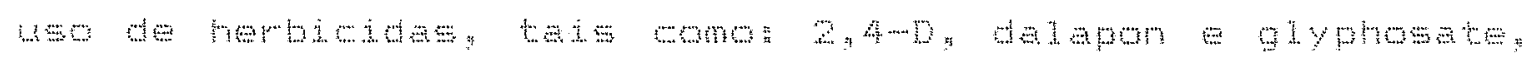

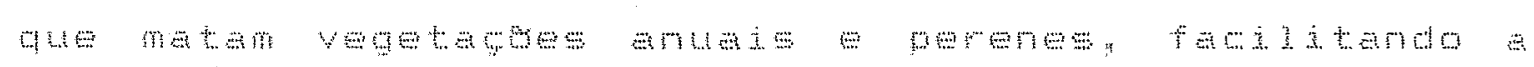
mand

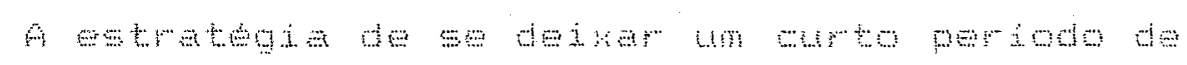

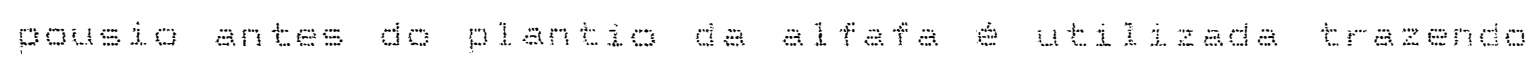

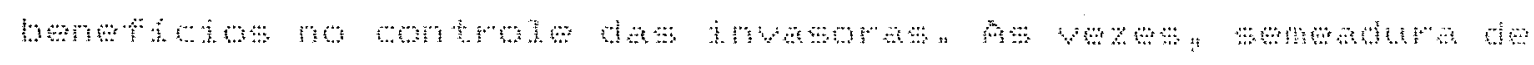




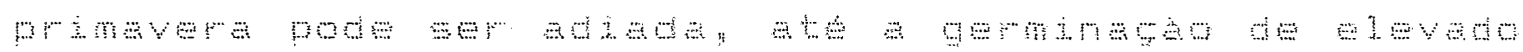

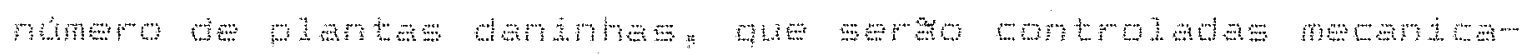

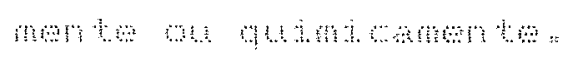

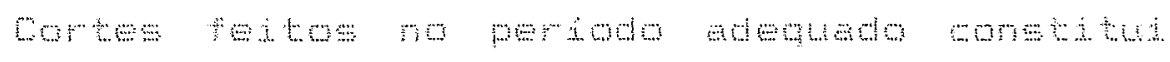

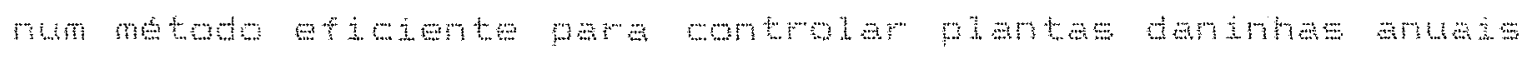

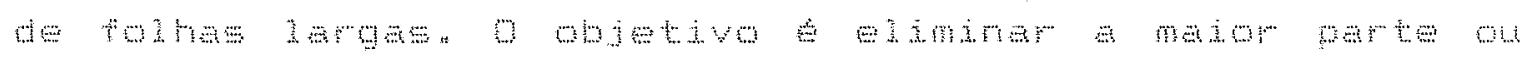

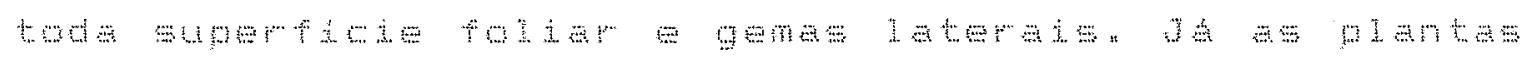

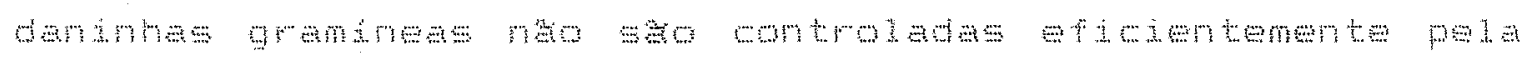

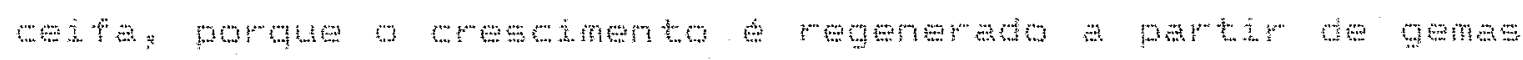

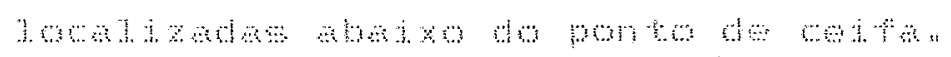

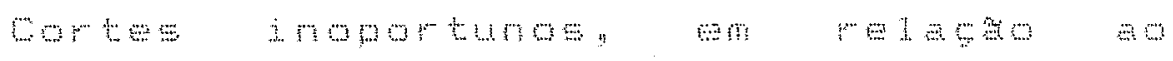

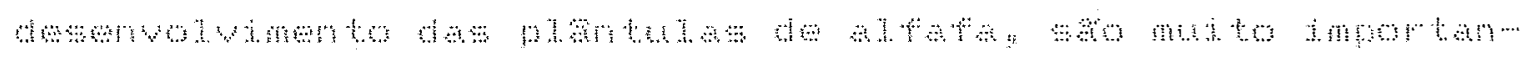

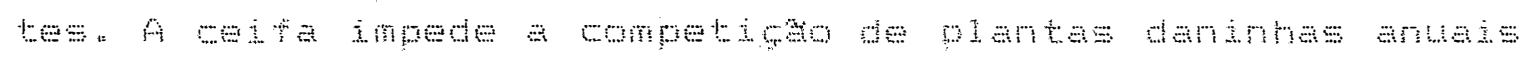

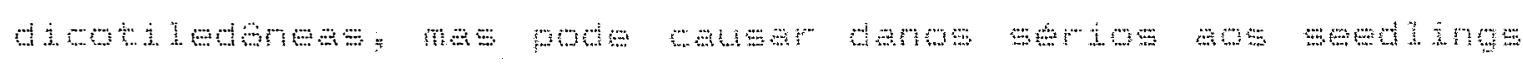

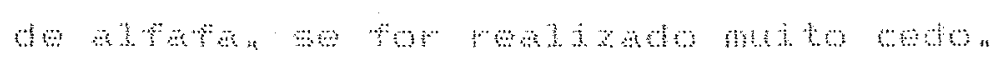

\subsubsection{Controle quimico}

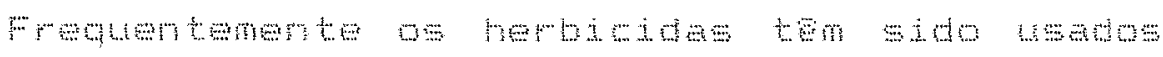

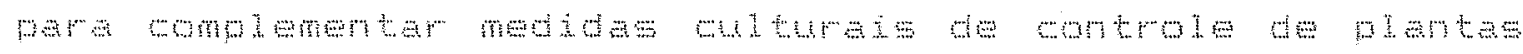

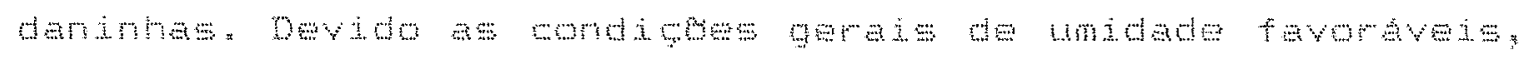

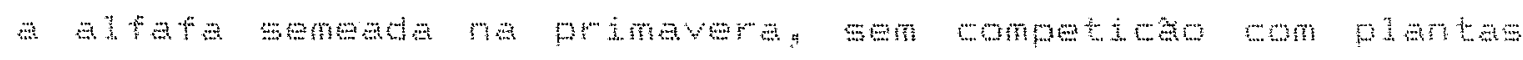

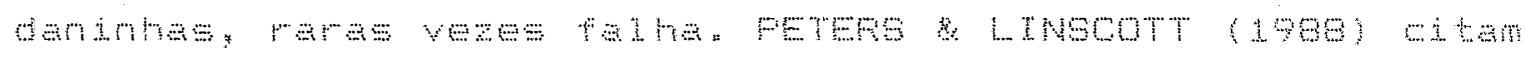

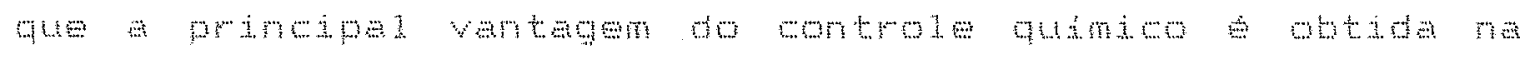

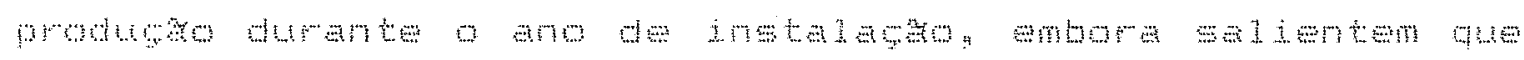

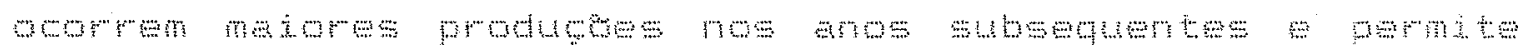




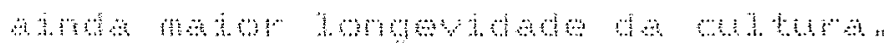

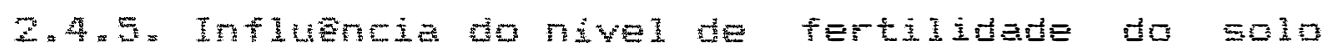 sobre cuntrue de plantas daninhas
}

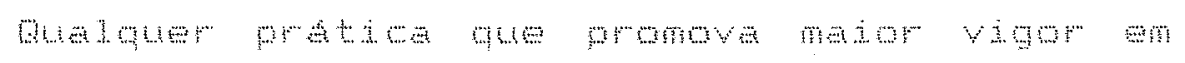

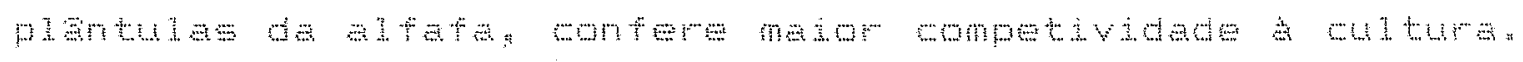

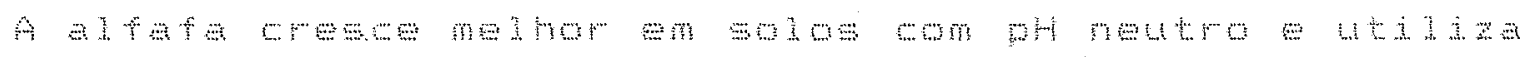

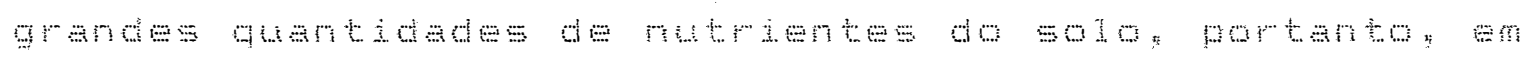

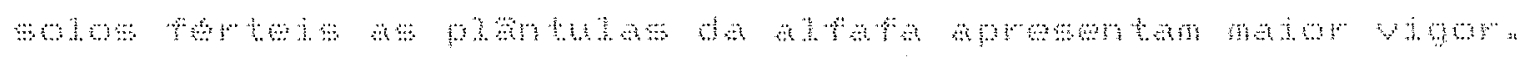

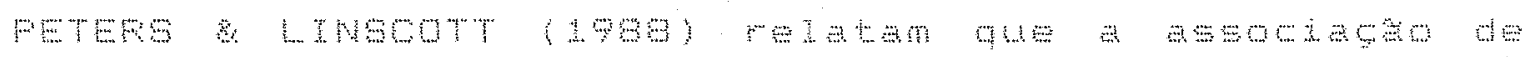

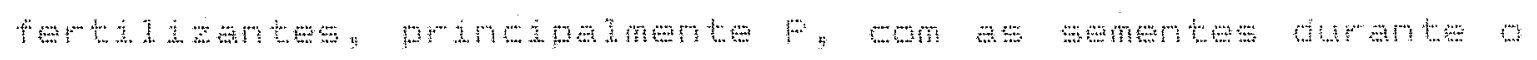

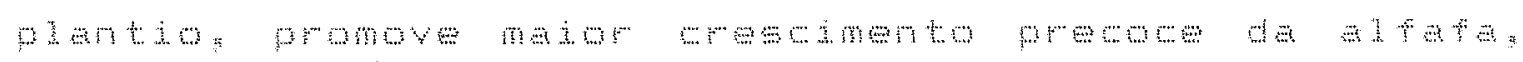

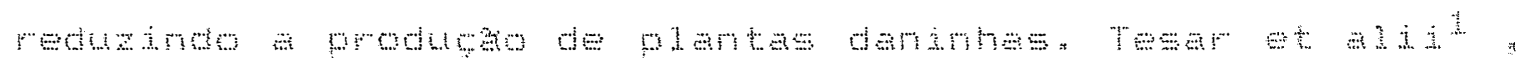

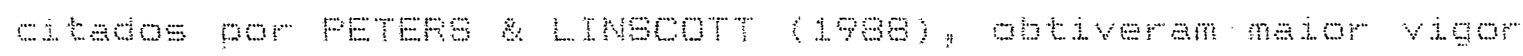

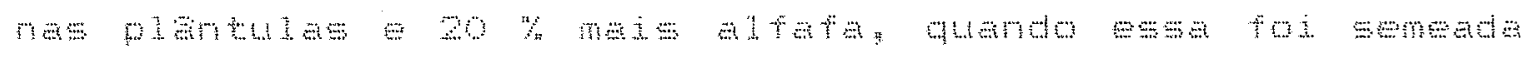

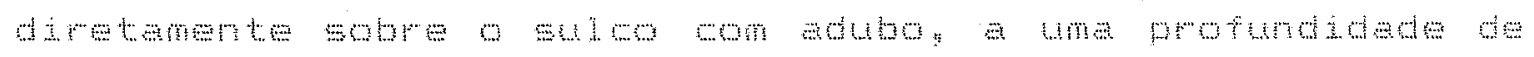

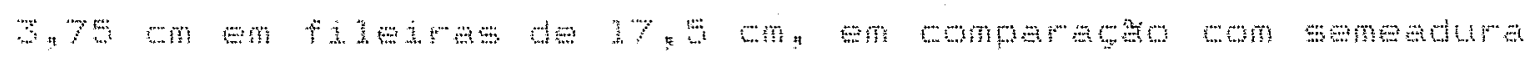

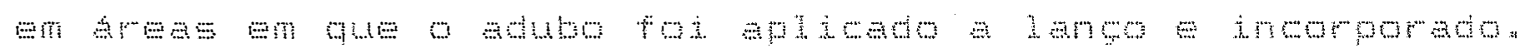

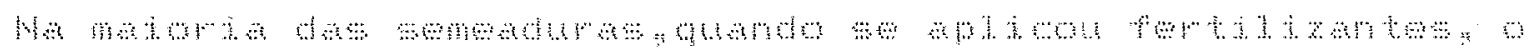

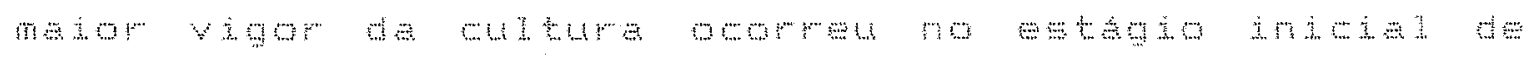

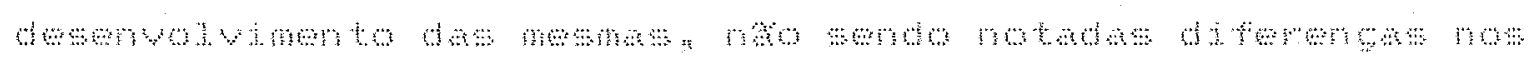

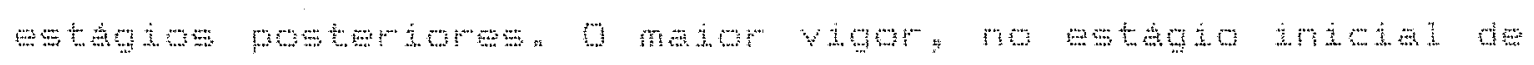

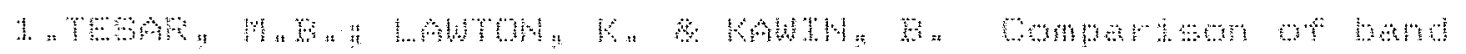

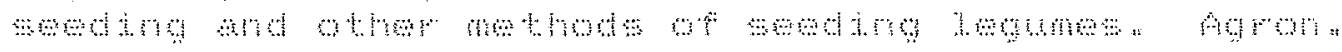

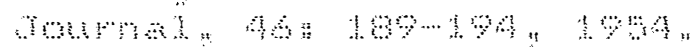




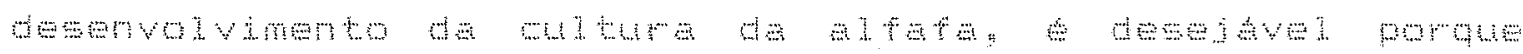

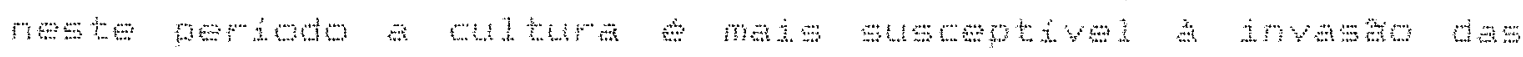

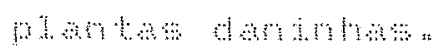

Entresmbo; nen todos nutrientes promoven wa

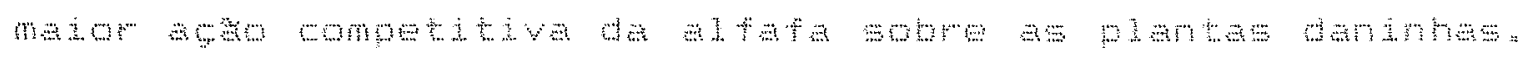

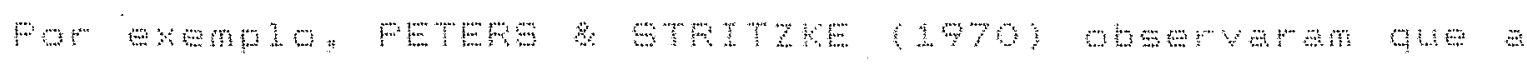

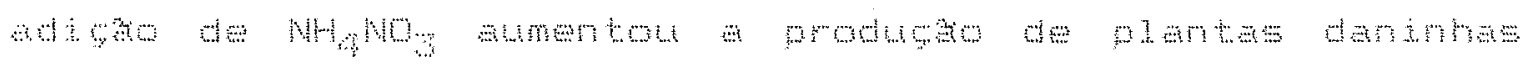

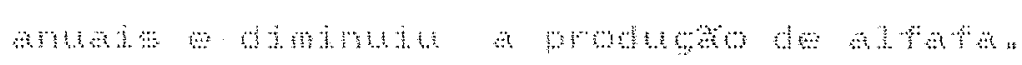

\subsubsection{Outros metodos de controle na ingtalaço da alfata}

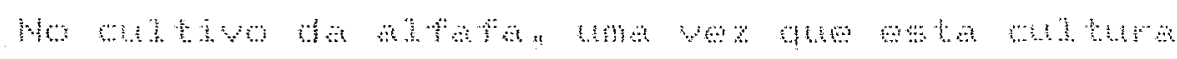

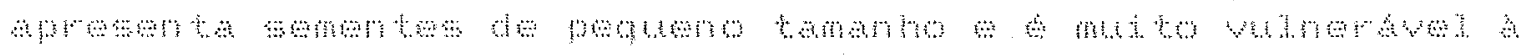

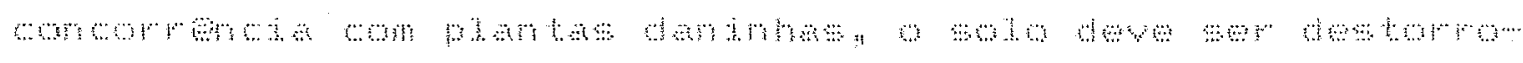

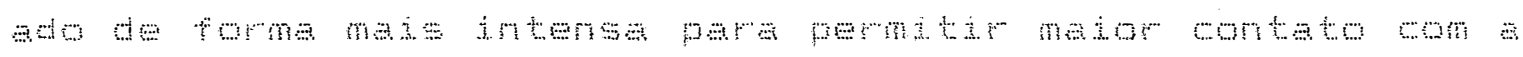

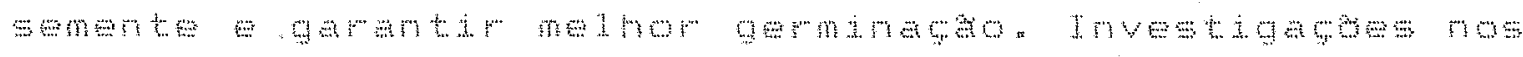

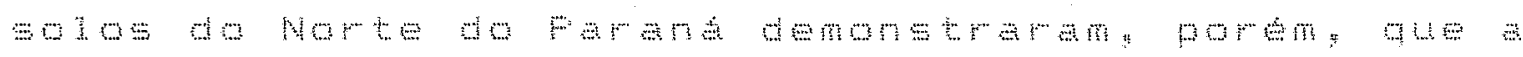

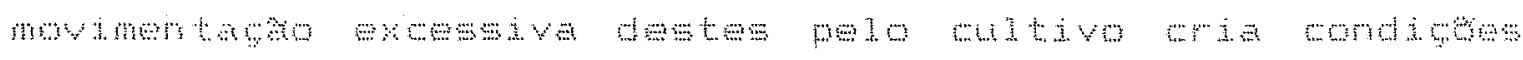
An

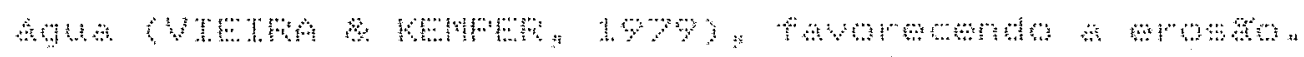

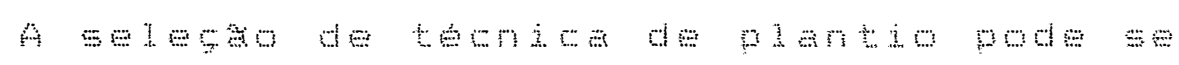

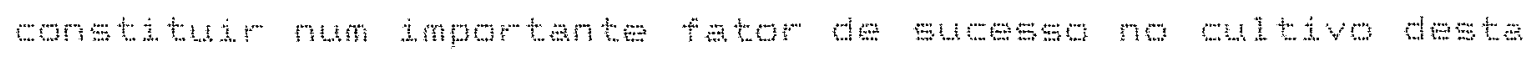
1.

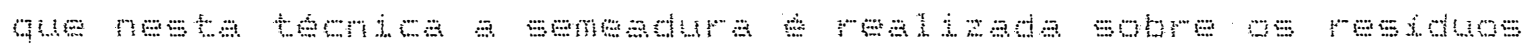

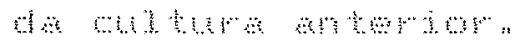




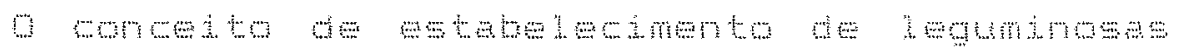

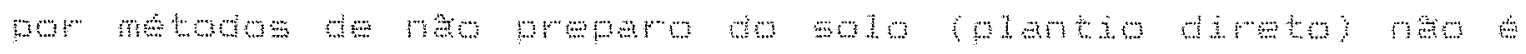

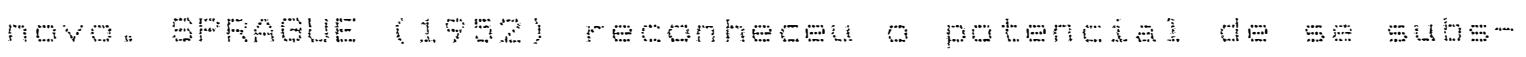

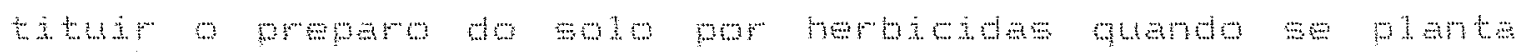

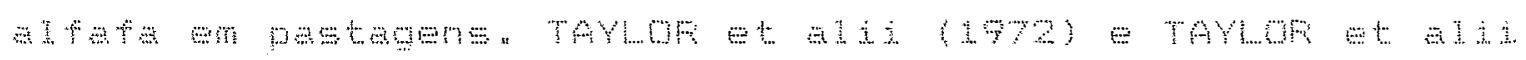

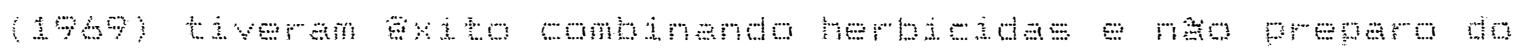

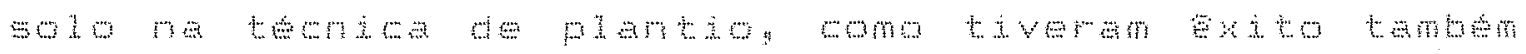

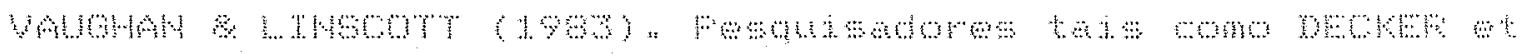

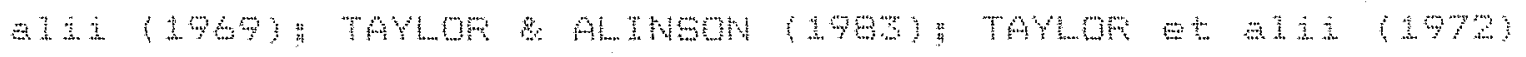

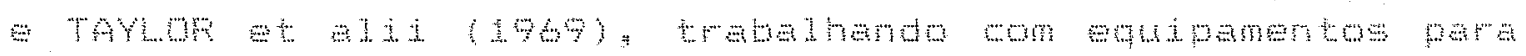

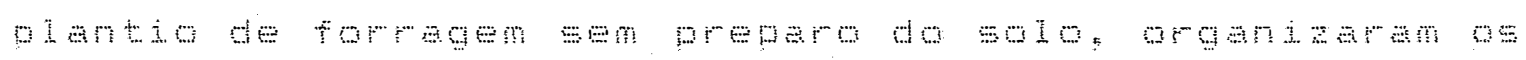

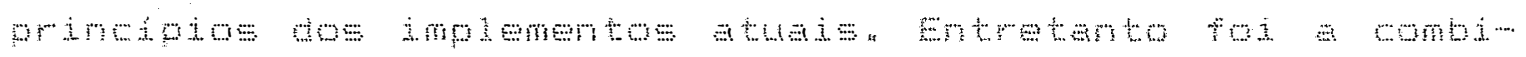

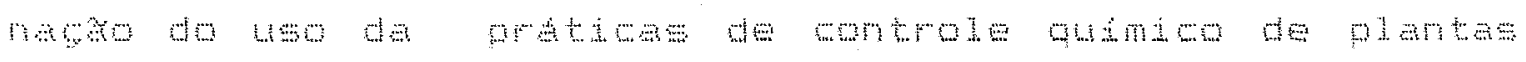

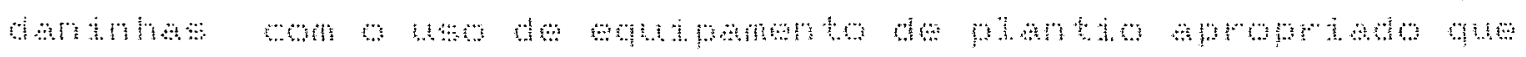

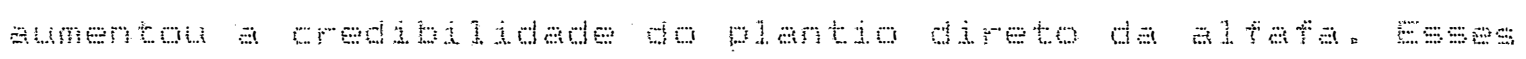

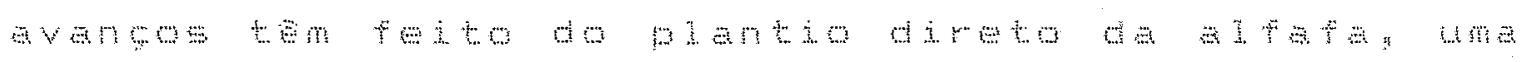

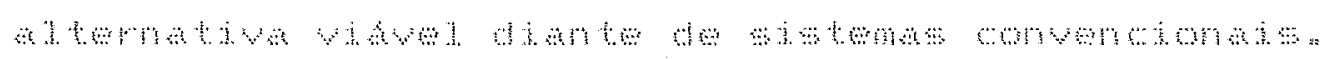

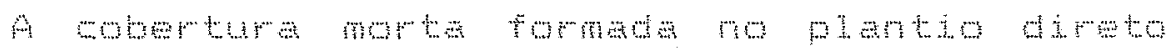

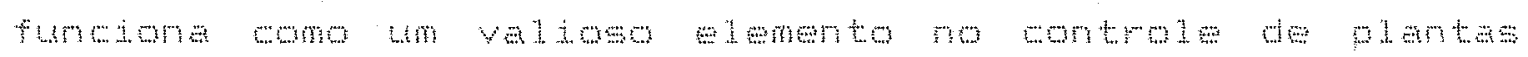

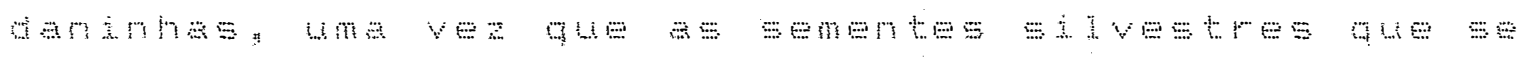

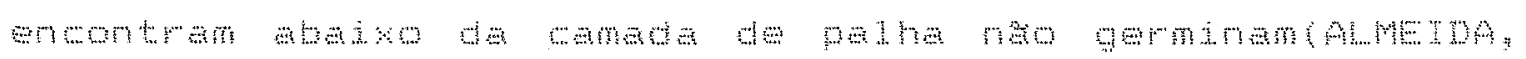

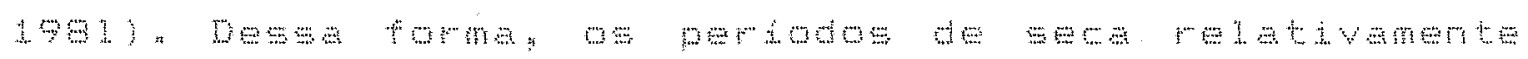

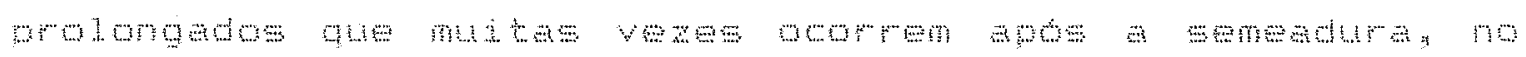

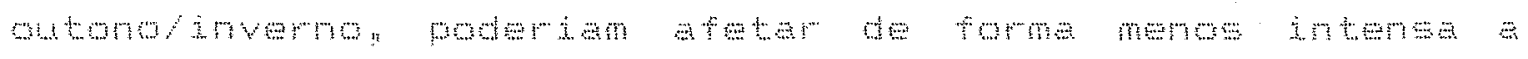

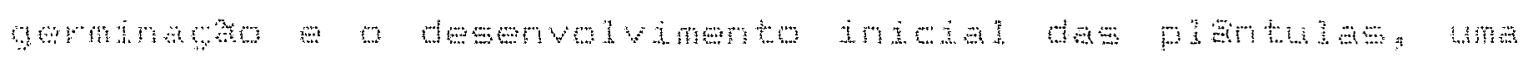

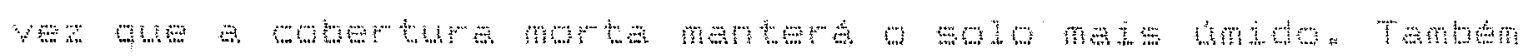


a

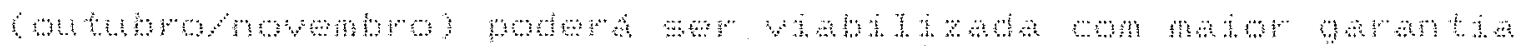
сы

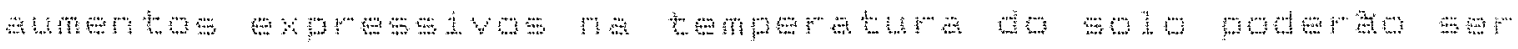

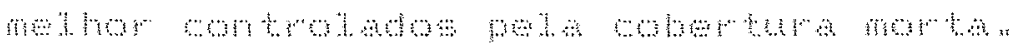

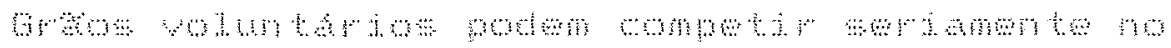

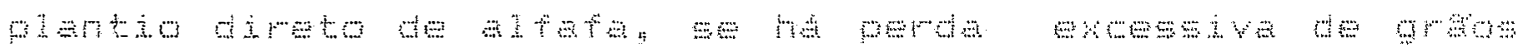

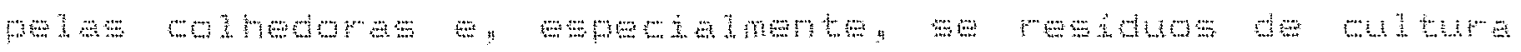

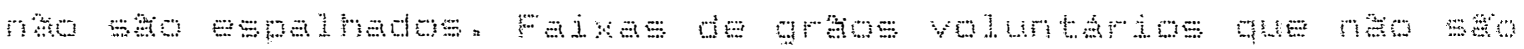

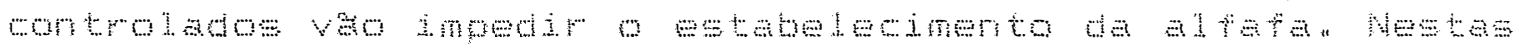

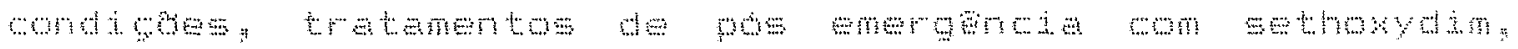
Fमn

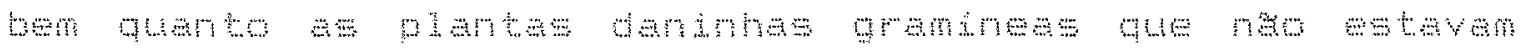
mom mан mom

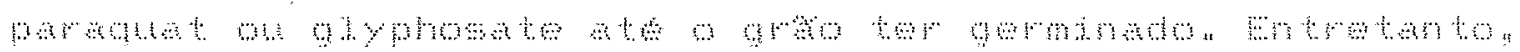

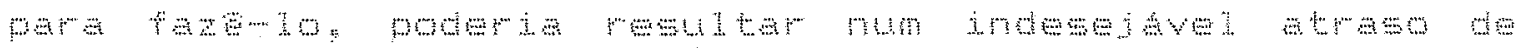

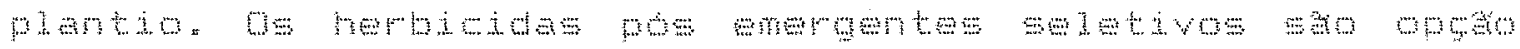

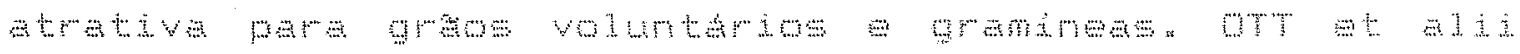

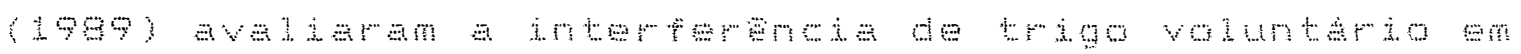

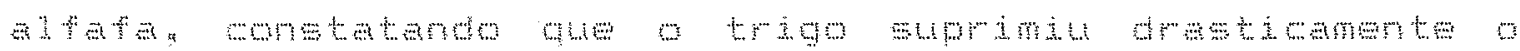

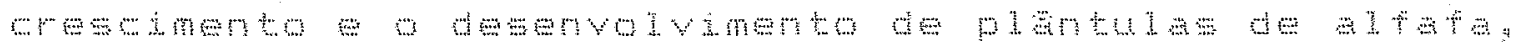

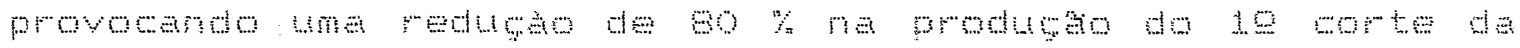

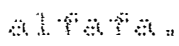




\title{
3 - MATERIAL E METODOS
}

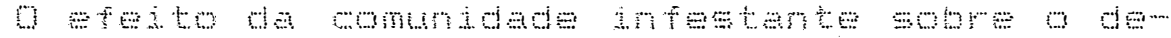

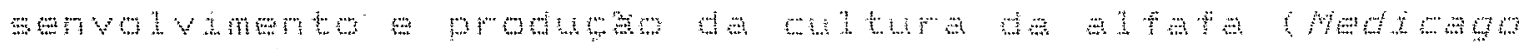

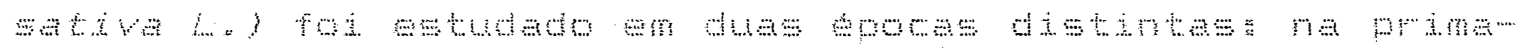 \\ vera

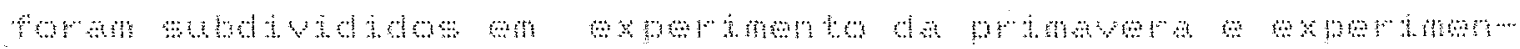 \\ to do menton
}

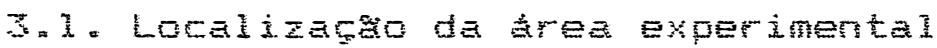

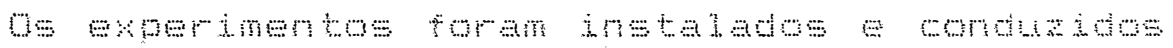

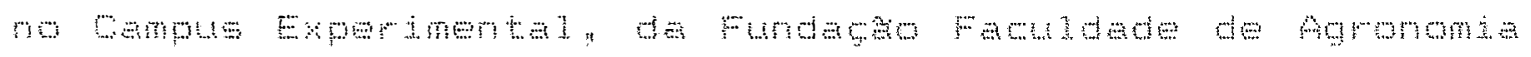

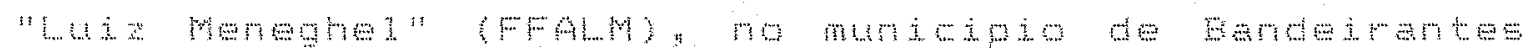

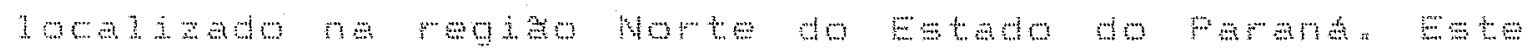
muncososa

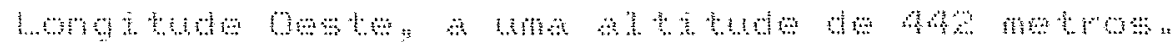

\subsection{Chima $E 5010$}




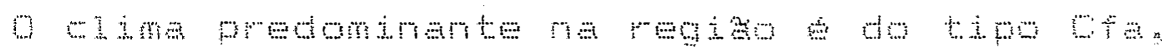

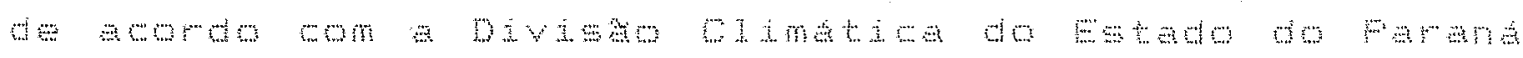

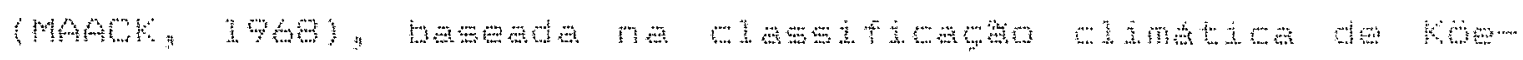

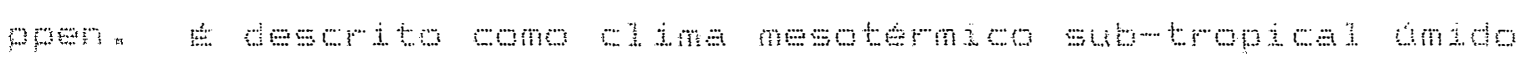
क्ष

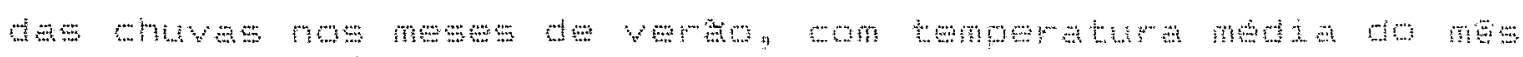

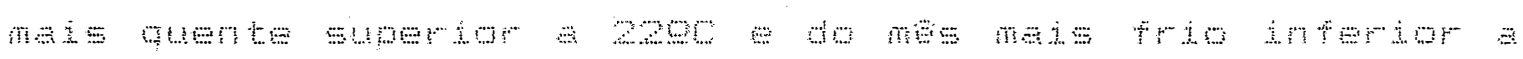

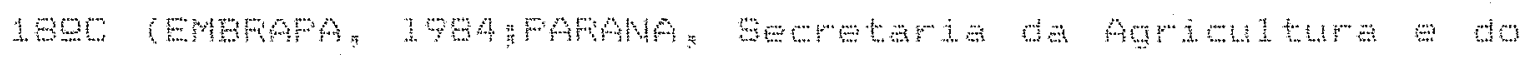

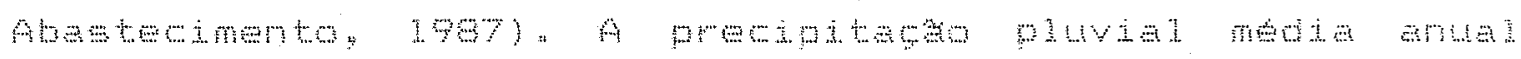

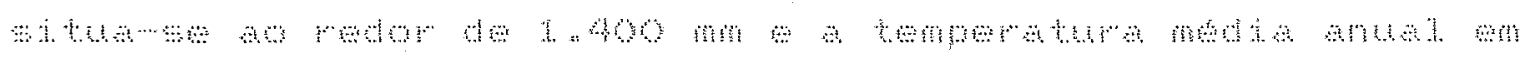

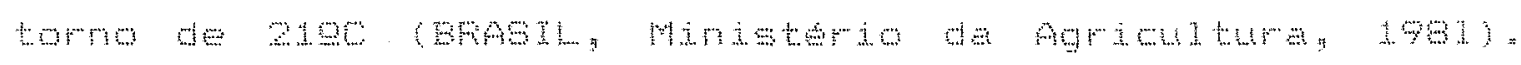

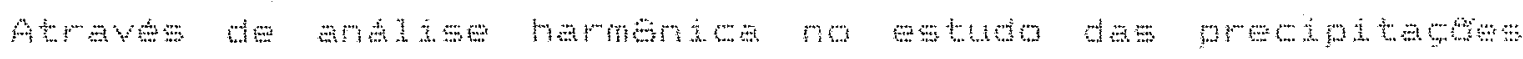

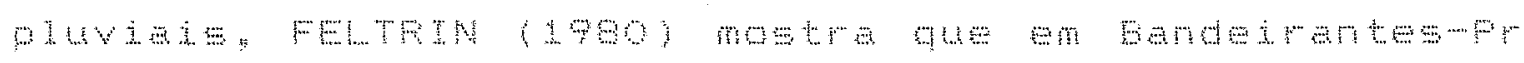

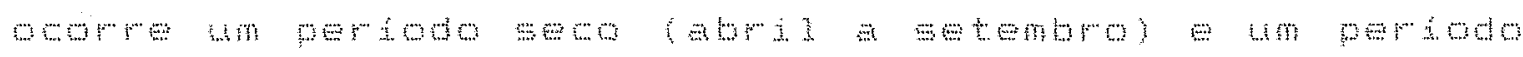

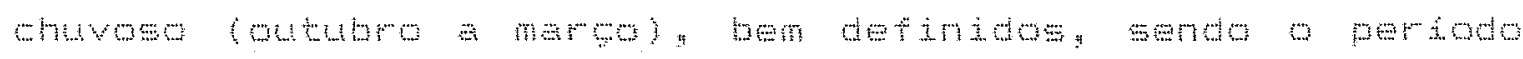

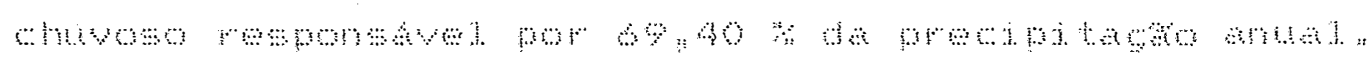

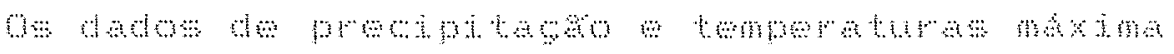

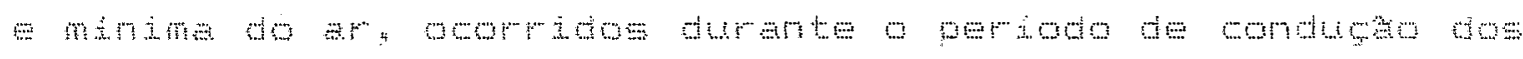

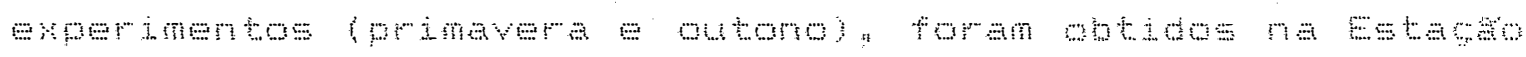

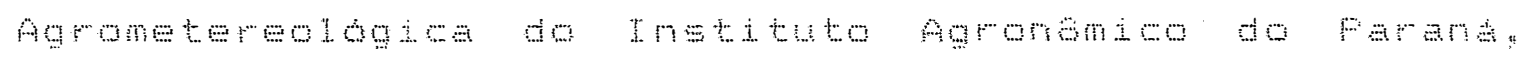

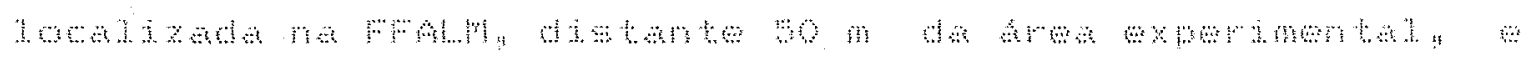

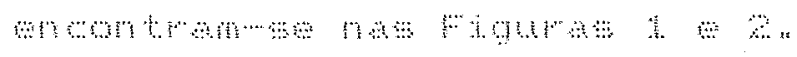

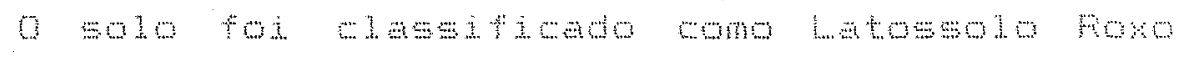

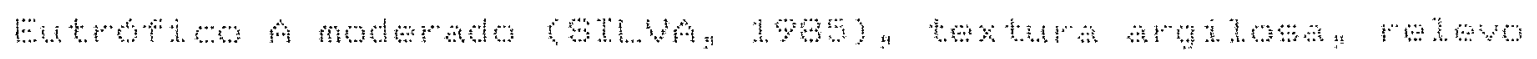

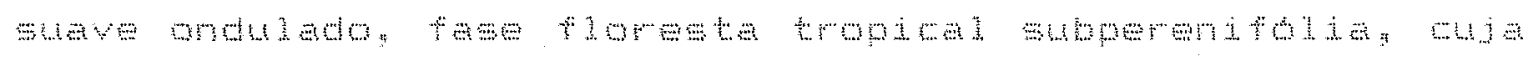

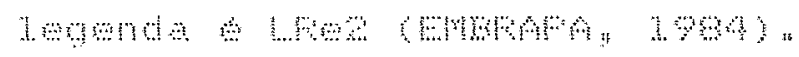




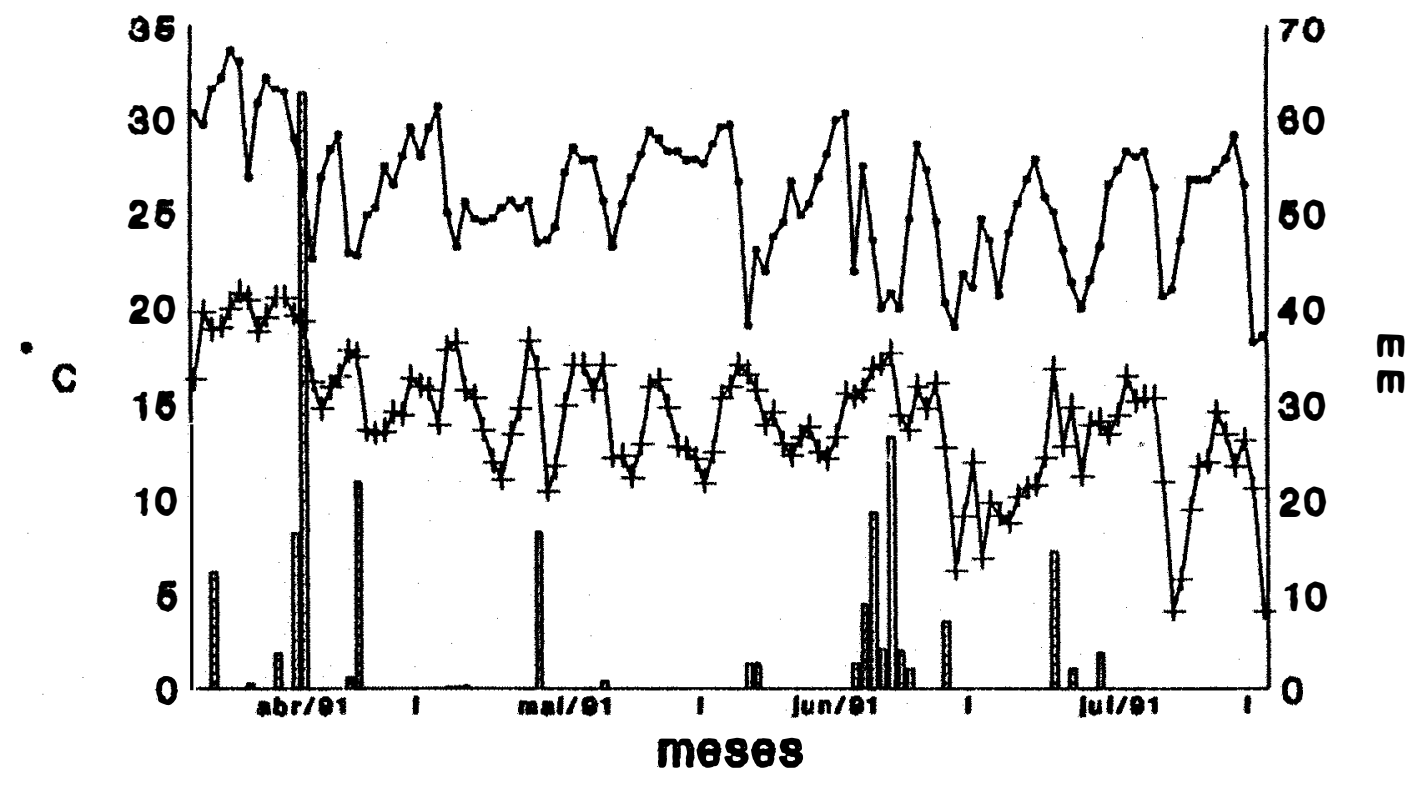

- Tomp. Max. + Tomp. Min. Preclpltacao

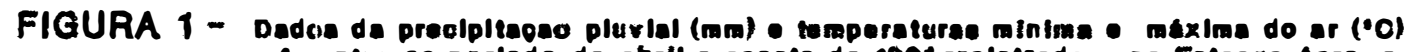

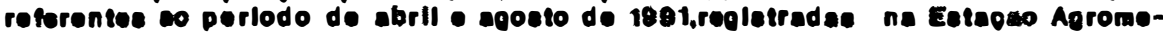
teoraloglea da FRALM - Bandeirantee, Ph.

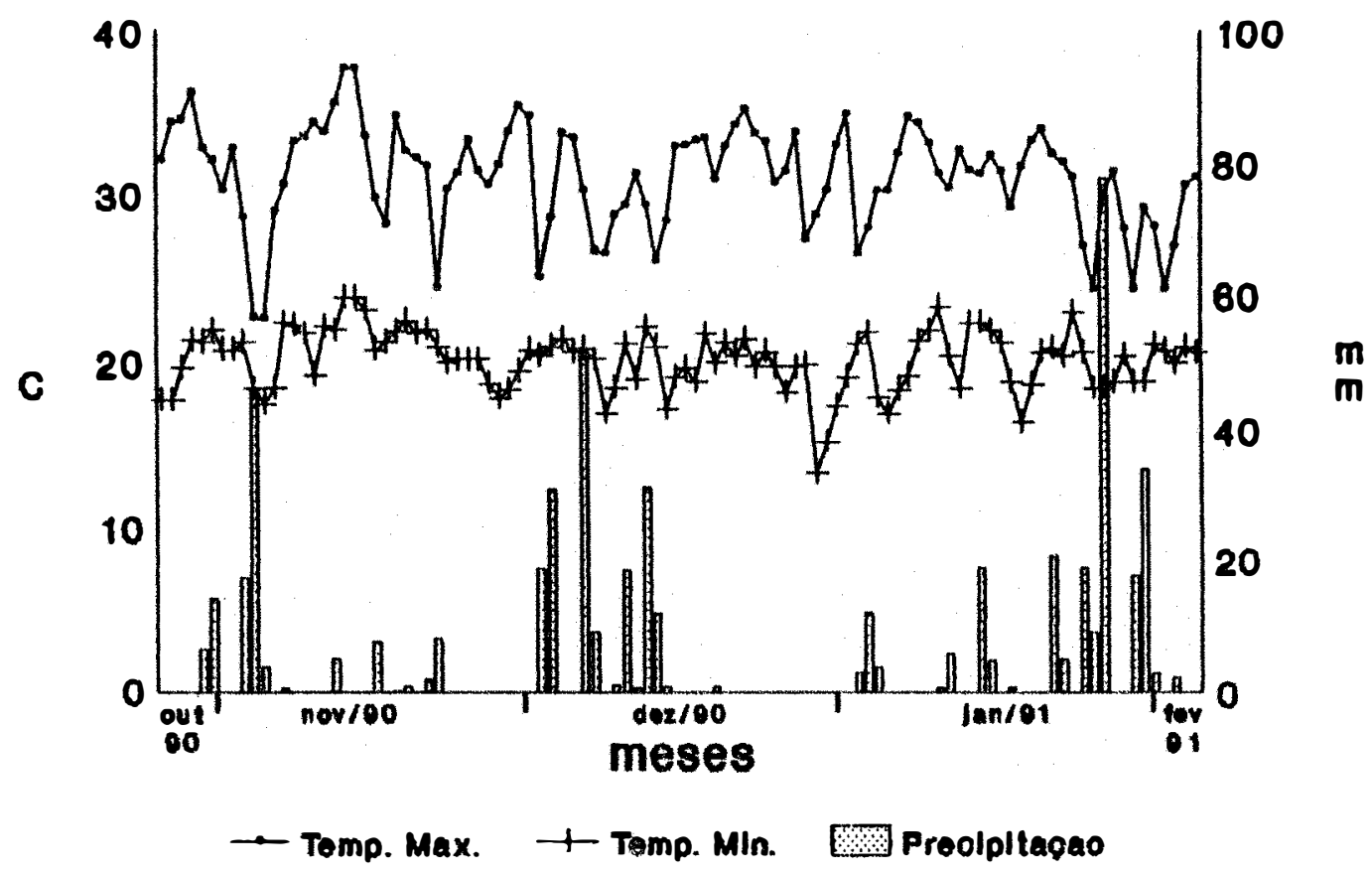

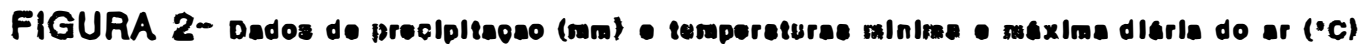
reforentes 0 perlodo de outubro de 1000 a feverolre de 1001 , regletradoe na

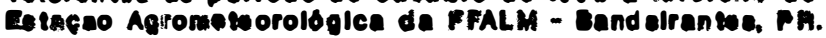




\section{S. S. CHeivar}

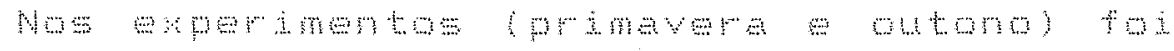

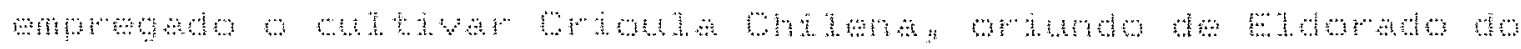

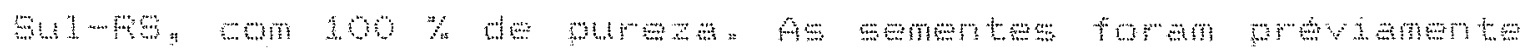

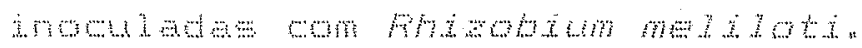

\subsection{Tratamentos e delineamento experimental}

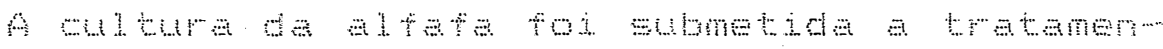

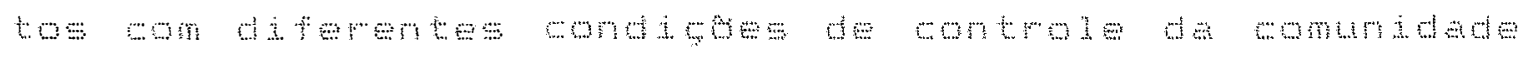

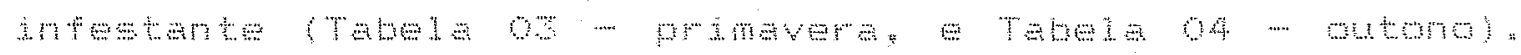

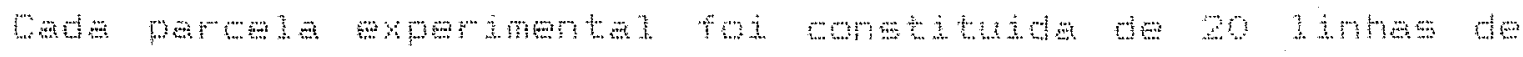

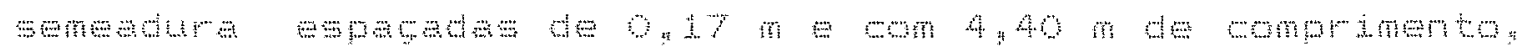

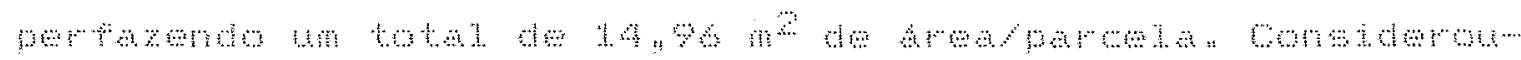

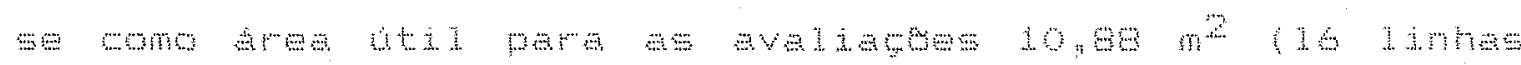

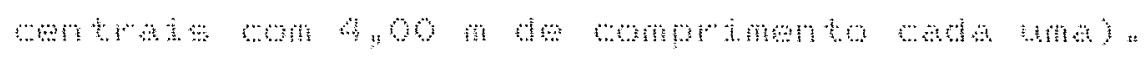

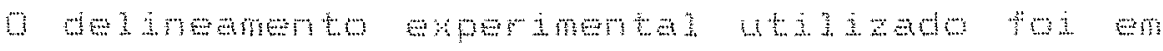

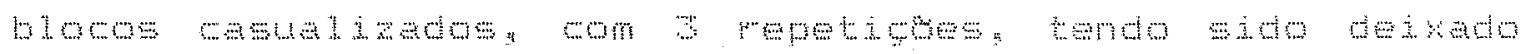

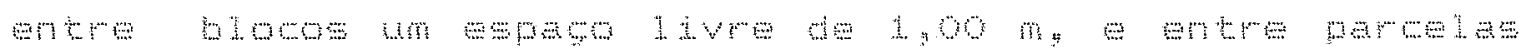

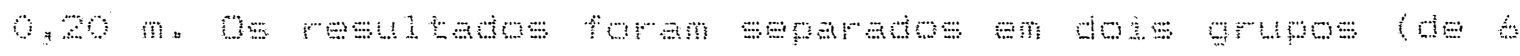

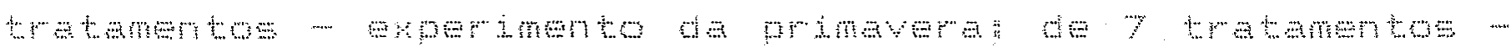

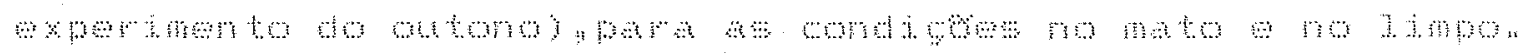

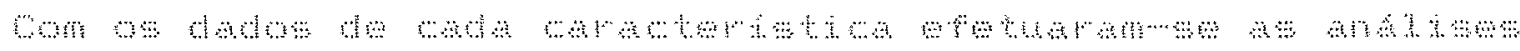

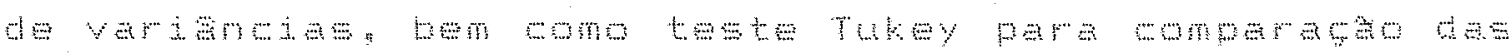
minisis: 


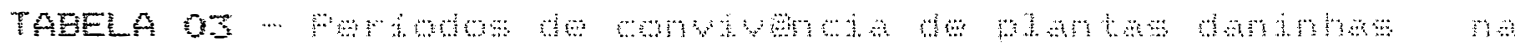

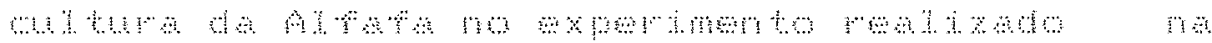

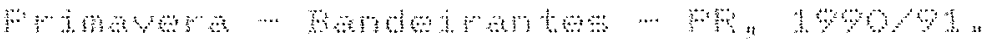

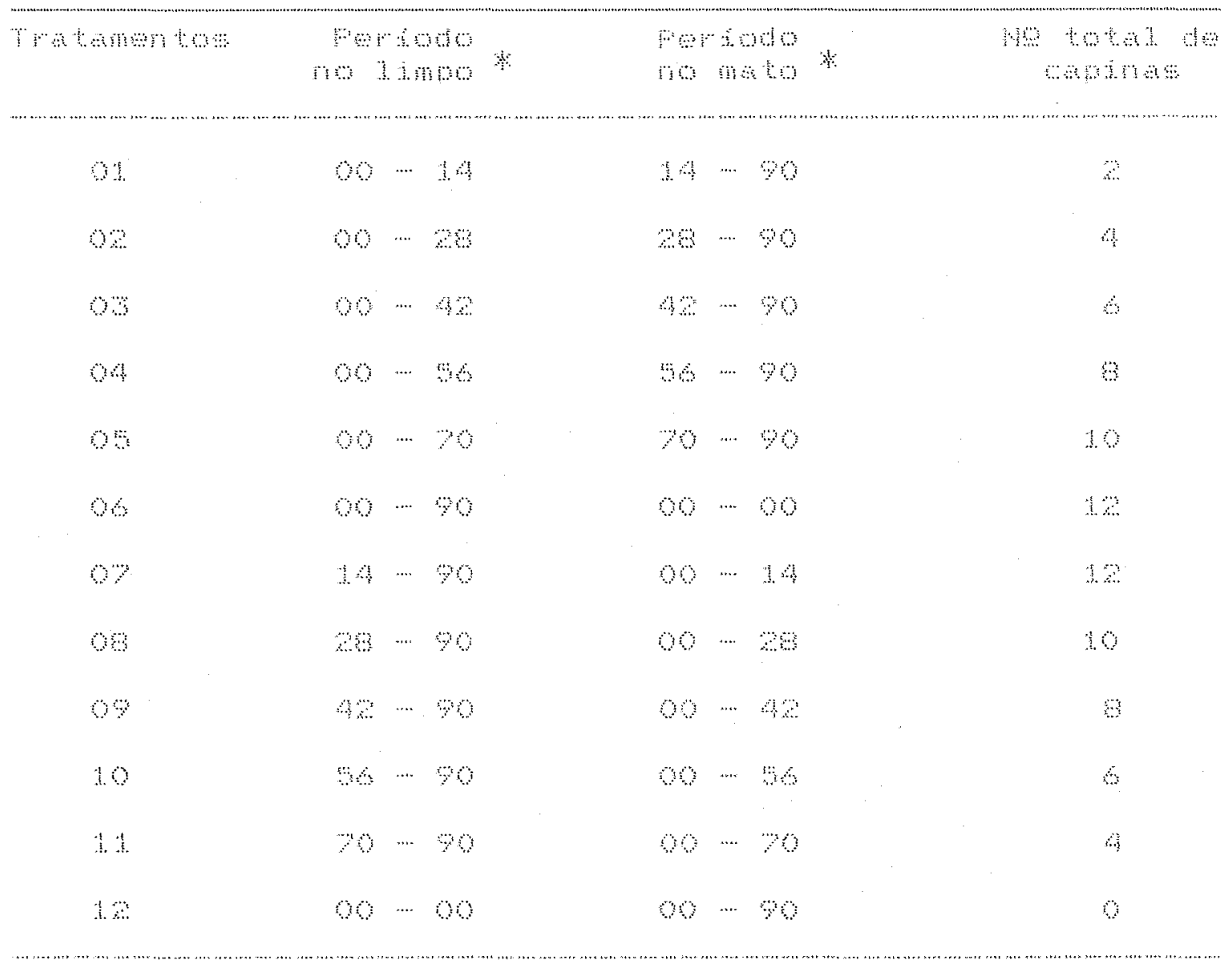

H.

Whan m.

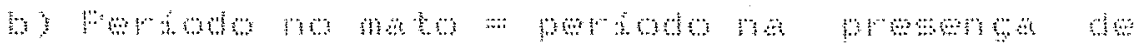

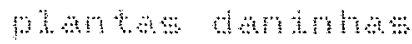




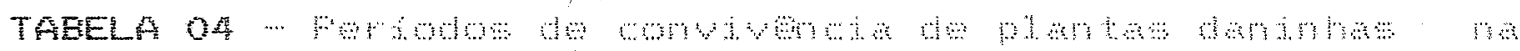

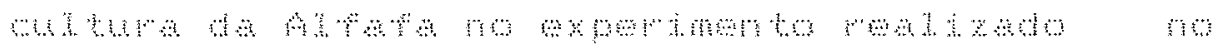

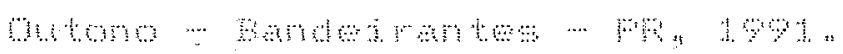

\begin{tabular}{|c|c|c|c|c|c|}
\hline Masmantom & $m$ & $\begin{array}{c}\text { seno } \\
\operatorname{simpo}\end{array}$ & $\begin{array}{l}m i s \\
m o\end{array}$ & 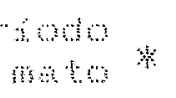 & $\begin{array}{c}\text { Metert de } \\
\text { opsmas }\end{array}$ \\
\hline e. & o & A & 14 & $\ldots \quad 10$ & 2 \\
\hline n & 0 & 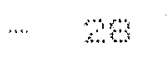 & 28 & $\ldots \quad 10$ & 4 \\
\hline$\%$ & ळ & $4:$ & : & 110 & $\dot{\alpha}$ \\
\hline 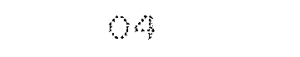 & क & $\ldots$ & 6 & $\ldots \quad 110$ & в \\
\hline in & ০ & $\ldots \quad 0$ & 9 & 110 & 10 \\
\hline$\infty$ & क & $\ldots$ & 84 & $\mathrm{NO}$ & 12 \\
\hline$\%$ & o & $\ldots .1 \mathrm{n}$ & e & ओ & 18 \\
\hline 0 & 19 & $\ldots \ldots$ & 0 & 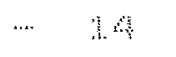 & 14 \\
\hline \% & $\approx 3$ & $\ldots+10$ & क & 2 & 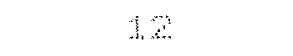 \\
\hline 1 & $4 \%$ & $\ldots+10$ & ळ & 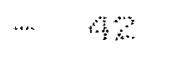 & 10 \\
\hline 4 & 8 & $\ldots 110$ & ळ & $\pi$ & 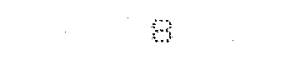 \\
\hline 12 & $\%$ & $\ldots 10$ & ओ & $\ldots$. & 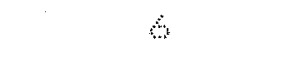 \\
\hline 3 & e & $\ldots \quad 1 \mathrm{H}$ & ब & $\ldots$ & 9 \\
\hline 16 & 0 & ... क & 0 & $\cdots \quad 110$ & 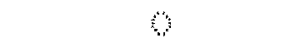 \\
\hline
\end{tabular}

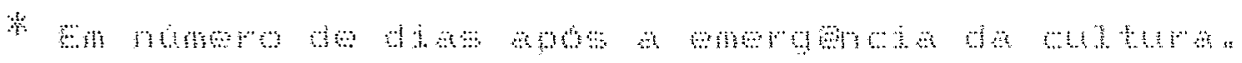

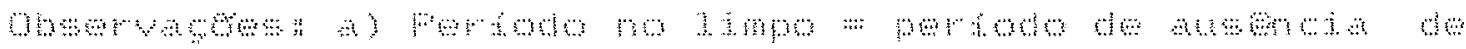

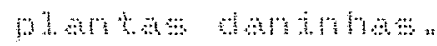

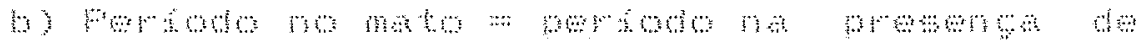

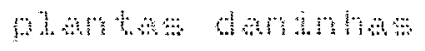




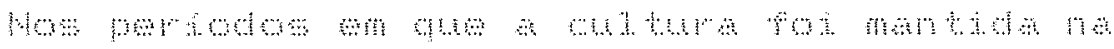

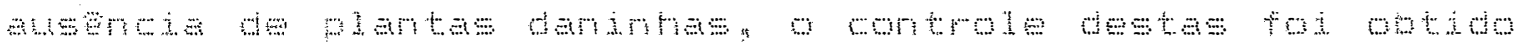

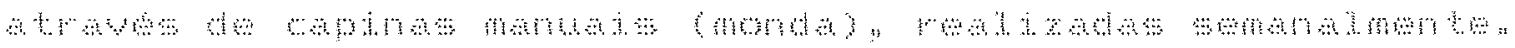

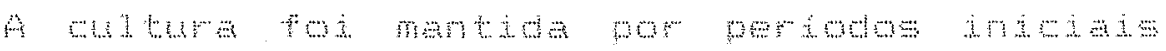

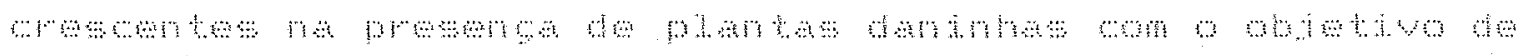

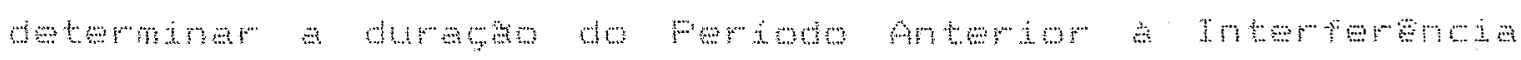

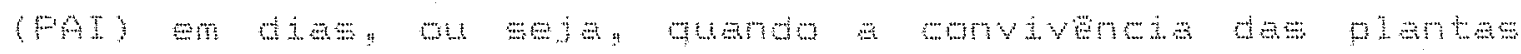

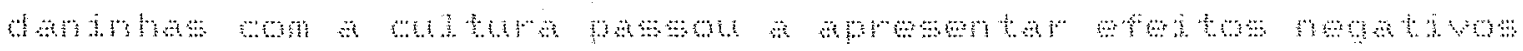

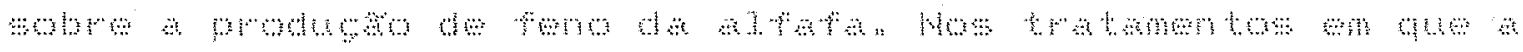

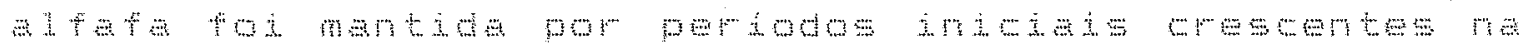

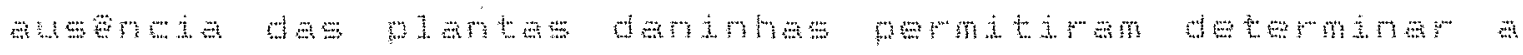

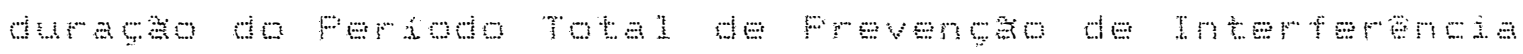

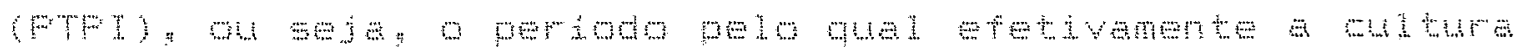

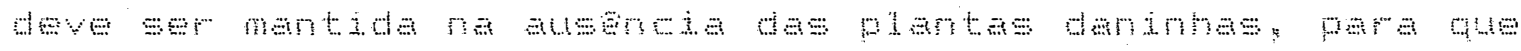

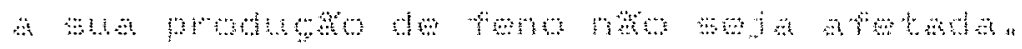

\section{S. S. Instalaca dos experimentos}

\section{5 .1 Experimento da Frimavera}

\section{S.5.1.1 = Freparo e adubaço do 50 lo}

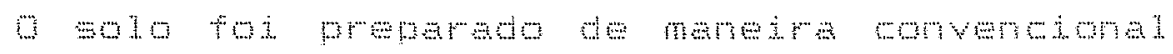

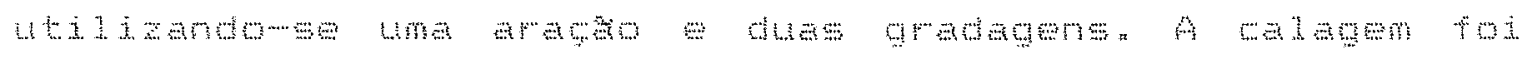

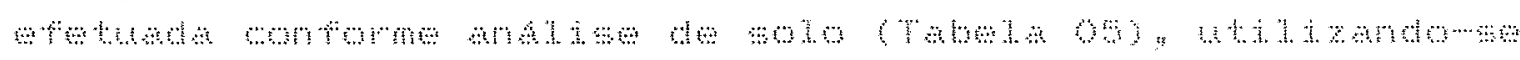

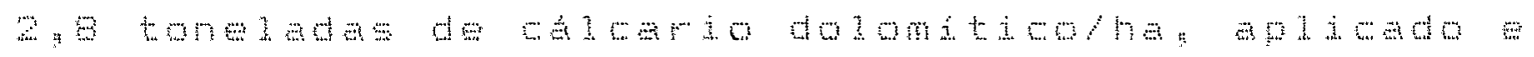




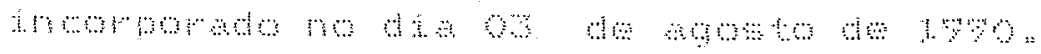

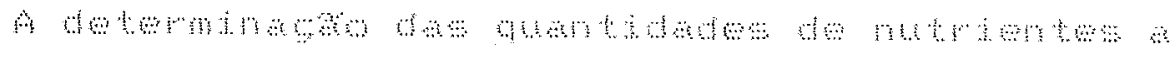
\%

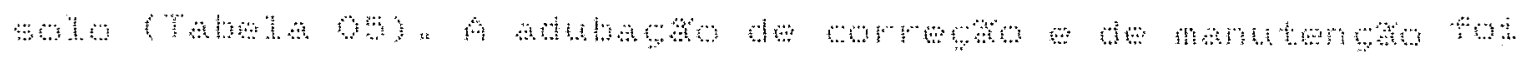
"as

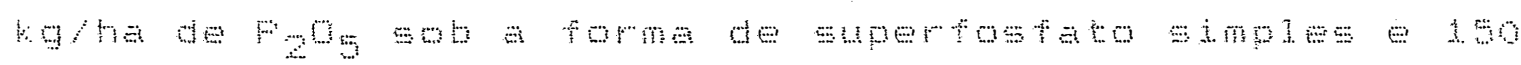

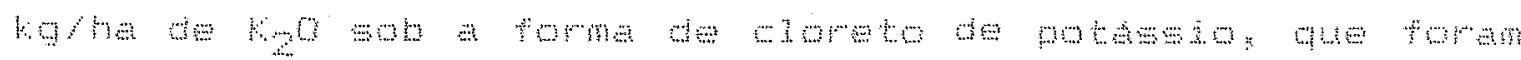

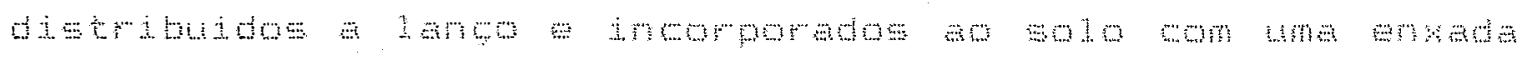

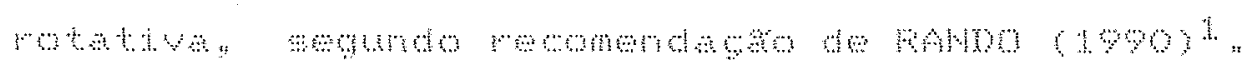

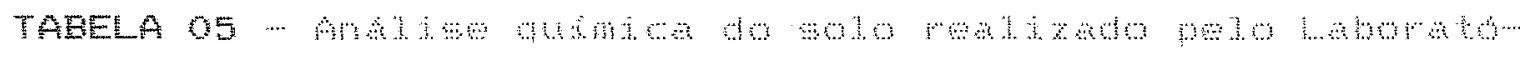

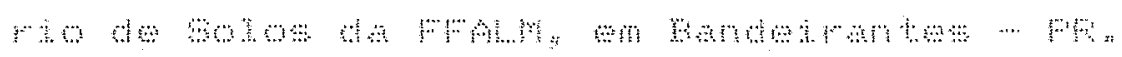

\begin{tabular}{|c|c|c|c|c|c|c|c|}
\hline \multirow{2}{*}{$\begin{array}{c}\mathrm{pH} \\
\mathrm{m}\end{array}$} & \multicolumn{5}{|c|}{ man } & \multirow{2}{*}{ 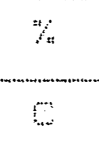 } & \multirow{2}{*}{ ma } \\
\hline & m & $M+M$ & m & 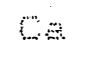 & H & & \\
\hline 5,1 & $\theta_{4}$ & $4: 3$ & $\because: 0$ & 7.2 & 1) & 1.2 & 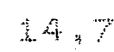 \\
\hline
\end{tabular}

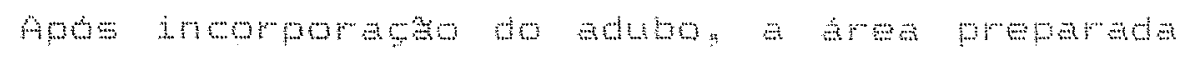

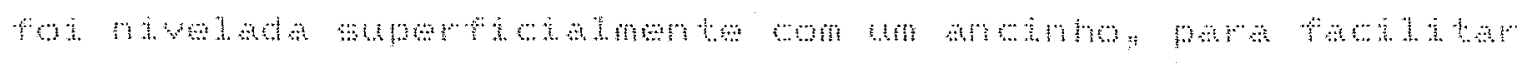
a mentum

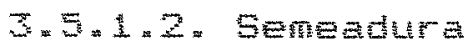

A $\quad$ s

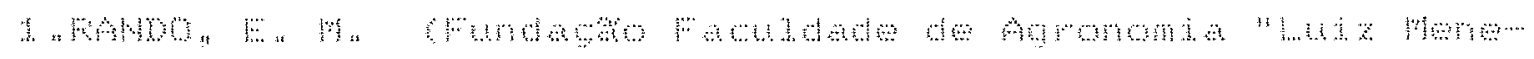

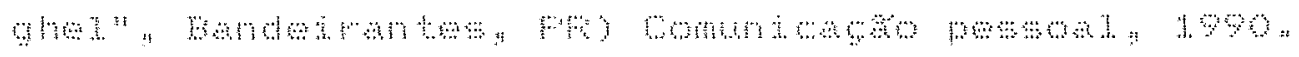




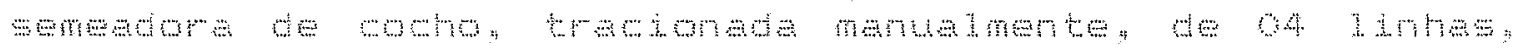
=papades de th

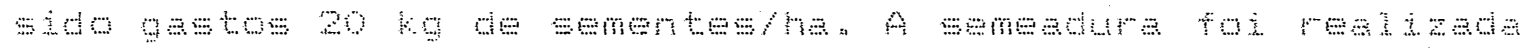
mo dн

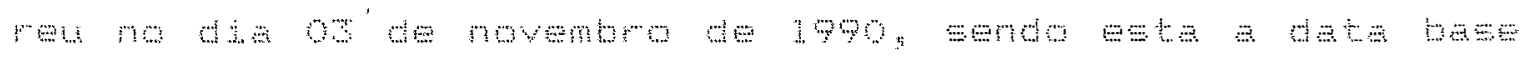

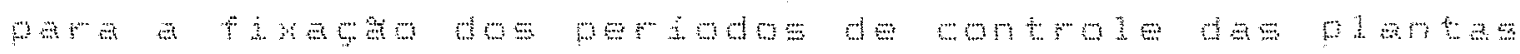
ingshes:

\section{5. 1.3. Controle fitoseanitario}

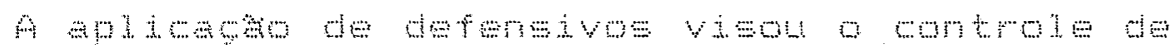

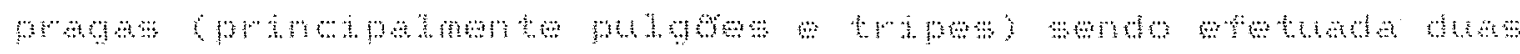

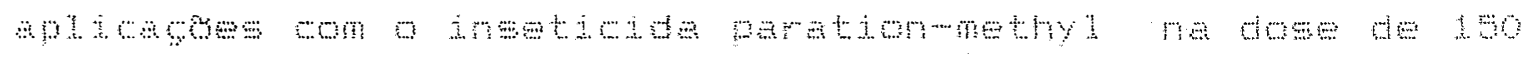

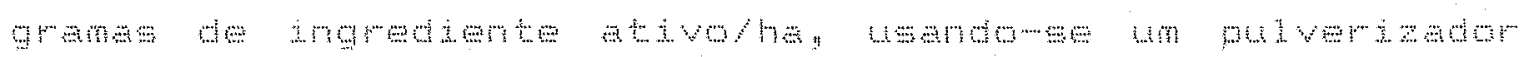
metal moman.

\subsubsection{Experimento do outono}

\subsubsection{Freptro do Eq}

पs

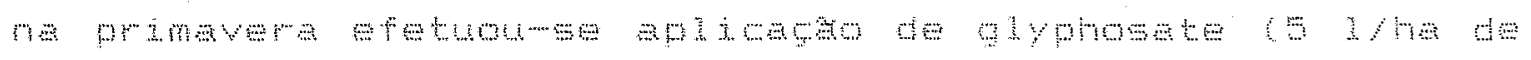

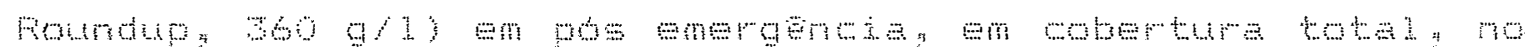
din 20 कि

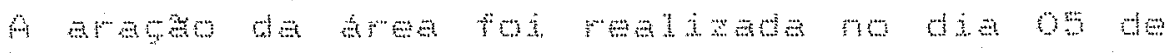

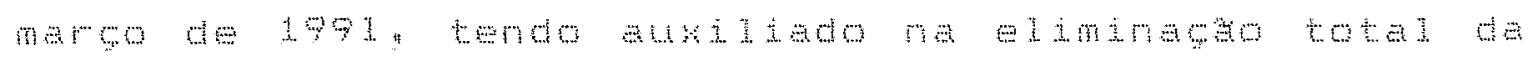




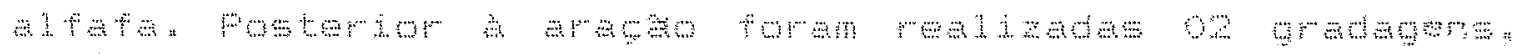

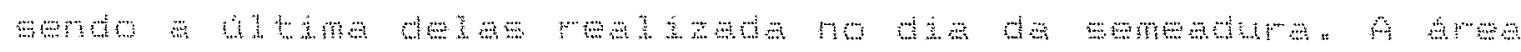

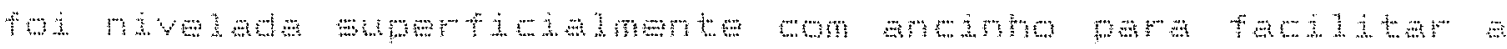

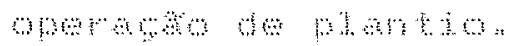

\section{$3=5.2 .2 .5 e m e a d u r a$}

क wmendum

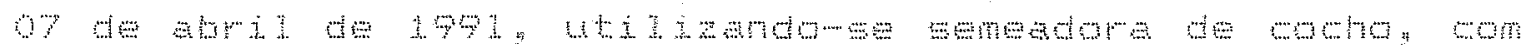

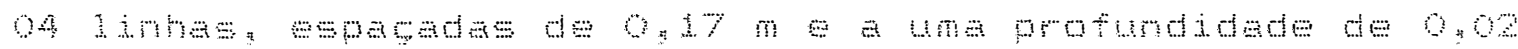

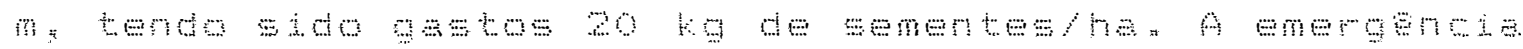

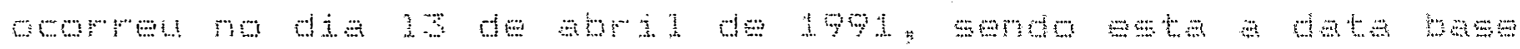

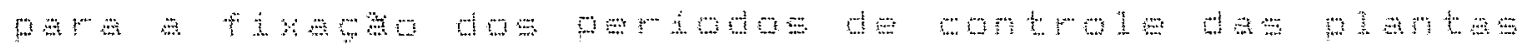
dithen.

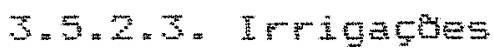

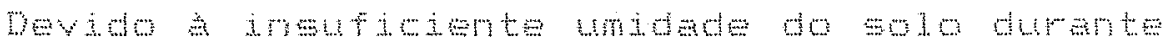

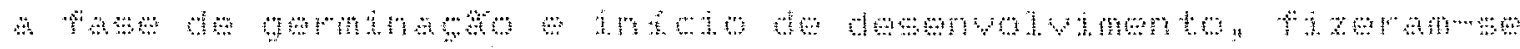

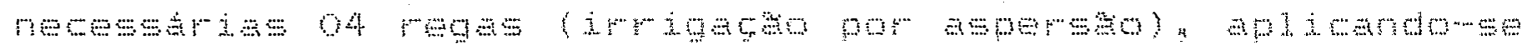

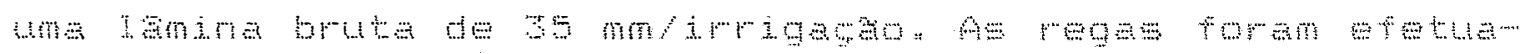
на

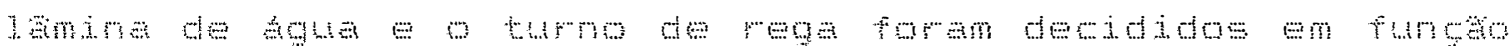

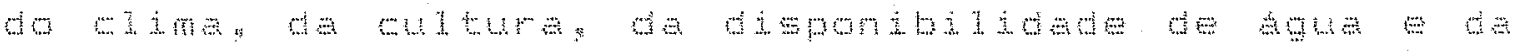

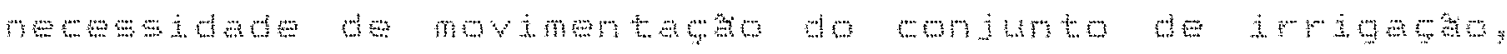




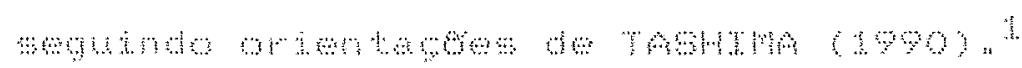

\subsubsection{Controie titoseanitario}

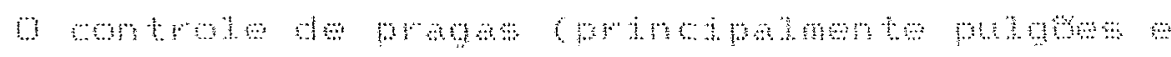

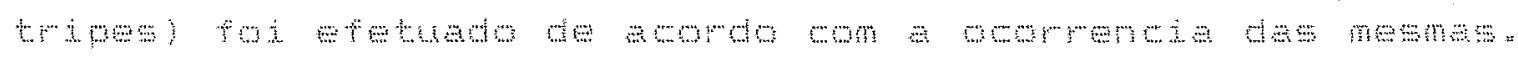

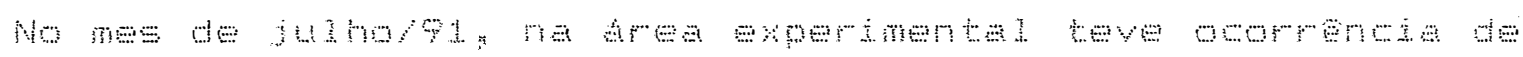

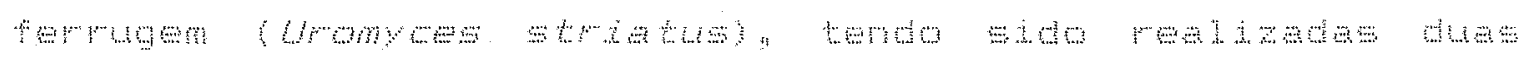

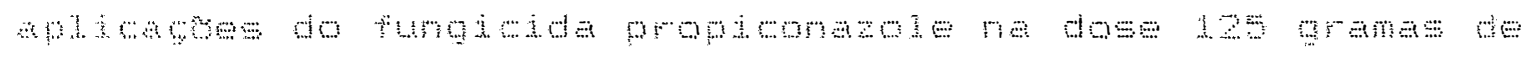

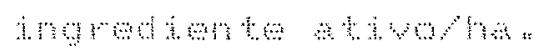

\subsection{Avaliagoes referentes a comunidade infestante}

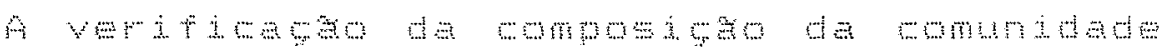
मан

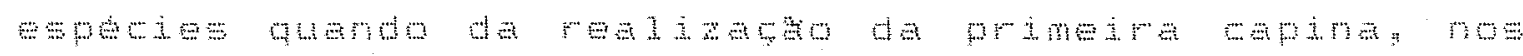

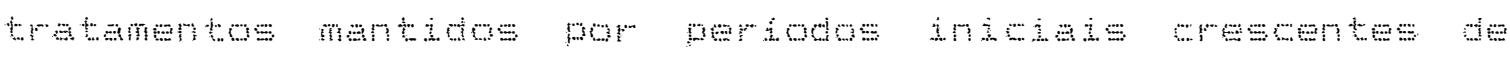

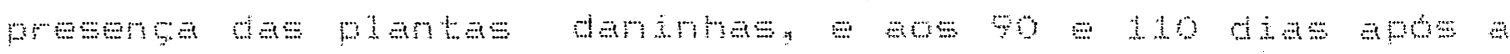

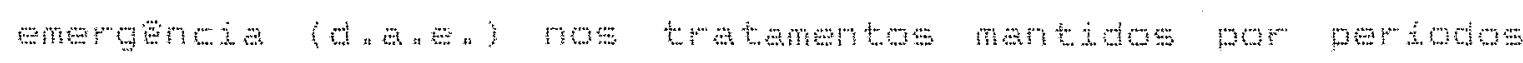

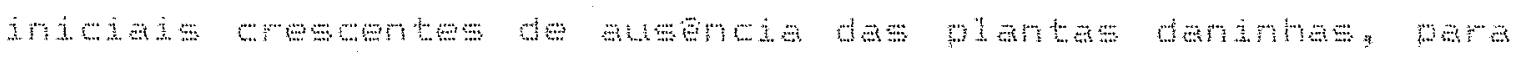

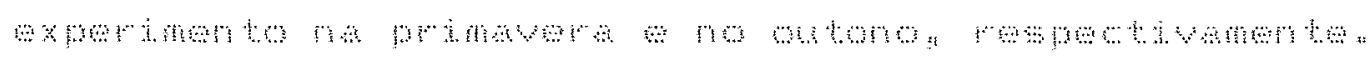

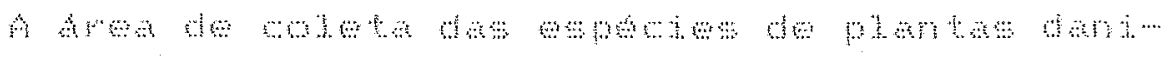

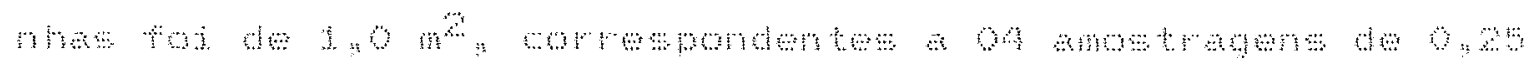
$n^{2}$, को $x$, 


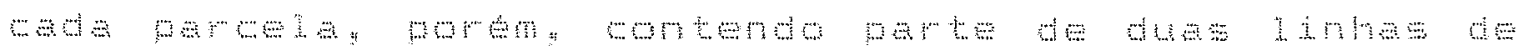

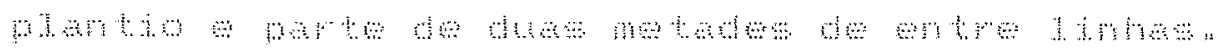

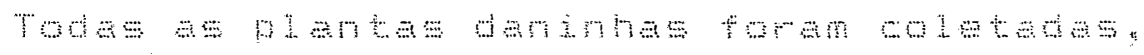

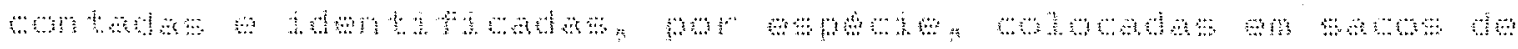
pon

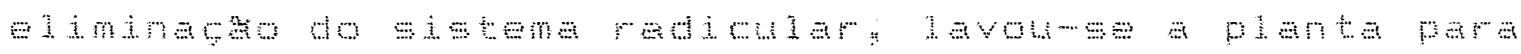

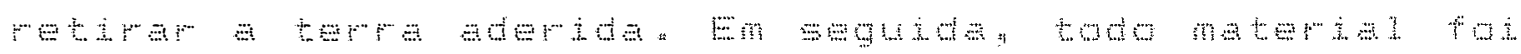
ammal

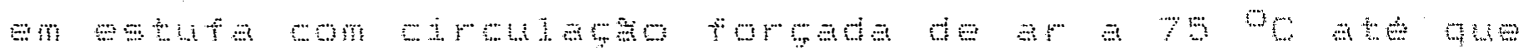
a thy ims a

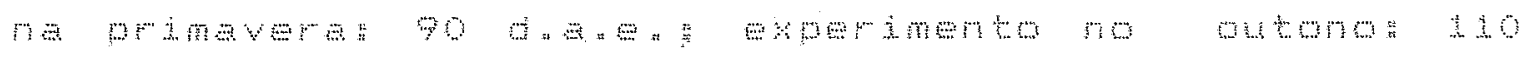

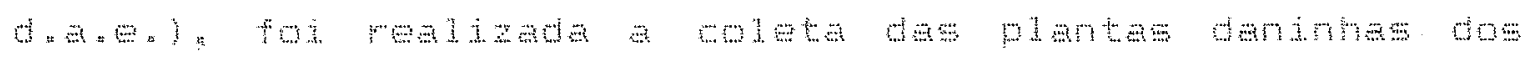

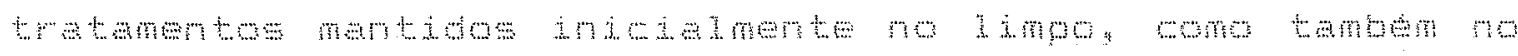

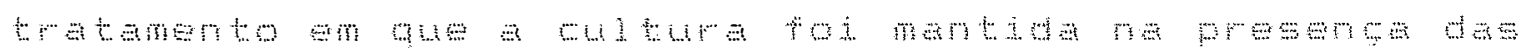

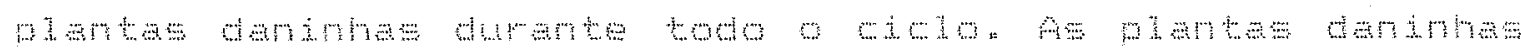
remertor a

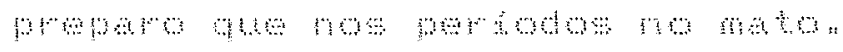

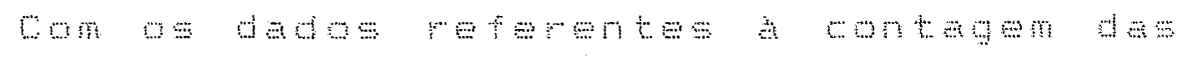

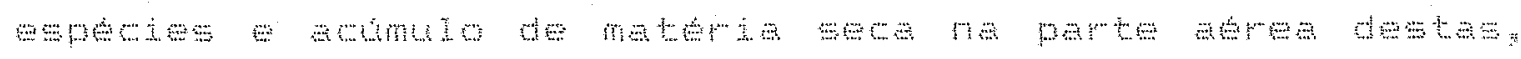

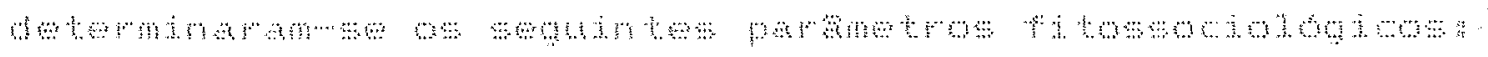

\section{- Densidade relegiva}

A

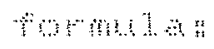

$$
\text { ओथ: ओं }
$$

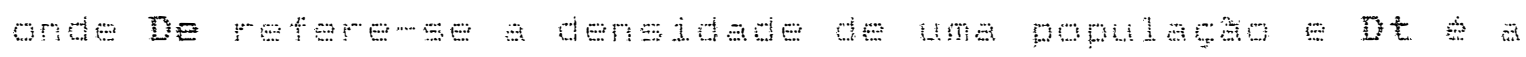




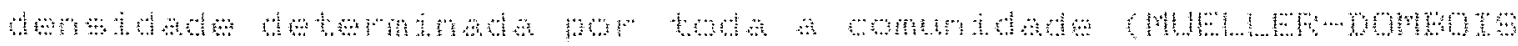

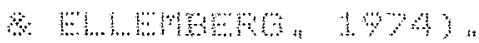

\section{- Dominancia Fielativa}

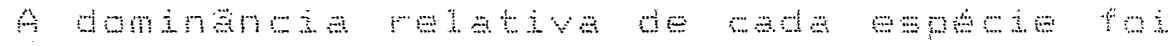

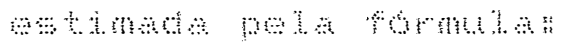

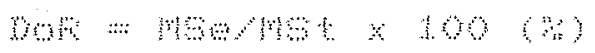

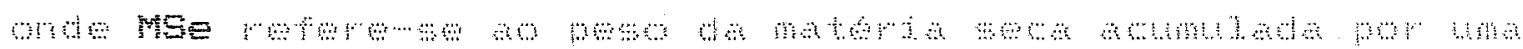

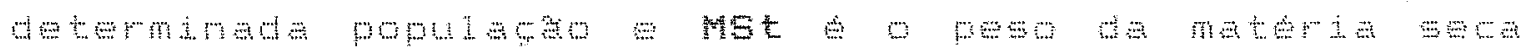

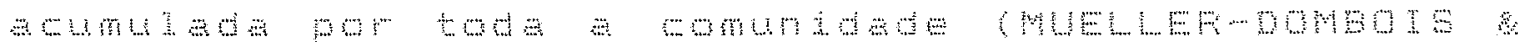
WmMmen "

\section{- Importancia Felativa}

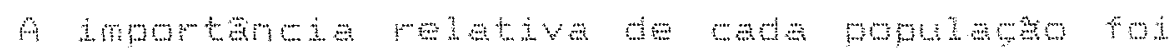

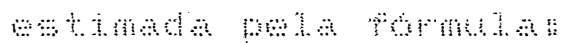

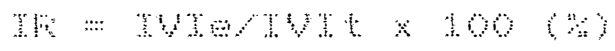

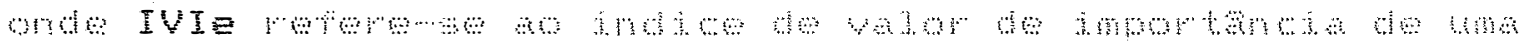
detemana popumbe

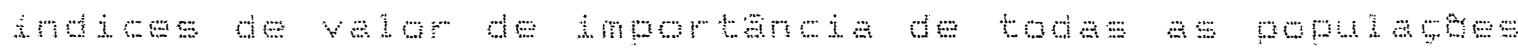

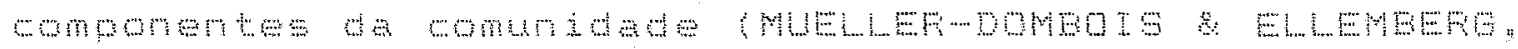
H,

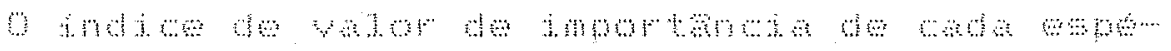

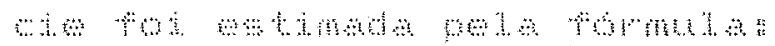

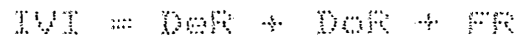

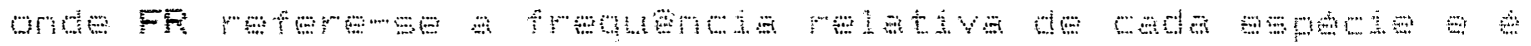




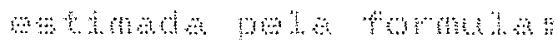

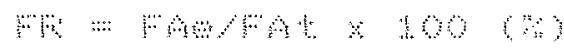

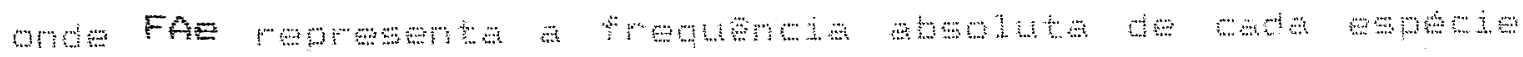

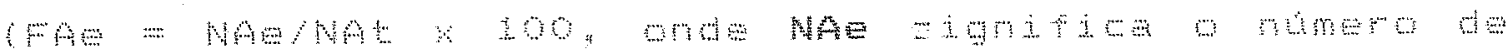

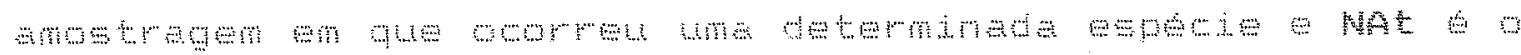

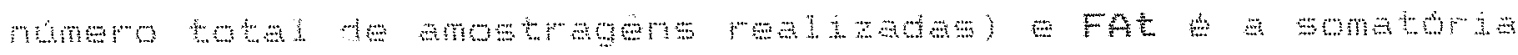

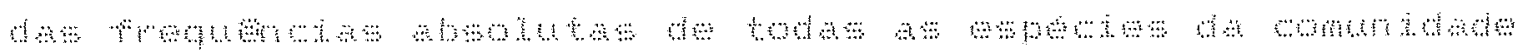

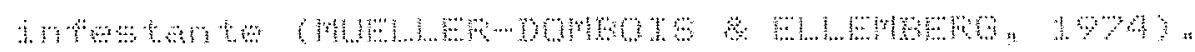

\section{צ.7. Avaliagbes biometricas peferentes a panta de alfafa}

\subsubsection{Biomassa e altura de plantas}

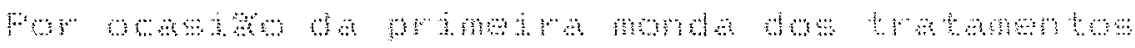

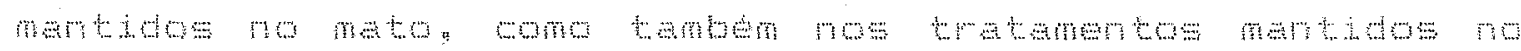

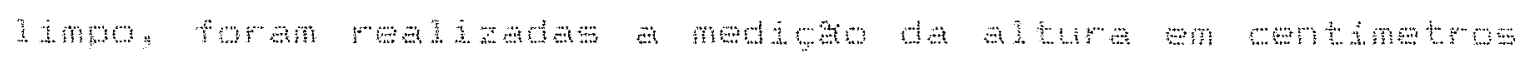

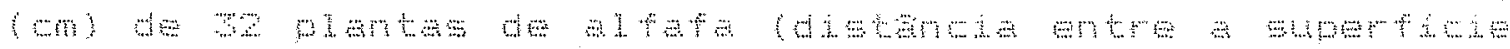
का

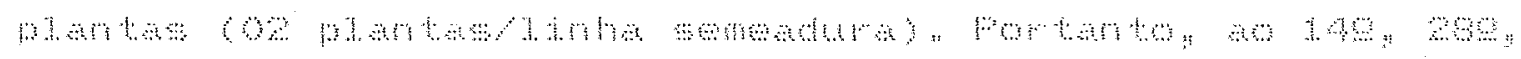
4,

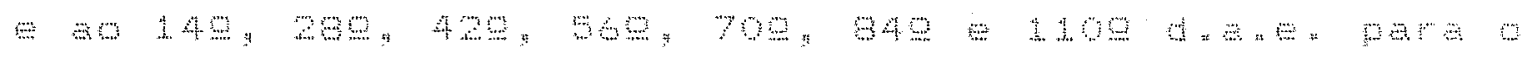
man

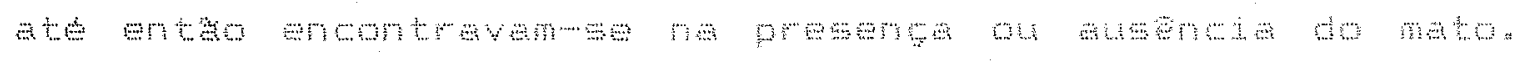

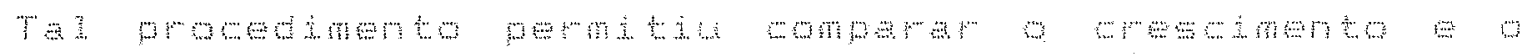

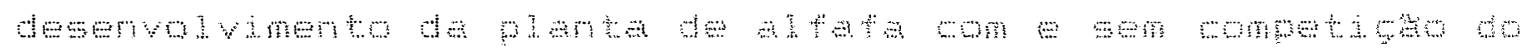
mis 


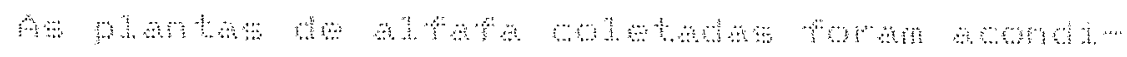

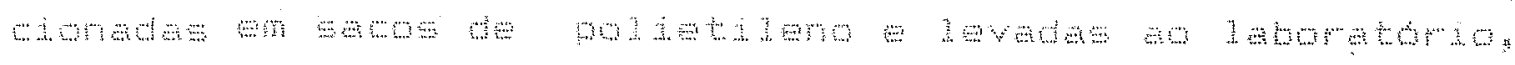

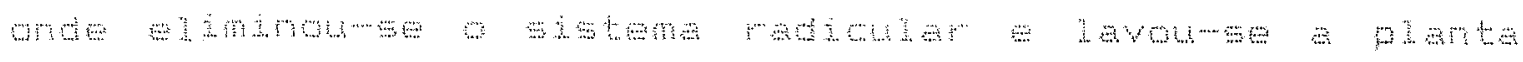

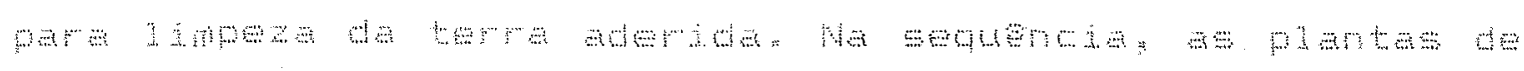

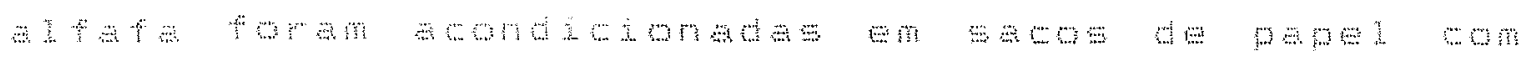

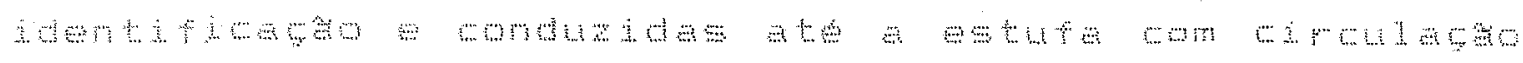

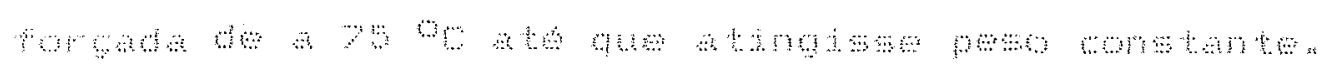

\section{Z.7.2. Whero de pertintos}

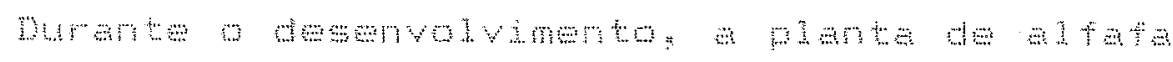

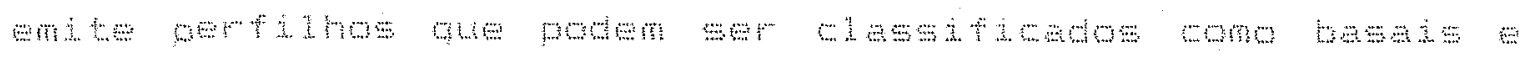

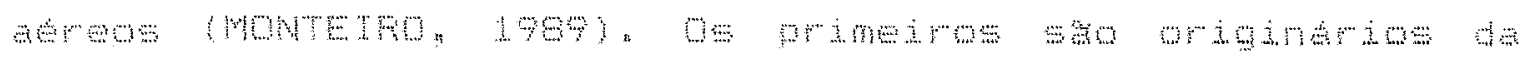

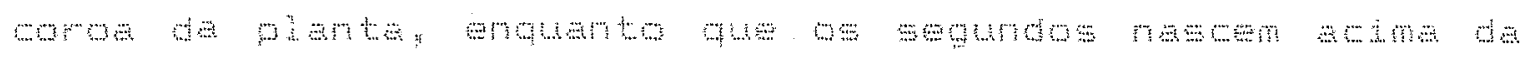

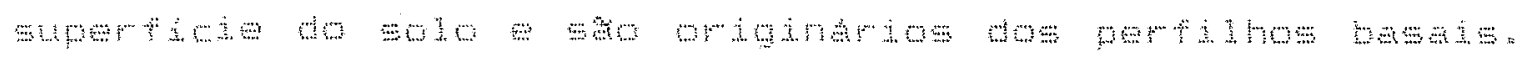

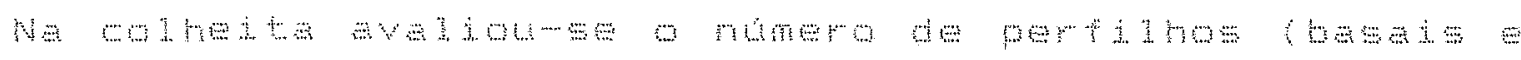

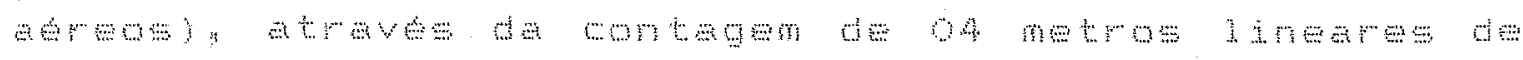
a

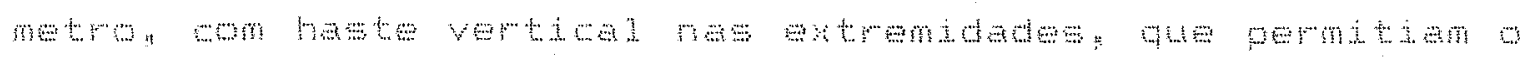

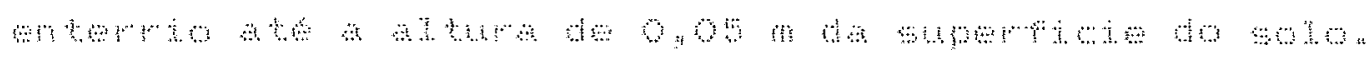

\subsection{7 . Altura da planta na colneita}

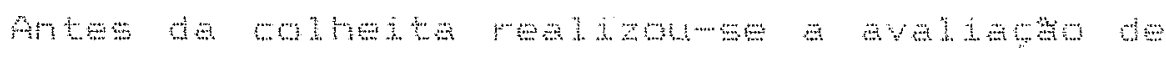

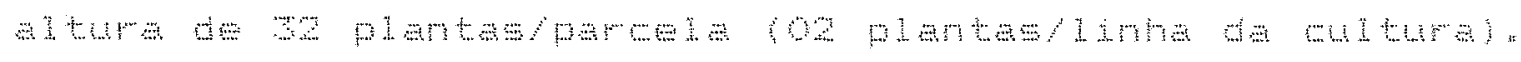
F" 
d

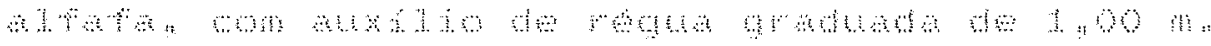

\title{
‥7․ 7 : Furescinento
}

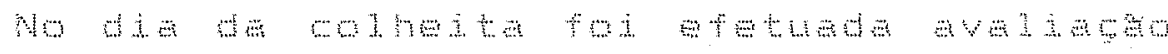 \\ Y \\ मक
}

\section{7.5 Froducto dE tero.}

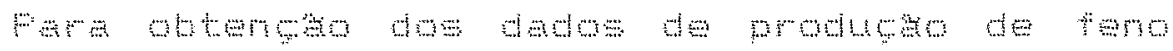

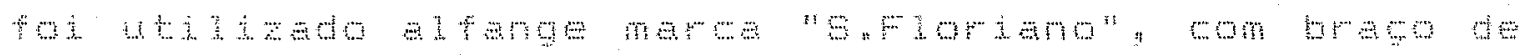

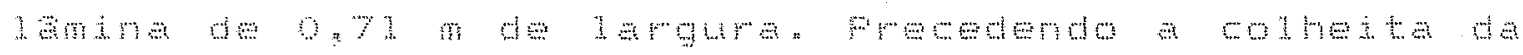

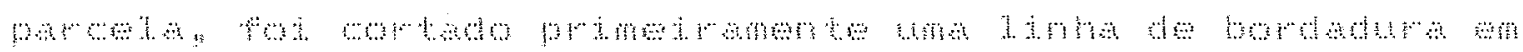

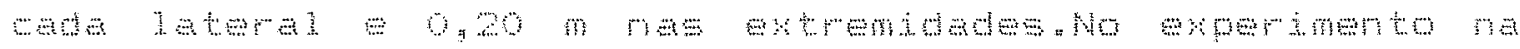

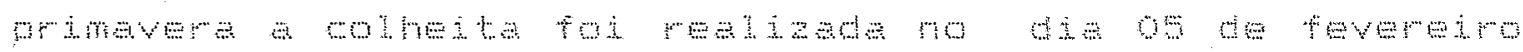

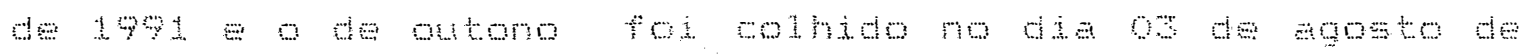

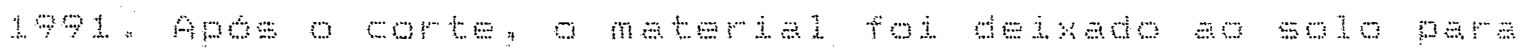

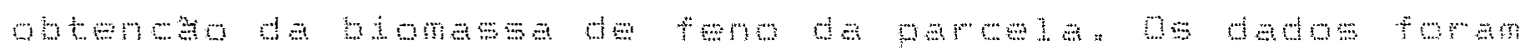
th 


\section{RESULFADOS E DISCUSSMO}

\subsection{Expermento da Primavera}

\section{4.}

\section{1 - 1 -}

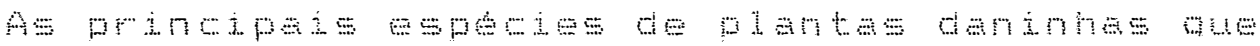

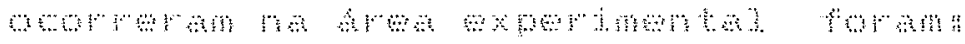

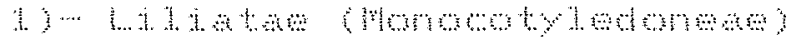

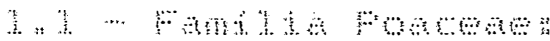

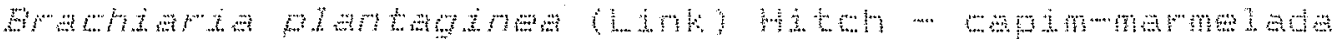

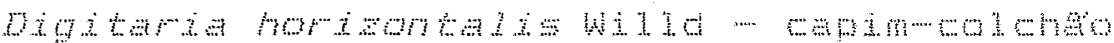

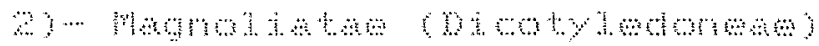

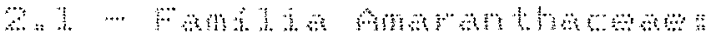

Am

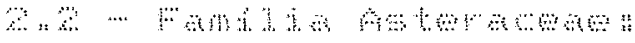

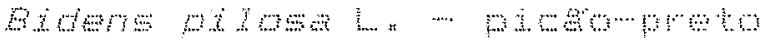




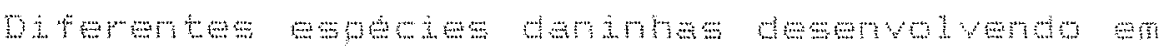

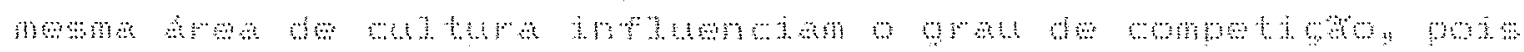

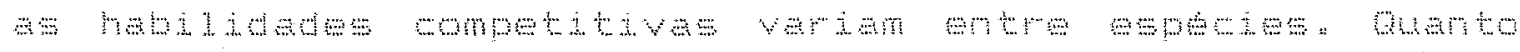

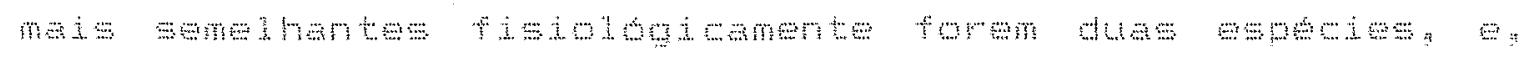

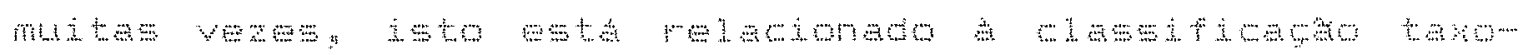

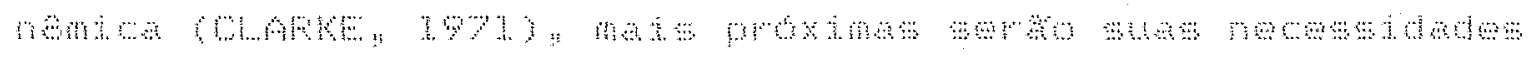

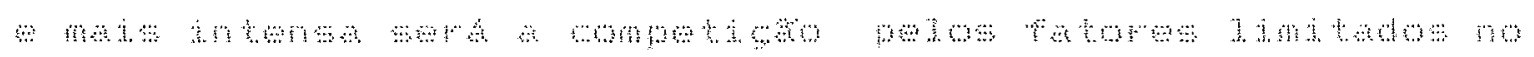

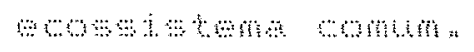

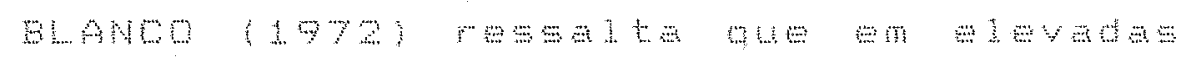

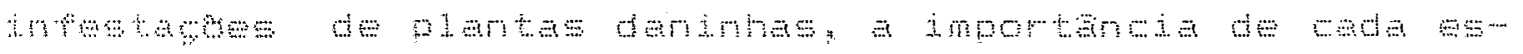

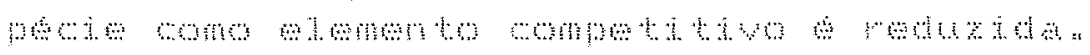

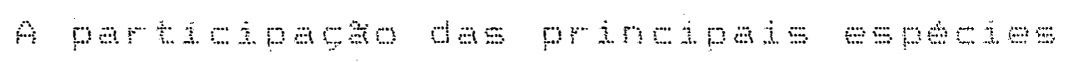

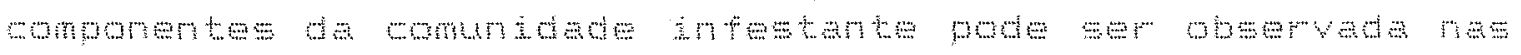

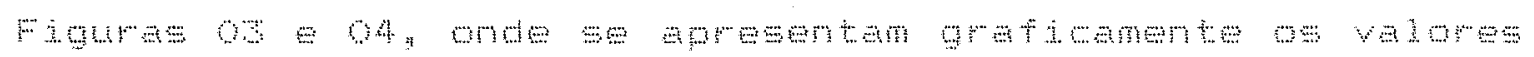

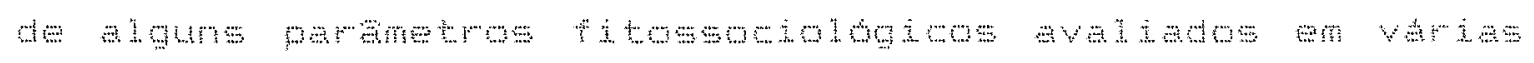

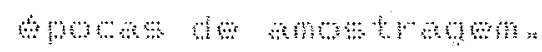

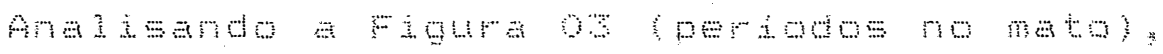

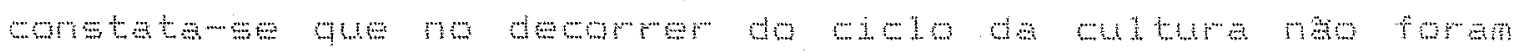

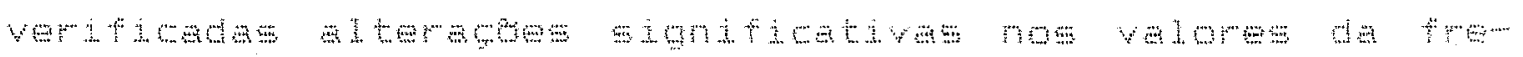

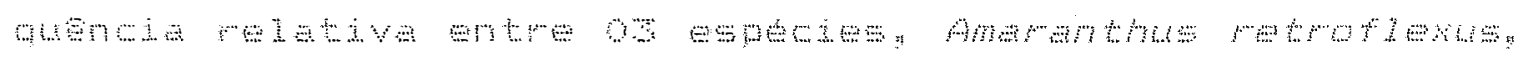

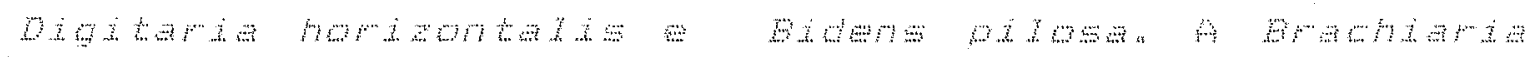

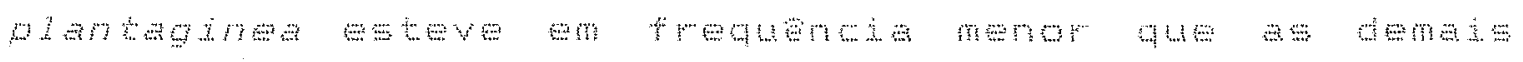

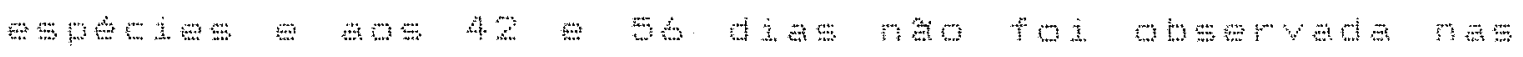
aras

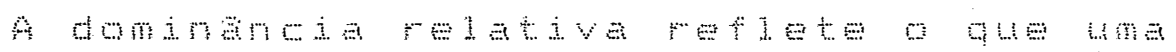

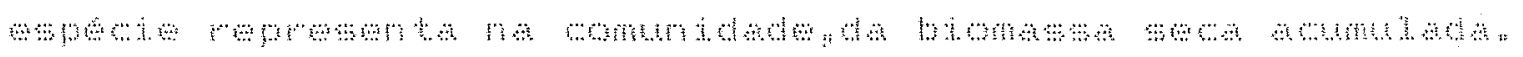



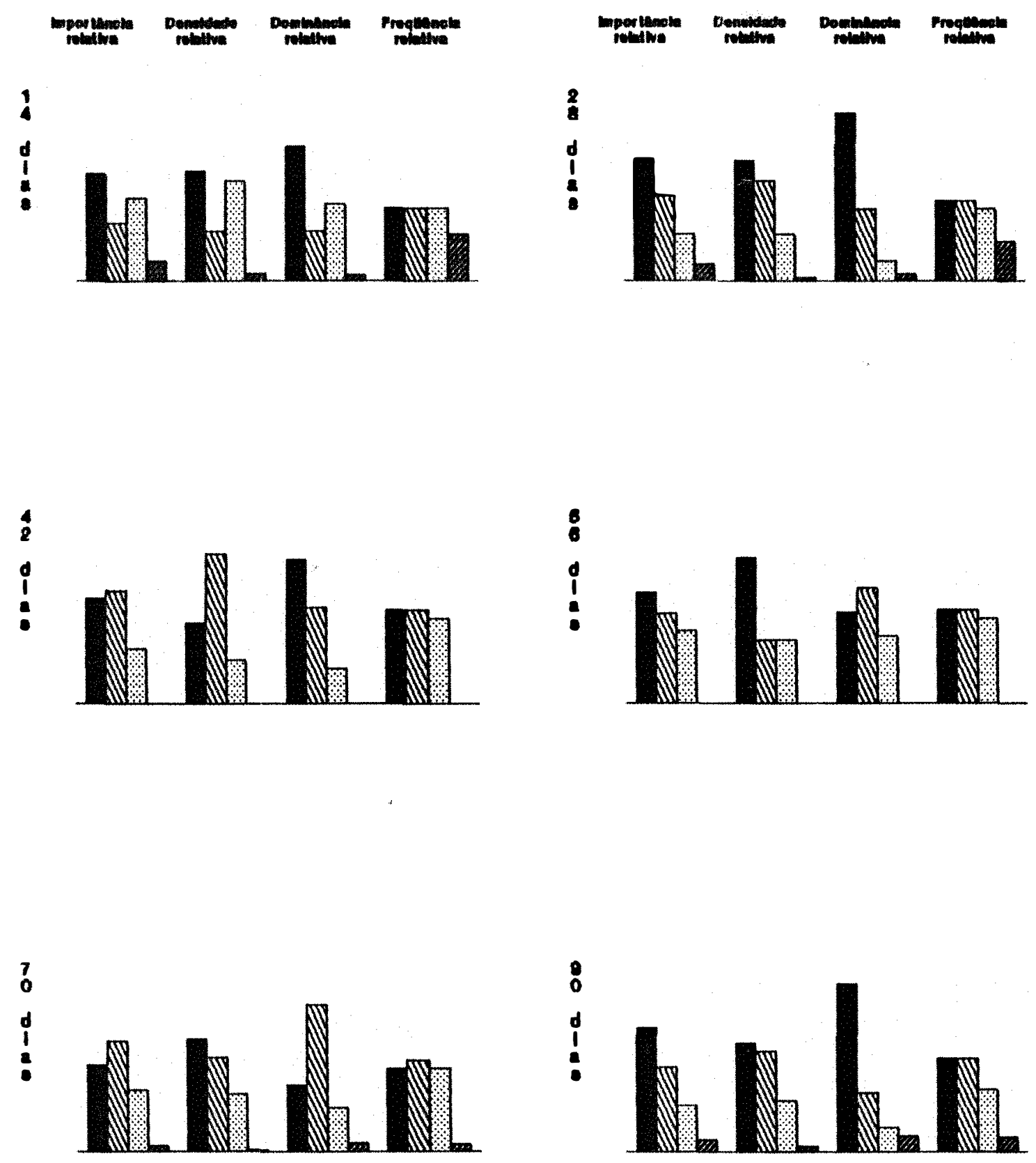

Flaura 09 - Importande, douldado, dominan cla - iropuencte relativas das princlpala os pecles cormponentes de comunidede intesten to no experimento ne prtmavero (perlodos no mato).

\section{LEQENDA}

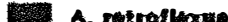

Caid athoce

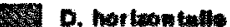

E. planenstors 
(1)

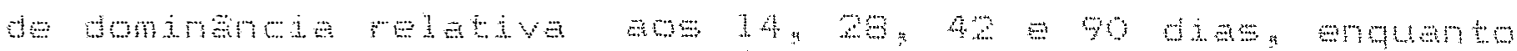

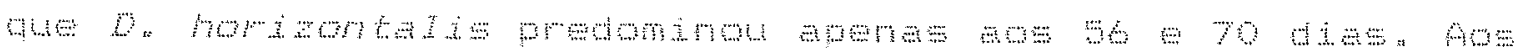

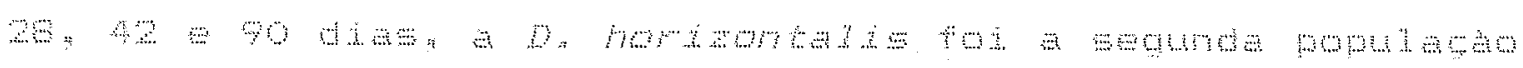

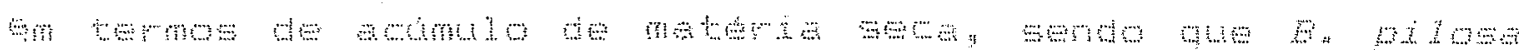

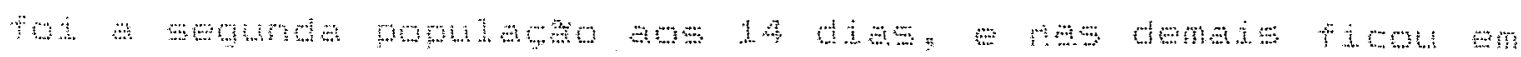
Ans

क मोल ндक mom

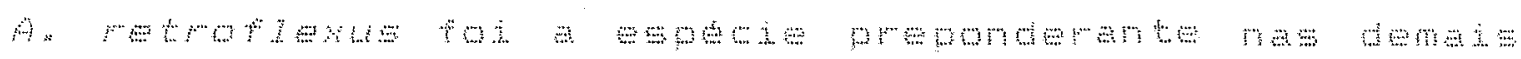

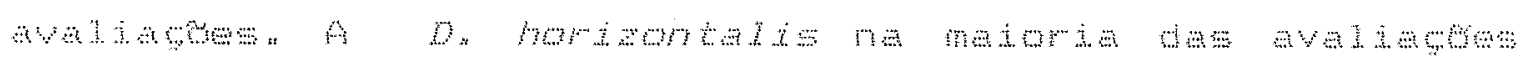

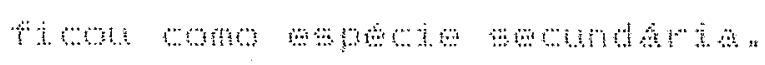

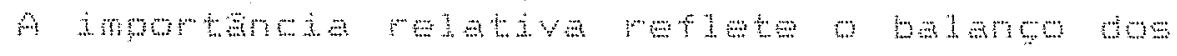
mpo म tөmo

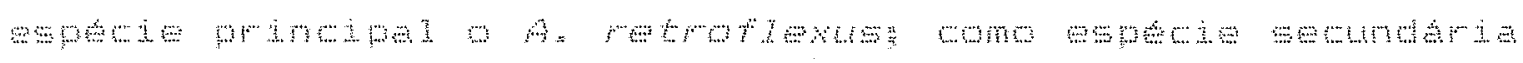

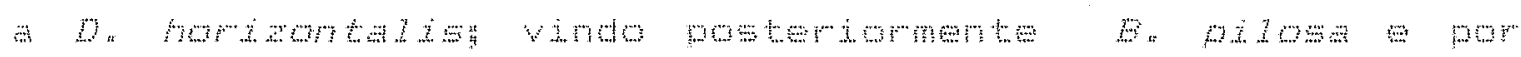
in

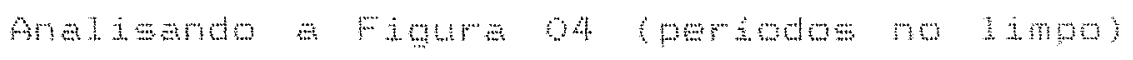

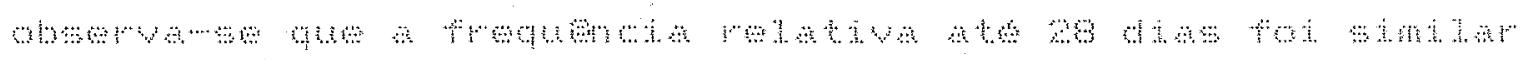

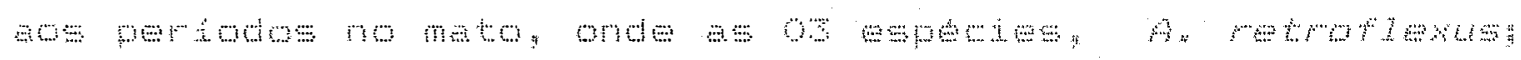
D. 7он

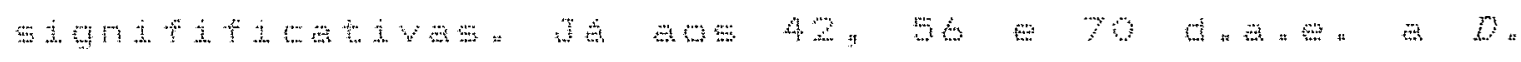

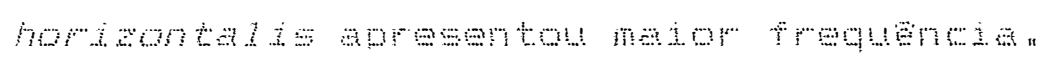



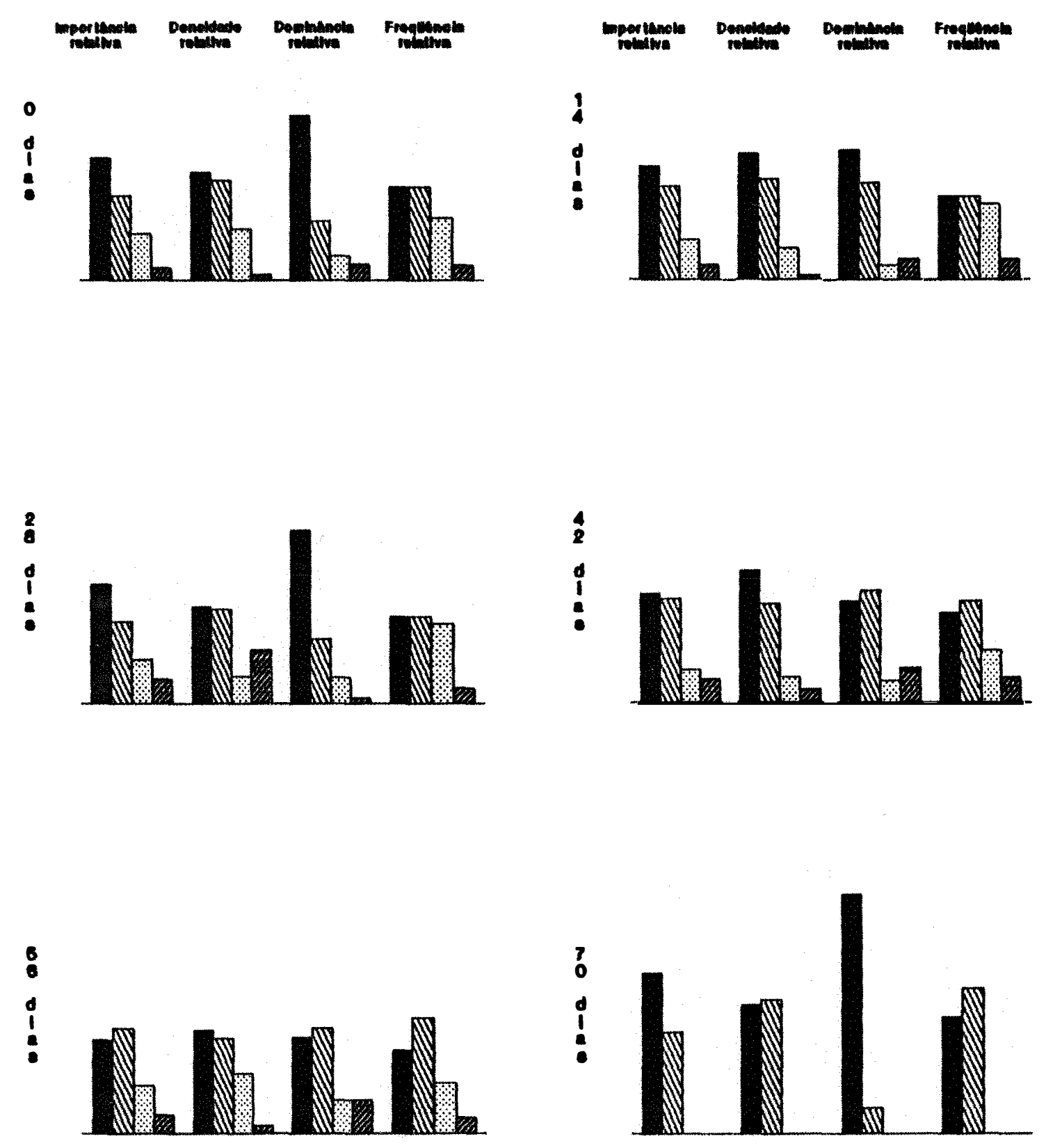

Figure 04 - importancle, densidade, dominan cis - troquencle relotivas das princtodo 08 peoles componenter de comunlolece inferten to no experitionto ne prtmanere (pertodos no LEQENDA limpe).

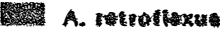

[ind plow

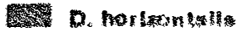

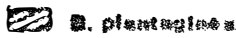




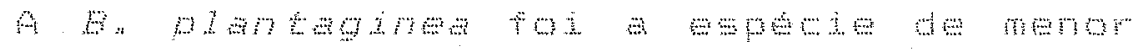

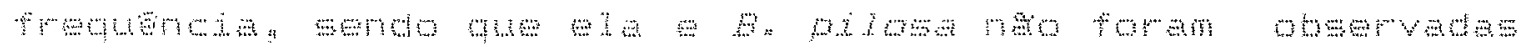

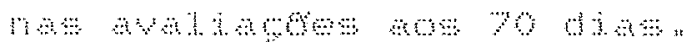

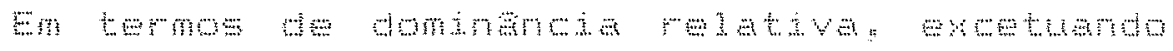

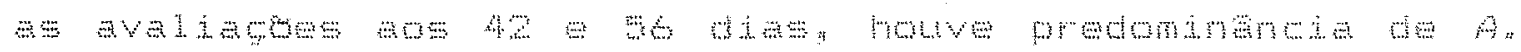

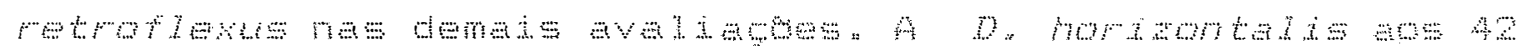

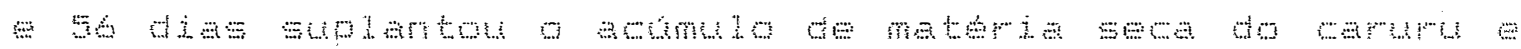

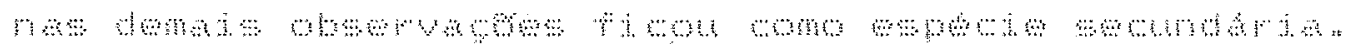

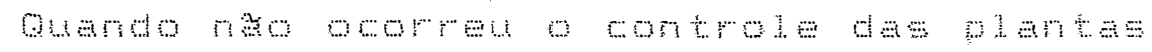

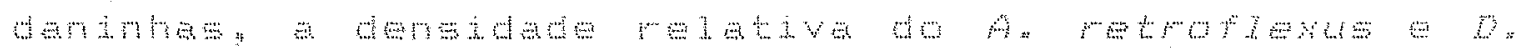
Mrm,

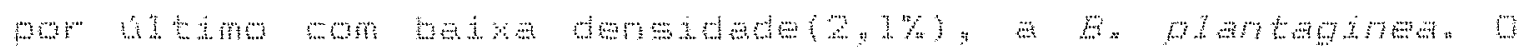

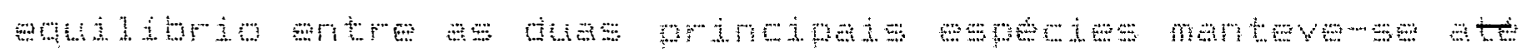

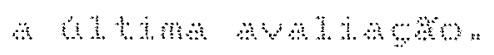

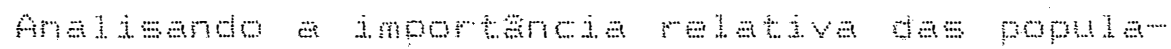

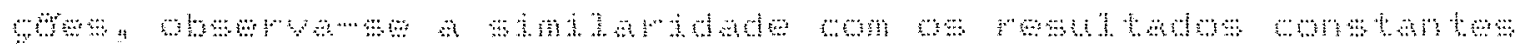

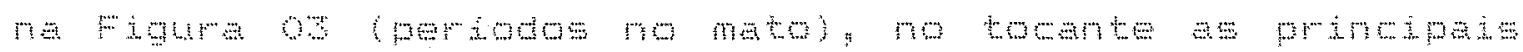

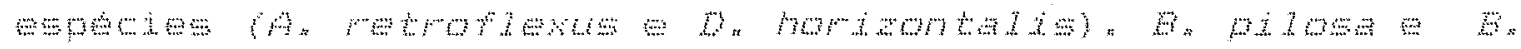

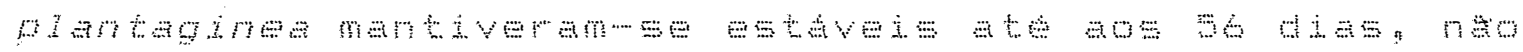

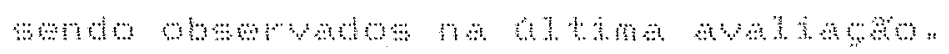

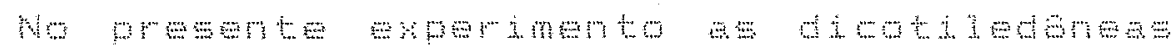

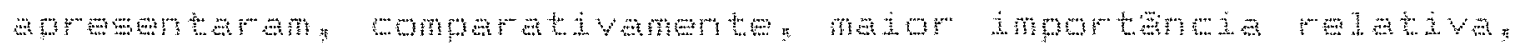

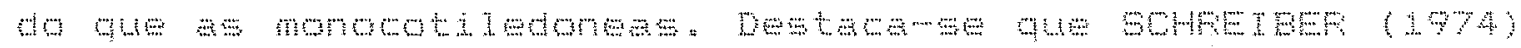

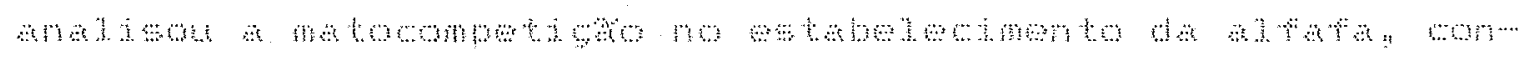

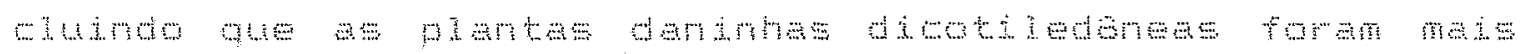

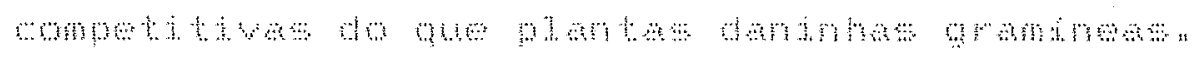




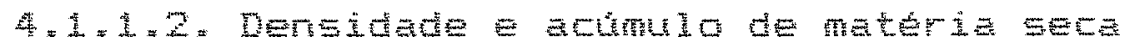

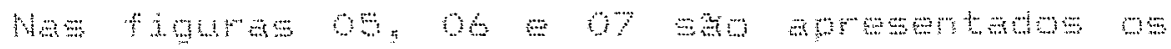

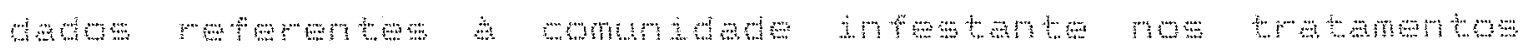

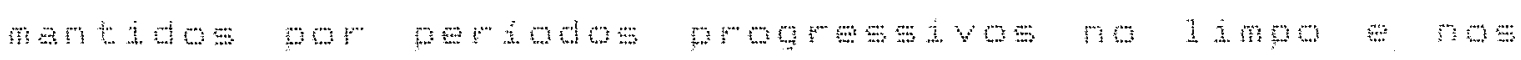
th

\section{a) Densidade}

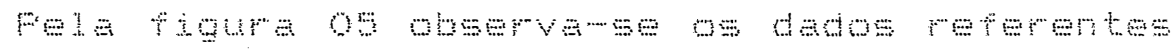

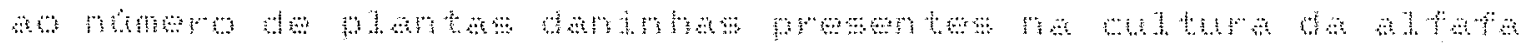
mun

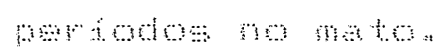

1 m

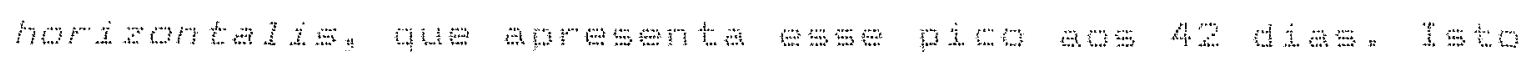

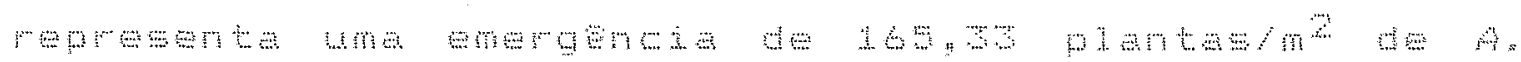

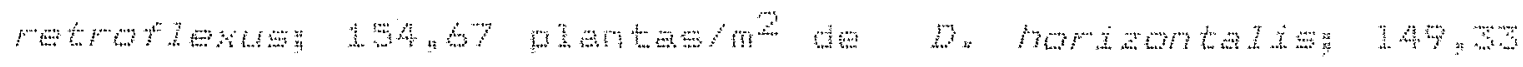

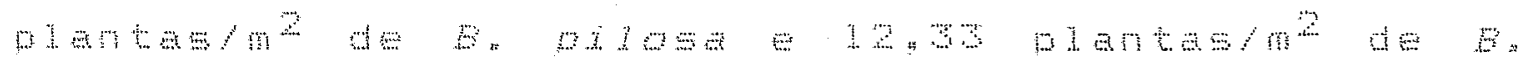
in whing in

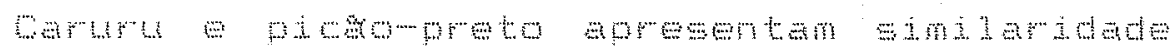

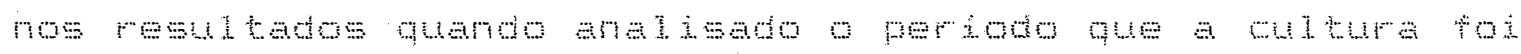

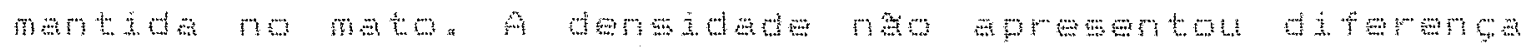

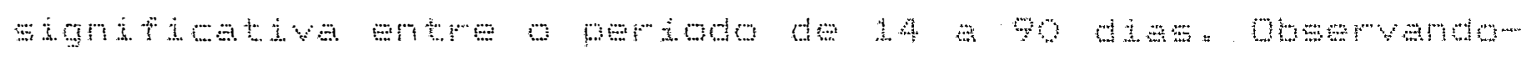

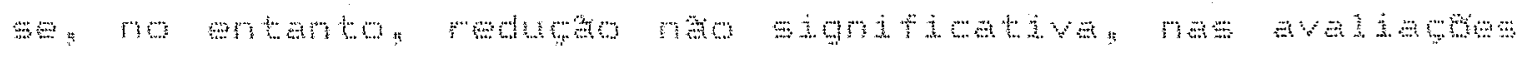

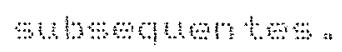



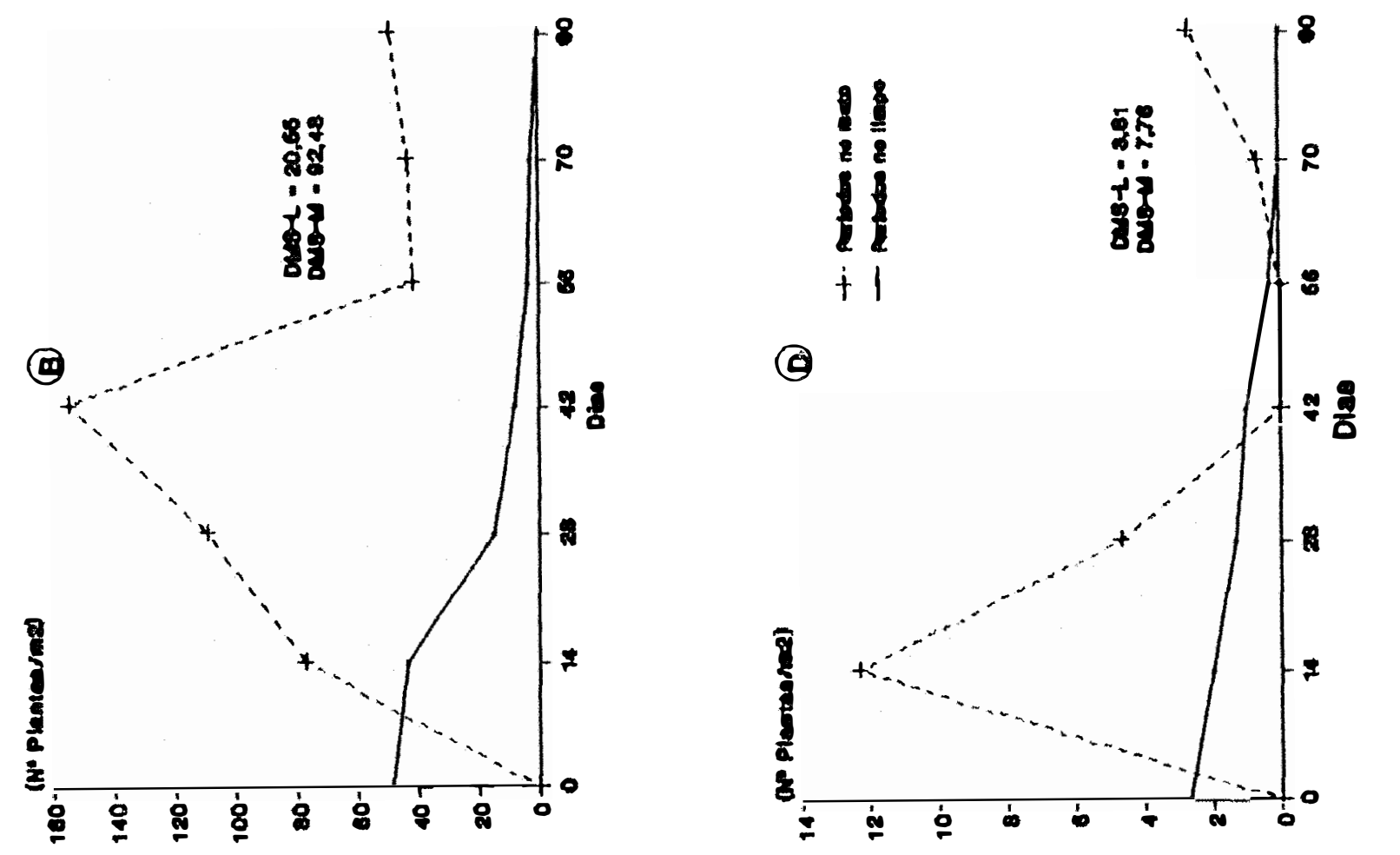

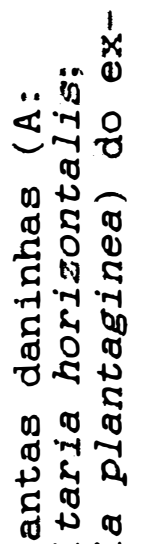
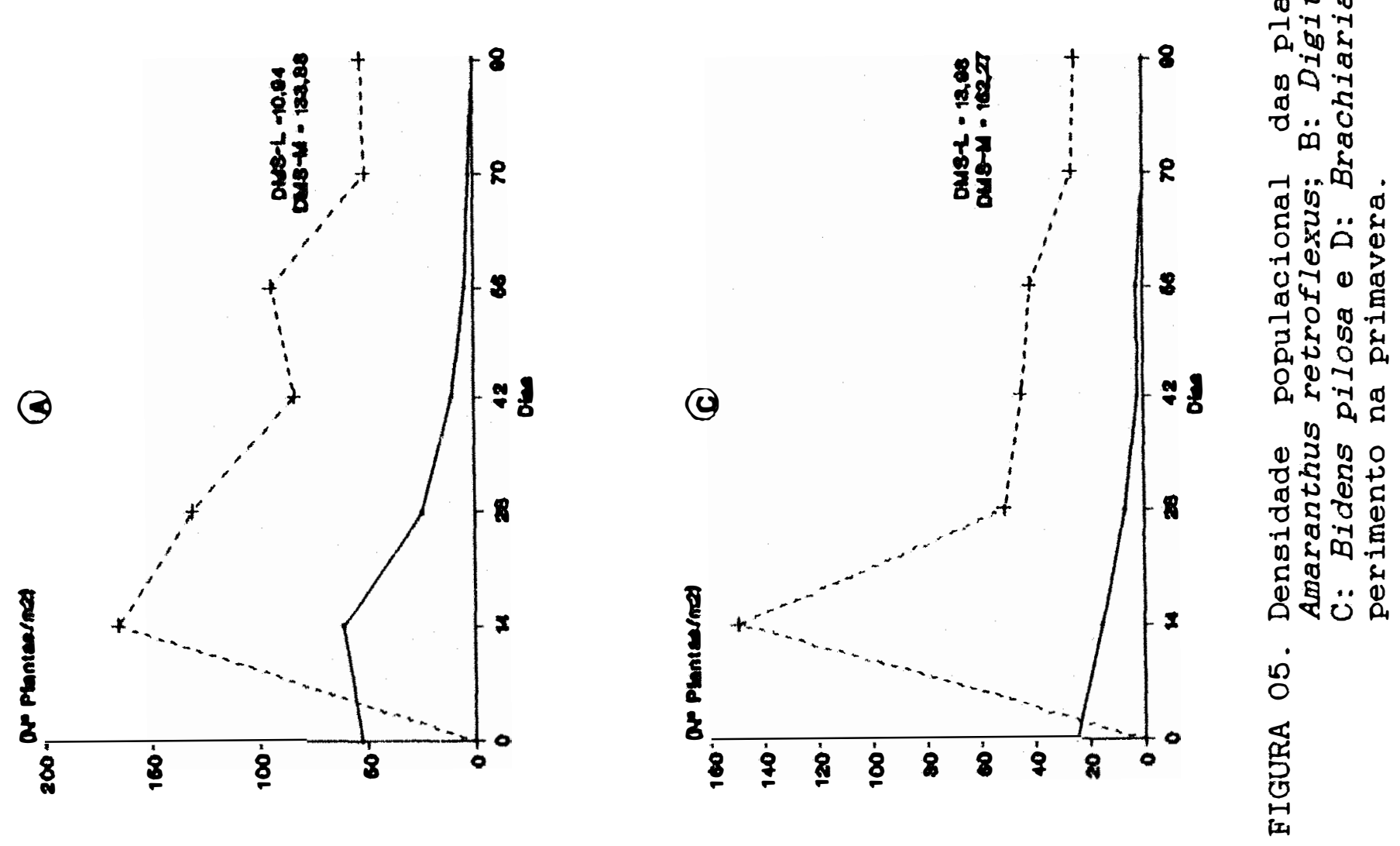


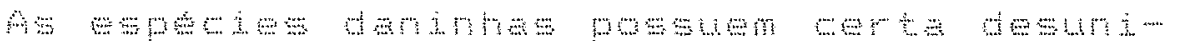

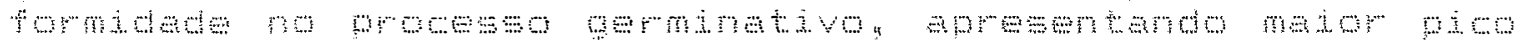
dн 1550 \&

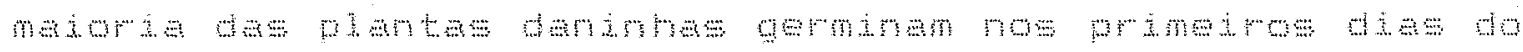

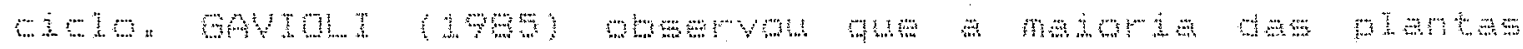

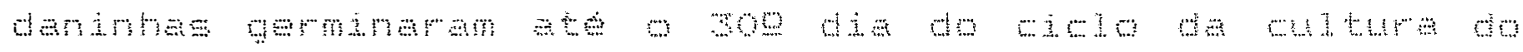

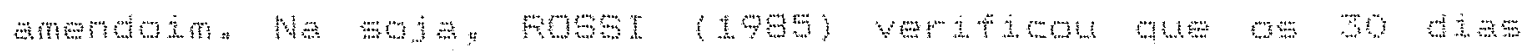

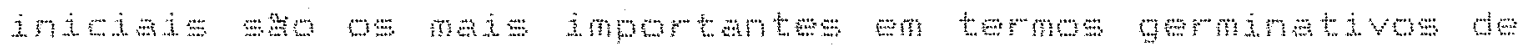

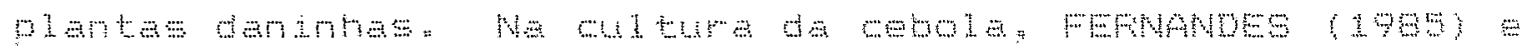

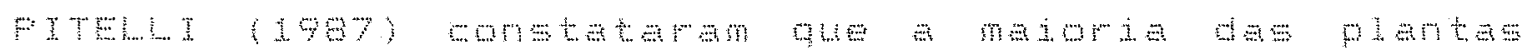

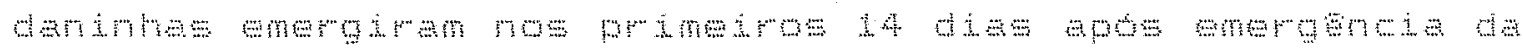
(n)

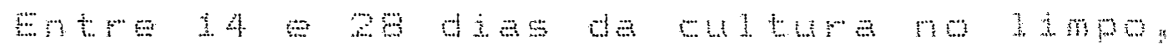

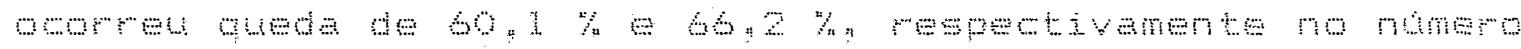

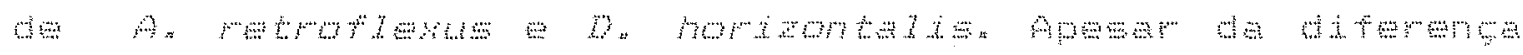

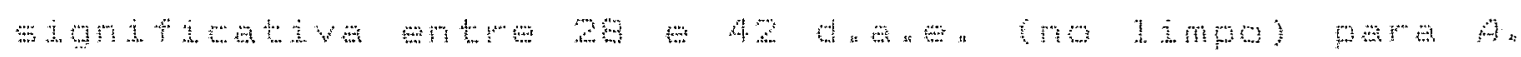

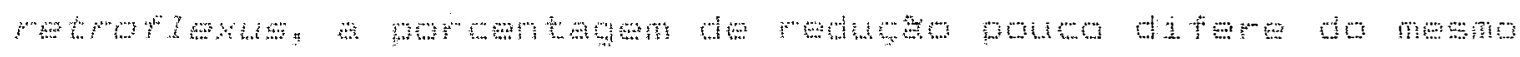

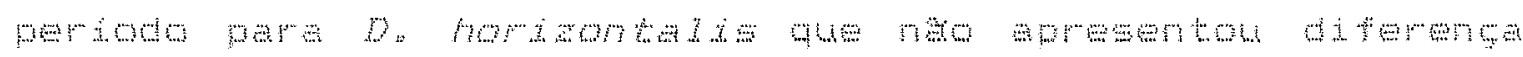

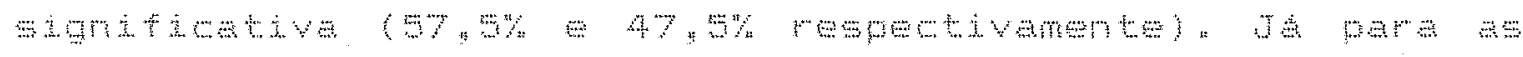

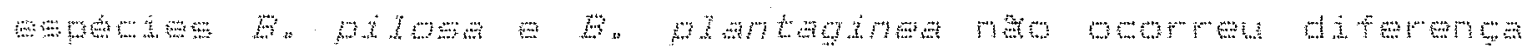

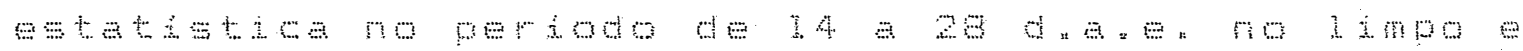

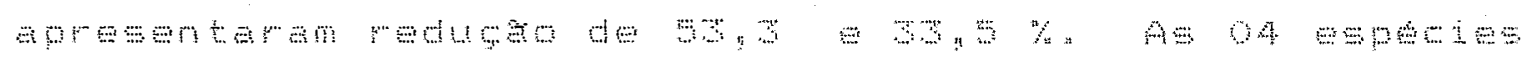

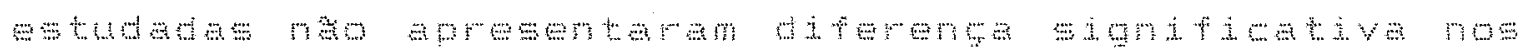

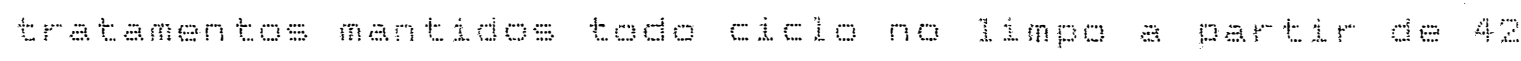

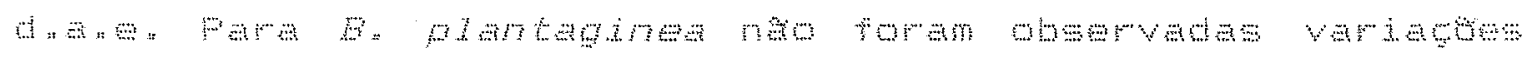




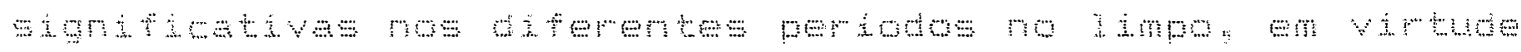

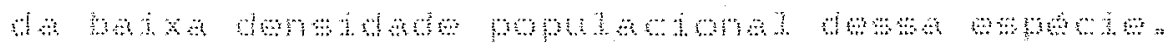

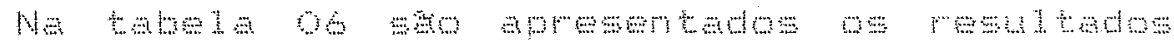

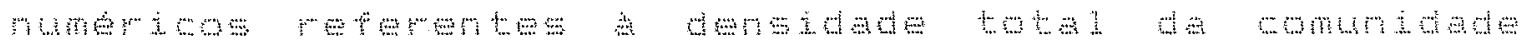

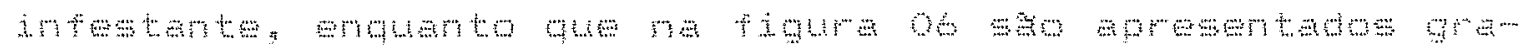

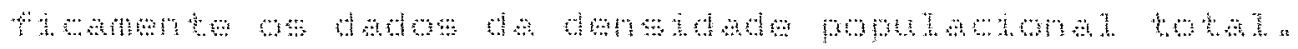

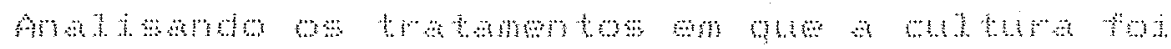

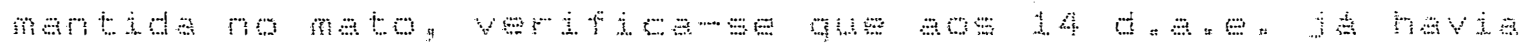
का

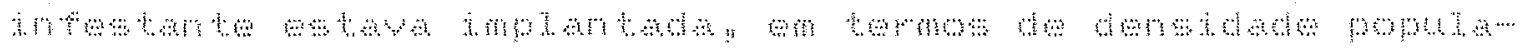
m.mal

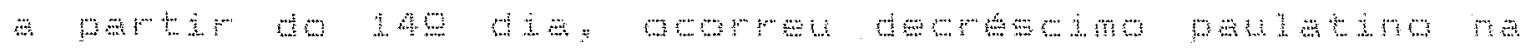

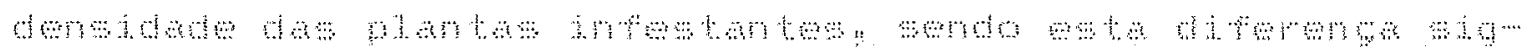
मf

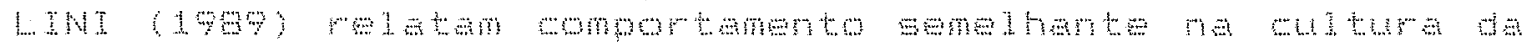

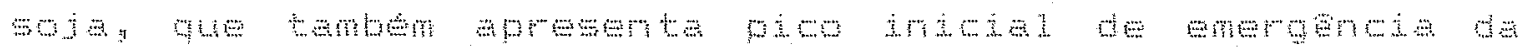

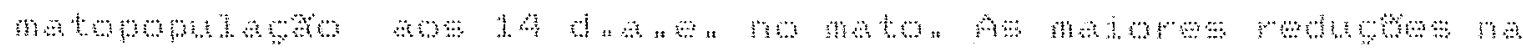
dн

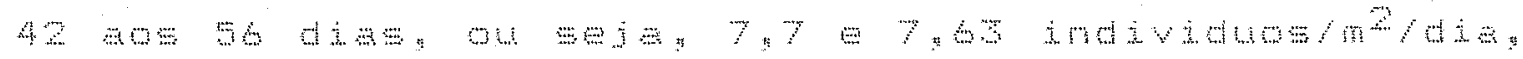

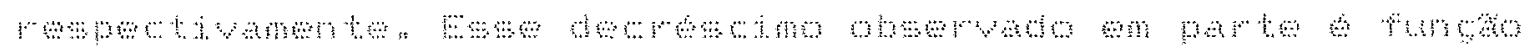

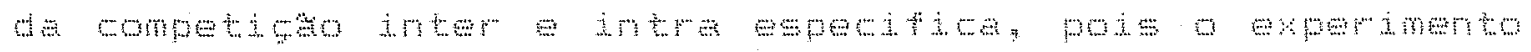
सम 


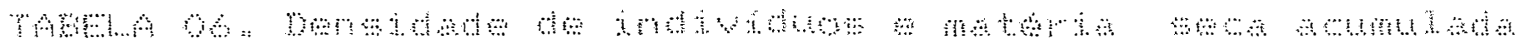

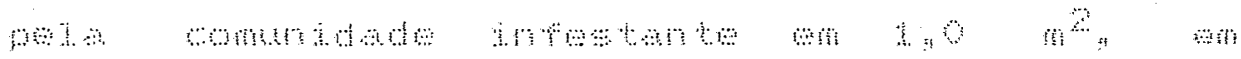
मे He

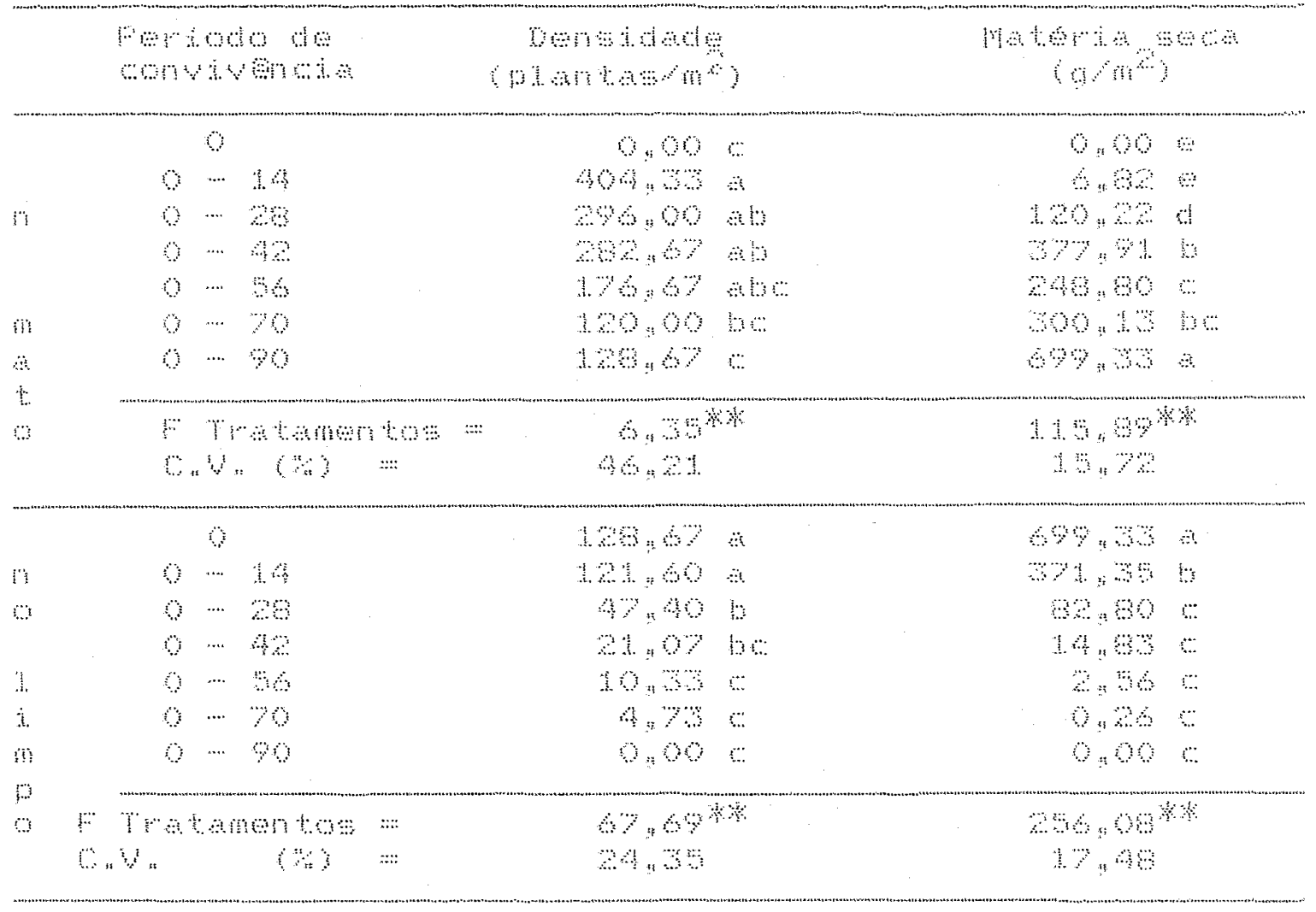

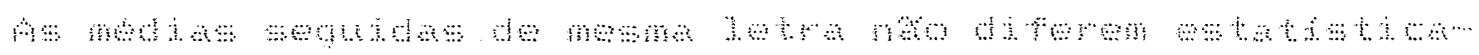

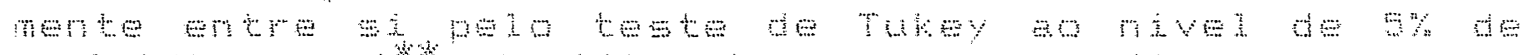

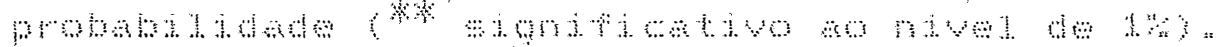

obervando se tratementes mantados por peram

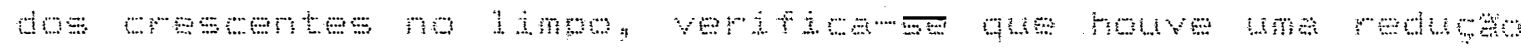

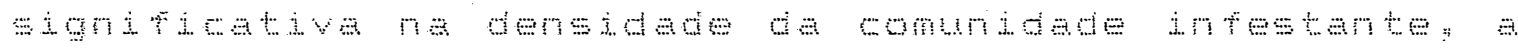

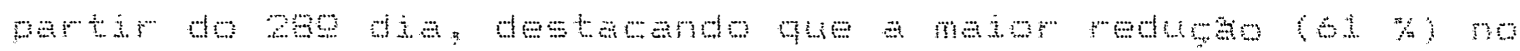

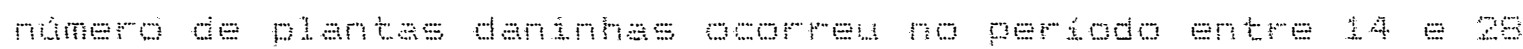
त 


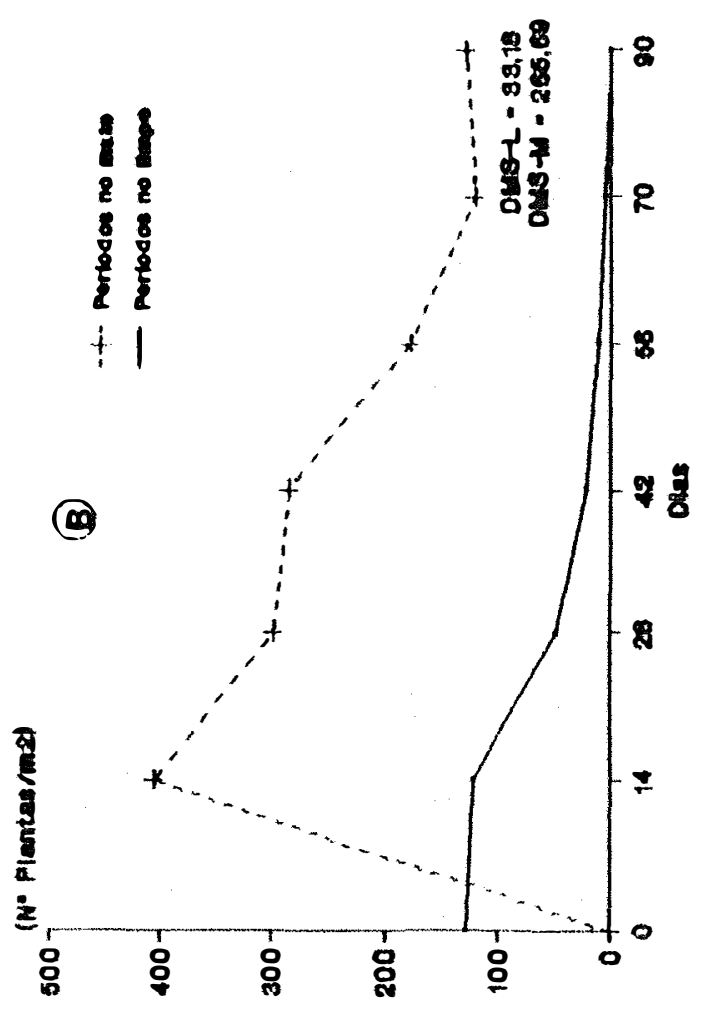

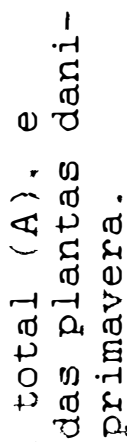

б

两

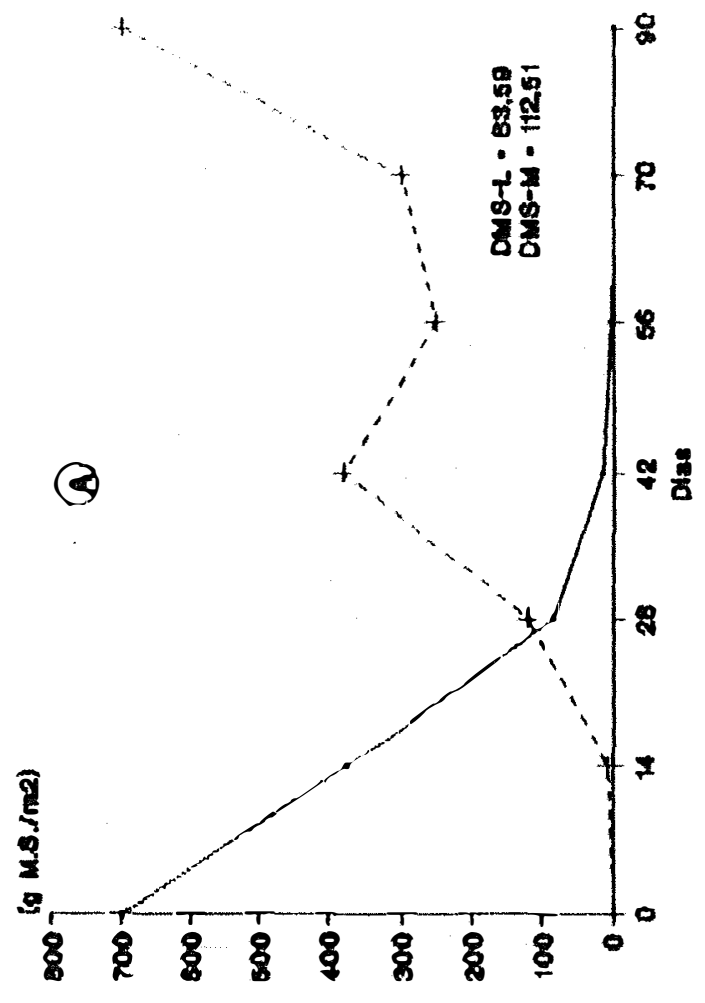

实

ปั

ช 10

(1) मे

0

in $\sigma$

ब

क्त 0 C

(1) ช

山雨の

ช

a $\mathrm{C}$

(1)

(1)

ถ

क

苗

Е 凹

•

$\ddot{0}$

$\sum_{\substack{1 \\ n_{1}}}^{\infty}$ 


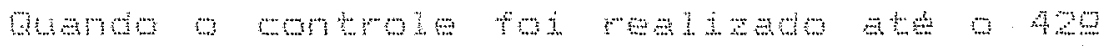

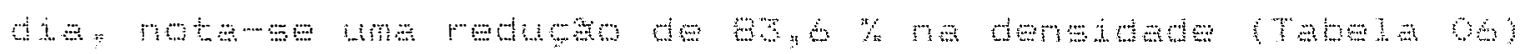

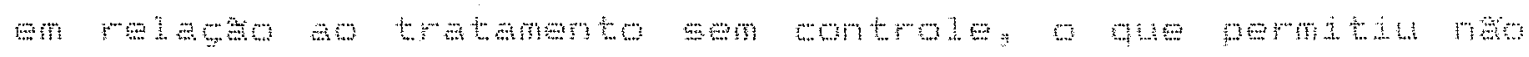

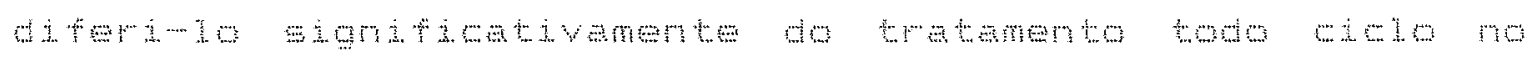

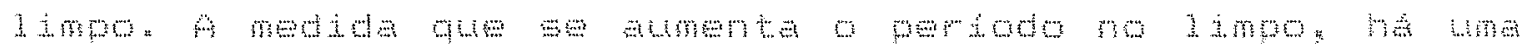

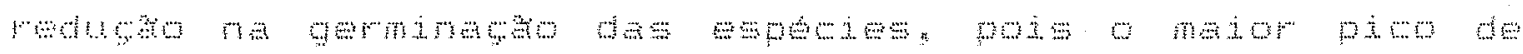

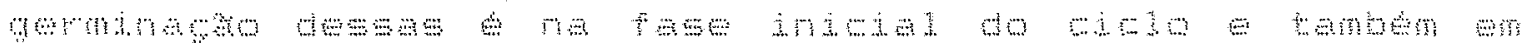

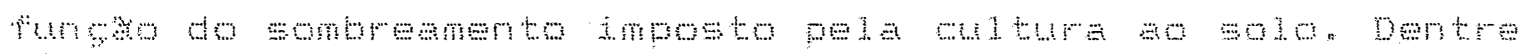

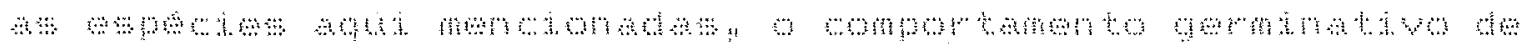

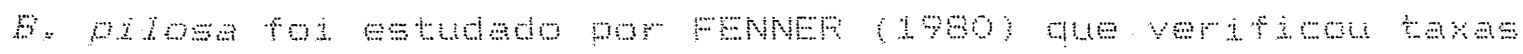

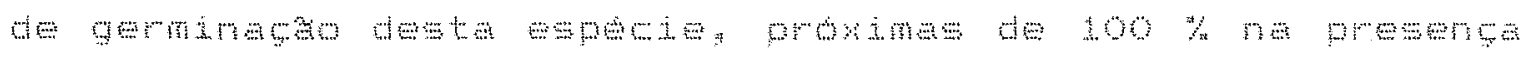

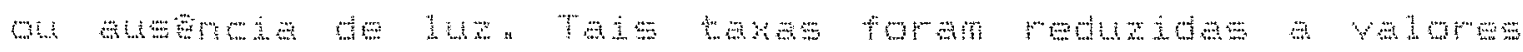

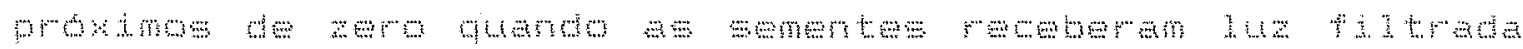

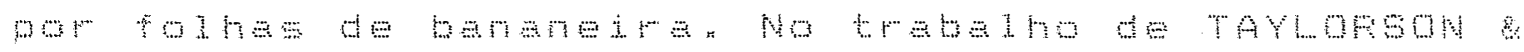

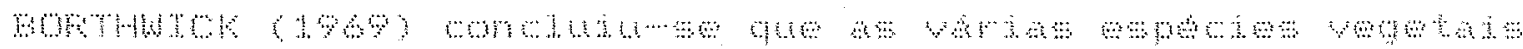

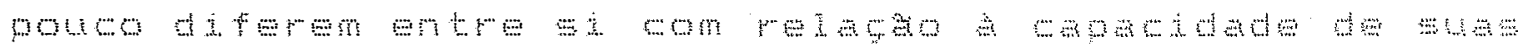

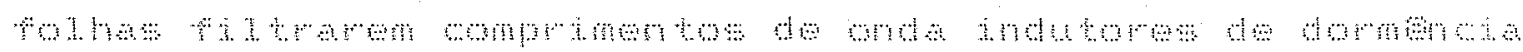

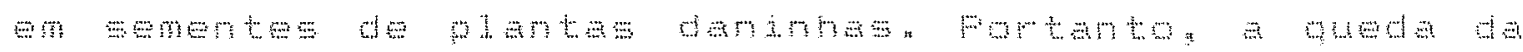

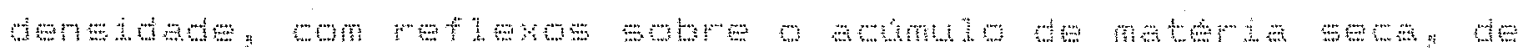

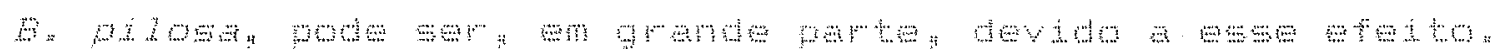

\title{
b) Actimula de materia
}

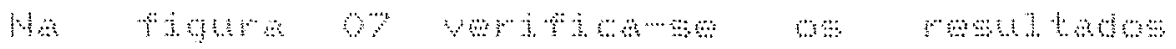



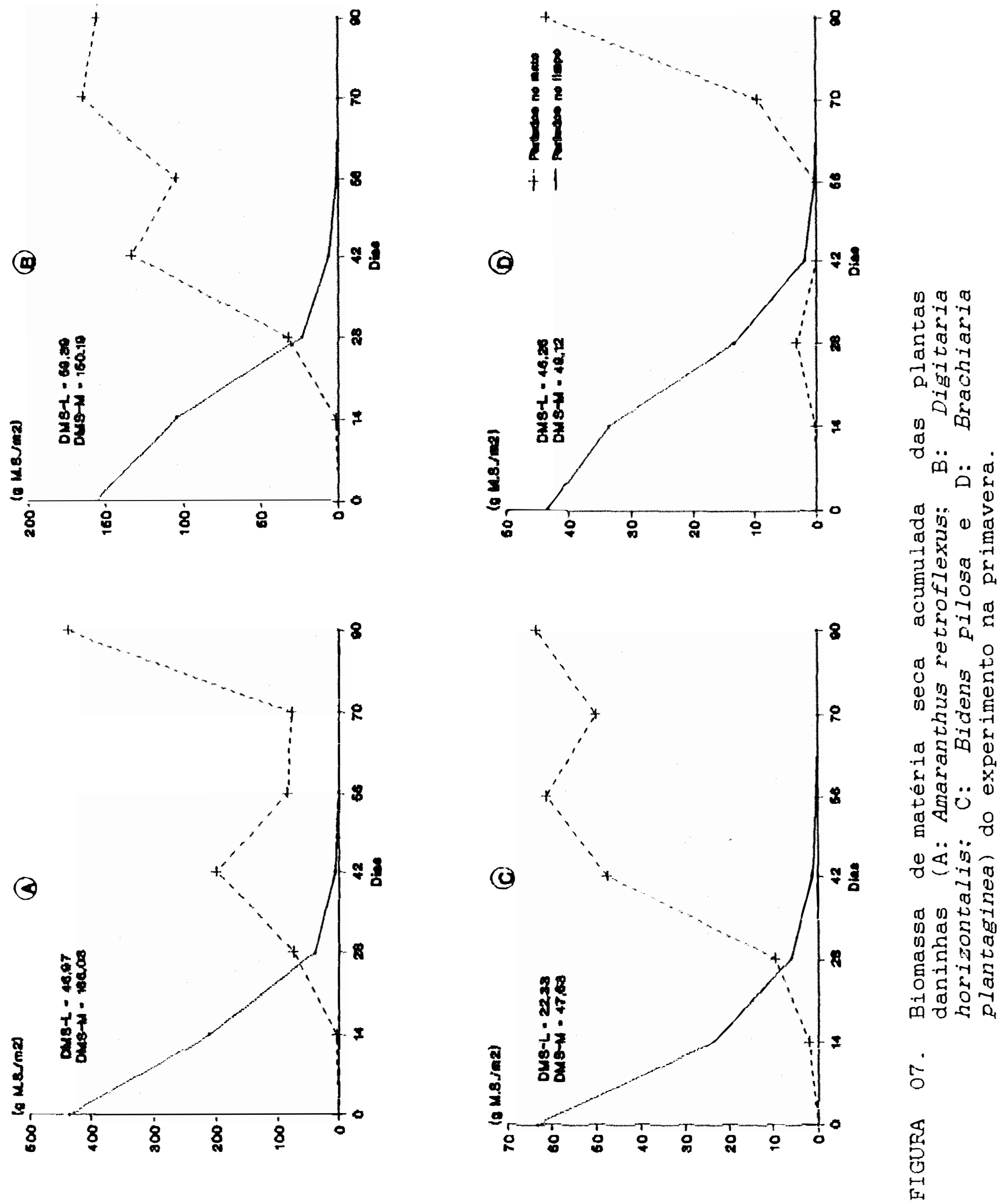


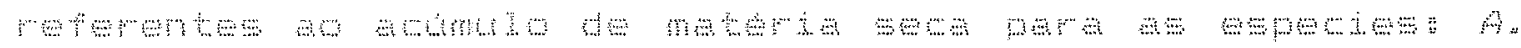

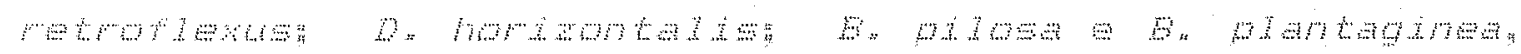

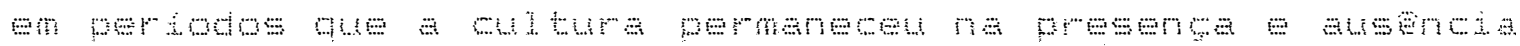

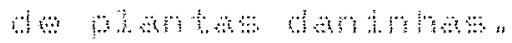

mom D. hom

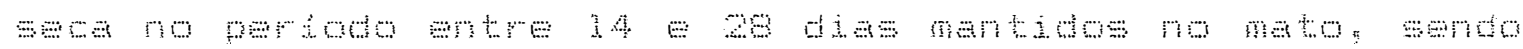

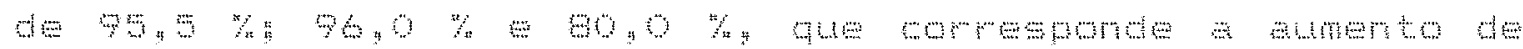

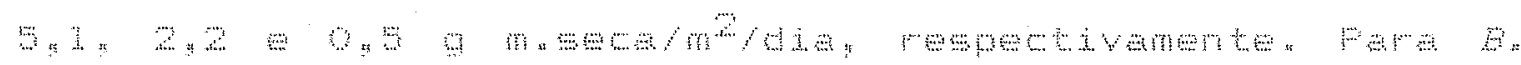

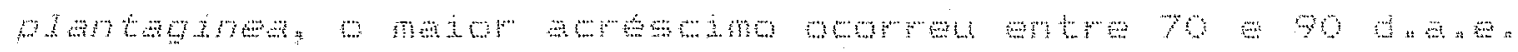

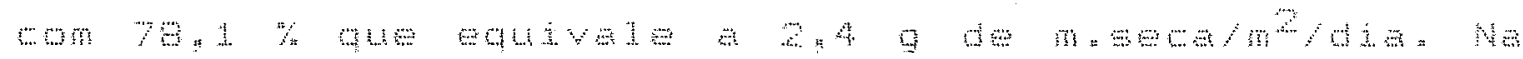

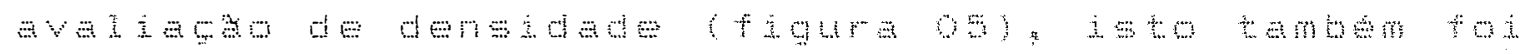

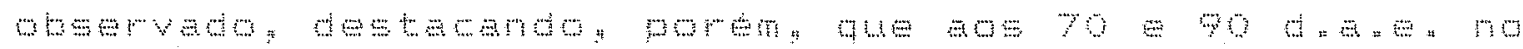

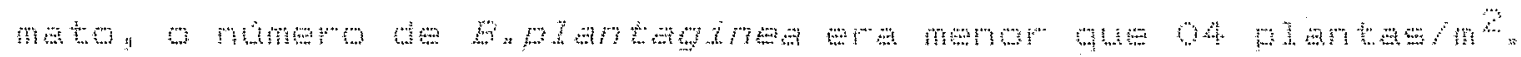
A partir de 20 ate 90 a a

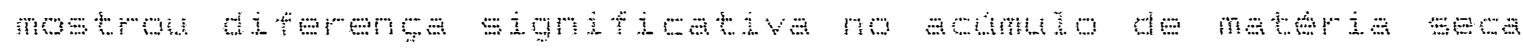

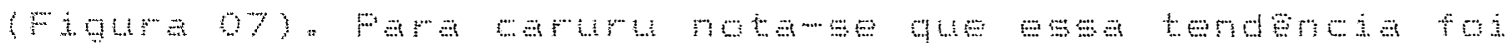

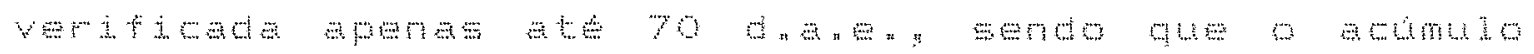
obserado aоs 9 d a

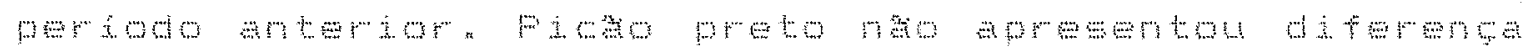

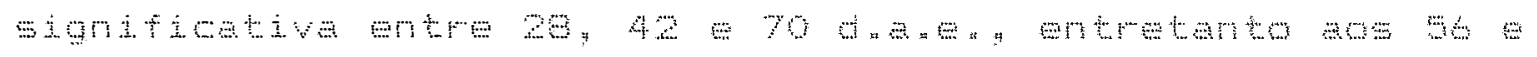

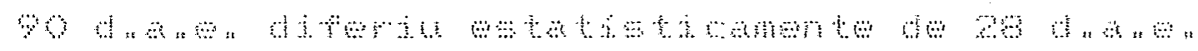

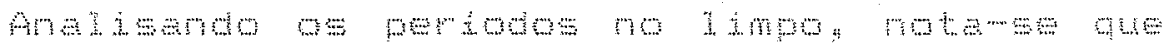

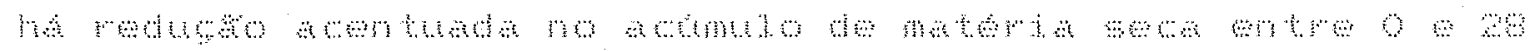

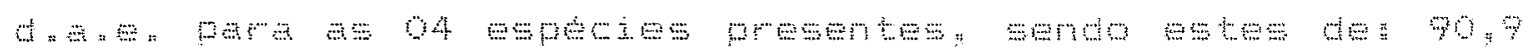

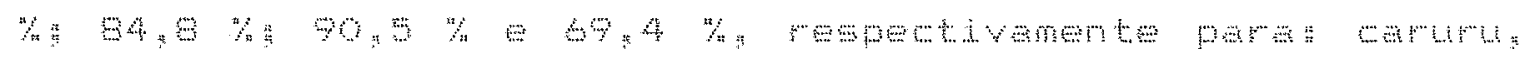




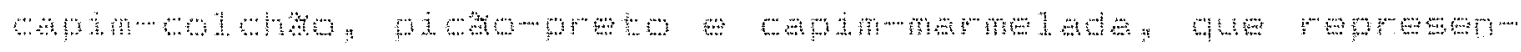

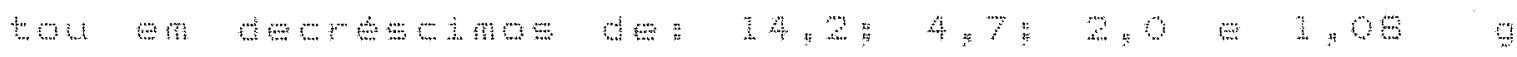
m.

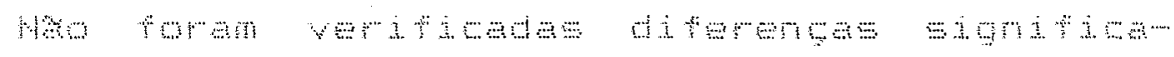

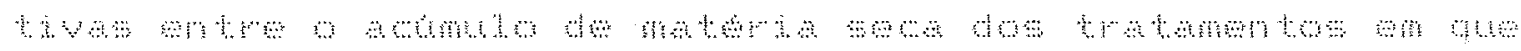

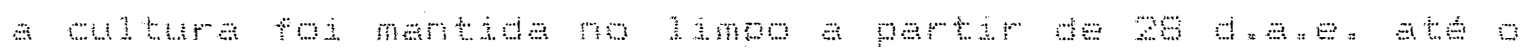

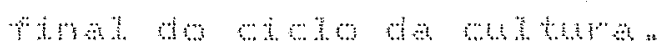

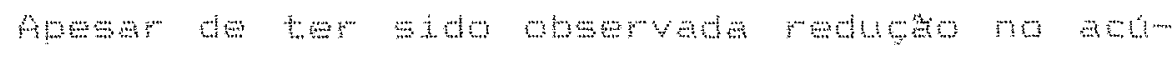

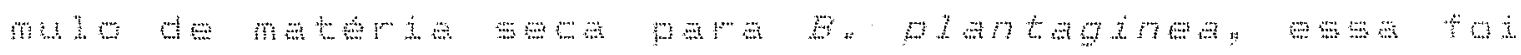

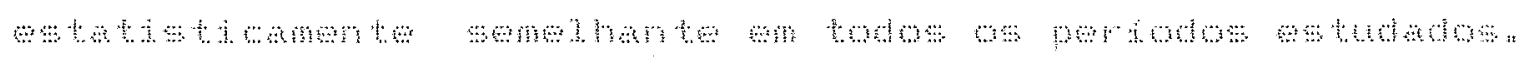

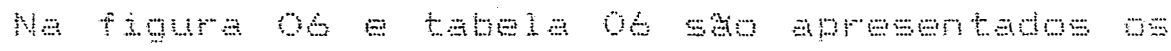

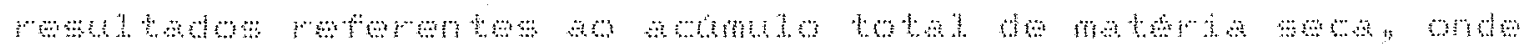

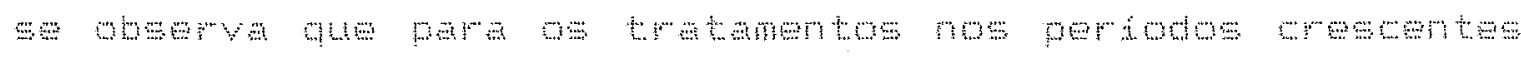

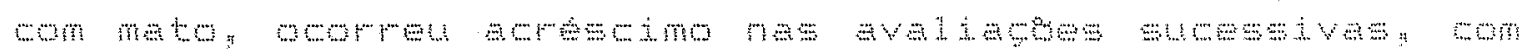

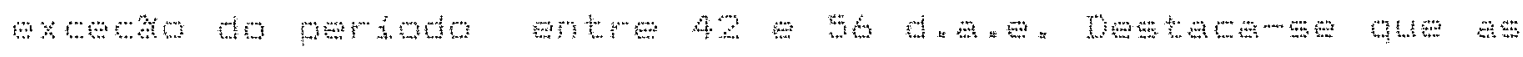

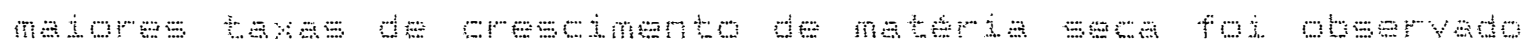
antre

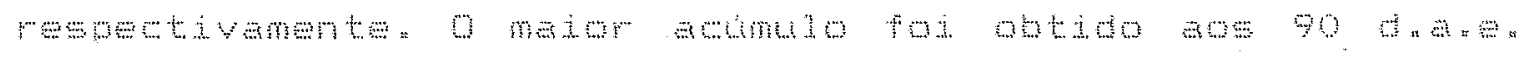

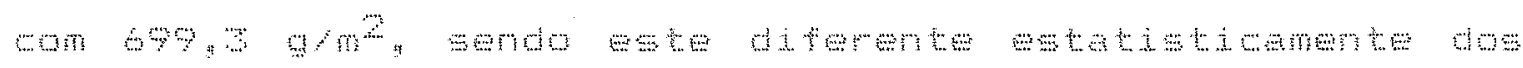
mants:

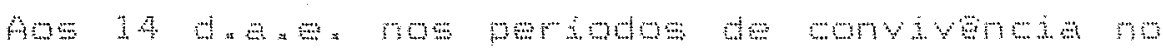

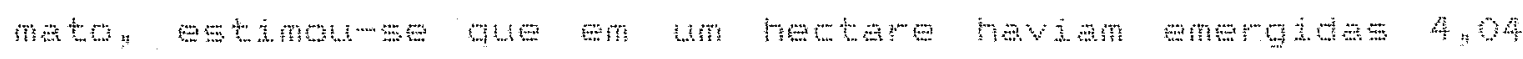

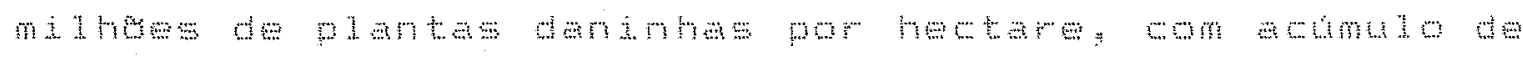
क्ष

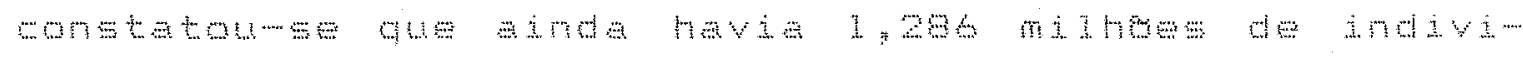

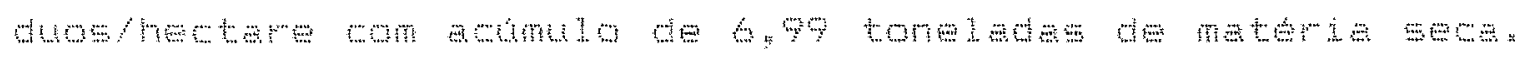




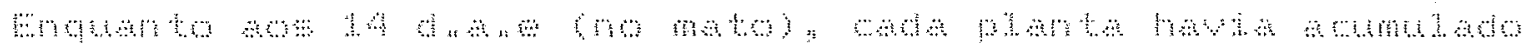

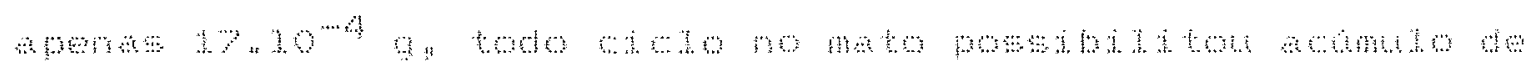

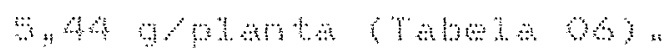

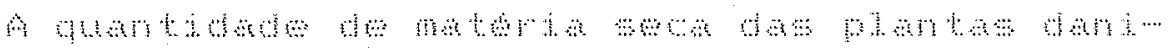

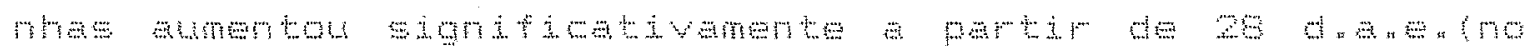

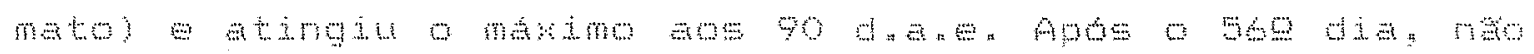

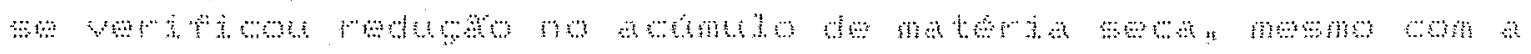

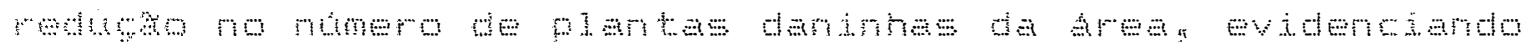

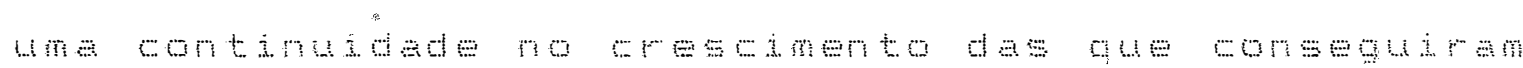
\%कm

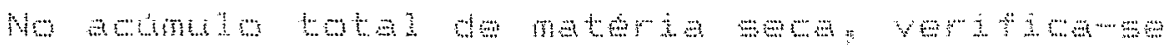

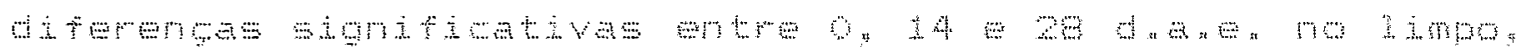

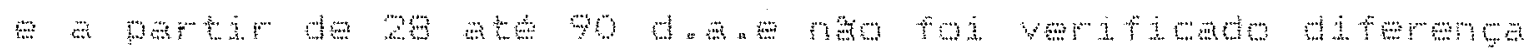

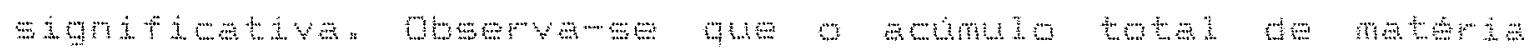

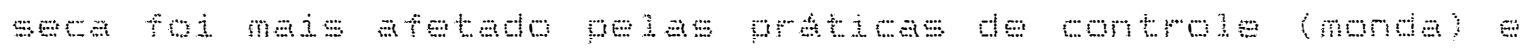

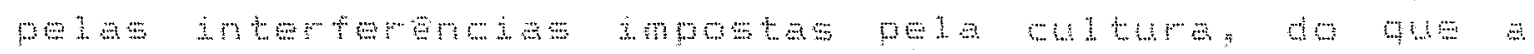

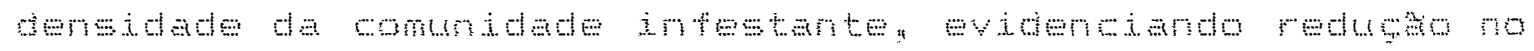

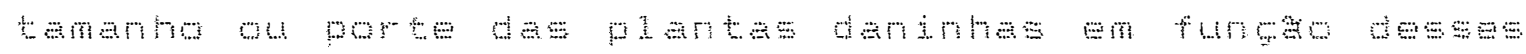

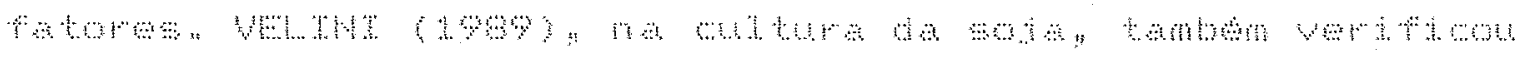

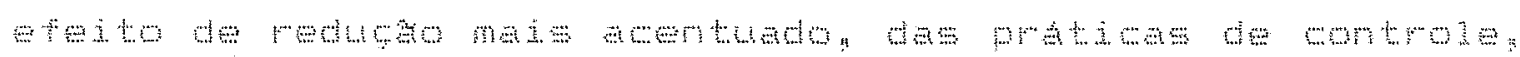
का

\subsubsection{Avaliagees referentes a cultura da aliata}



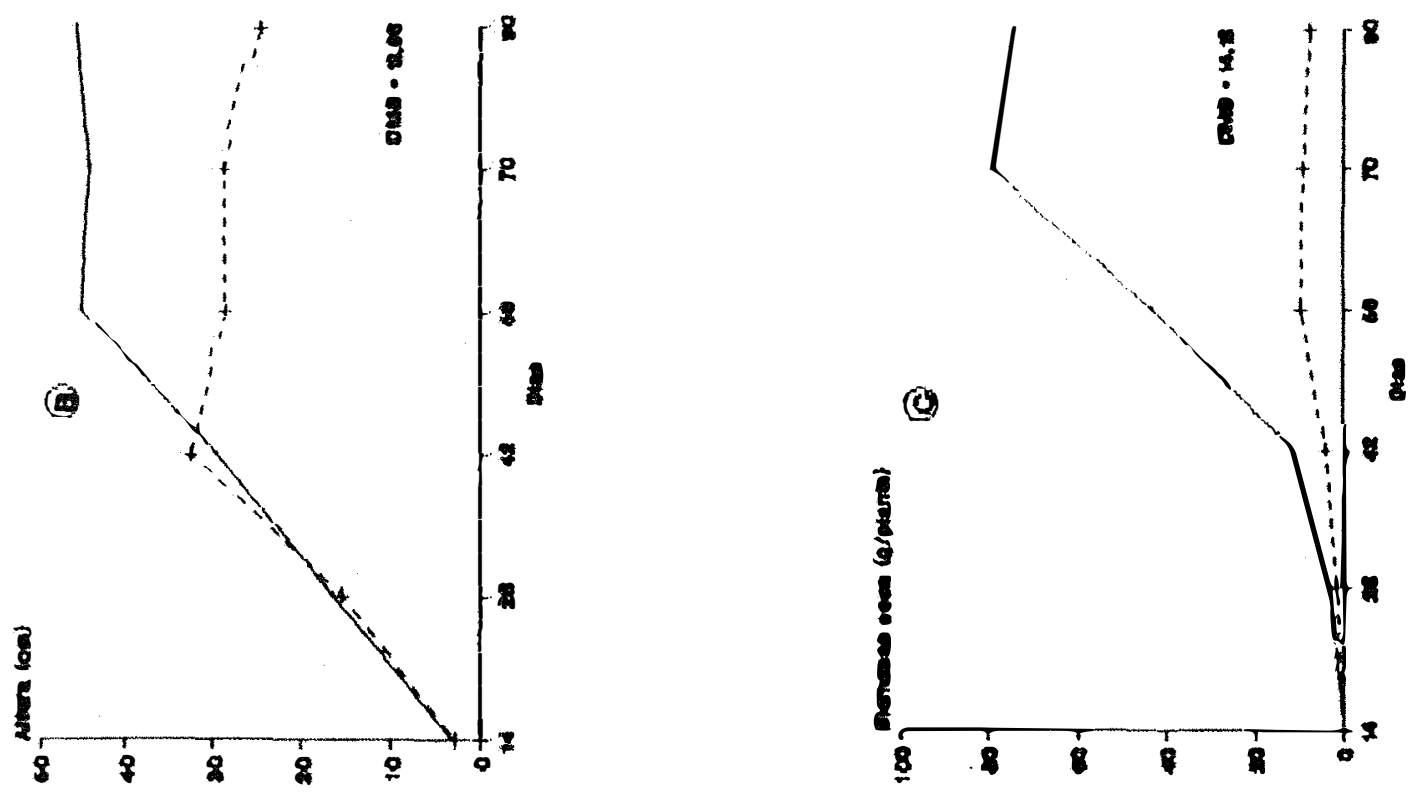

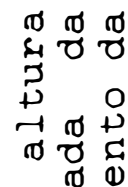

. 先

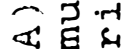

-

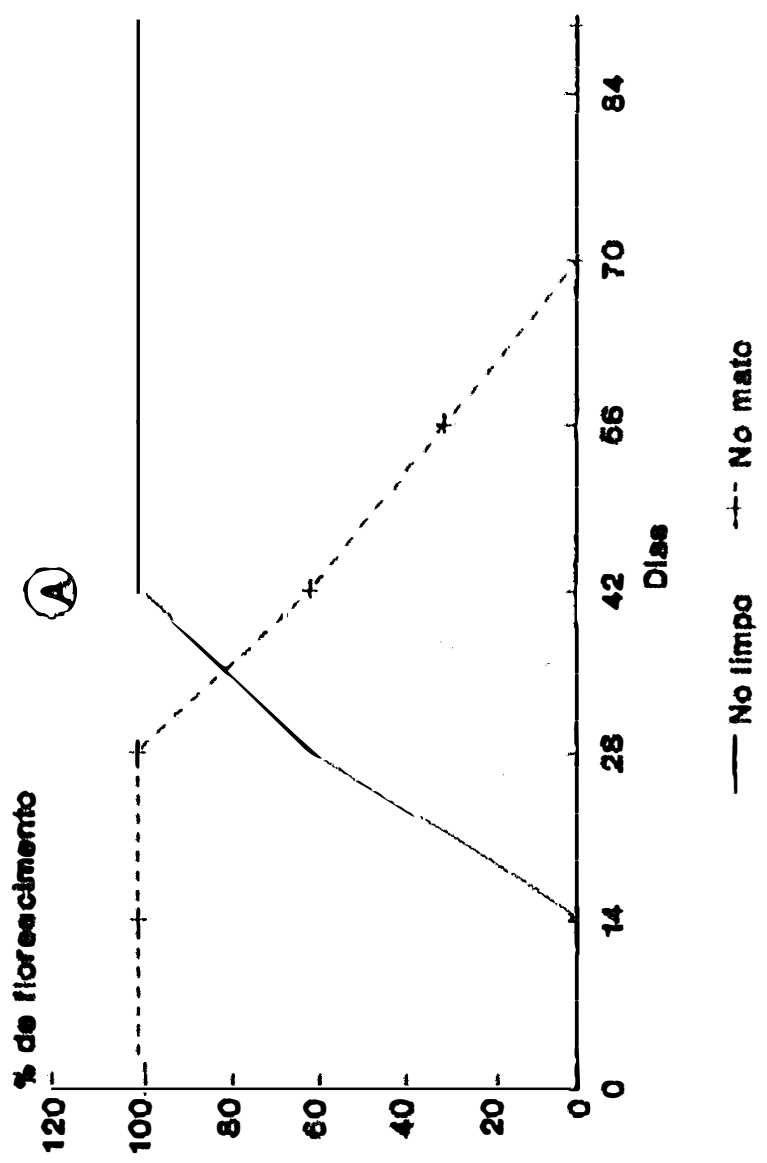

क

્ય न 0 O D क ส द. 0.4 व क्ष ट $\widetilde{0}$ (1) E ह 0 U 0 ๑) \& 0 है O क 0 तै क

घ्घ Q ह $\mathbb{D}_{0}^{0} 0$

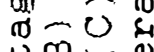

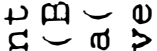
(1) 04 ช (c) $\cdot$ - 1 ह \& व 41 . म. है तु

$\ddot{\infty}$

否 


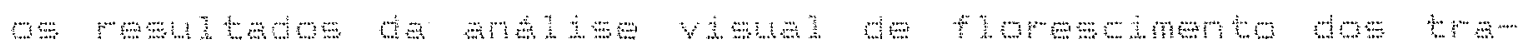

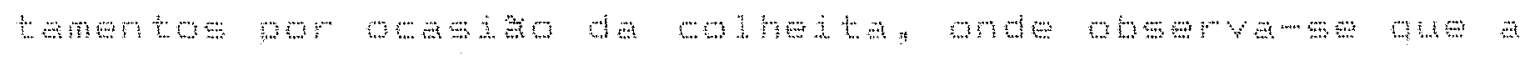

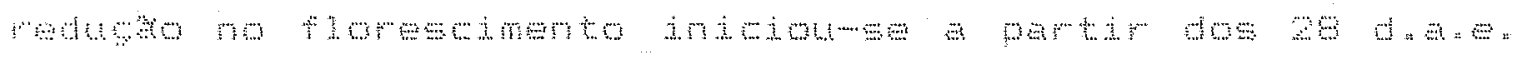

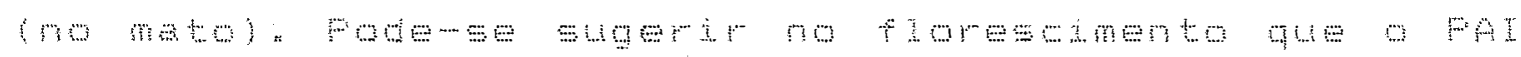

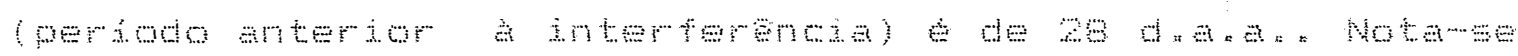

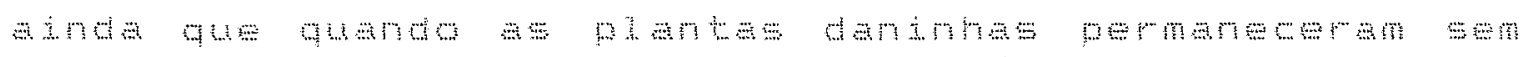

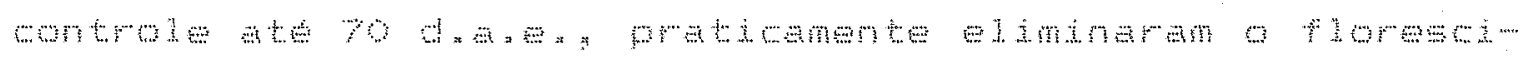

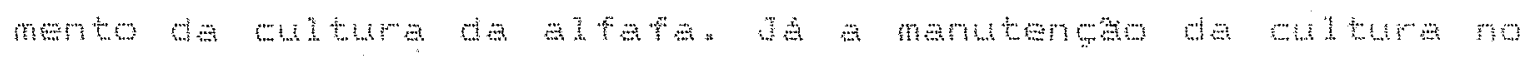

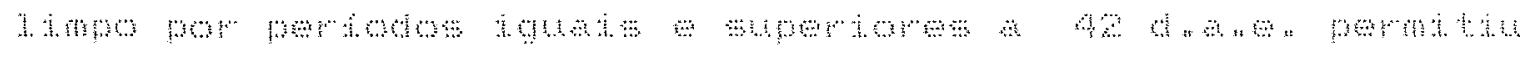

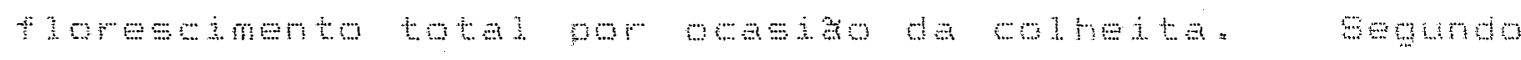

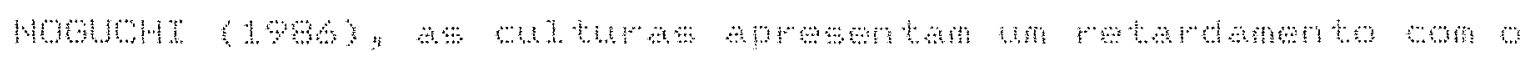

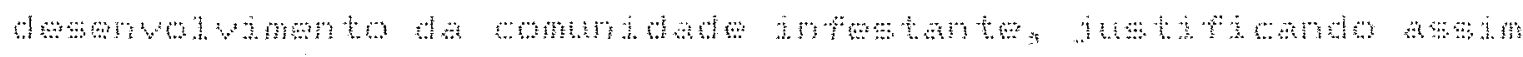
a An

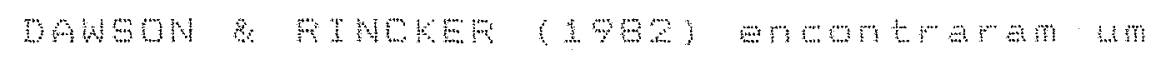

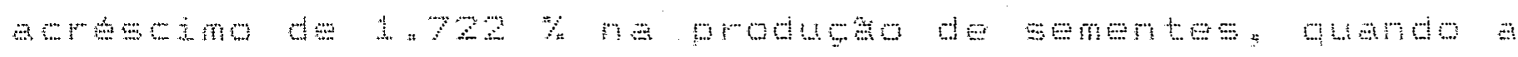

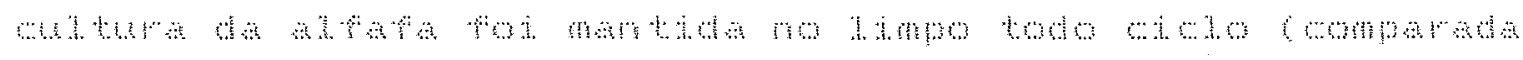

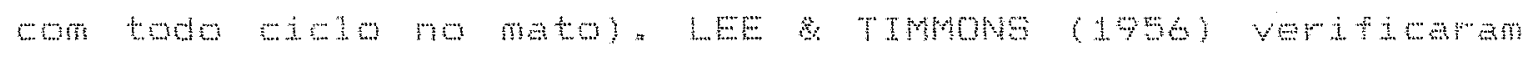

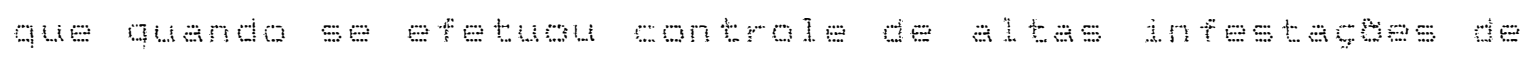

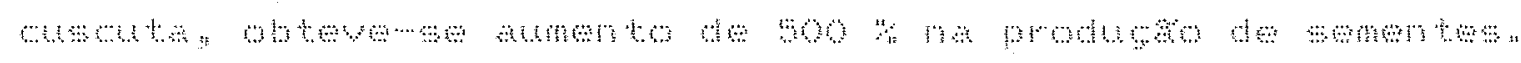

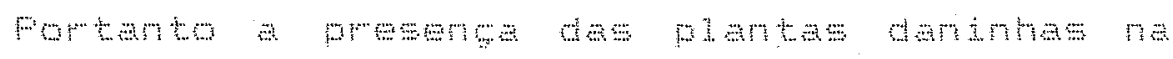

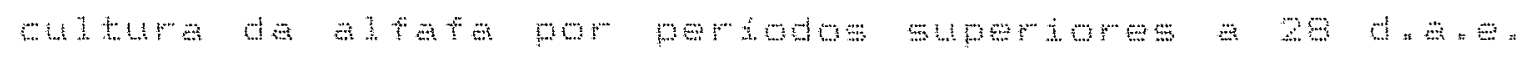

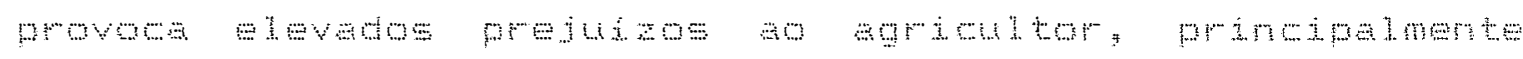

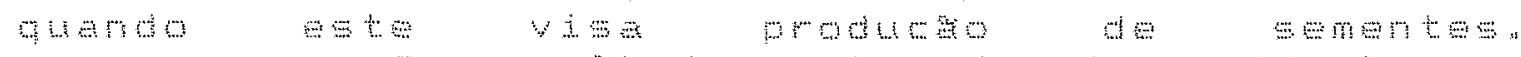

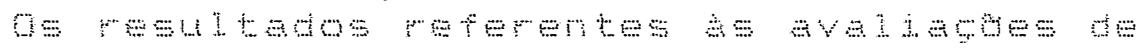

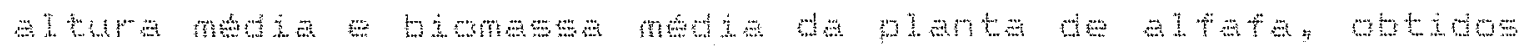

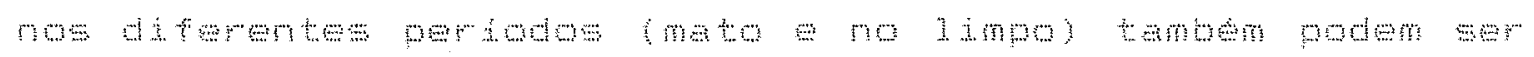

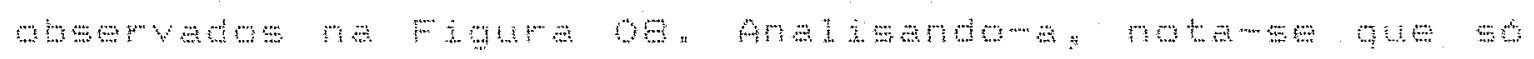




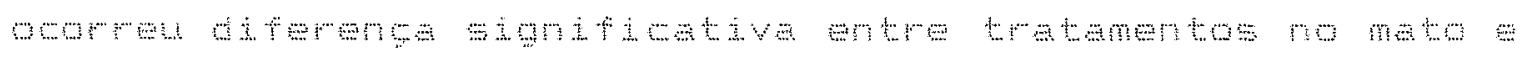

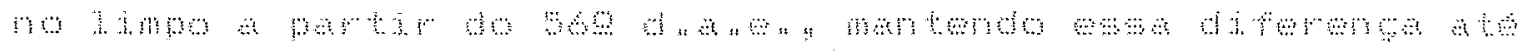

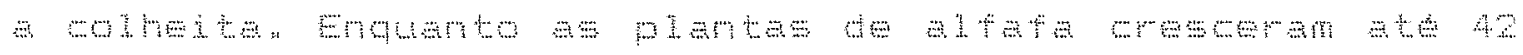

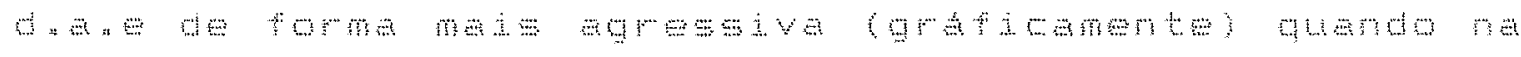

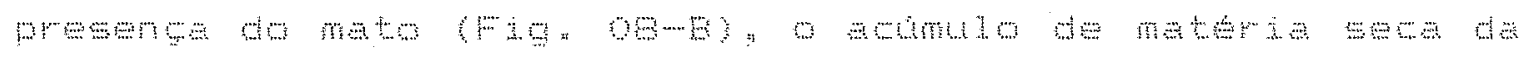

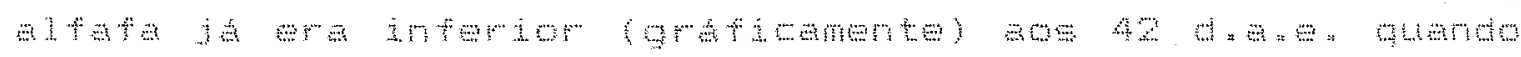

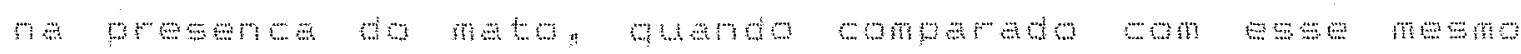

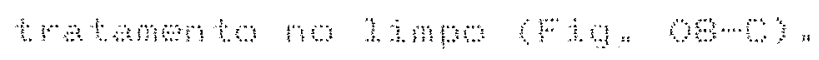

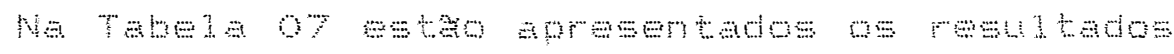

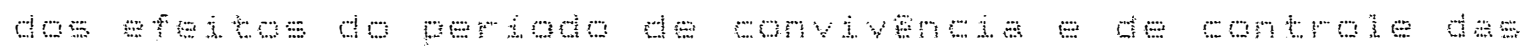

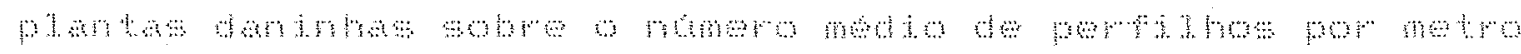

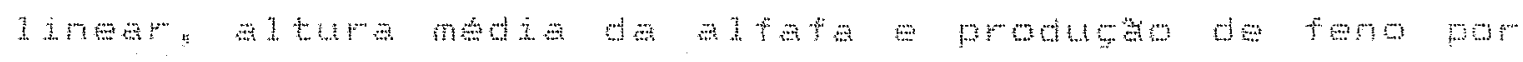

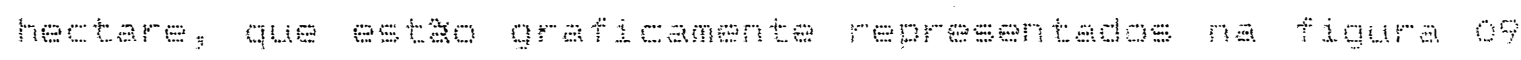

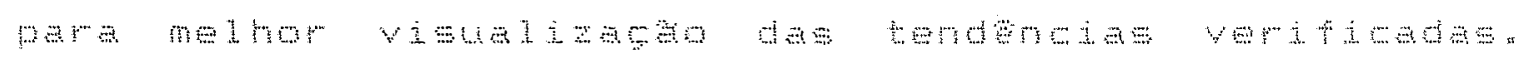

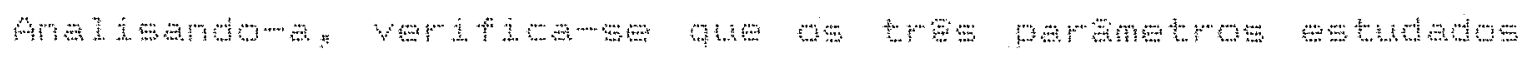

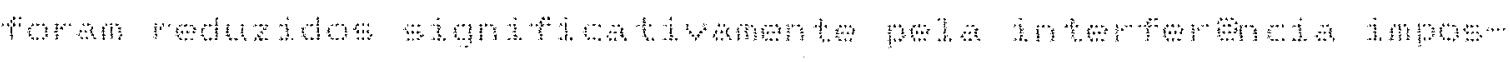

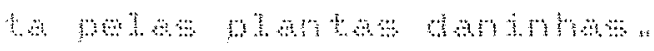

mampmo

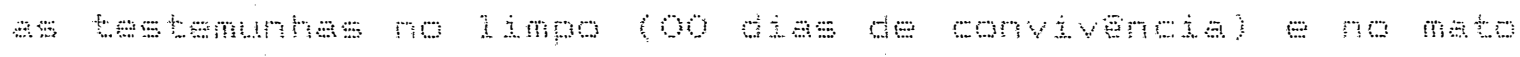

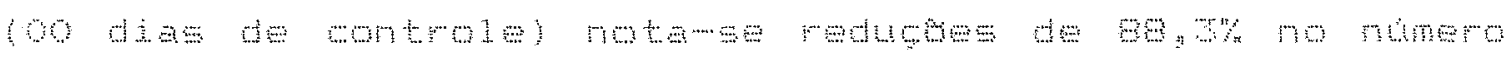

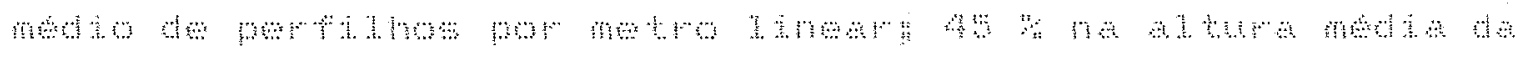
ал)

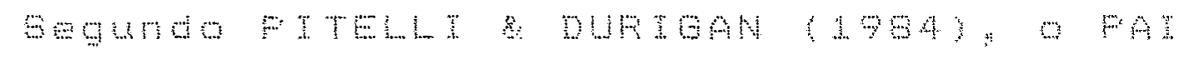

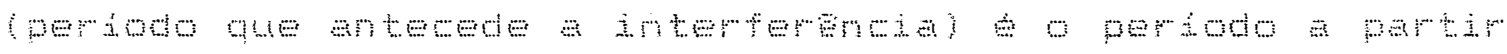

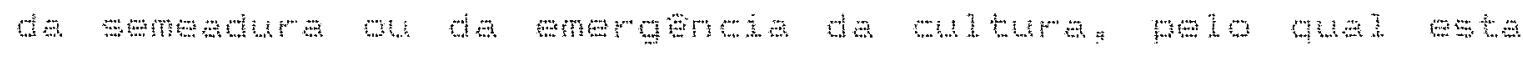

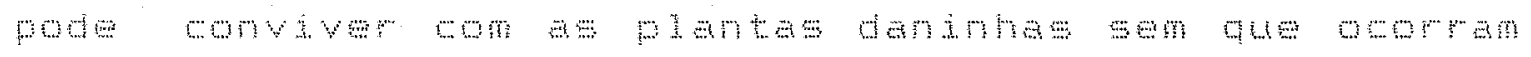




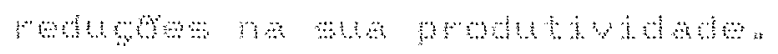

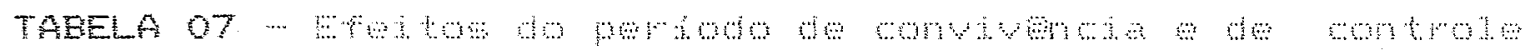

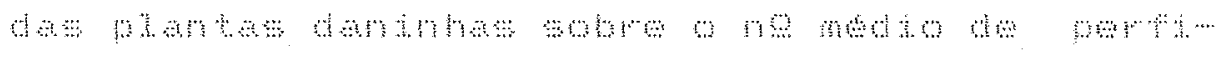

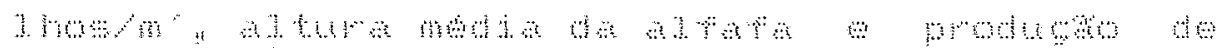

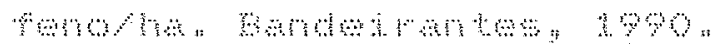

\begin{tabular}{|c|c|c|c|c|c|}
\hline & & 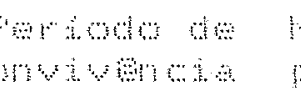 & 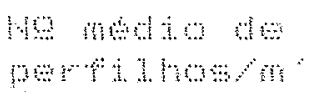 & 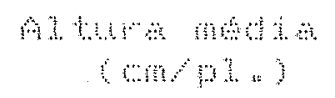 & $\begin{array}{c}\text { moduch of } \\
\text { (mones }\end{array}$ \\
\hline & & 0 & $\mathrm{ag}=4$ & बै & 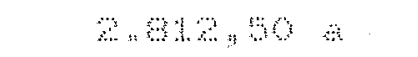 \\
\hline & & \% & $1 \%, 6 \%$ & $44: 50$ a & $=84,20$ \\
\hline$n$ & & y $\quad \ldots \quad y$ & $10, \infty 0 \mathrm{a}$ & 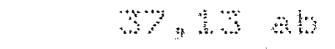 & $1,8 \%$, क $\mathrm{b}$ \\
\hline 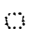 & & $0 \quad \cdots \quad$ & en, sm & अ & 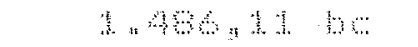 \\
\hline & & $0 \quad \cdots \quad 6$ & \%, $3 \mathrm{~s}$ & 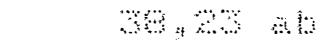 & a 190,6 \\
\hline in & & 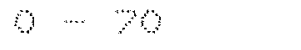 & \% & 3,776 & $39: 3 \% \mathrm{~d}$ \\
\hline a & & \% $\cdots$ & 18,$6 ;$ & a , 10 & $A 2,3 \mathrm{~d}$ \\
\hline 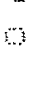 & F' & 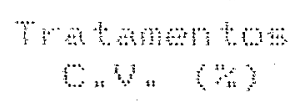 & 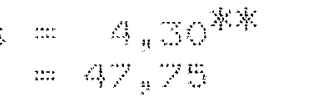 & 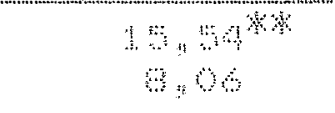 & $\begin{array}{l}3,9 \% \text { कर } \\
1,8 \%\end{array}$ \\
\hline & & \% & $1, \%$ & $23: 10 \quad \ldots$ & a \\
\hline$n$ & & औ $\quad \cdots \quad 4$ & $4,6 \%$ & $\mathrm{~b}, 4 \%$ & $3 \%: 9 \%$ \\
\hline 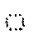 & & क $\quad-\quad 0$ & 13,38 ж & $A s: 4 \%$ a & : $, 1,69$ \\
\hline & & o $\cdots$ & 1900 : & 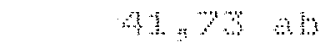 & 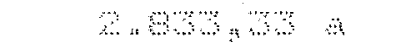 \\
\hline l. & & $9 \quad \cdots \quad 8$ & 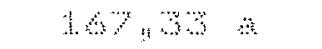 & $49,3 \%$ & : $990 ;: \%$ \\
\hline$i$ & & ओ $\cdots \cdots$ & $12 \theta_{0} 6$ a & $39: 10 \mathrm{a}$ & 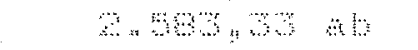 \\
\hline$n$ & & $0 \quad \cdots$ & $19 \%, 00$ & 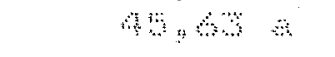 & 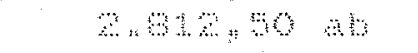 \\
\hline$\cdots$ & $F$ & 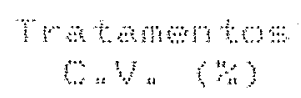 & 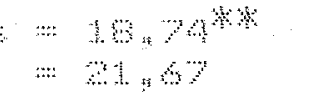 & 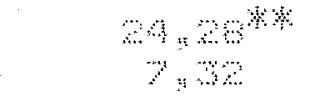 & 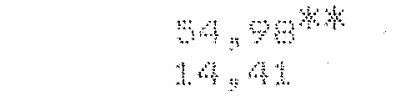 \\
\hline
\end{tabular}

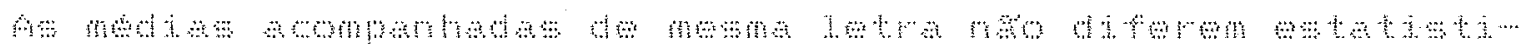

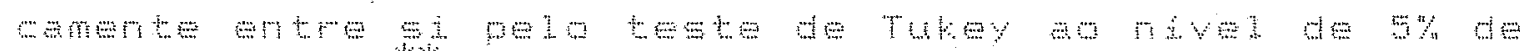
mobata

कma

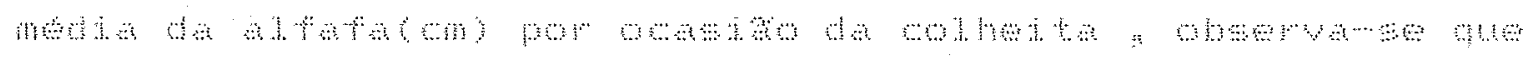

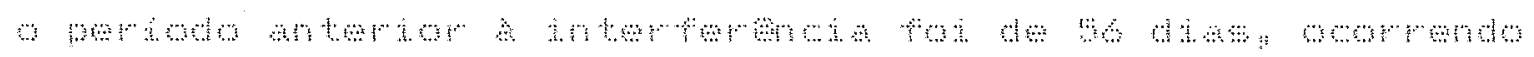



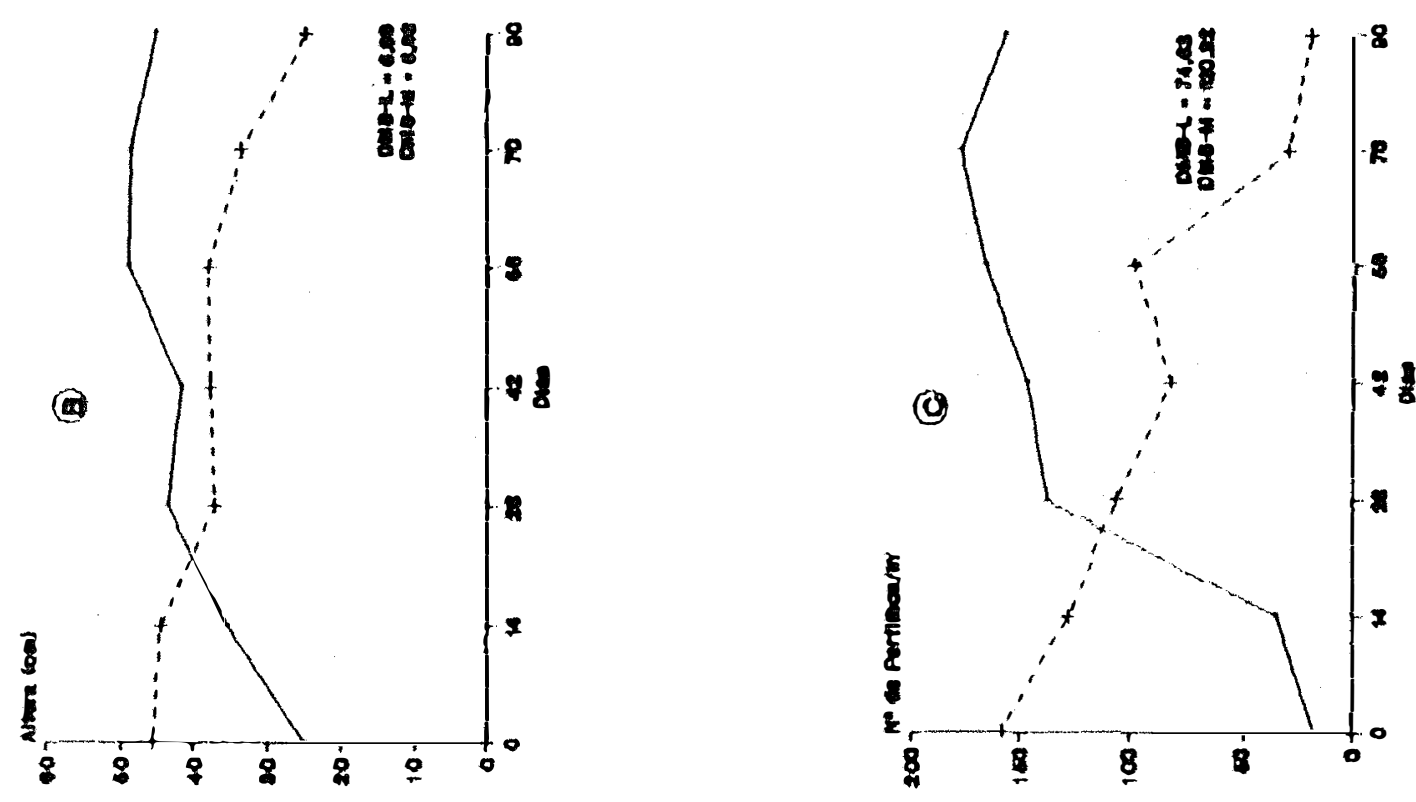

$\begin{array}{cc}\sigma & 1 \\ 0 & -1 \\ 0 & 4 \\ 0 & 4-1 \\ -1 & 0 \\ 0 & 0 \\ 0 & 0 \\ 0 & \end{array}$

ฮั

क्ष

मै.

ส

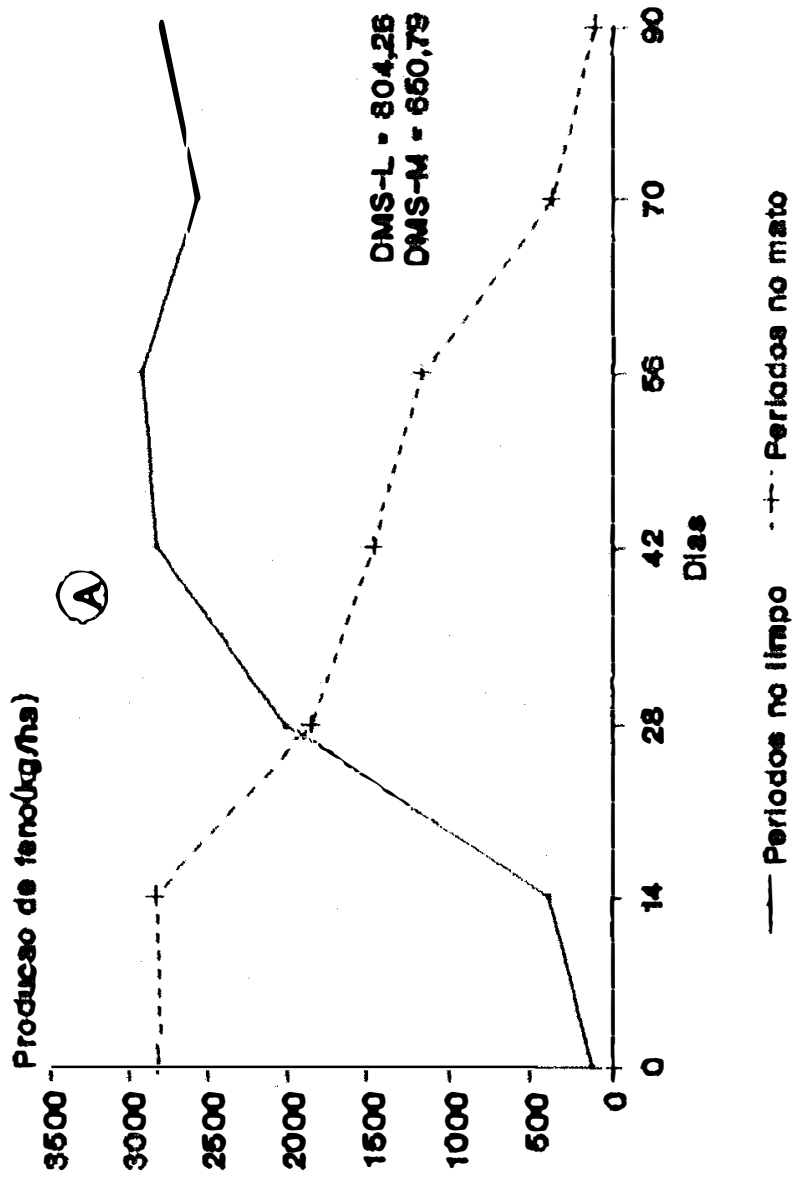

$\because 0 \stackrel{0}{\circ}$

ब \&

¿ E.

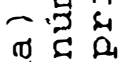

\& $\pi$

को 0 ช

st

ำ

Hㄷ

苟

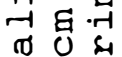

(1)

$\begin{array}{lll}\sigma & 0 & \rho_{1} \\ 0 & + & x \\ . & 0\end{array}$

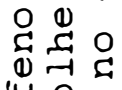

4 0 .

๑)

0 工

2 01

ชู

क्षि

$\ddot{\sigma}$

垈 


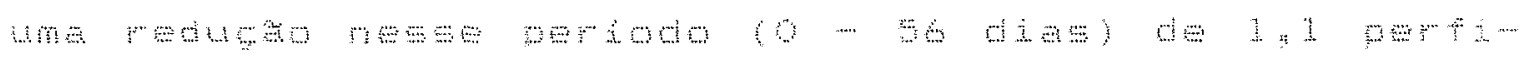
Hon fon 14;

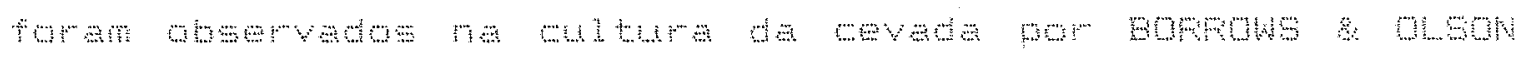

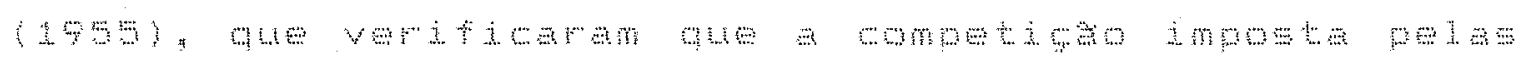

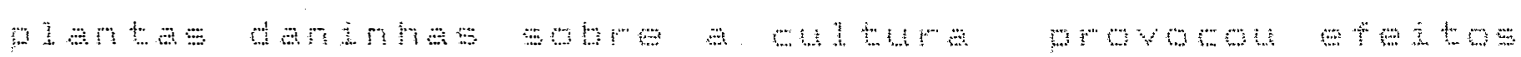
ван

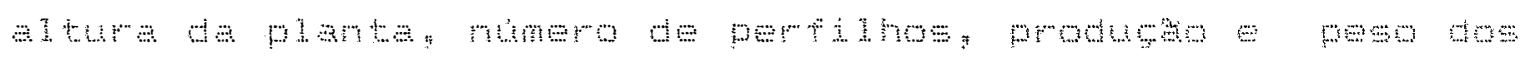

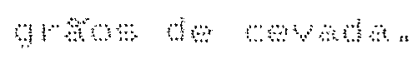

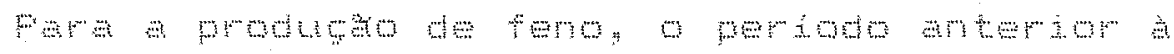

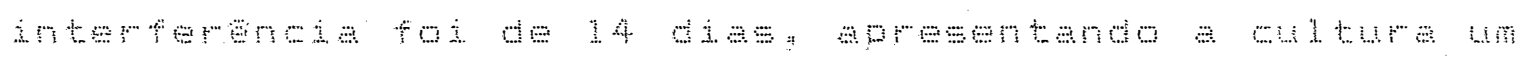
a

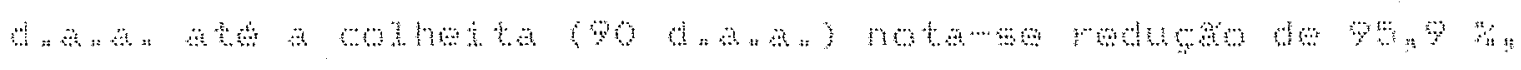

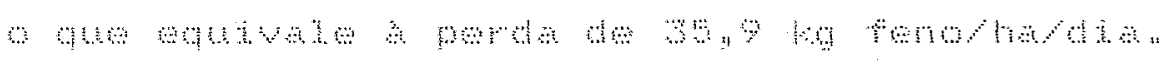

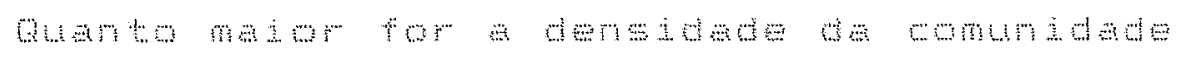
m

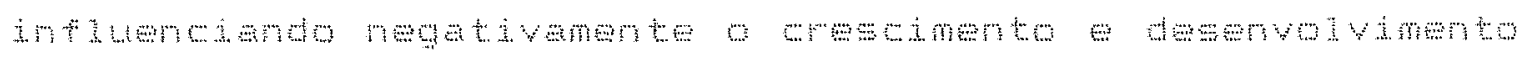

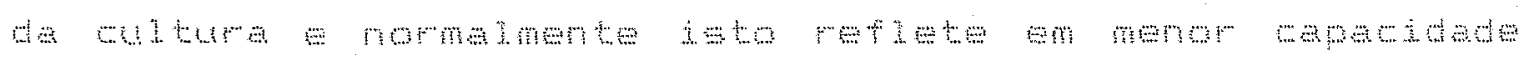

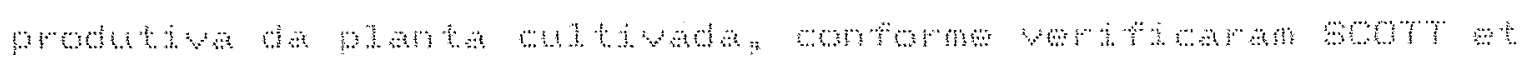

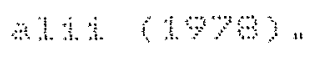

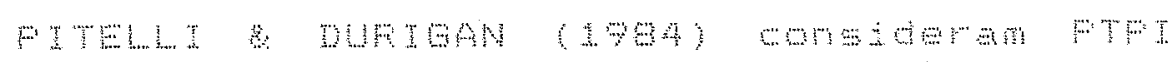

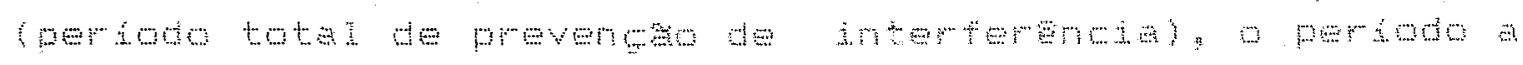

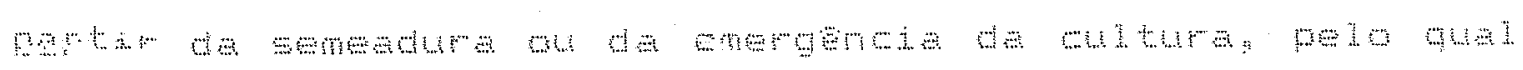

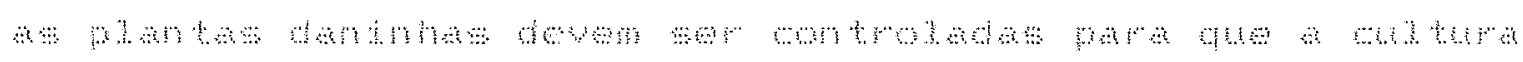

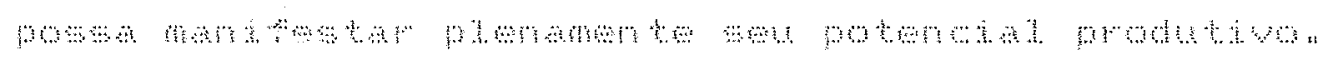




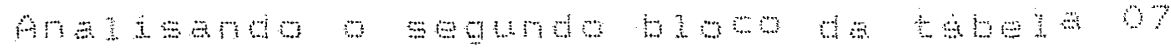

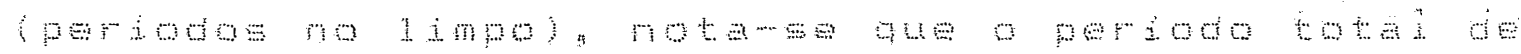

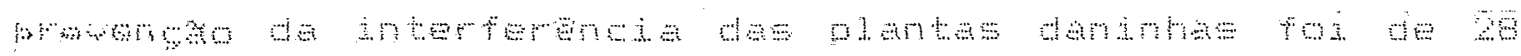

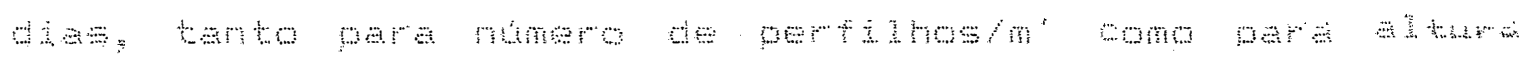

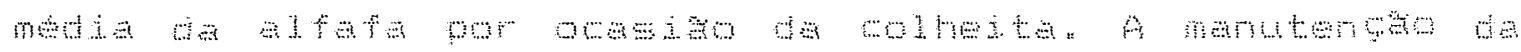

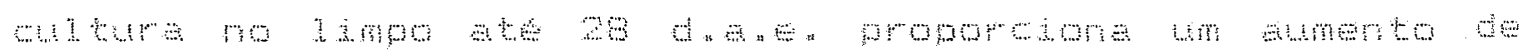

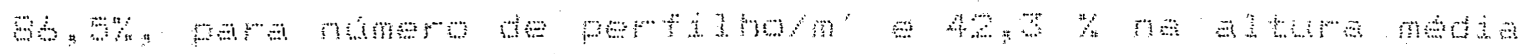

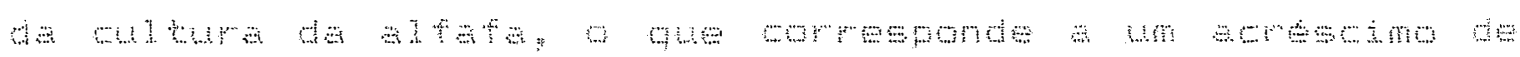

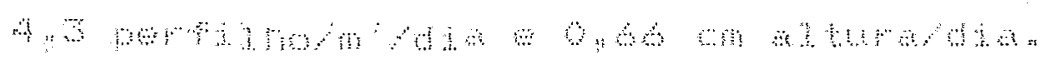

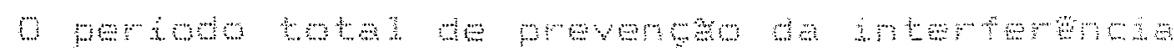

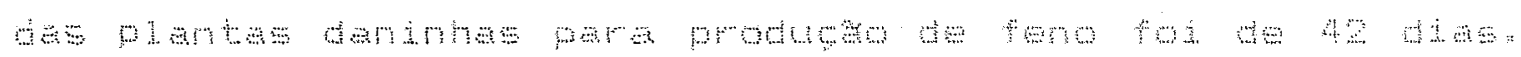

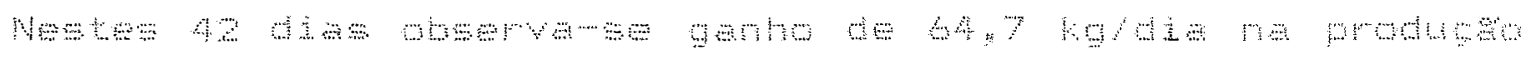

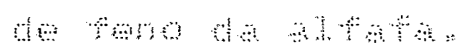

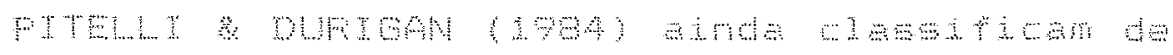

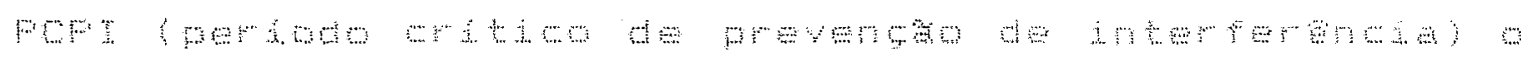

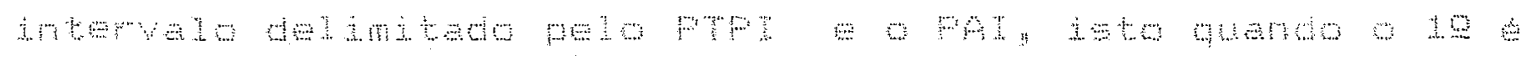
Whan

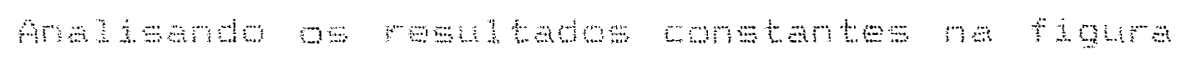
के गа

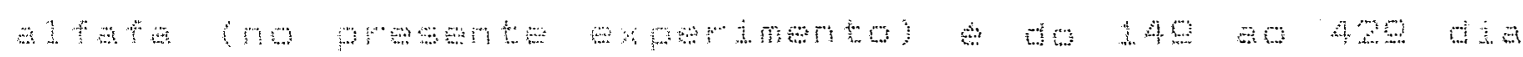
mo

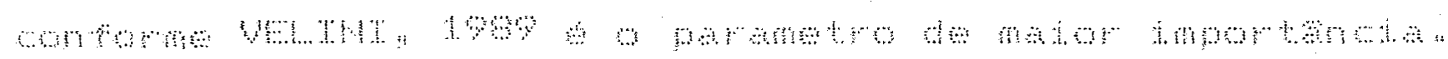

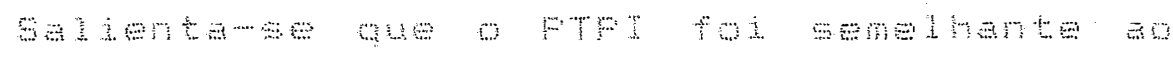
mor

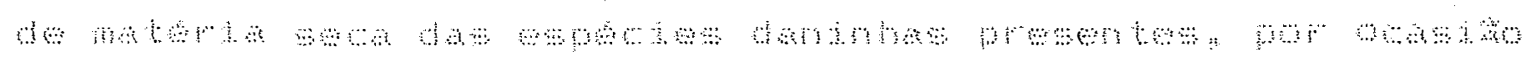

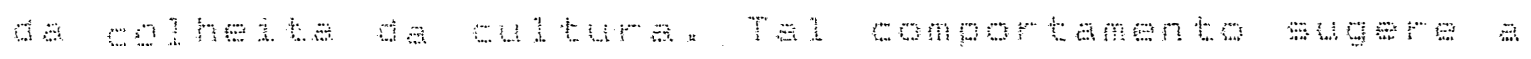




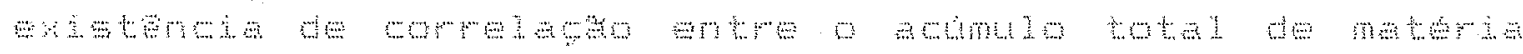
som

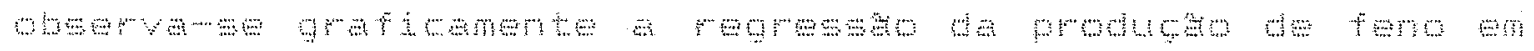

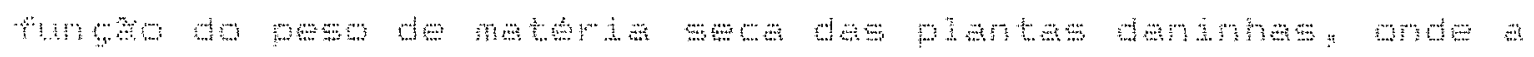

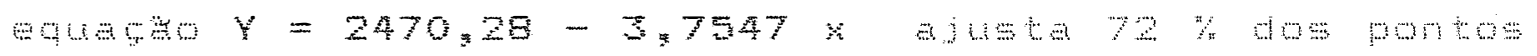

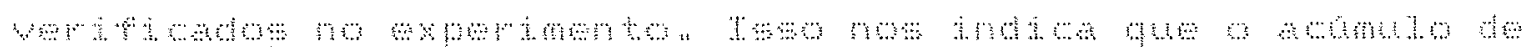

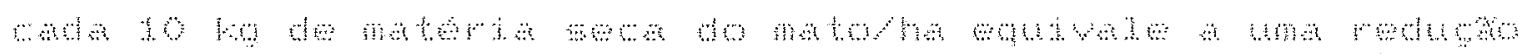

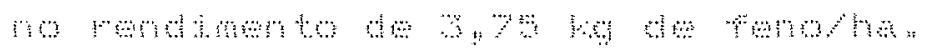

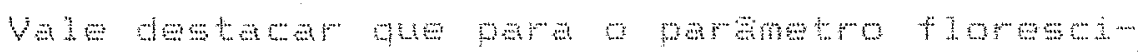
man

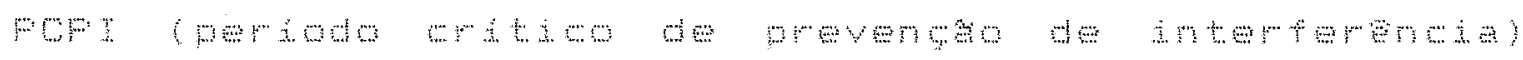

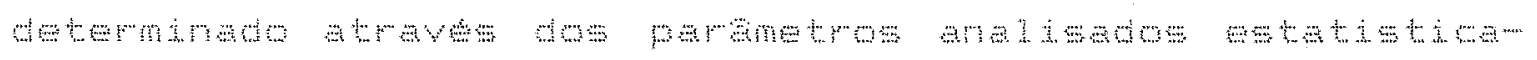

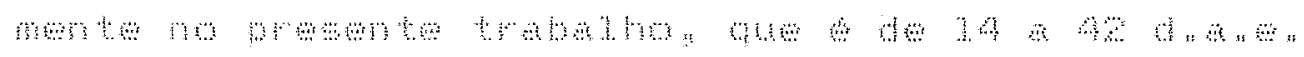

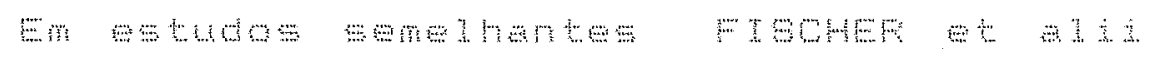

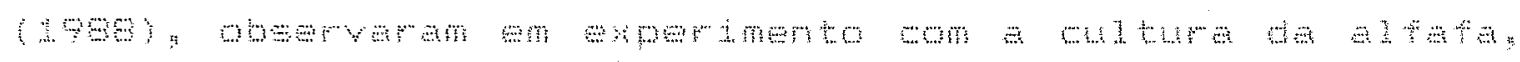

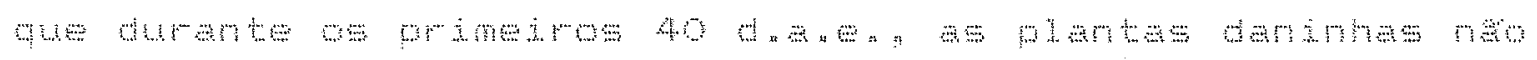

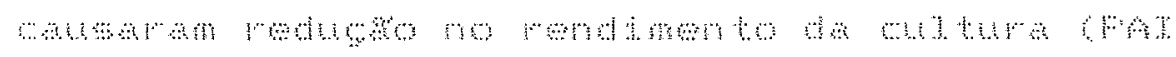

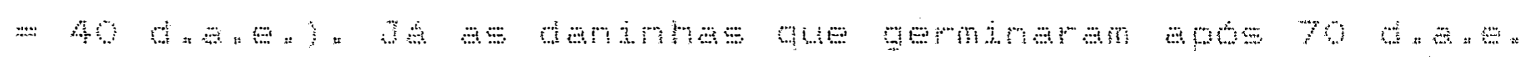

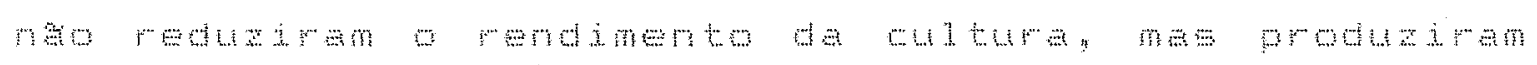

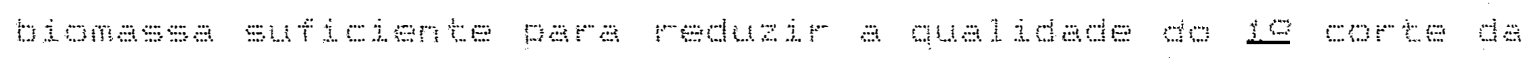

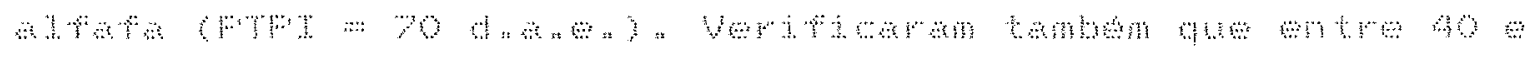

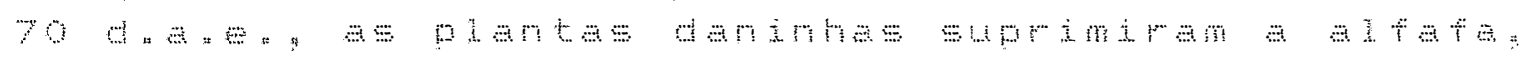

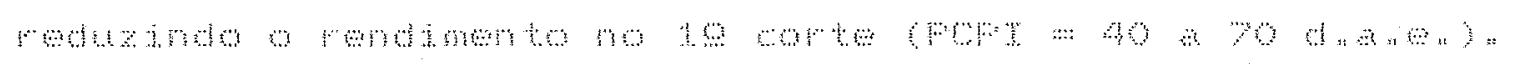

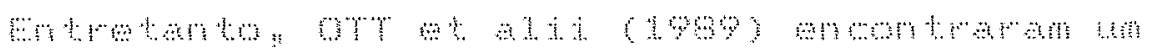
ma do a 


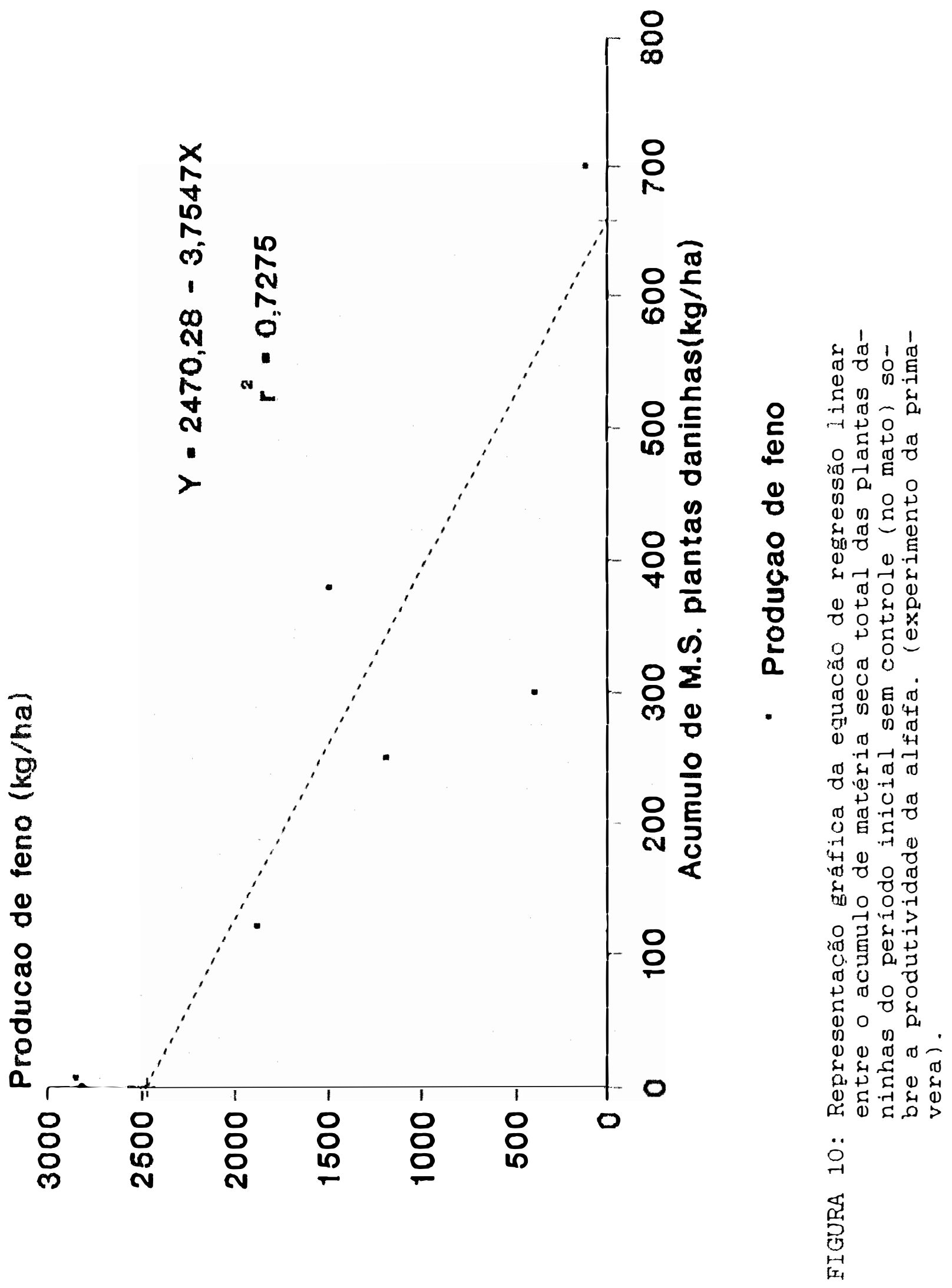




\section{$4=2=$ Experimento do Outono}

\section{$4: 2=1$. Avaliaçes Fererentes a Comundade Intestante}

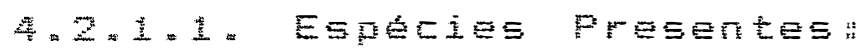

Aw mom

0

ma

expenimanas

$+\sin \bar{s}$

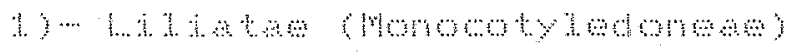

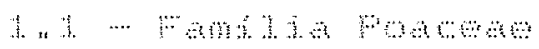

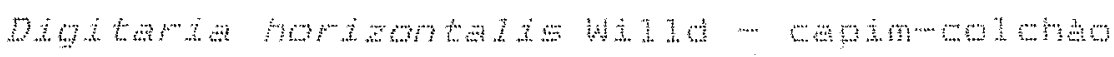

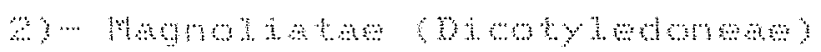

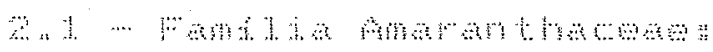

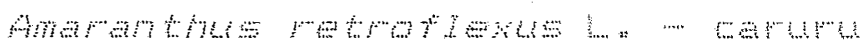

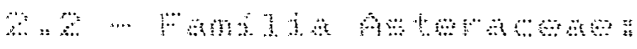

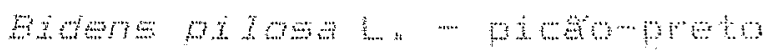

2.

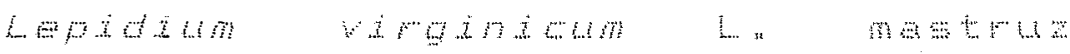

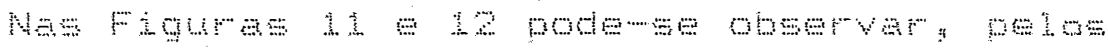

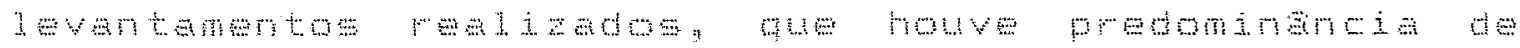

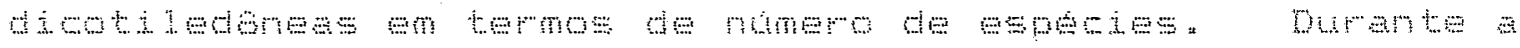

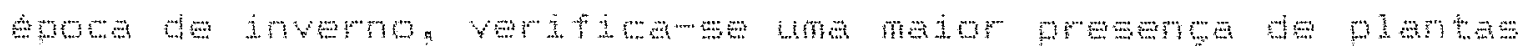




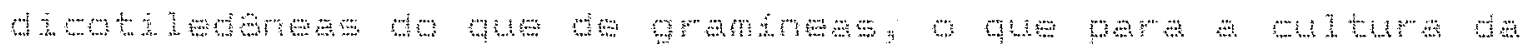

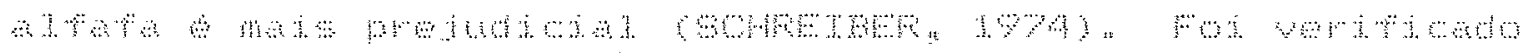

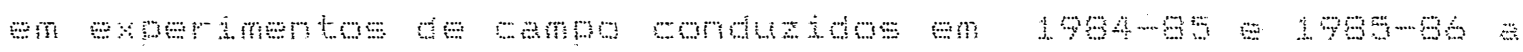

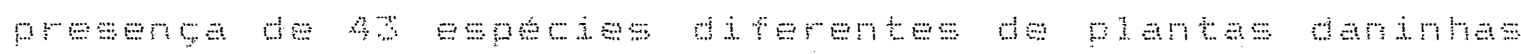

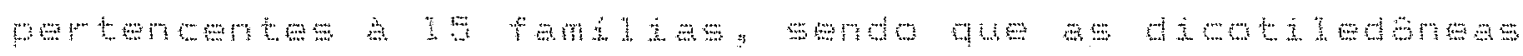

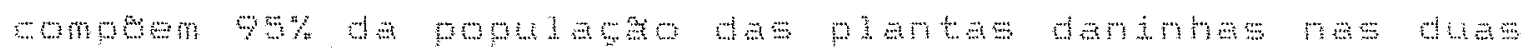

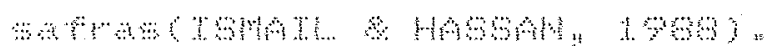

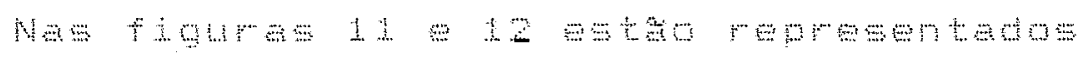

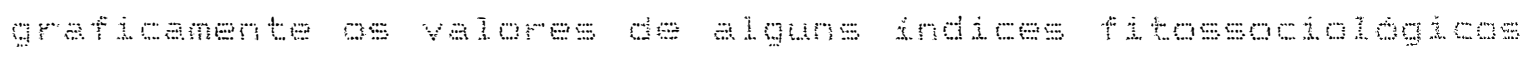

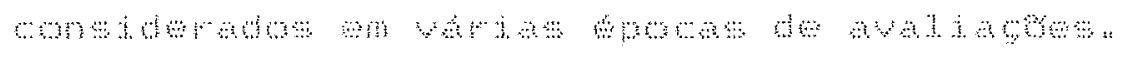

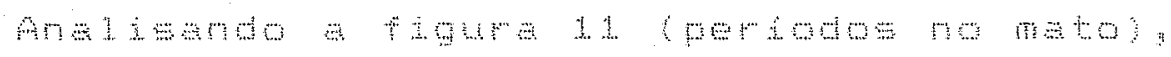

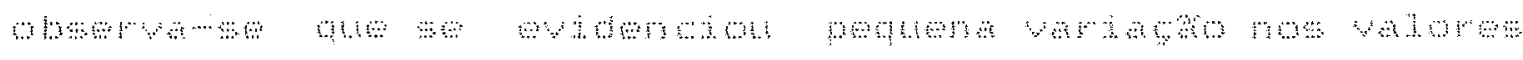

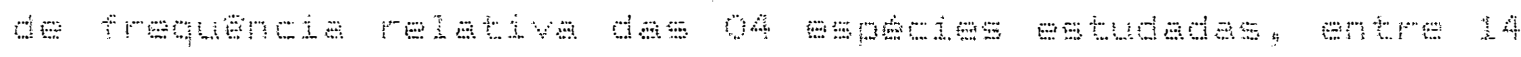

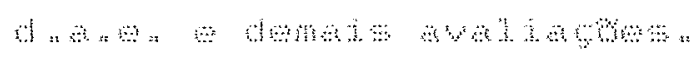

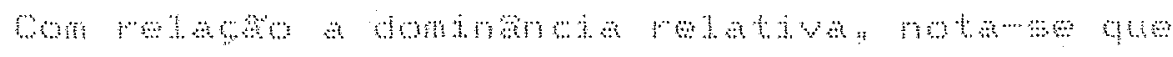

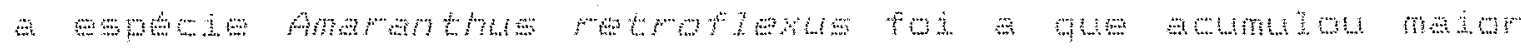

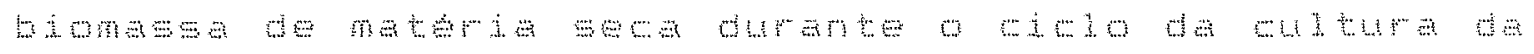
a $14 \%$

A thatem hom

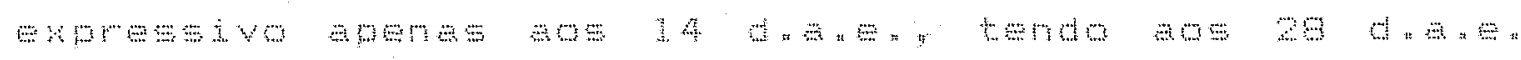

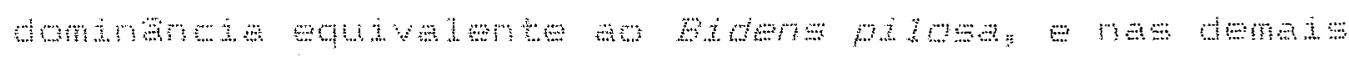

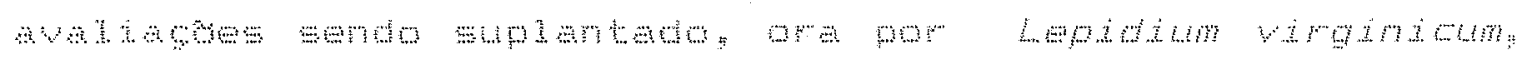

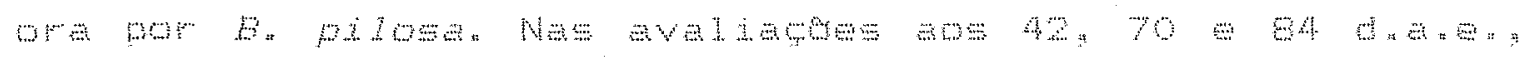

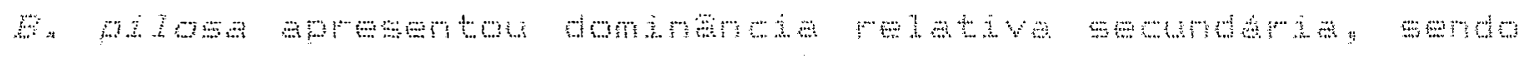

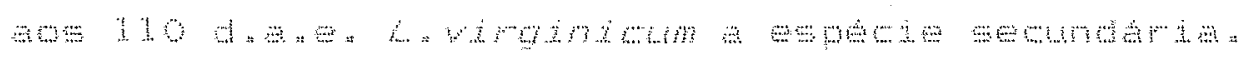



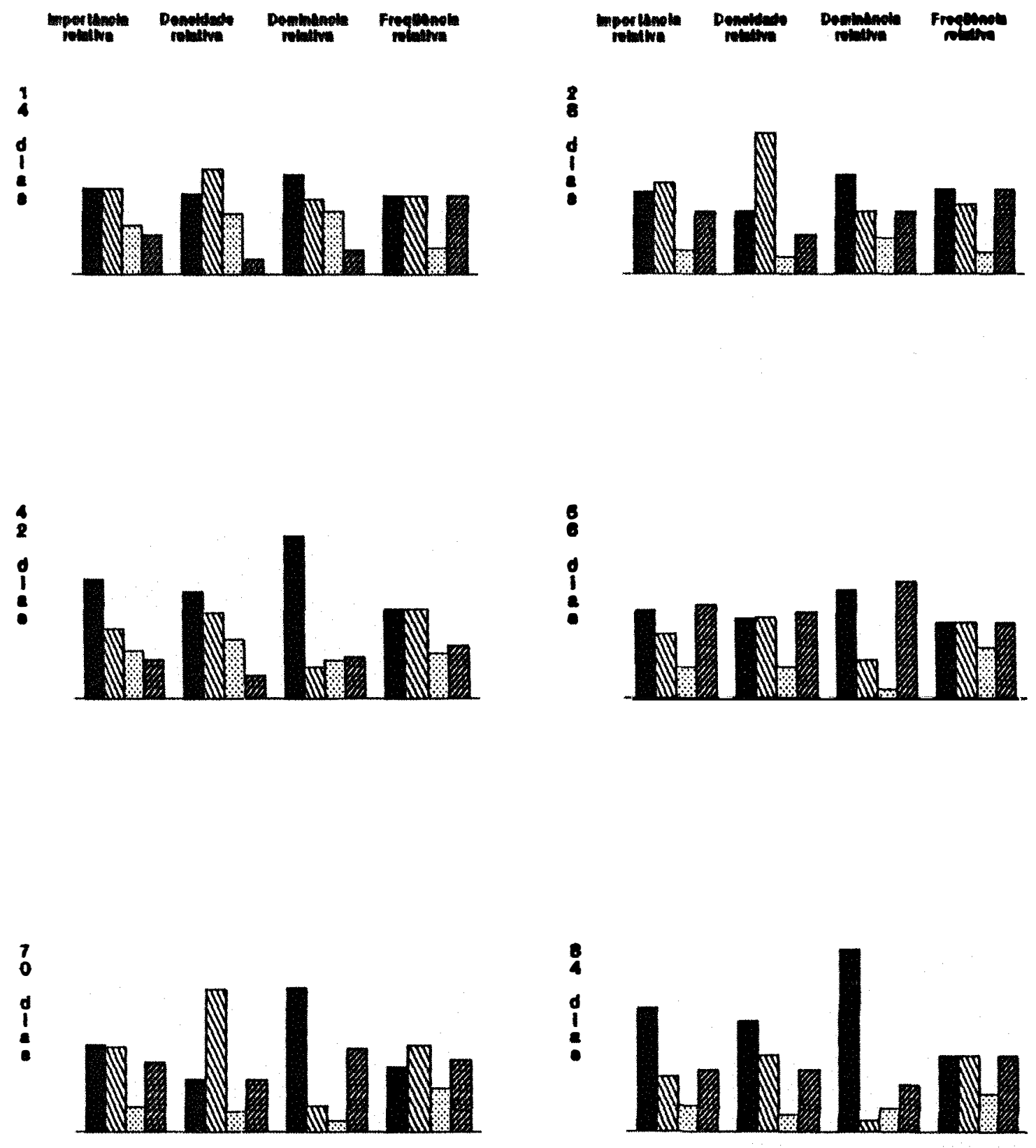

\section{LEGENDA}

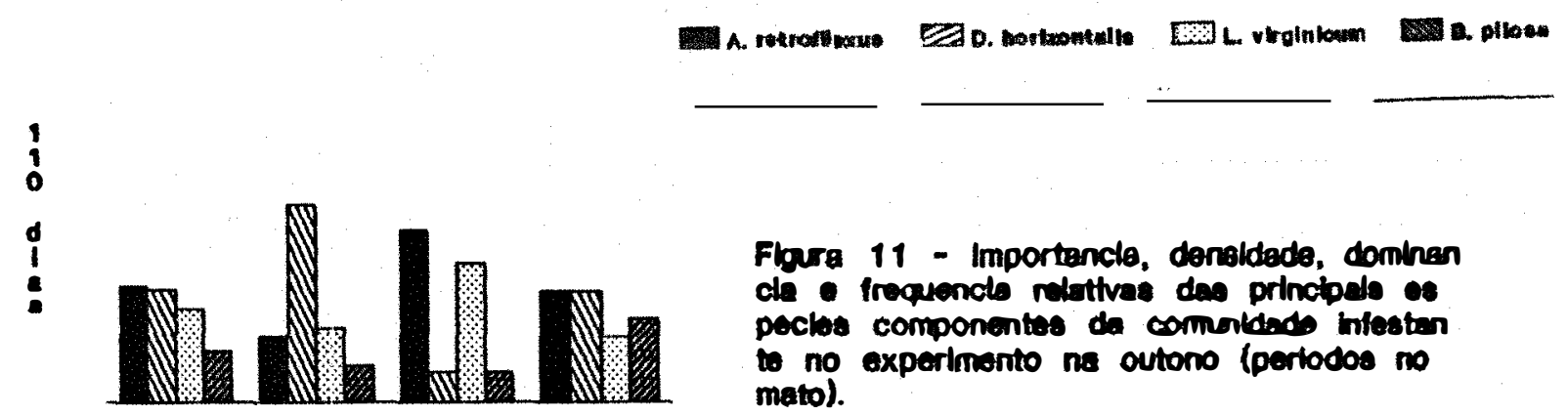




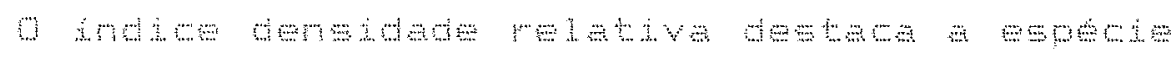

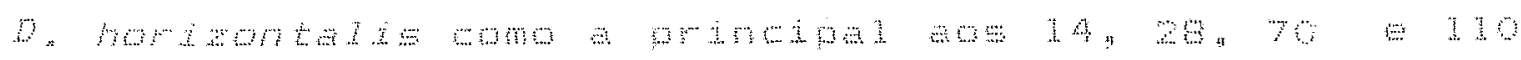

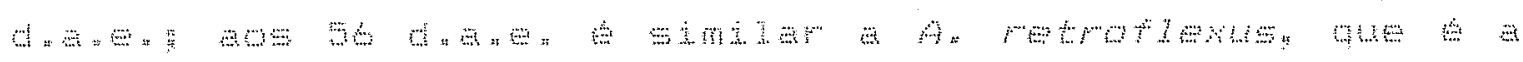

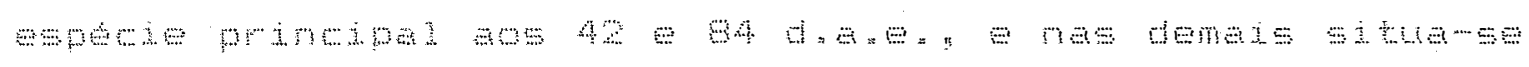

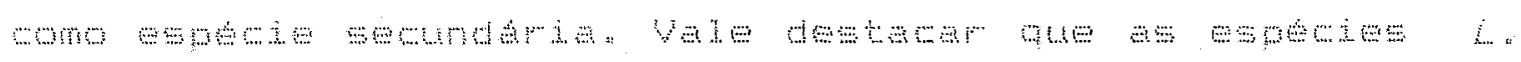

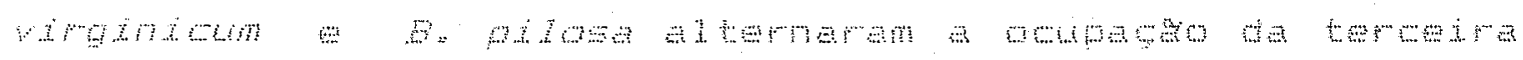

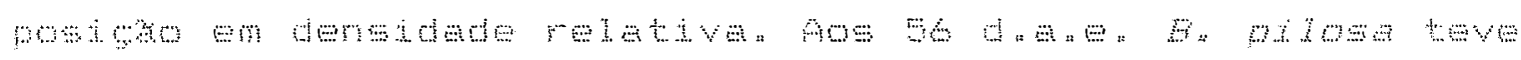

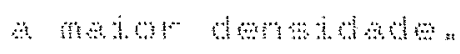

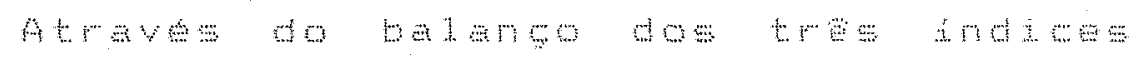

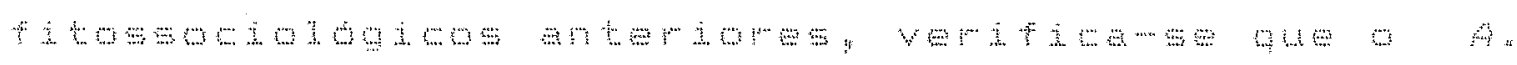

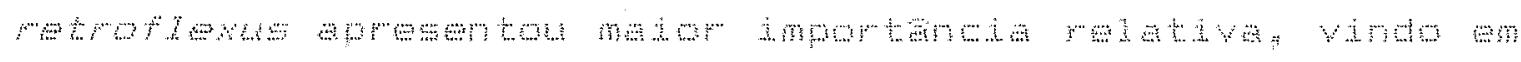

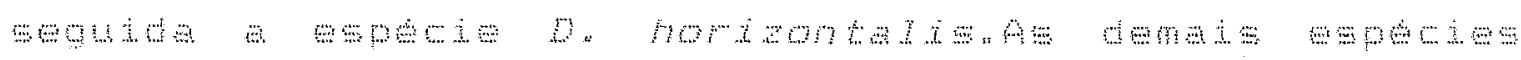

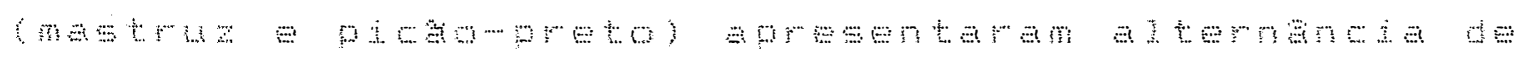

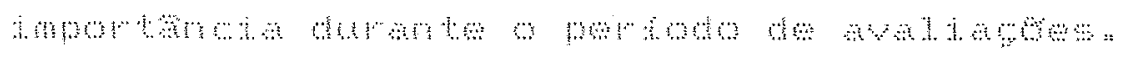

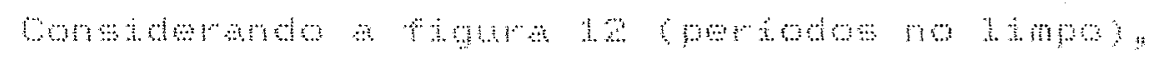

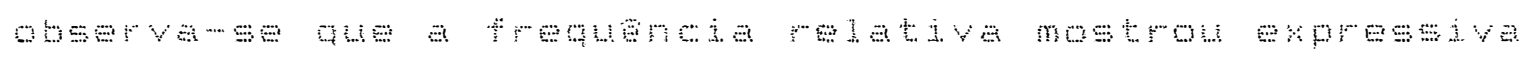

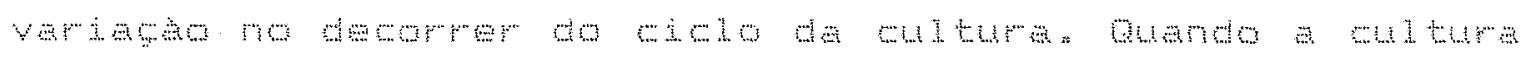

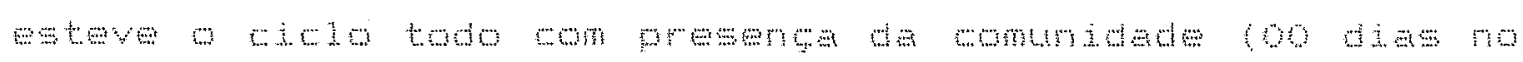

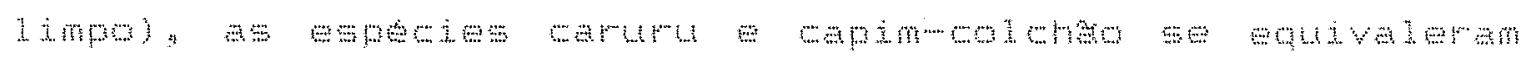
कmo prinompun,

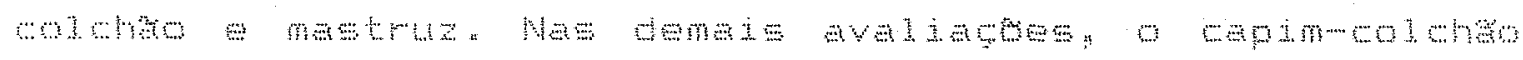

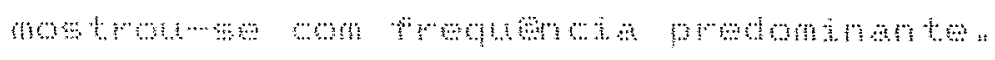

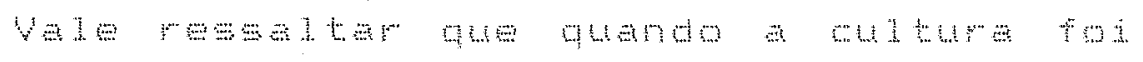

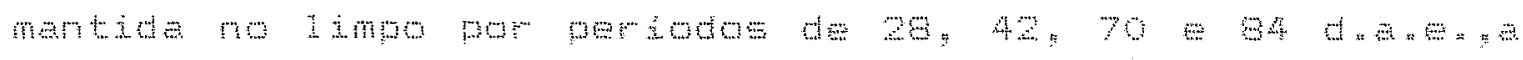

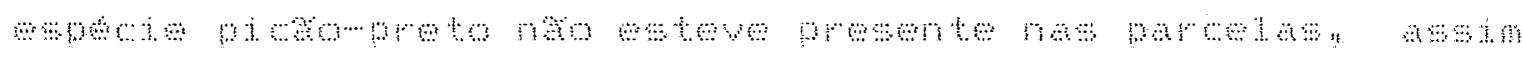



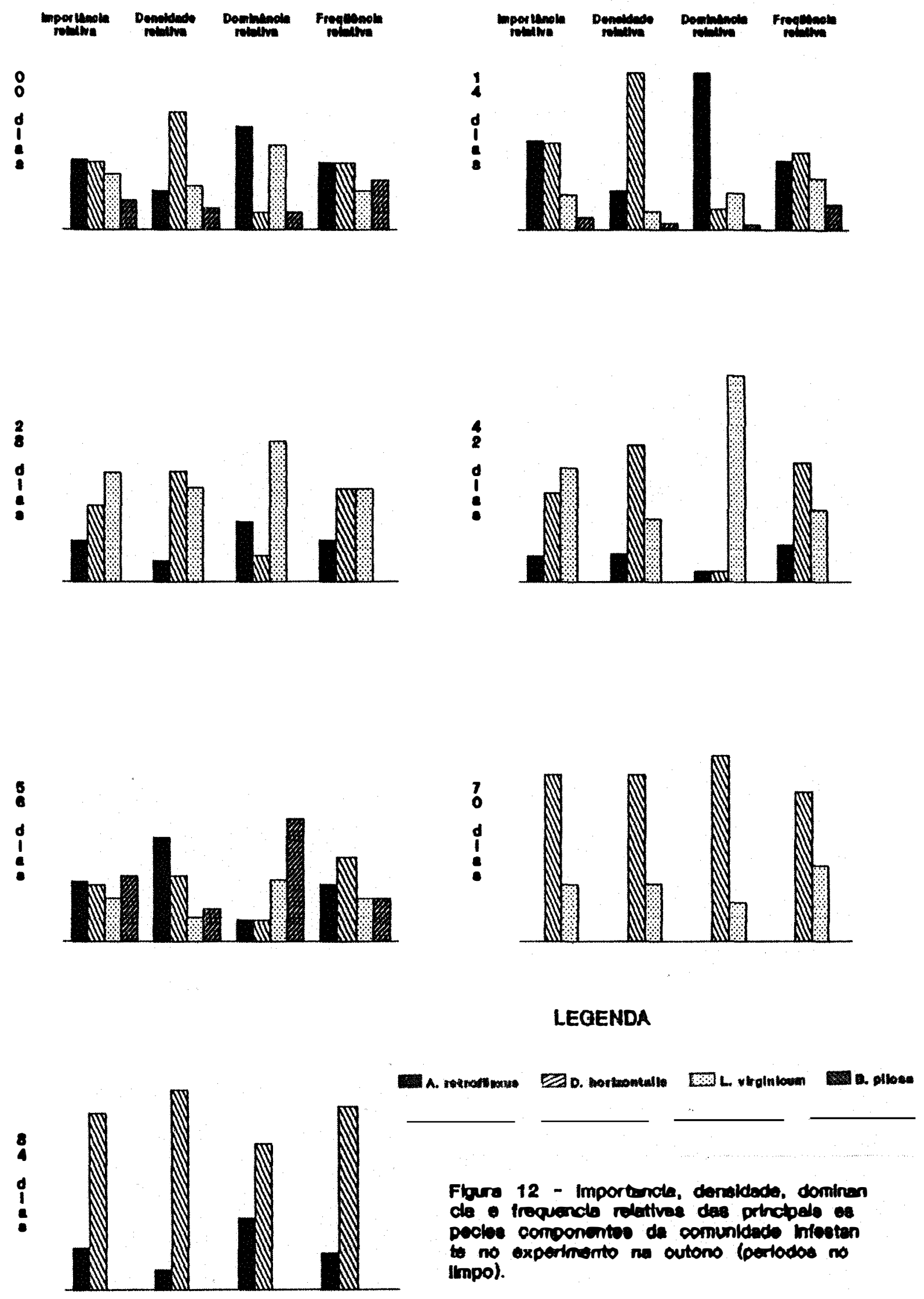

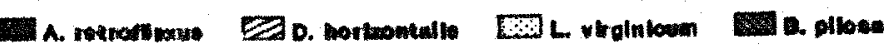

\section{LEGENDA}




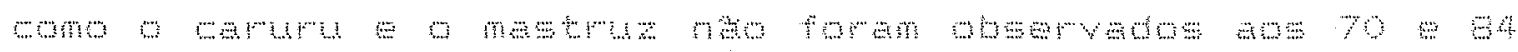

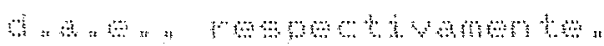

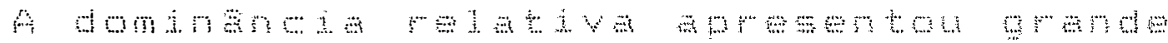

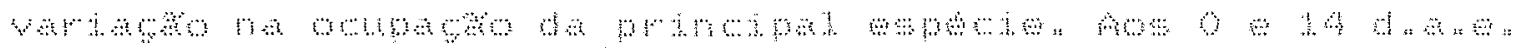

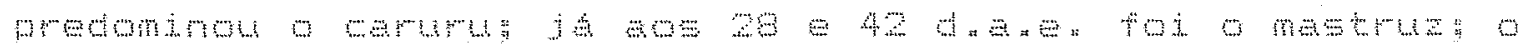
का के क्ष ,

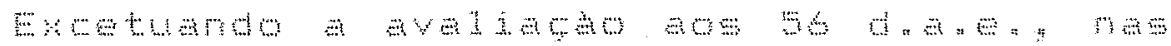

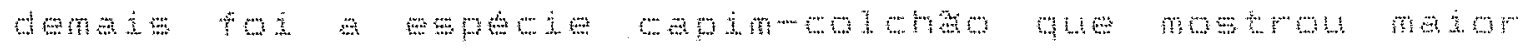

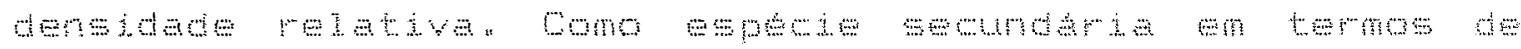

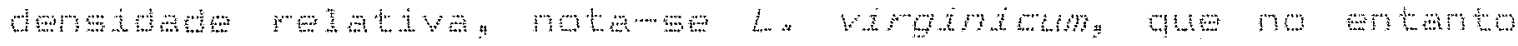

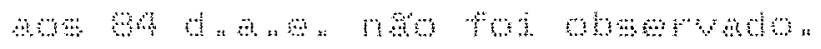

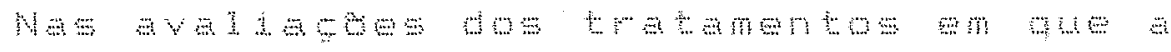

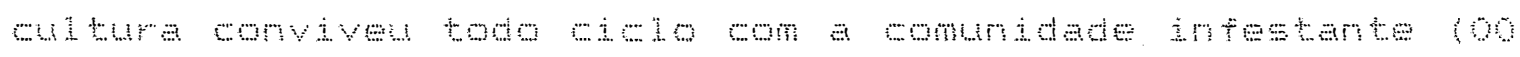

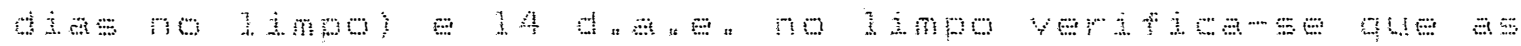

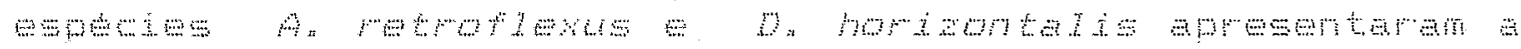

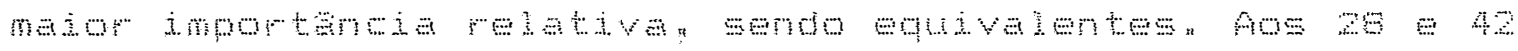

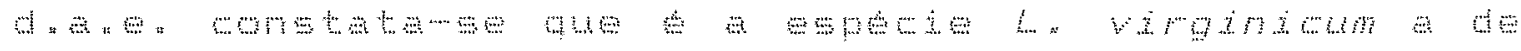

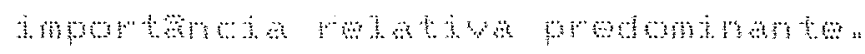

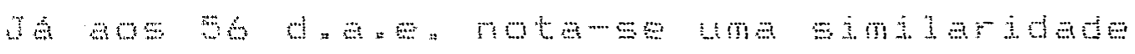
entre a mats

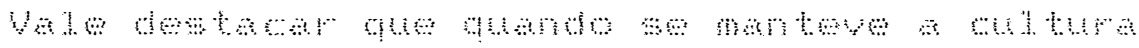
no 1 inpo ate 70 e 
when mon mon

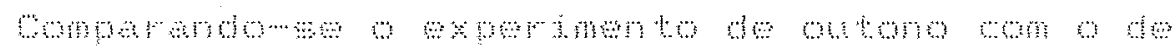

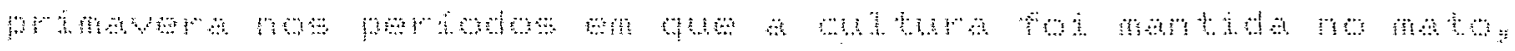

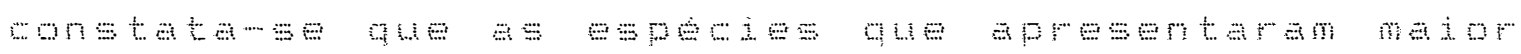

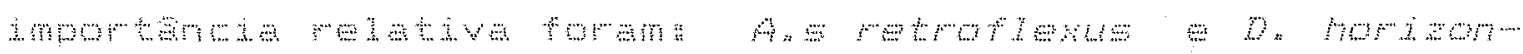

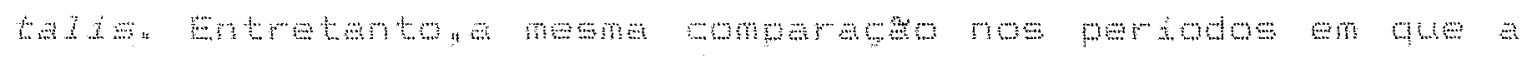

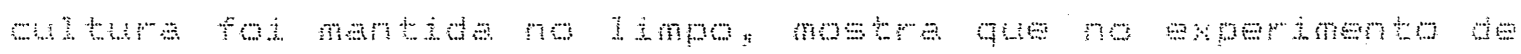
pн

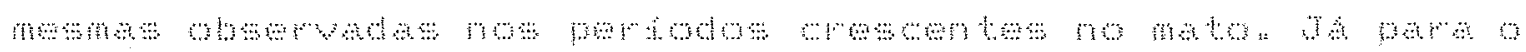

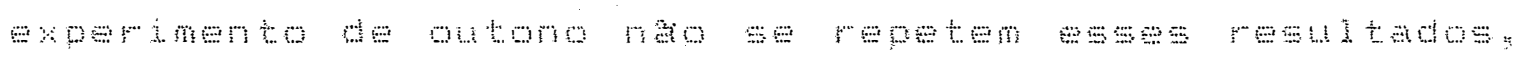

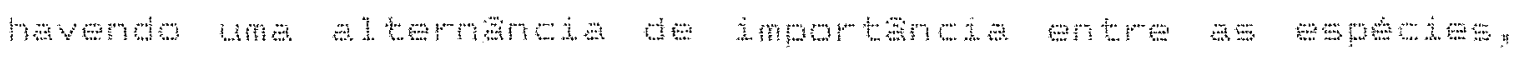
mas d A

\subsubsection{Densidade e achmolo de materia seca}

0 dedos referentes a commidede infestante

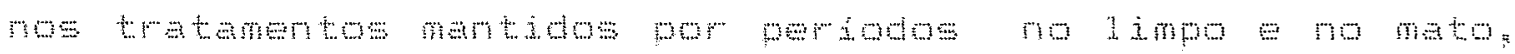
«ны

\section{a Dertaidade}

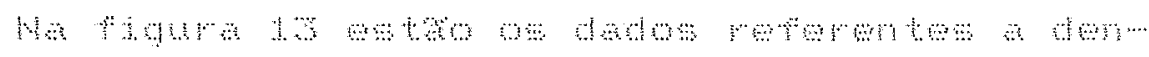

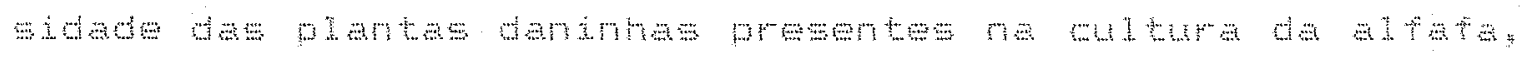
quandoses for mantida por merados mesentas no inpo $\min \operatorname{mos}_{\mathrm{n}}$ 

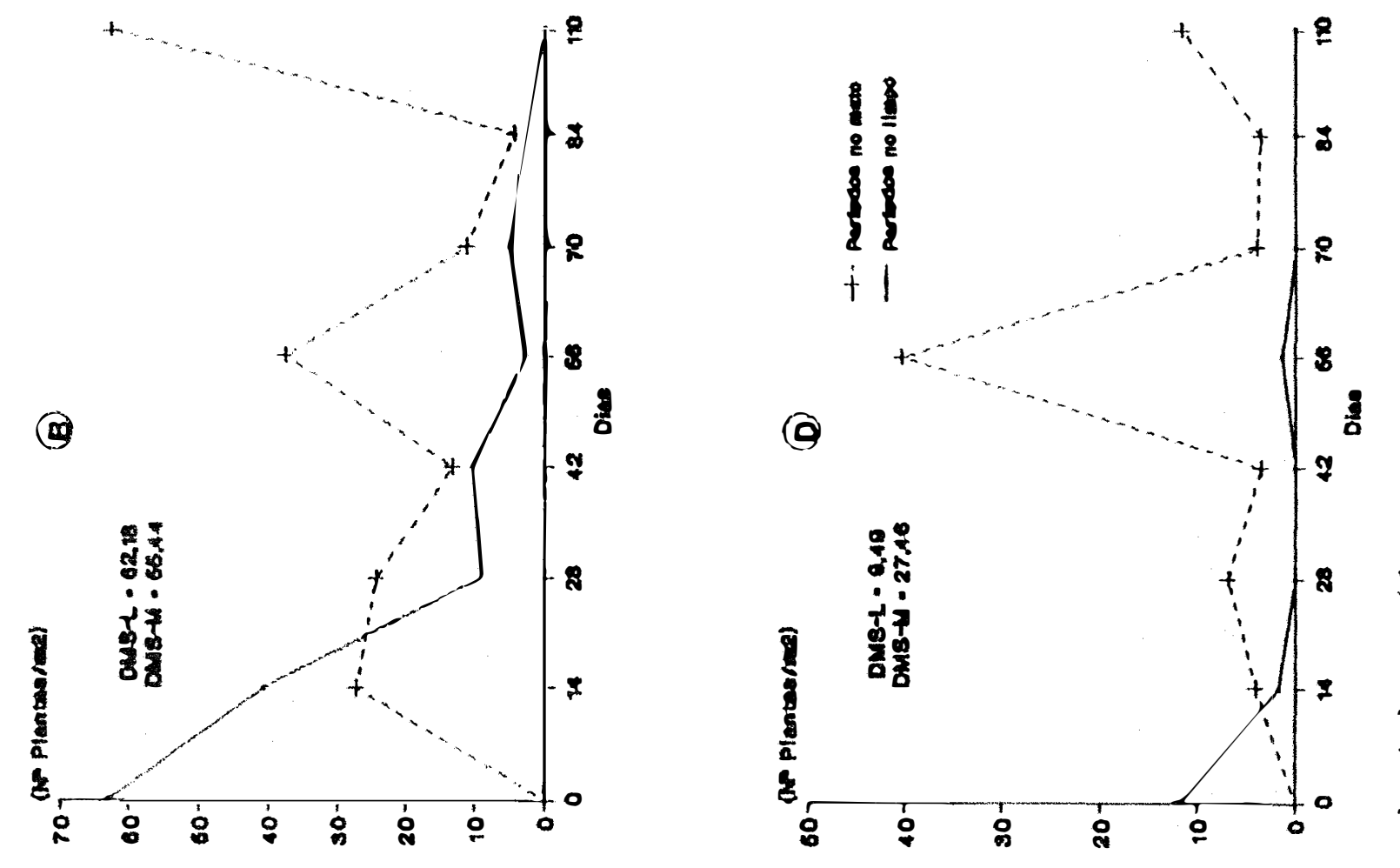

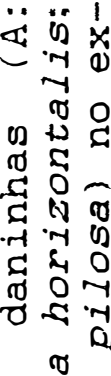

0

का कै वे

\& $w$
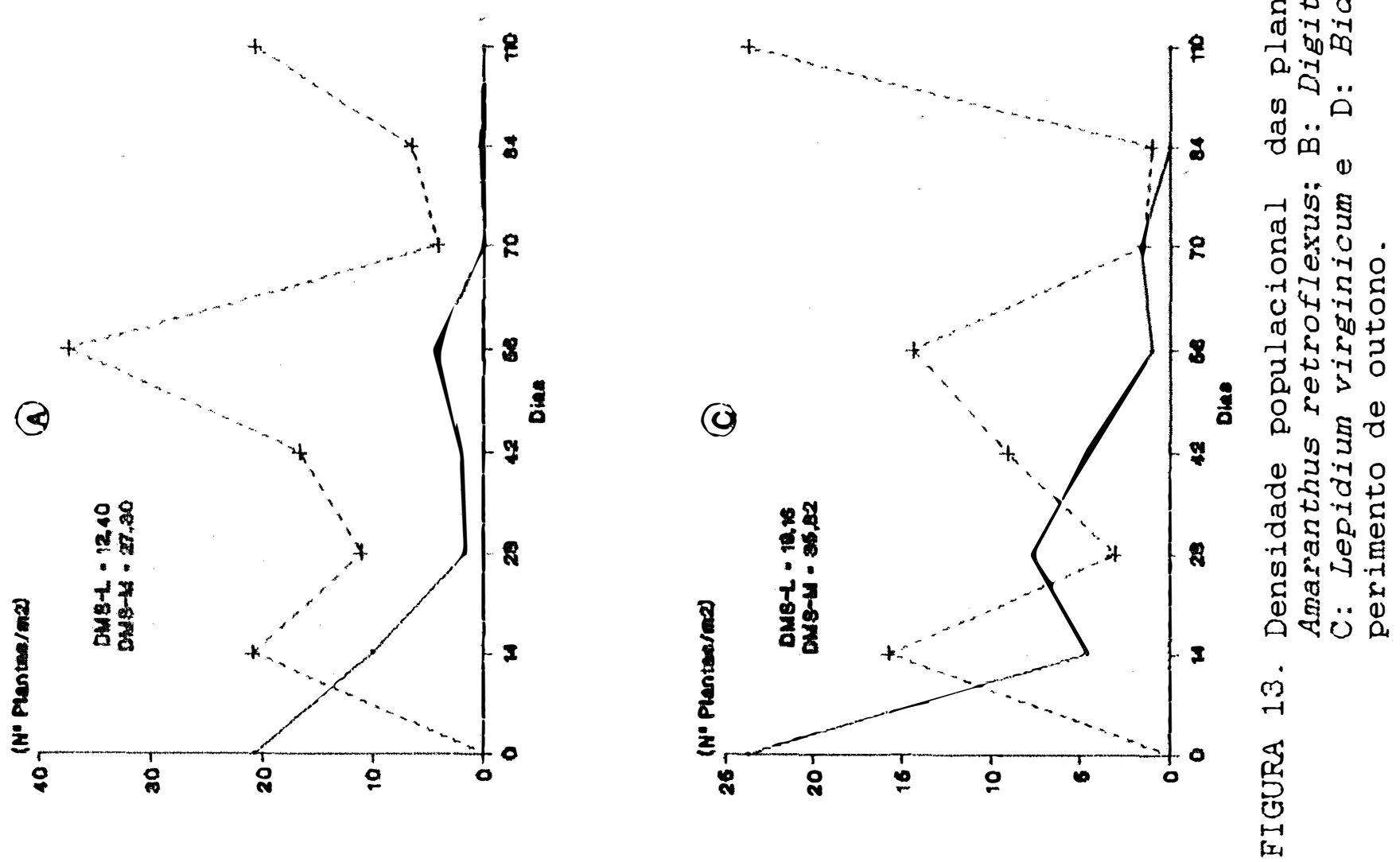


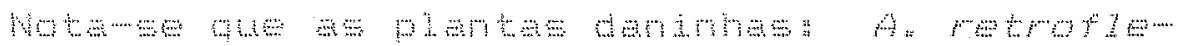

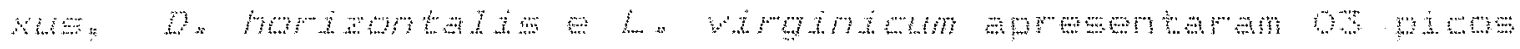

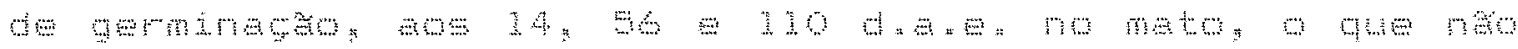

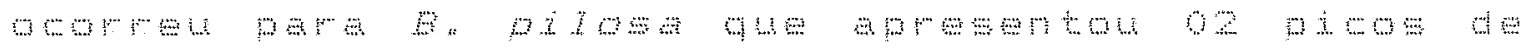

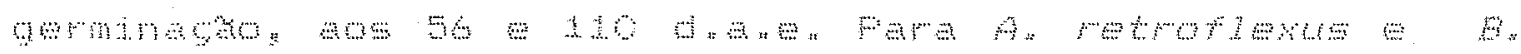

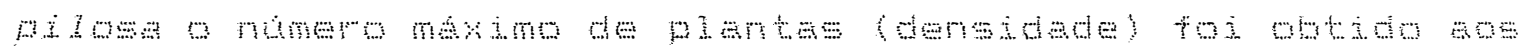

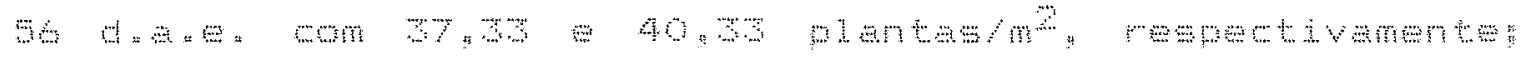

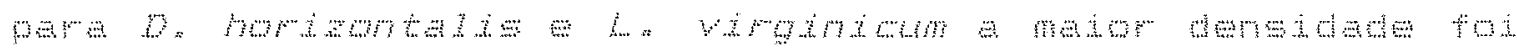
obta

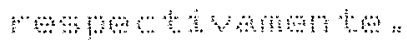

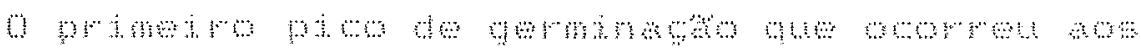
14 .

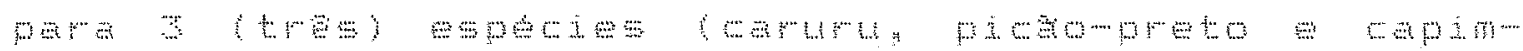

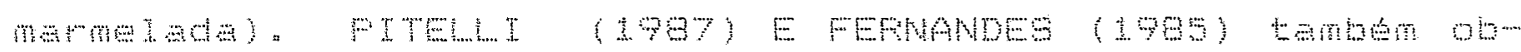

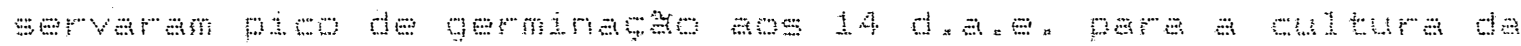
min

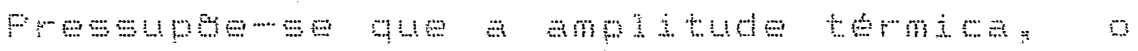

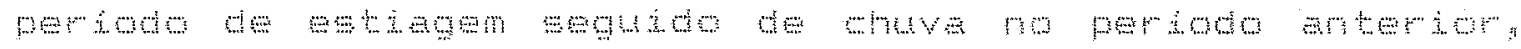

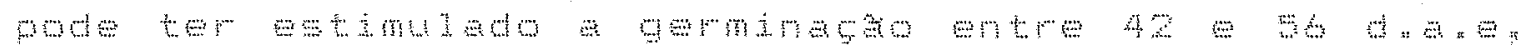

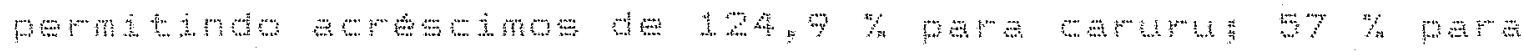
mastmon 182 z

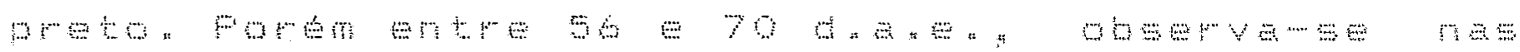

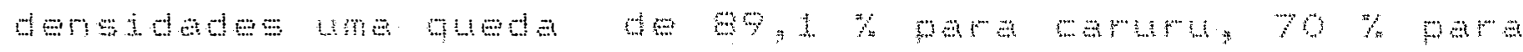
mprnmon

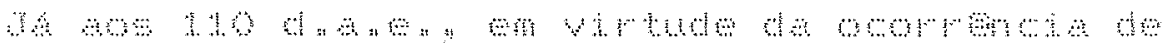




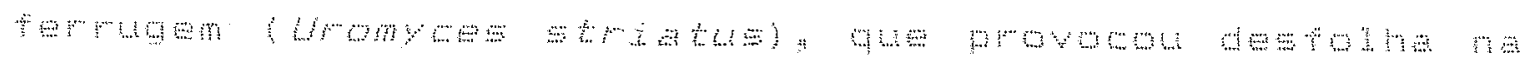

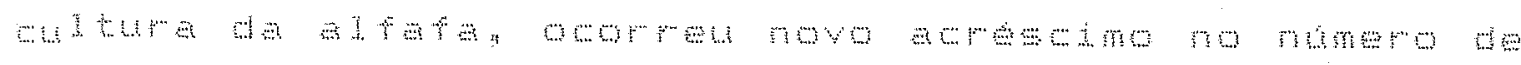

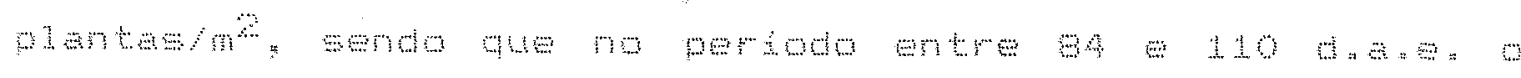

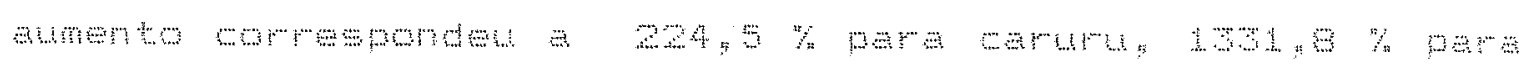

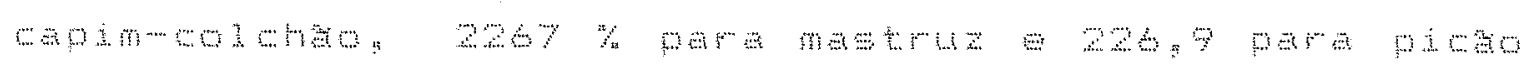
pin

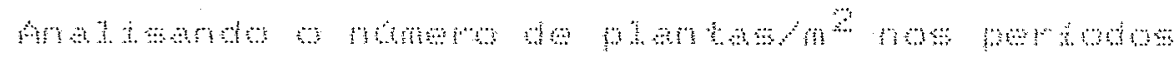
mescentes mo 1 impo rer

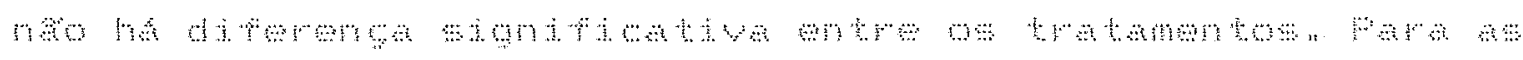

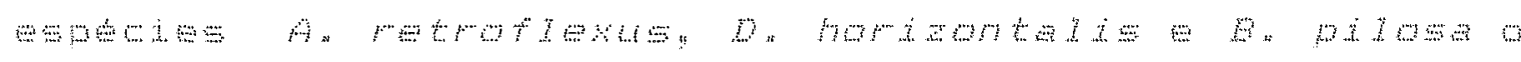

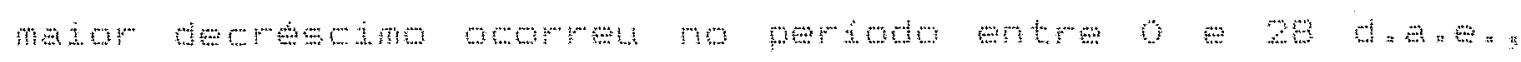

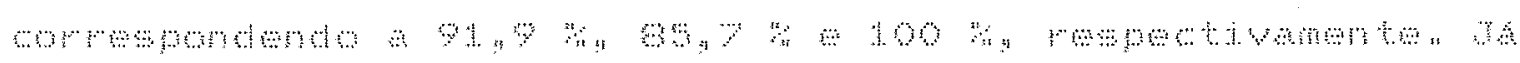

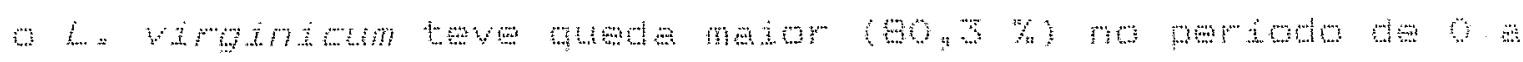
$1,4, \ldots \ldots$

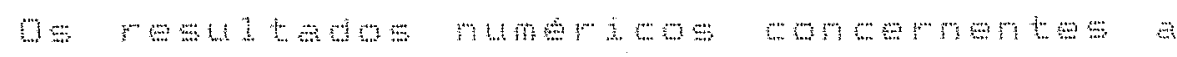

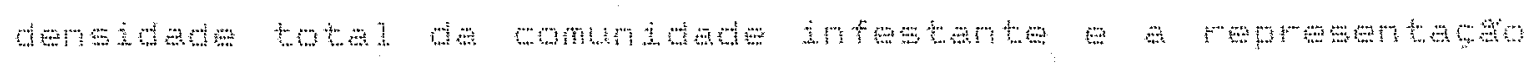

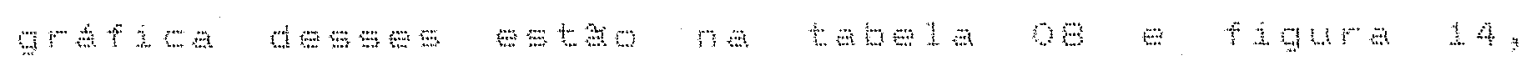

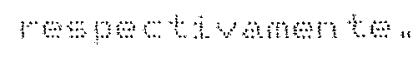

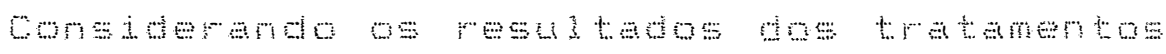

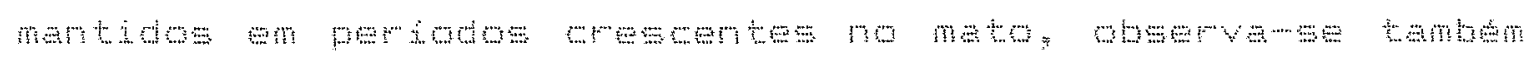

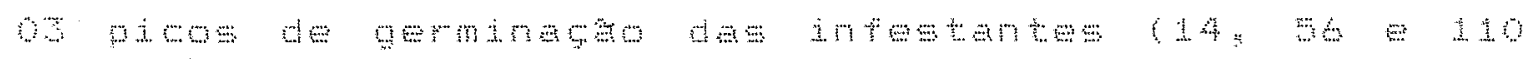

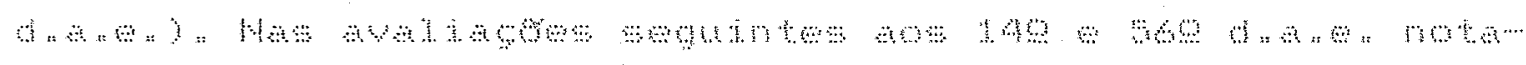
\% un

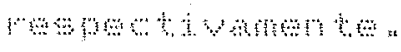

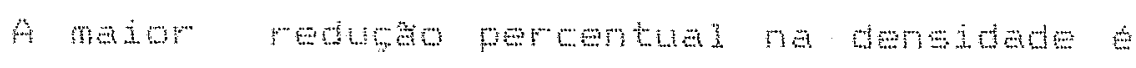




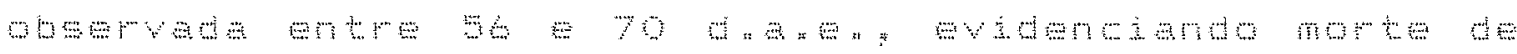

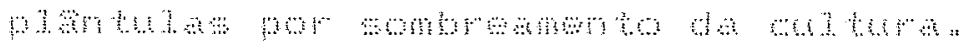

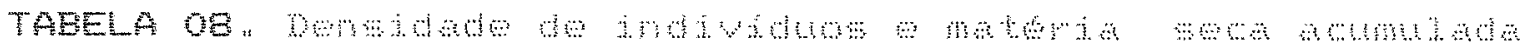

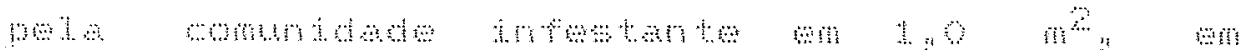

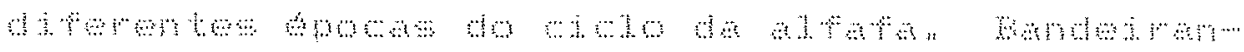

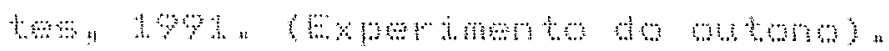

\begin{tabular}{|c|c|c|c|c|}
\hline & man & 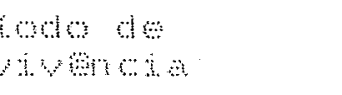 & 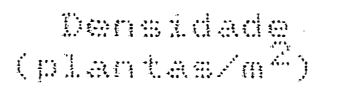 & 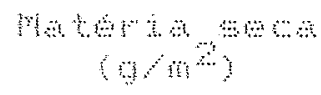 \\
\hline & & 0 & o,, & ओ \\
\hline & i & $\ldots . \quad 1.4$ & मश & 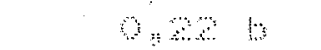 \\
\hline$m$ & 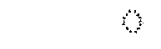 & $\ldots \quad \ldots$ & in: 1 & 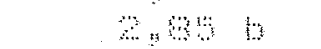 \\
\hline \multirow[t]{3}{*}{ 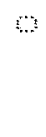 } & i & $\ldots$ & $4 \cdots: 40 \mathrm{~m}$ & 1949 an \\
\hline & i & $\cdots$ & $1294 x$ & अ, \\
\hline & i & $\ldots$ & $20: 7 \%$ & me \\
\hline$n$ & i & $\ldots$. & 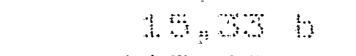 & $9 \%, 6$ an \\
\hline 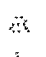 & 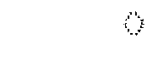 & $\cdots \quad 1 \mathrm{~s}$ & $119: 00$ & $1 \cdots \%$; \\
\hline \multirow[t]{2}{*}{ w } & I:.: & 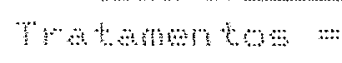 & $8, \cdots$ & $3_{31} 94$ क \\
\hline & & $y_{n}(y) \quad \cdots$ & $2 \%: 1$ & क: \\
\hline & & \% & $11 \%$ की & $2 \% y_{*} 4 \pi$ \\
\hline ni & 0 & $\cdots$ & औ & $3+4=6$ \\
\hline \multirow[t]{3}{*}{ 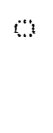 } & i & $\ldots \quad 2 \%$ & 16,8 & 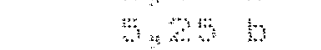 \\
\hline & i & $\ldots \quad n$ & $1 \% 00 \mathrm{~b}$ & y \\
\hline & i & $\ldots$. & 9,89 & औin \\
\hline t. & 0 & $\cdots \quad y$ & $8: 6 \%$ & क \\
\hline it. & i & $\ldots .9$ & $\begin{array}{lll}30 & 6\end{array}$ & ब, \\
\hline$m$ & 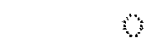 & $\cdots \quad 1 \mathrm{H}$ & o, & क \\
\hline \multirow[t]{2}{*}{ 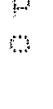 } & 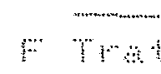 & mantos & $b_{2}, \ldots \%$ & $10: 6 x$ \\
\hline & $\theta_{4}$ & $(a) \quad \cdots$ & $9=1$ & म \\
\hline
\end{tabular}

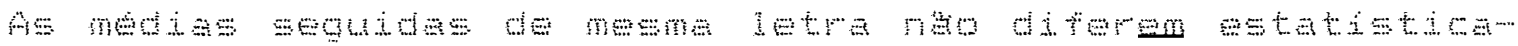

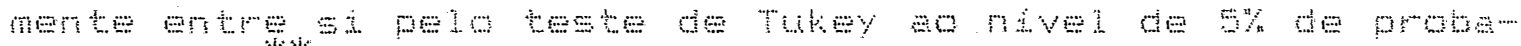
mind

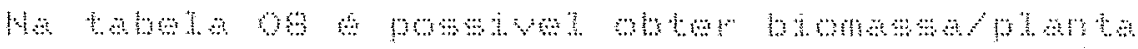

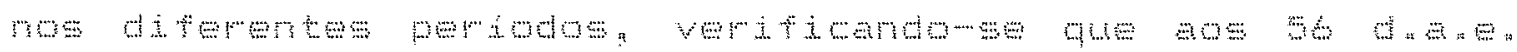




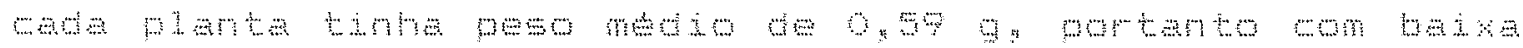

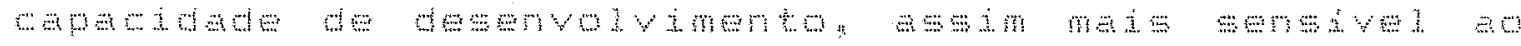
mantmanton

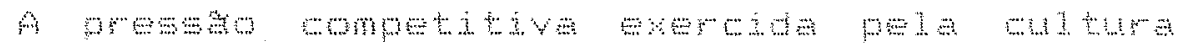

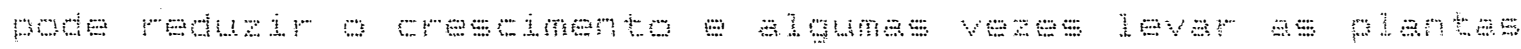

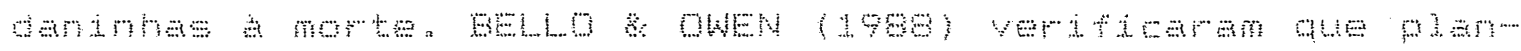

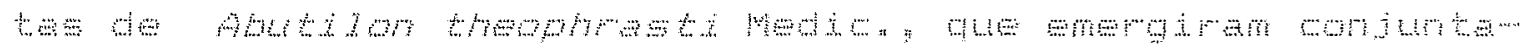

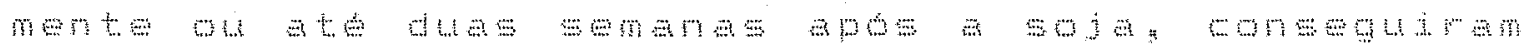

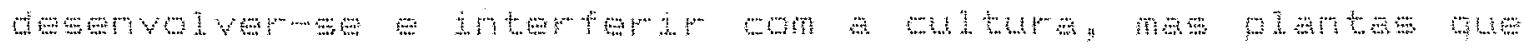

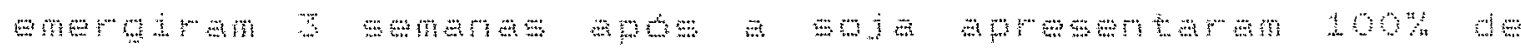

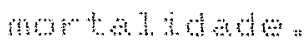

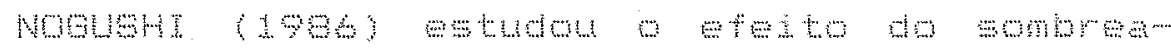

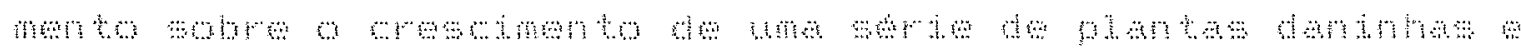

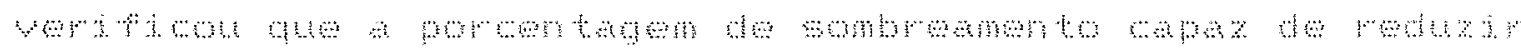
m ma m

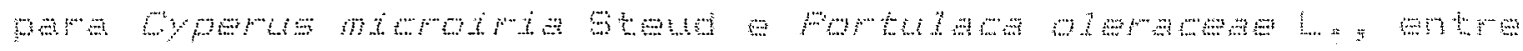

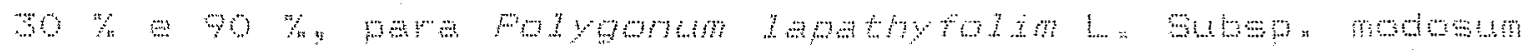

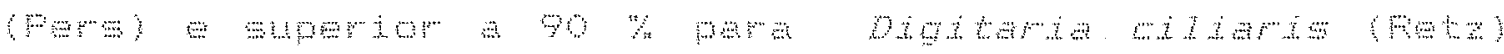
$\operatorname{Rem}: \cdots$

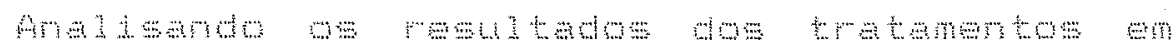

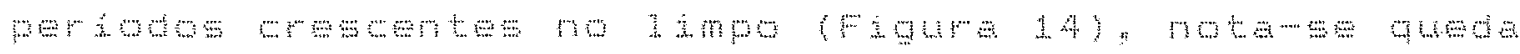

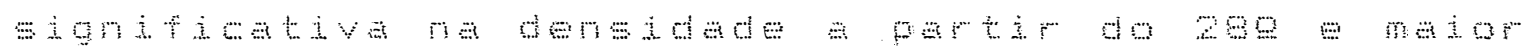

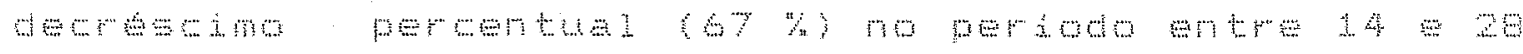
d "

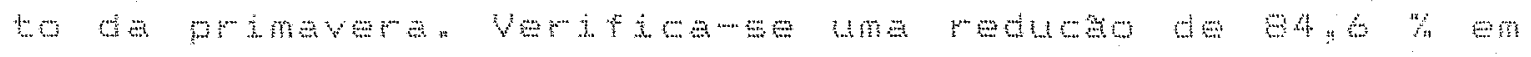

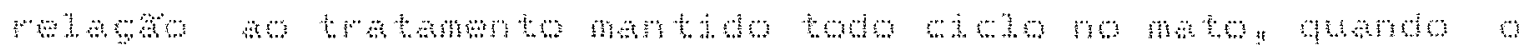



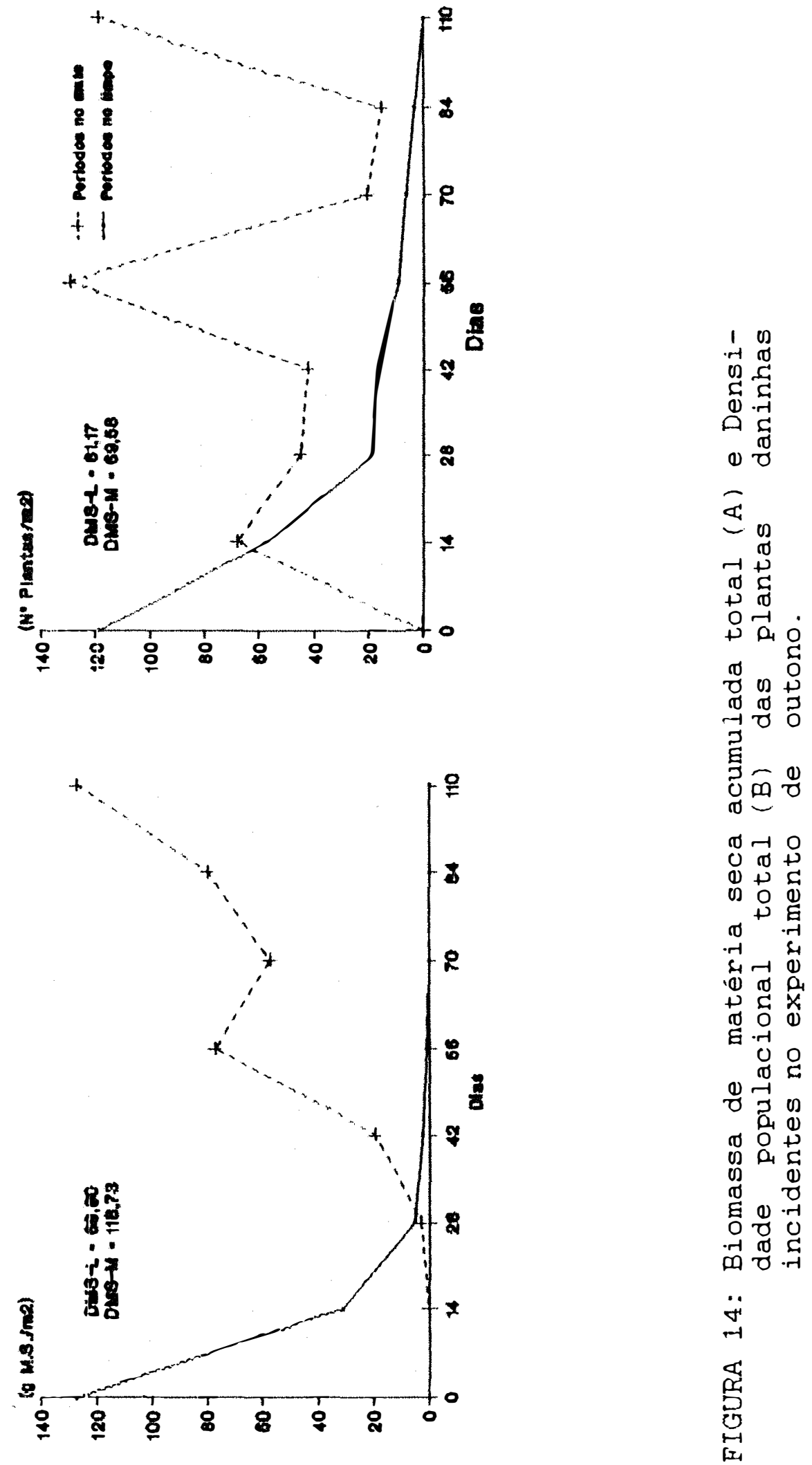


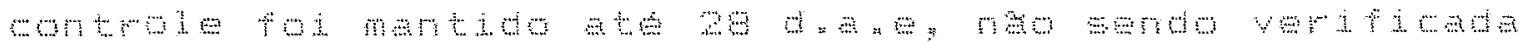
w

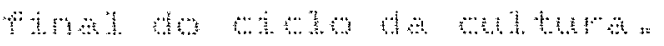

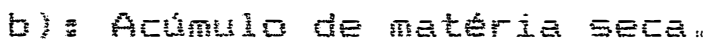

morman

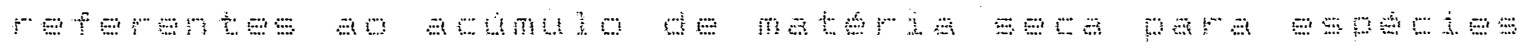

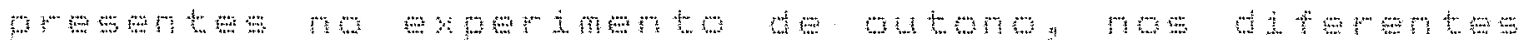
(m)

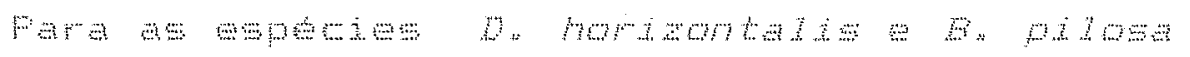

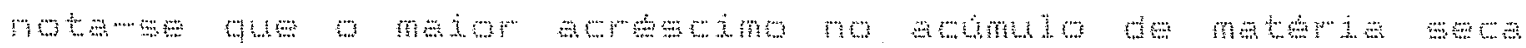

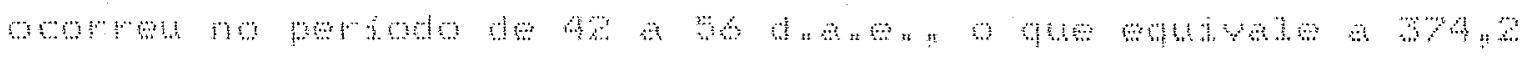
"y

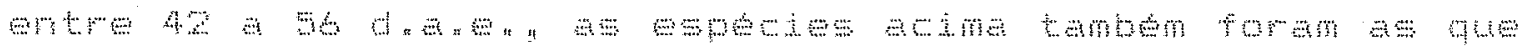

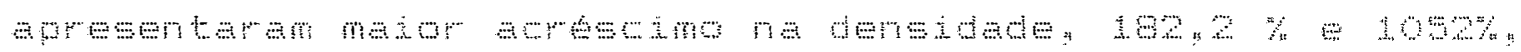

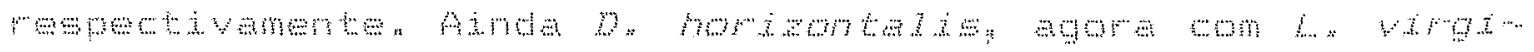

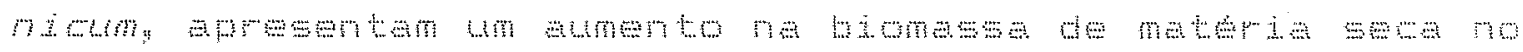

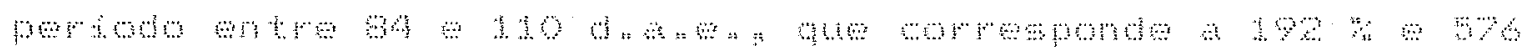
"n

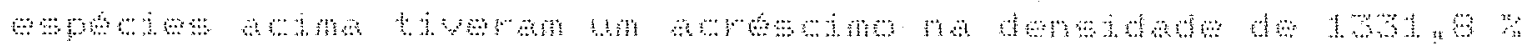

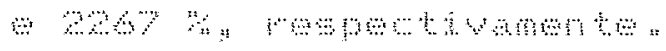

I.

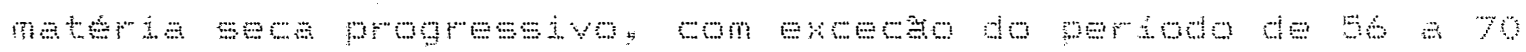

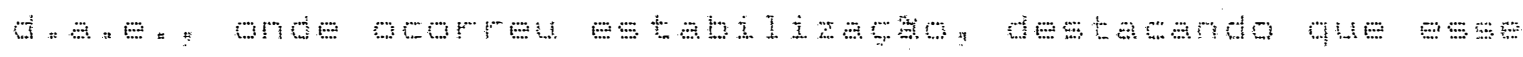

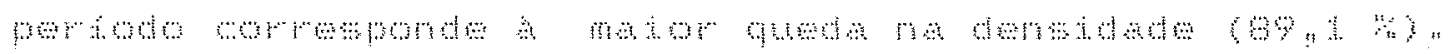



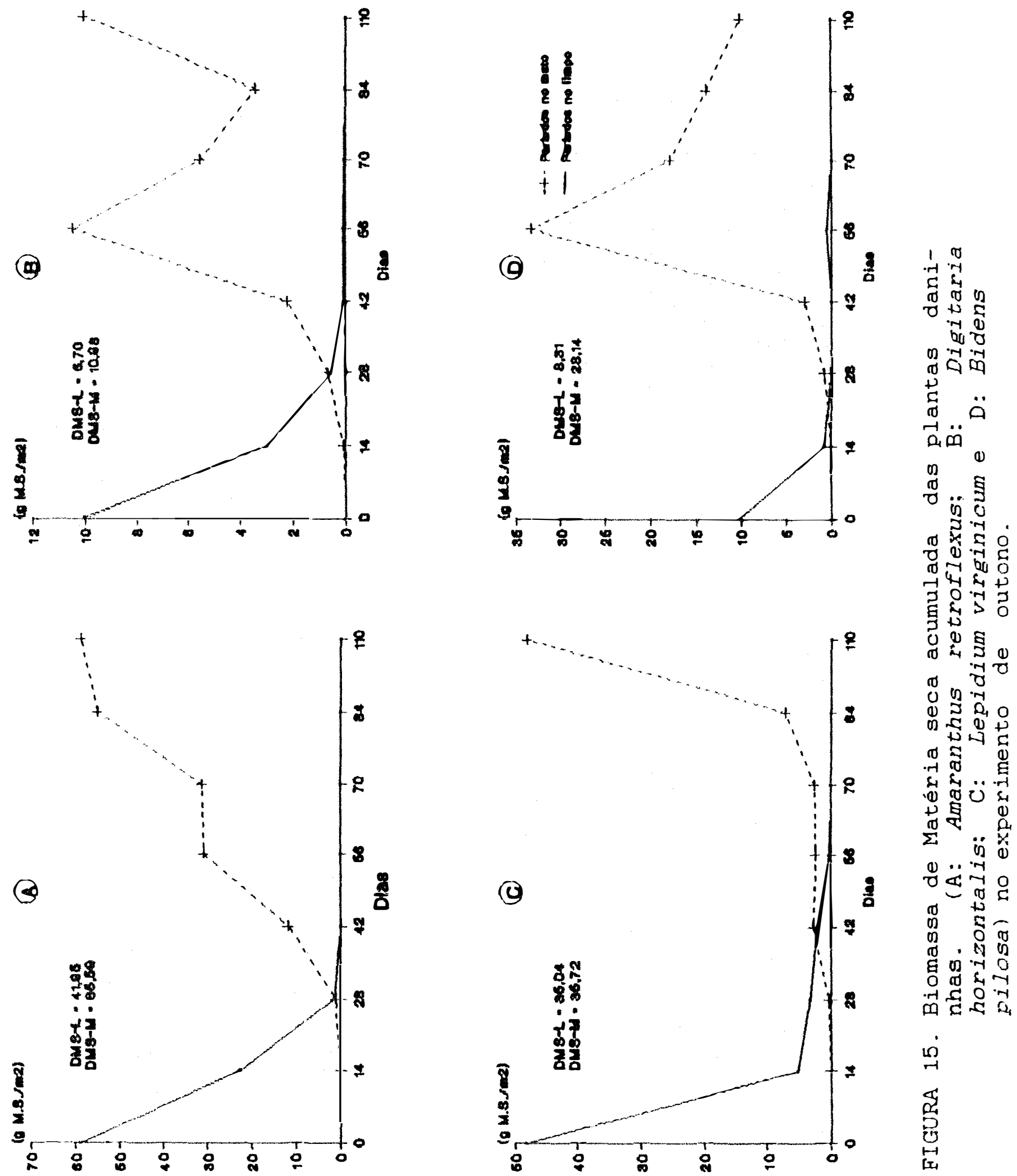


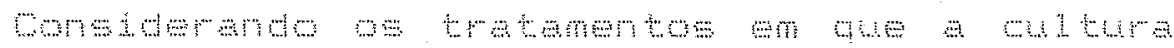

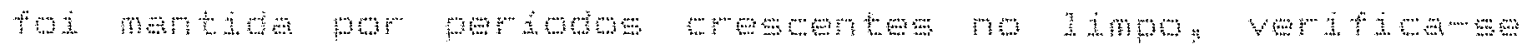

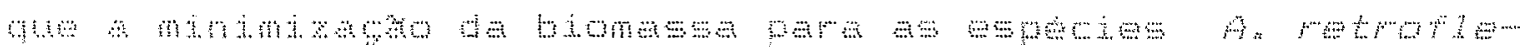

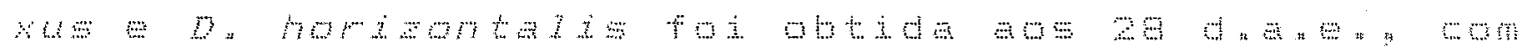

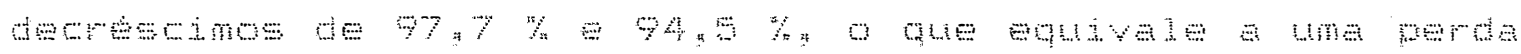
de

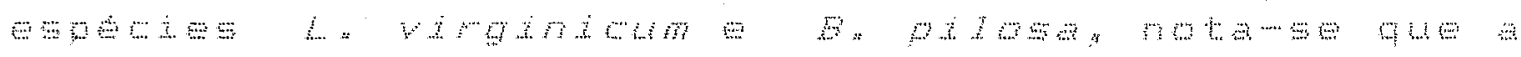

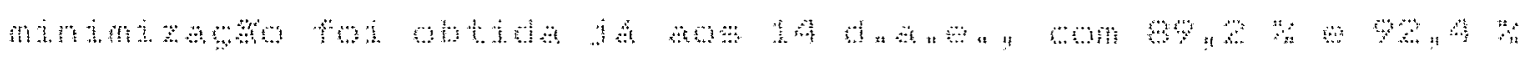

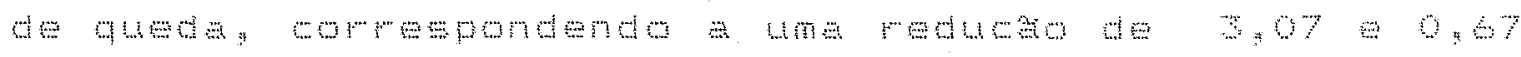

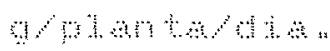

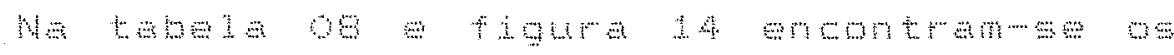

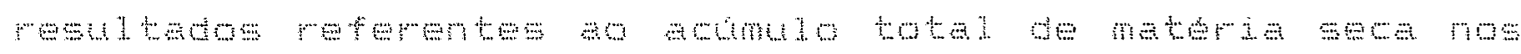

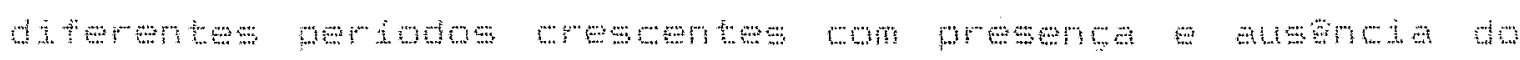
mate:

Comamando os tmatamentom mantom por

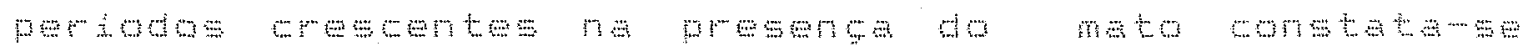

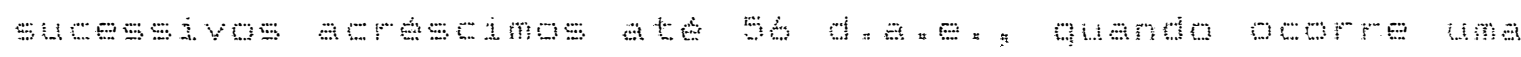

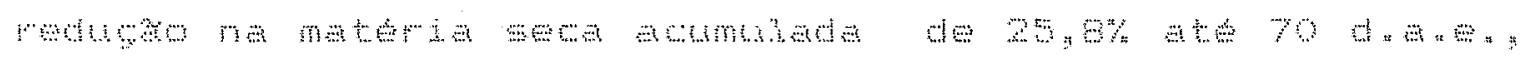

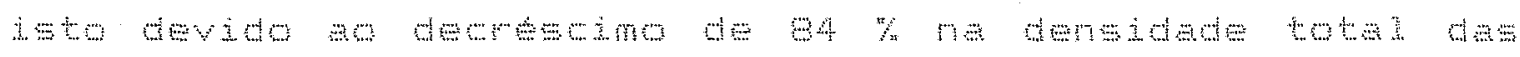

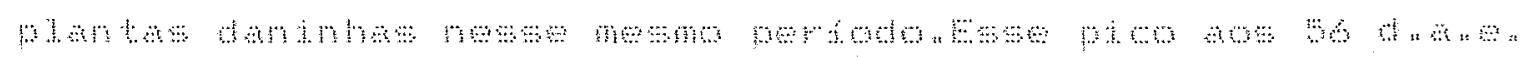

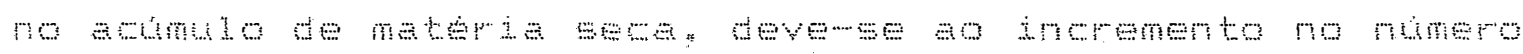

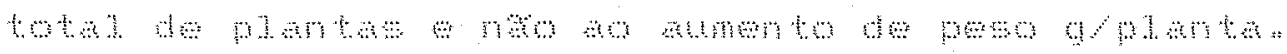

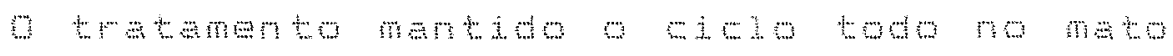

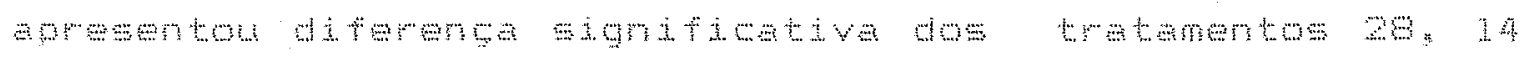

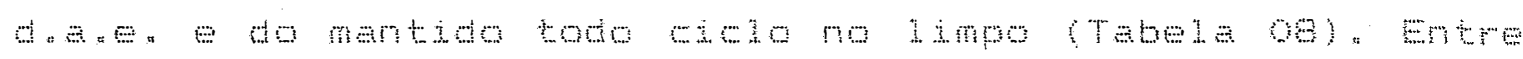

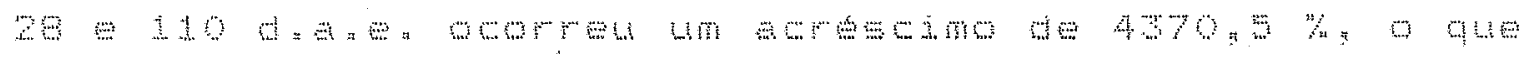




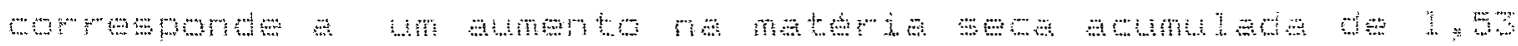
10

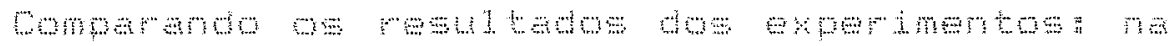

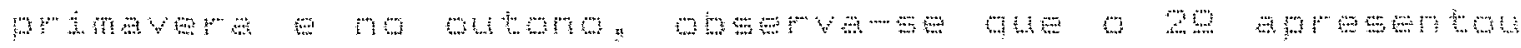
a

mhond

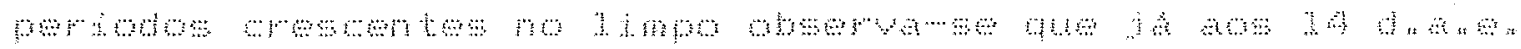
Пи

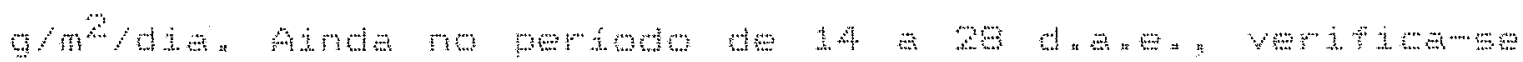

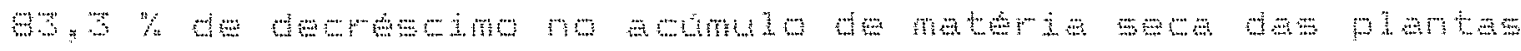

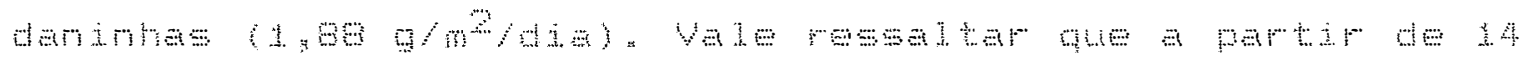
d th thin

\subsubsection{Avaliagues referentes a cultura da al 1 afa.}

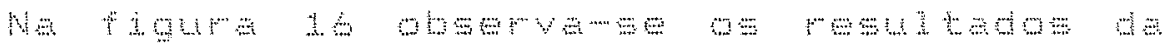
ast

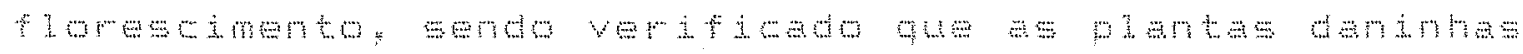
काये

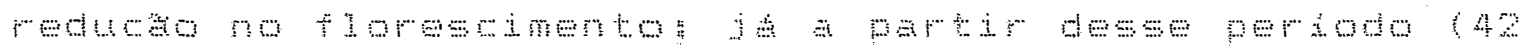
d. How

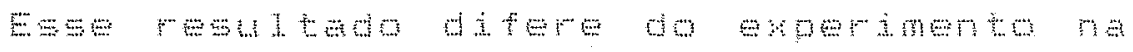

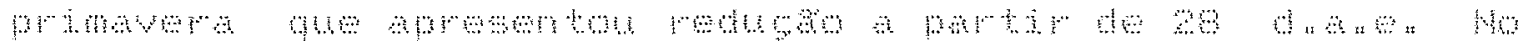



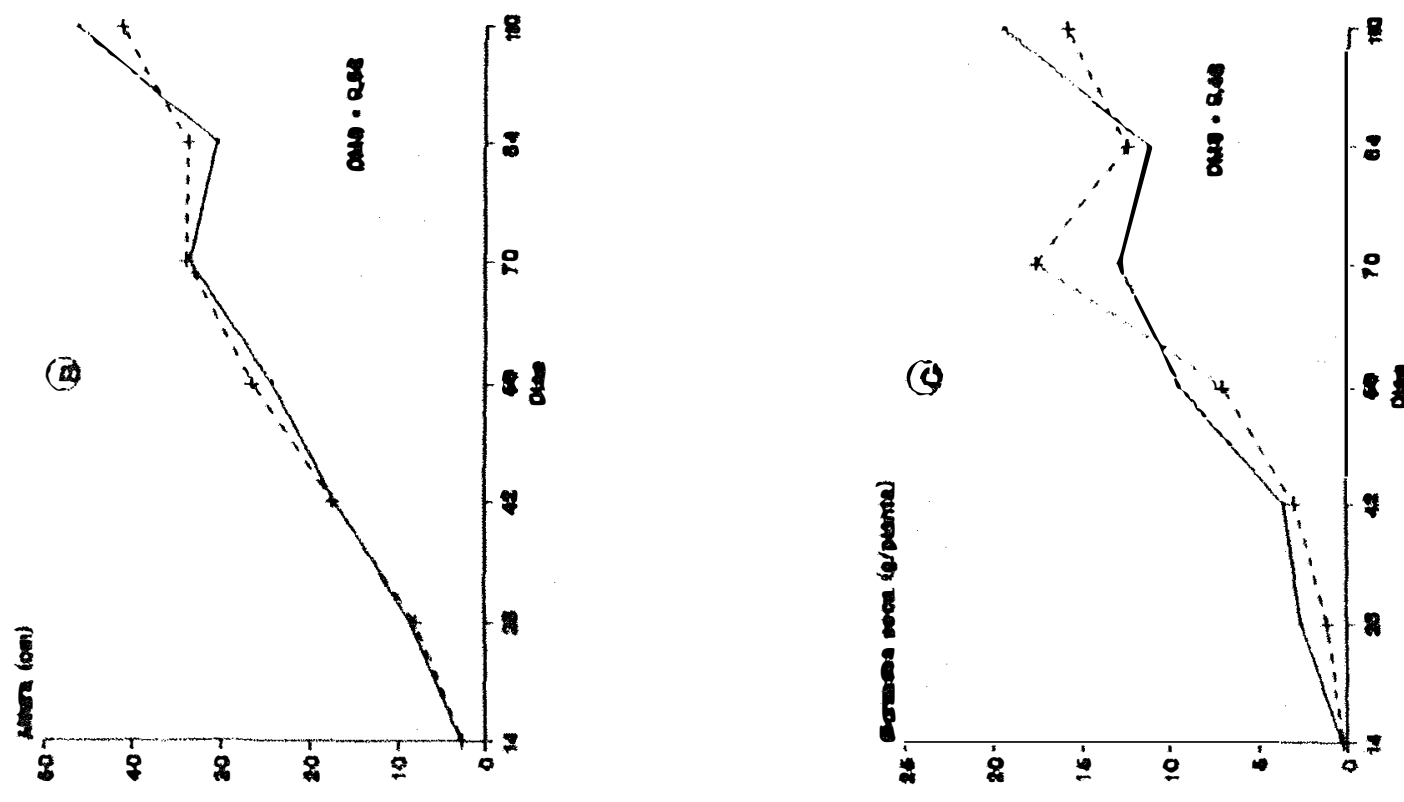

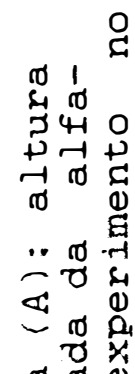

त) ชิ (1)

$+1$

- 5

ญ

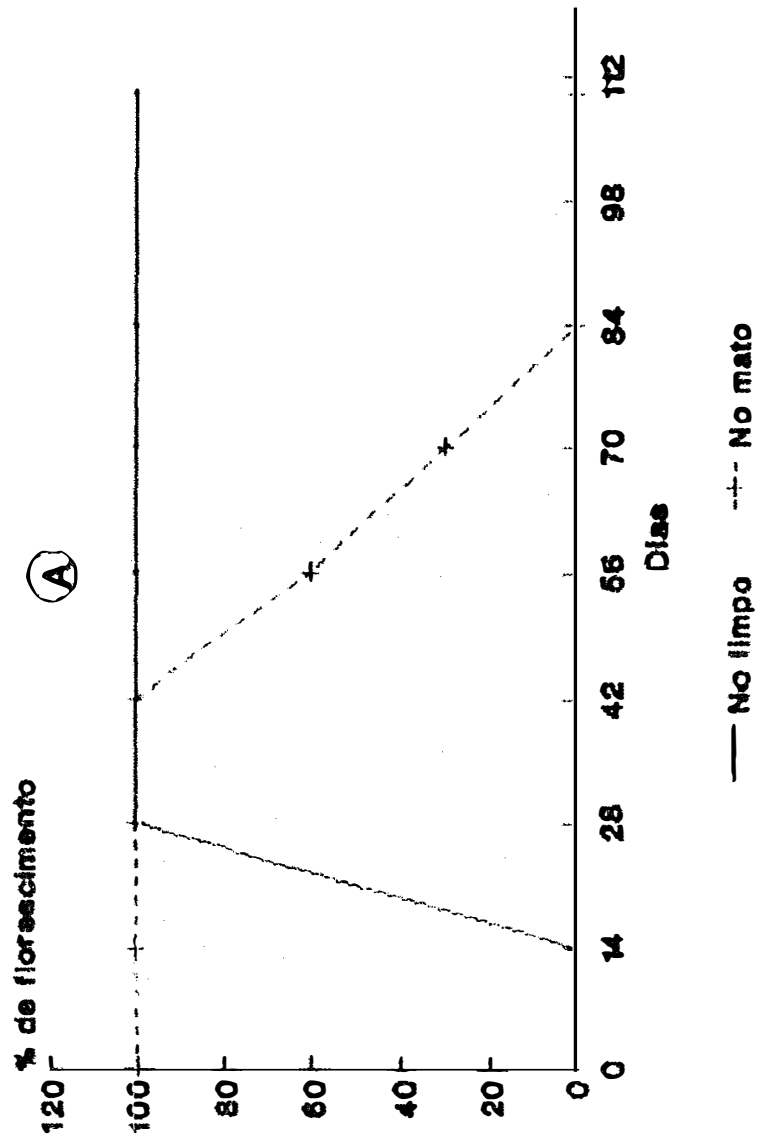

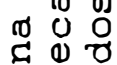
os 0 मे का 'न C. $\rightarrow$ D बै कि (1) - 00 o 1 (1) C \& 010 प्त 0 ४ै on $\cdot$-r () ర ठ० E $0 \stackrel{0}{0}$ bil 藏 武 0 ט.न क्ष गे ค.

$\ddot{\omega}$

要 


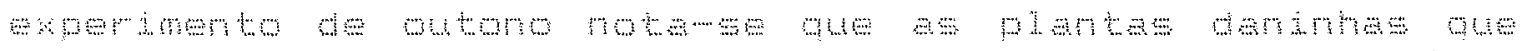

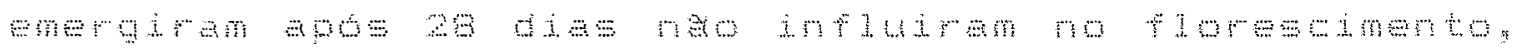

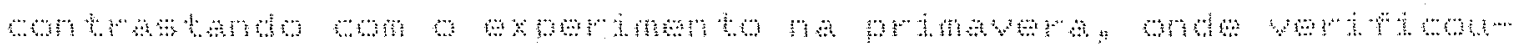
se que somente aps 42 a a

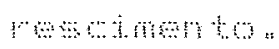

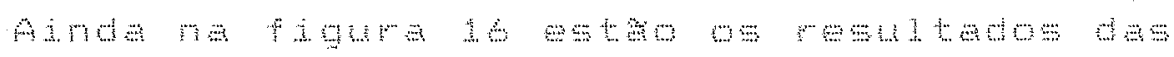

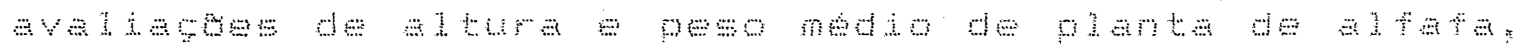

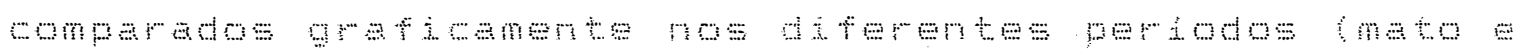

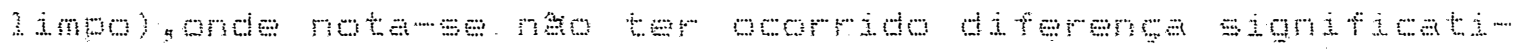

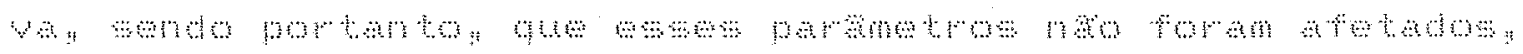

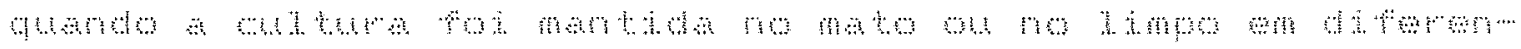
+.

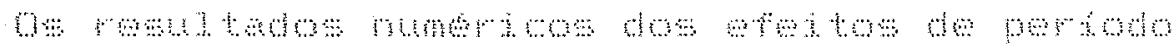

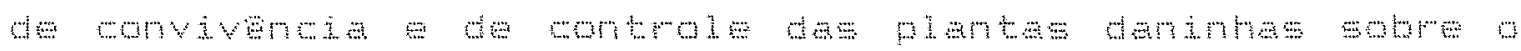

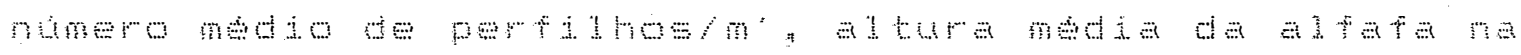

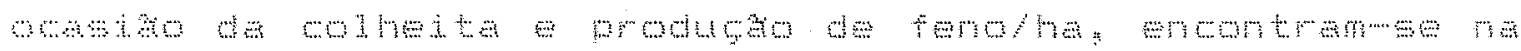

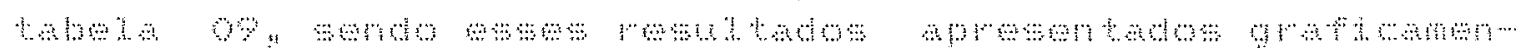

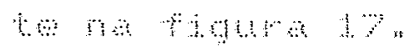

किक de क्ष

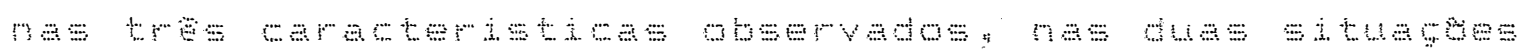

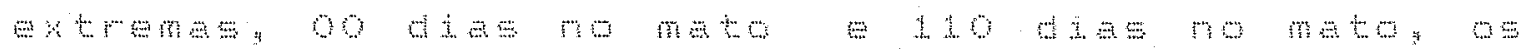

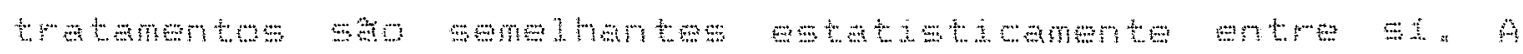

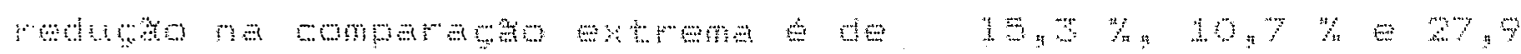

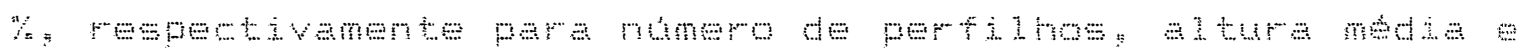

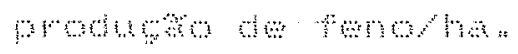

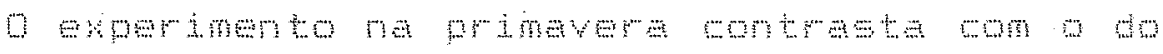




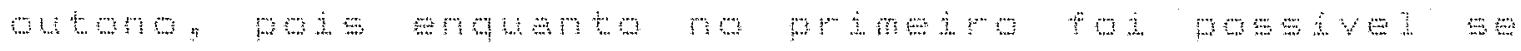

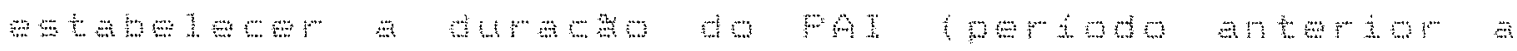

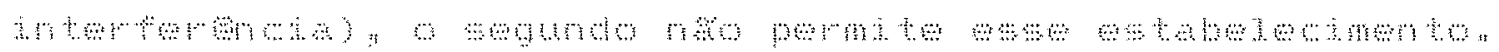

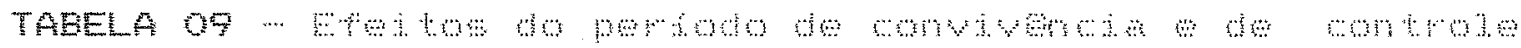

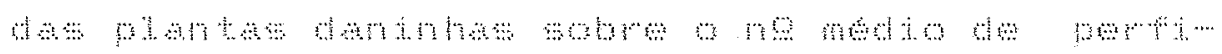

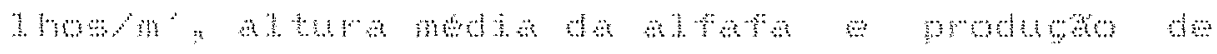

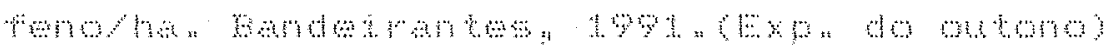

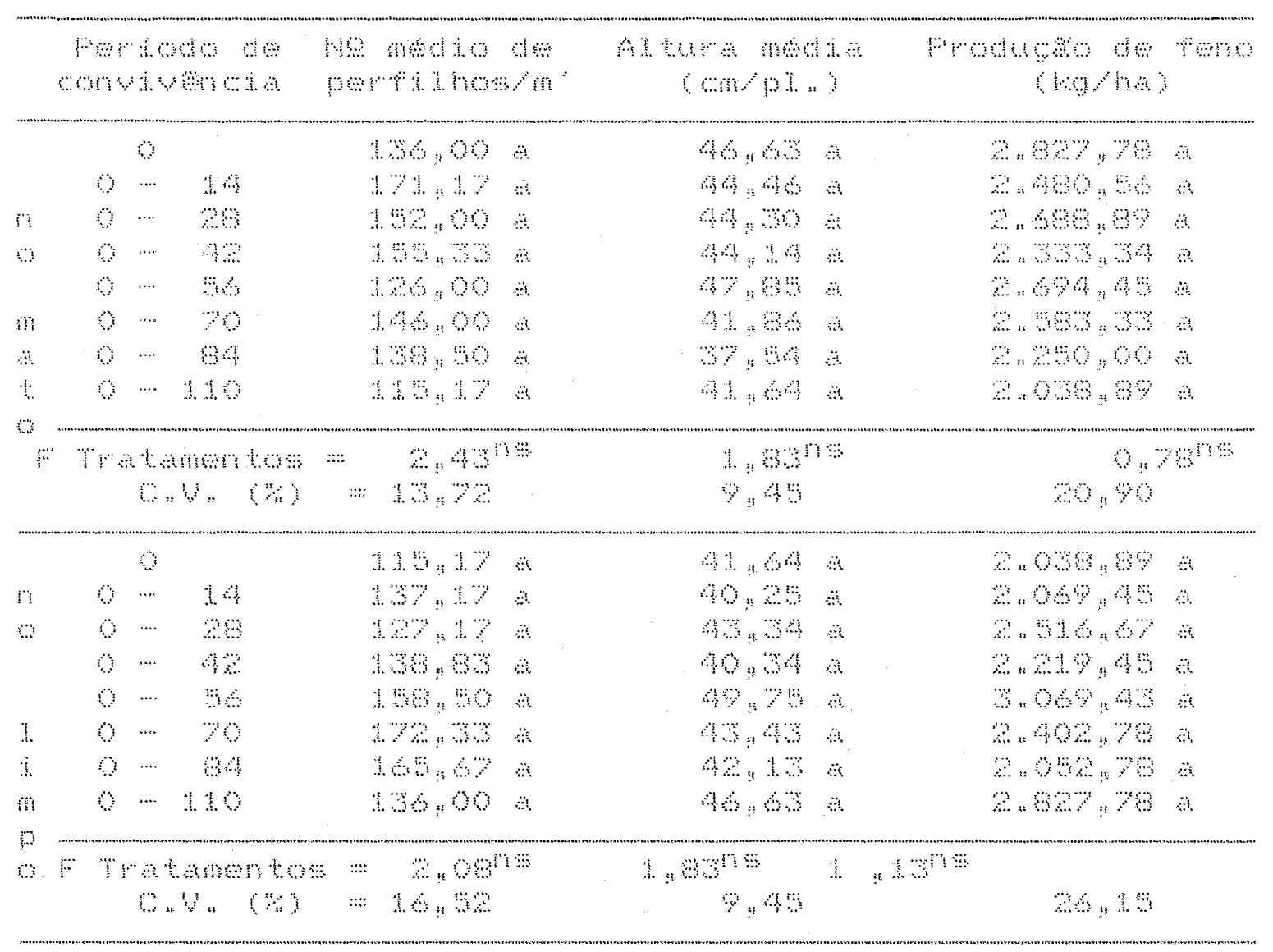

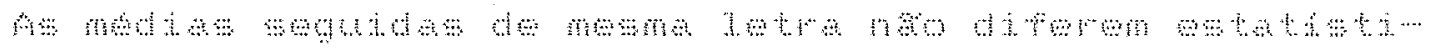

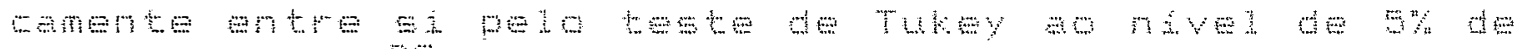
mobald 

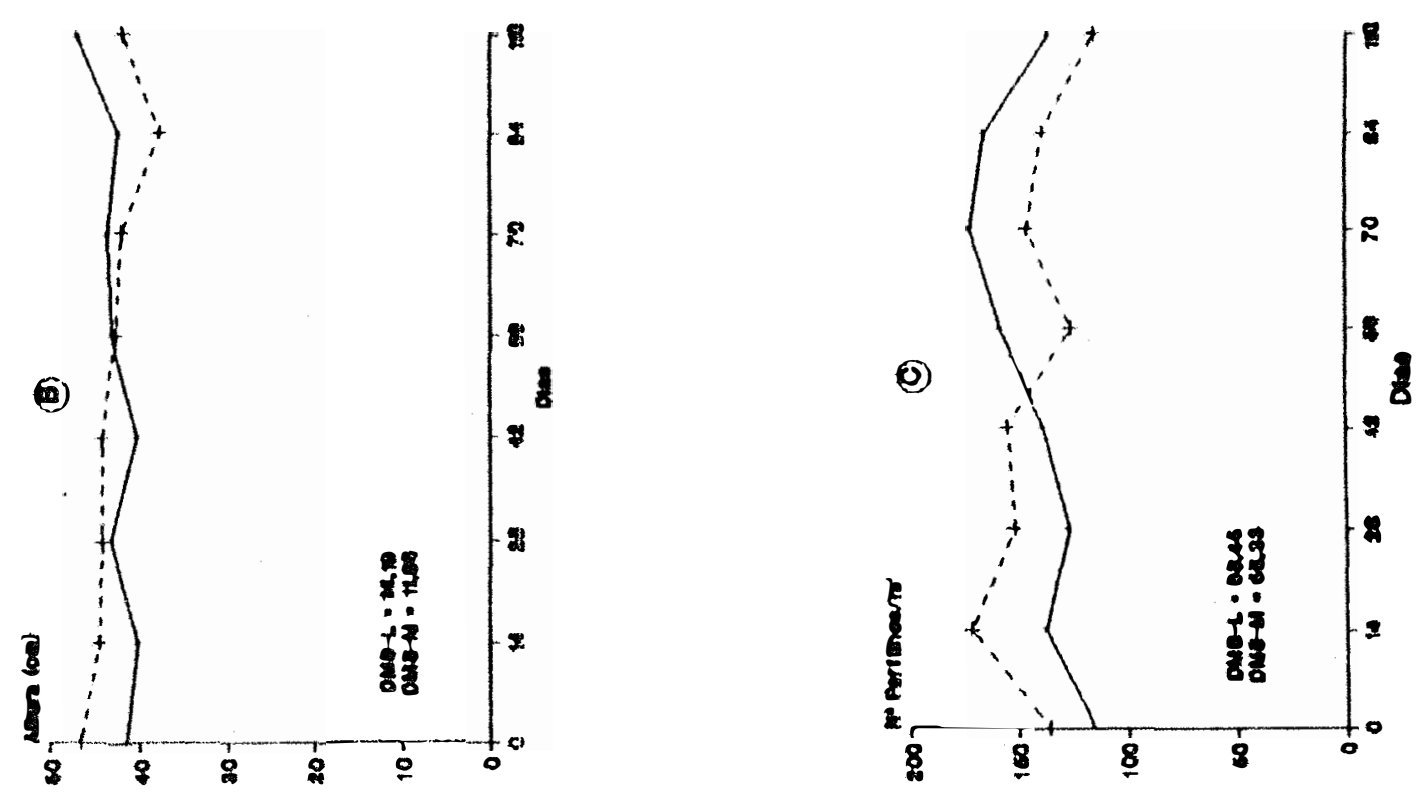

$\begin{array}{cc}0 & 1 \\ -1 & 4 \\ 0 & 0 \\ 0 \\ 0 \\ \text { E }\end{array}$

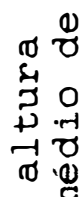

\& 0

.. 0 O

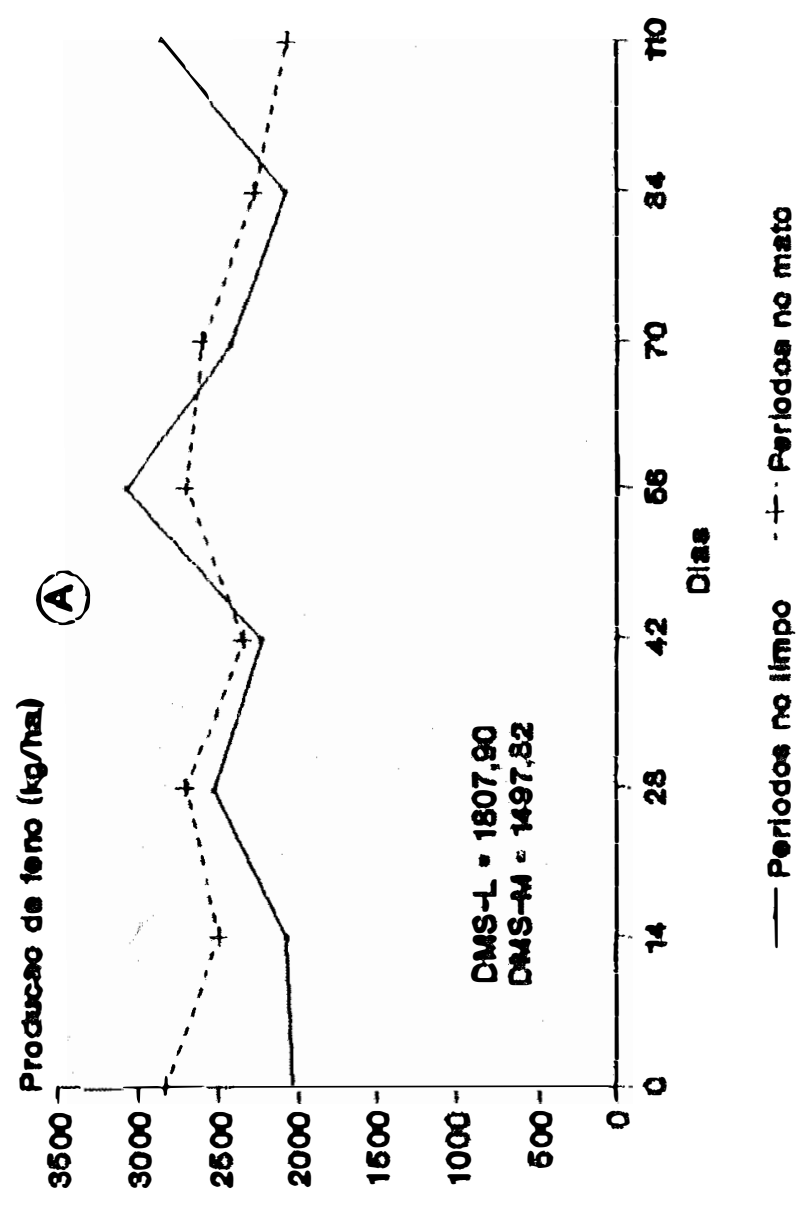

व

$\checkmark$ : 0

$-\stackrel{2}{ }$

(大) 0

nो 0

पू

б一

Hन.

(6) \&

-

0 (1)

마

○

¿ 0

(1) $0 \overparen{0}$

ช

○ 蛅

(क)

ชี

\& 0.7

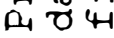

Ë

$\underset{0}{\underbrace{4}_{0}}$ 
लम

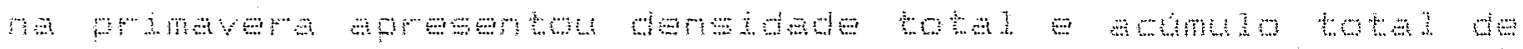

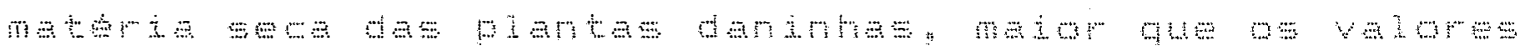

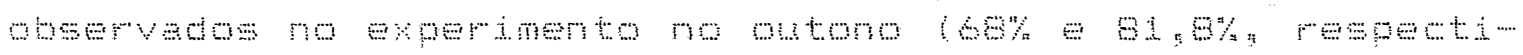
andingis:

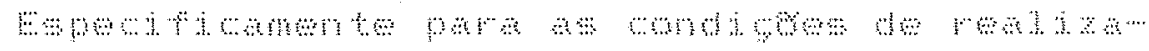
wo deste expermento, thou exidente gus m movivera da

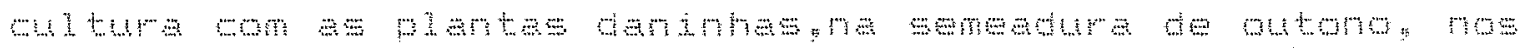

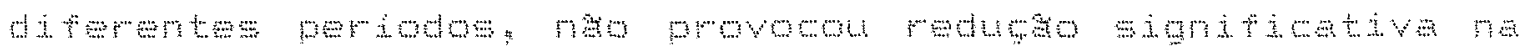

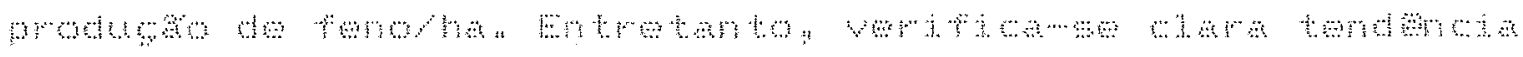

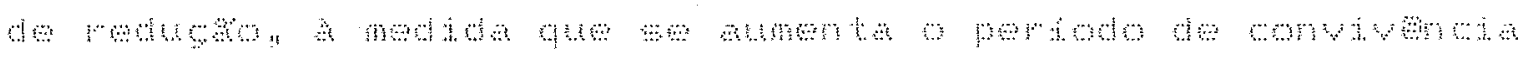

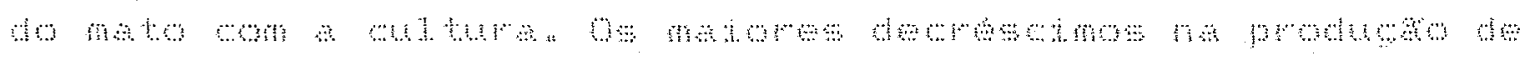

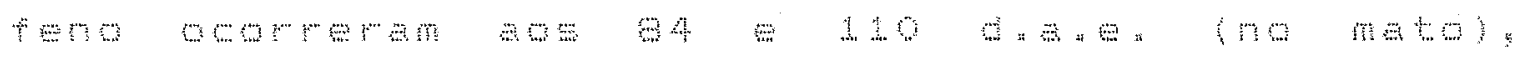
Men

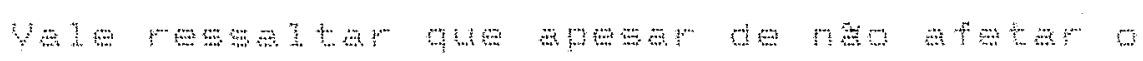

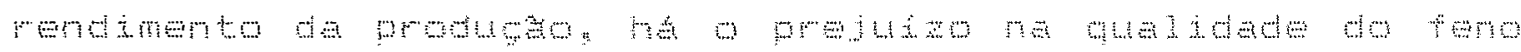

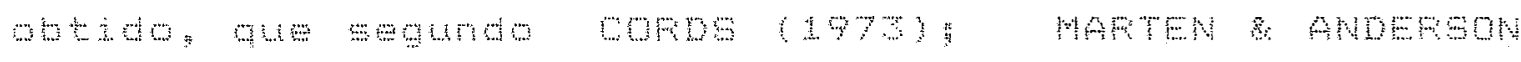
$(197$, , wUT अ

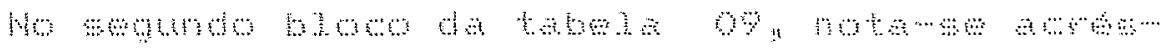

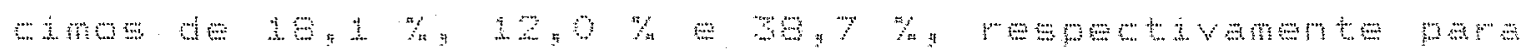

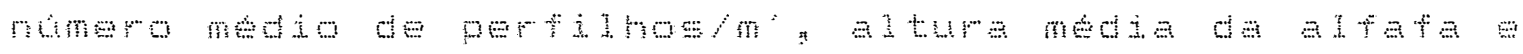
produmo de "reng quand

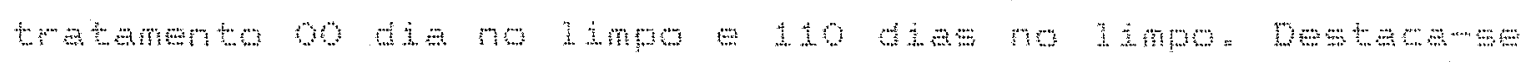

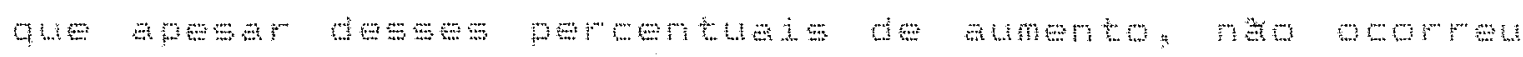

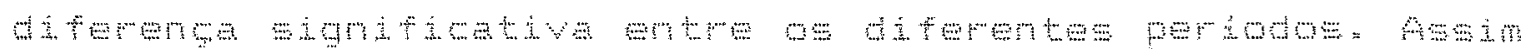




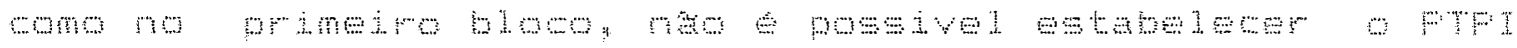

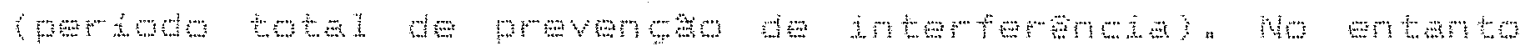

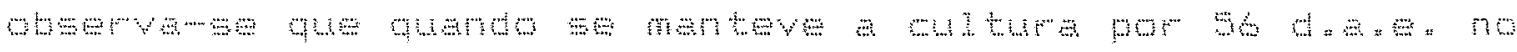

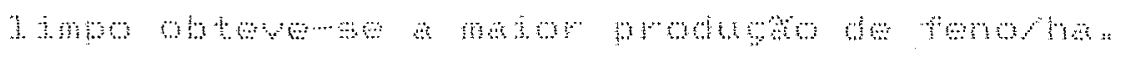

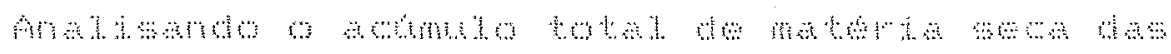

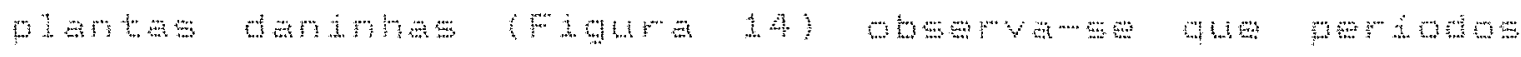

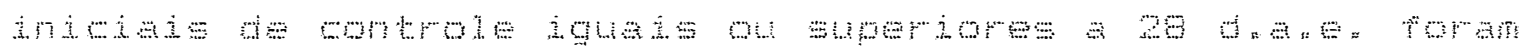

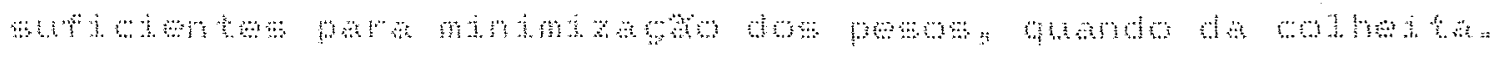

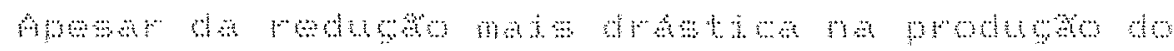

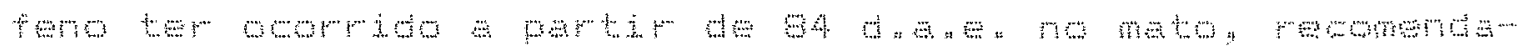

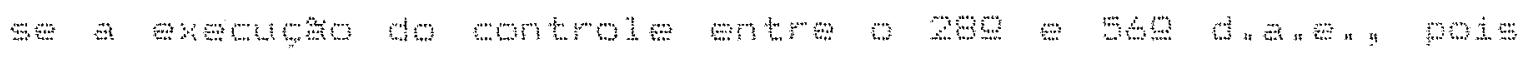

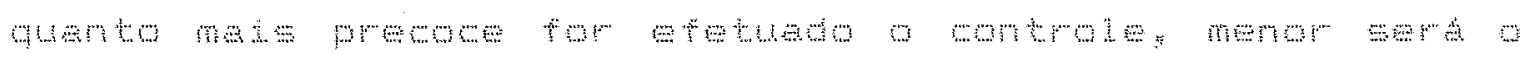

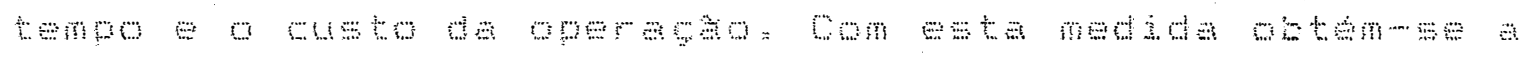

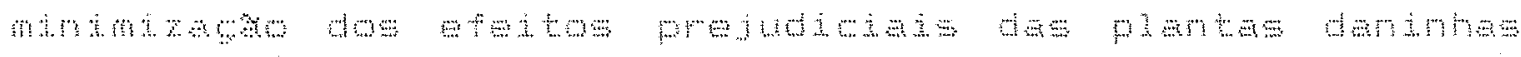

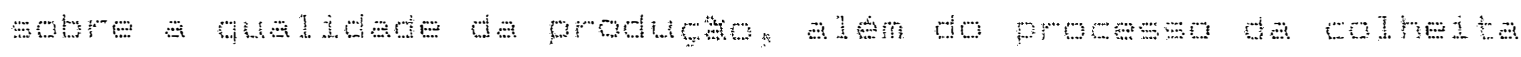

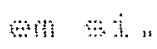

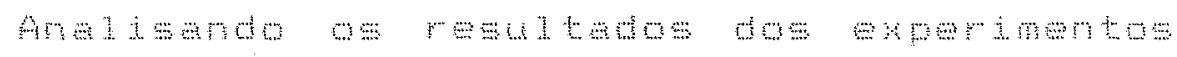

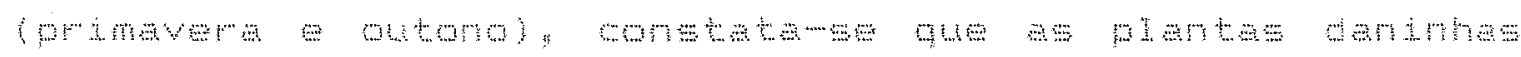

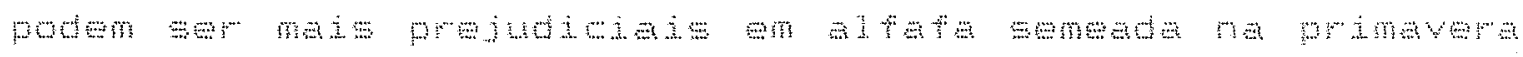

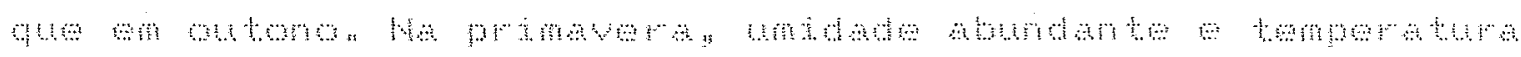

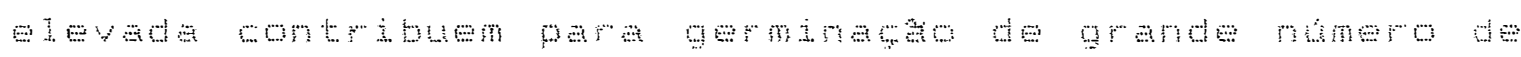

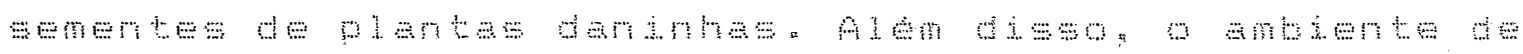

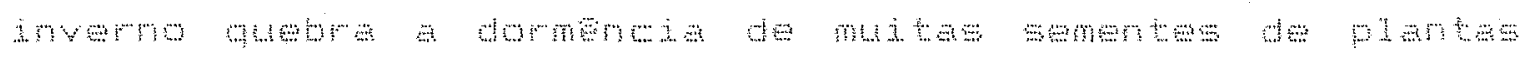

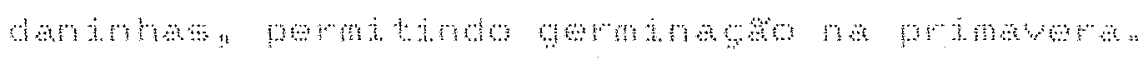

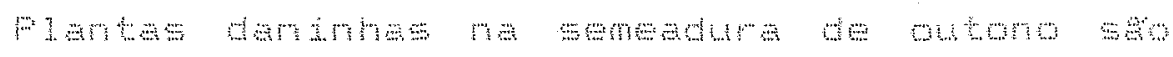

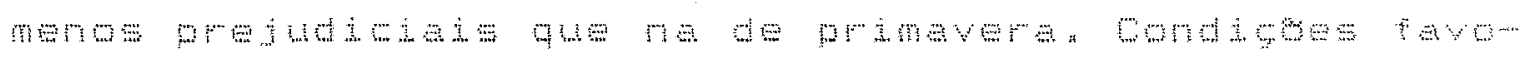


my 9w

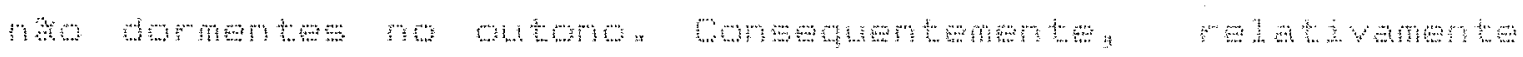

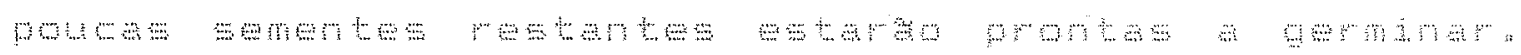

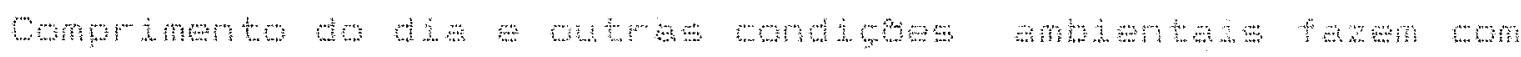

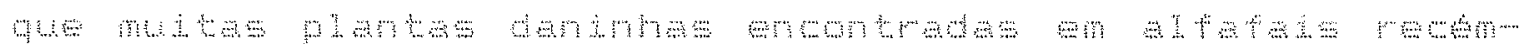

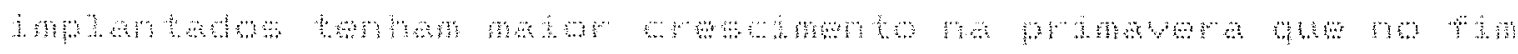

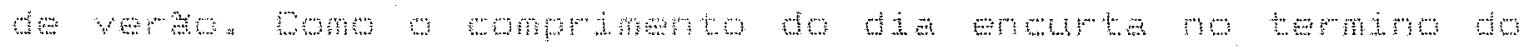
й

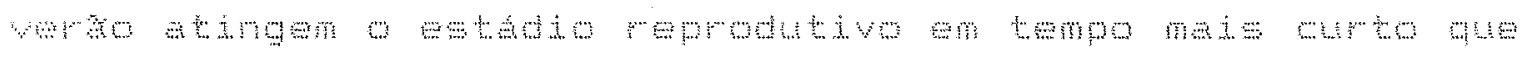

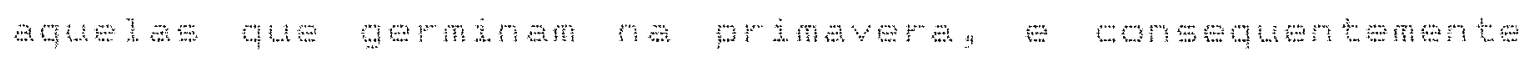

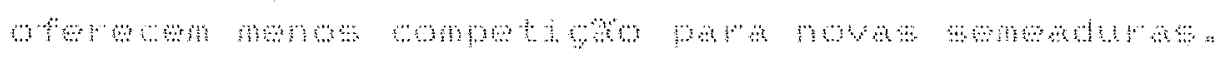




\section{5 . DONELUSCES}

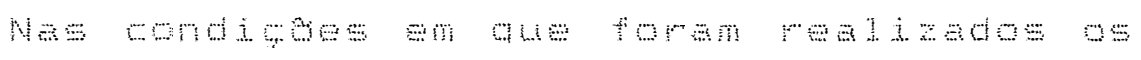

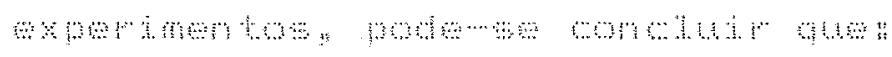

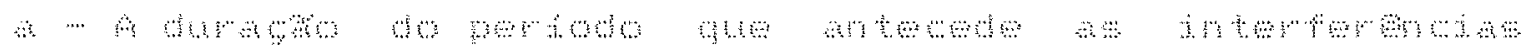

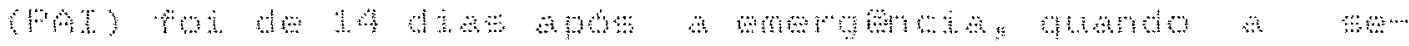

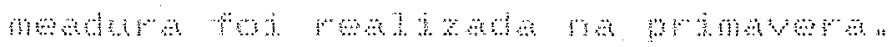

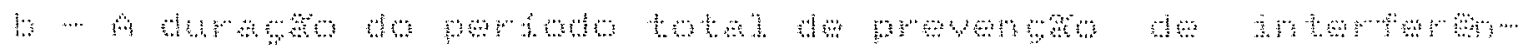

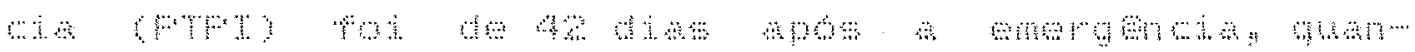

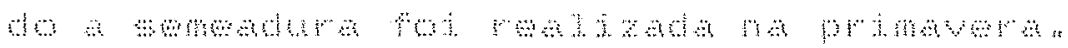

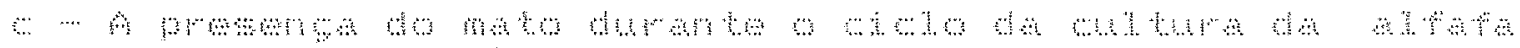

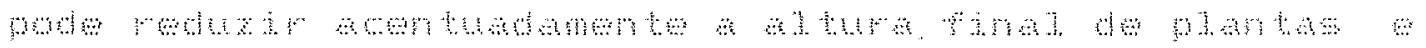

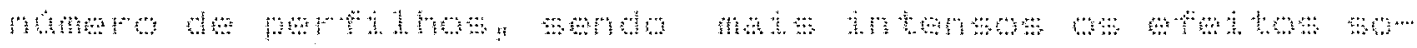

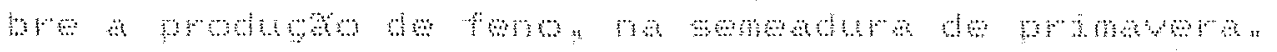




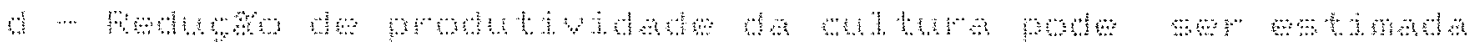
morm भम

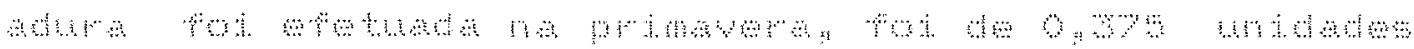

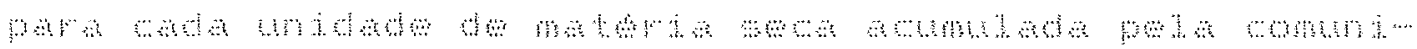
An

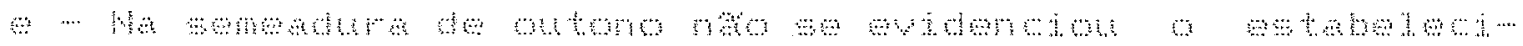

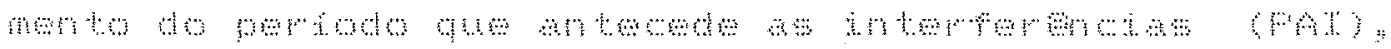

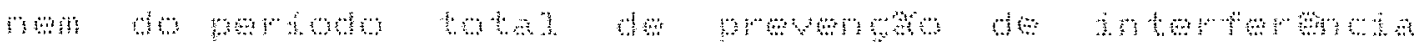
$(m+1)$

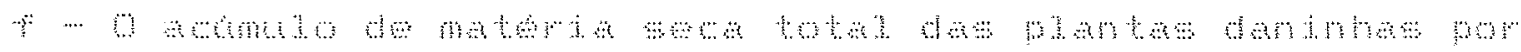
कв Mमn

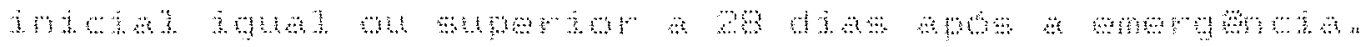




\section{$b$ FEFEFENEIAS EIDLLIOEFAF TCAS}

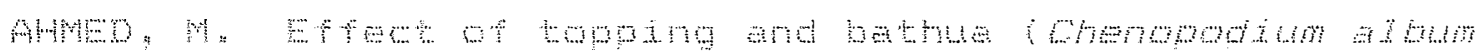

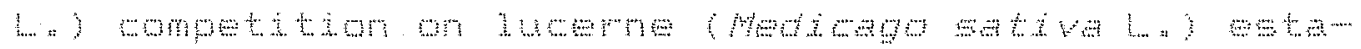

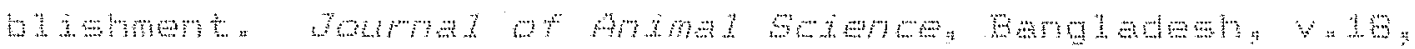

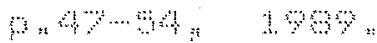

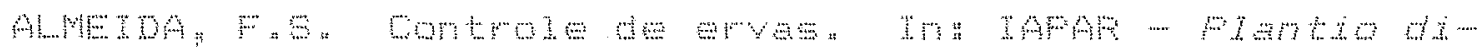

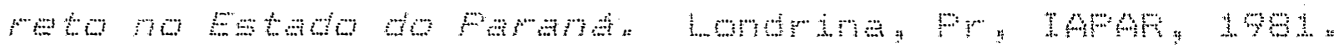

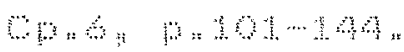

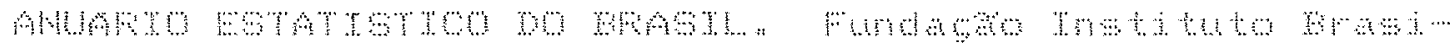

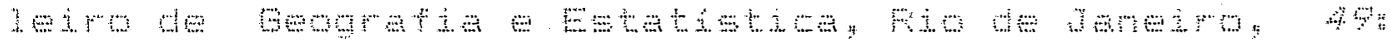
अ1. $19 \% \%$

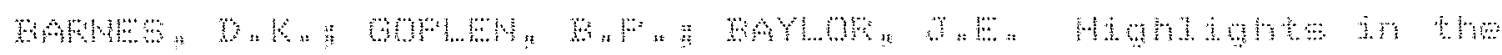

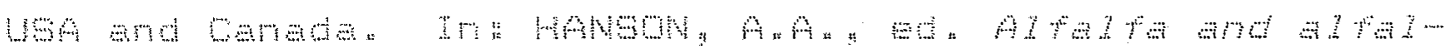

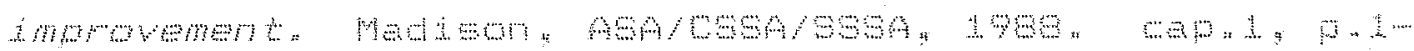


2

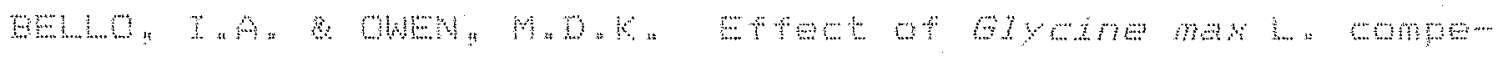

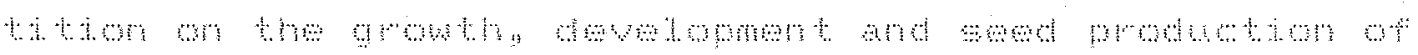

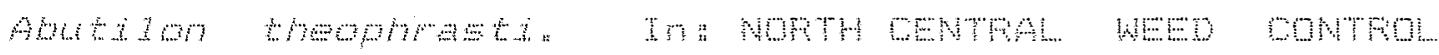

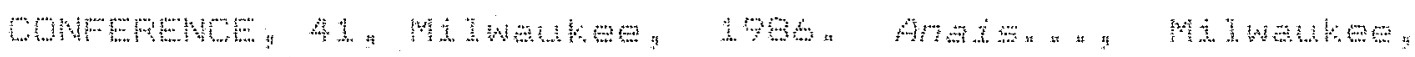

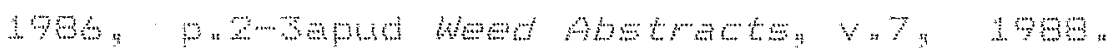

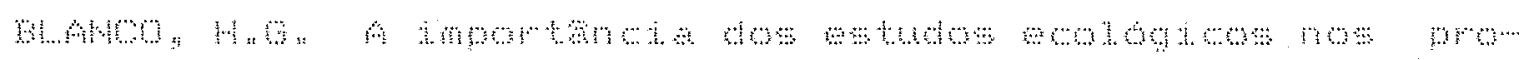

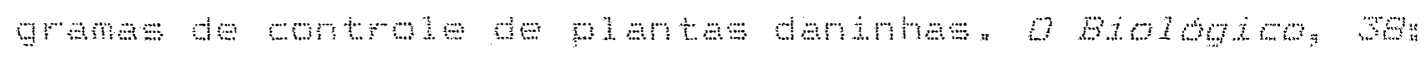
$349-390: 1 \% 2 \%$

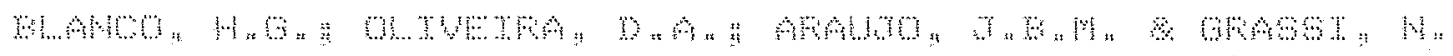

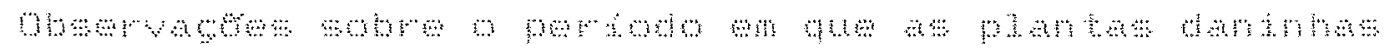
competw om a sor

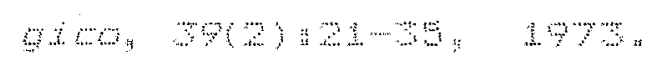

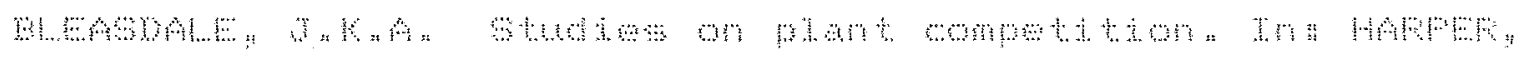

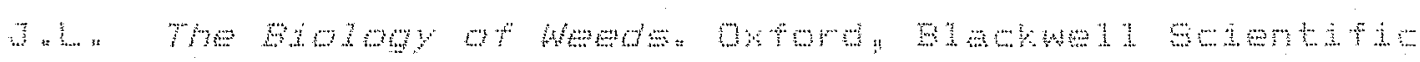

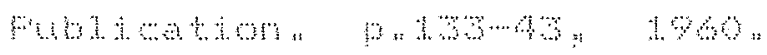

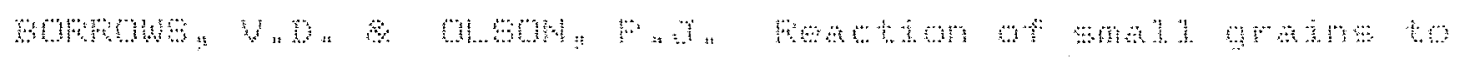
man dm

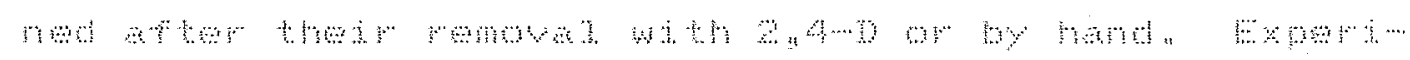

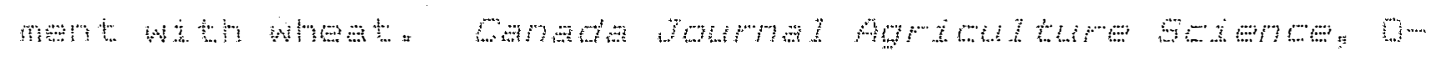
中tom 


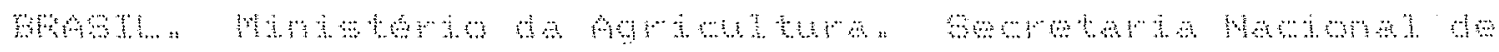

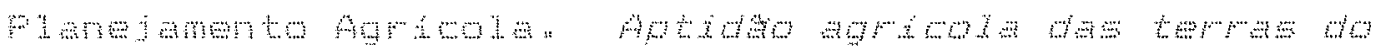

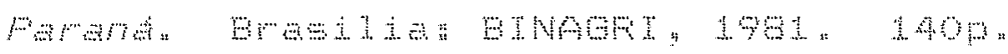

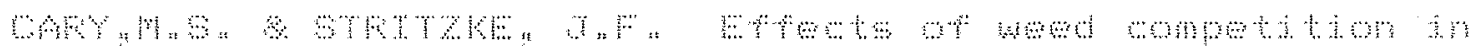

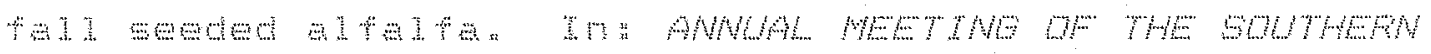
WEE SO

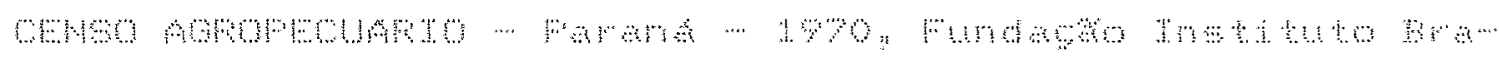

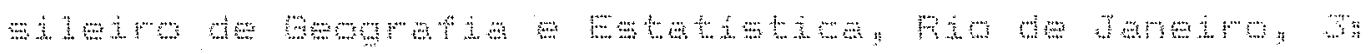
अ०: $19 \%:$

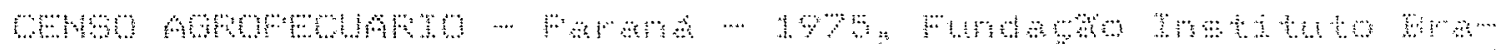

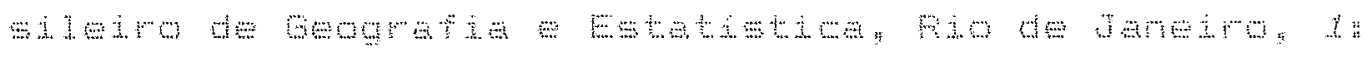
अव: $19 \%$,

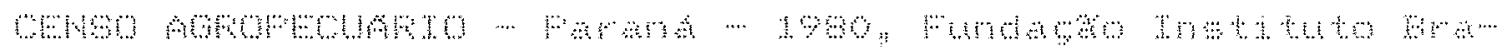

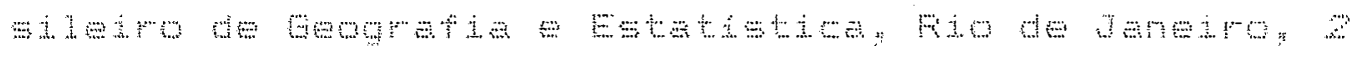
(20) $92,9-30,193 \%$

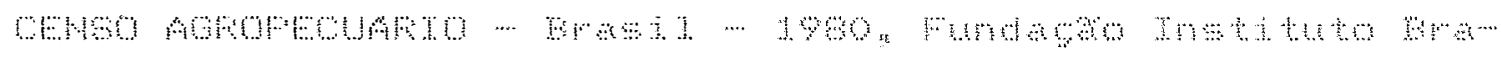

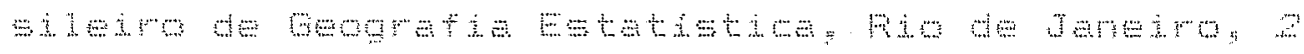
(1) $=41 \pm, \quad 196 \%$

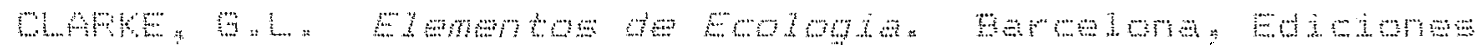




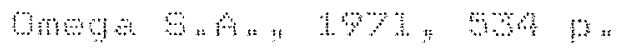

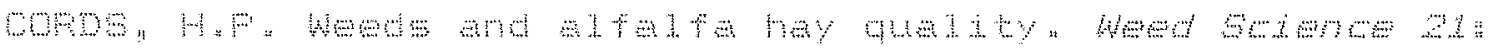
अ०क्षि: $1 \%$

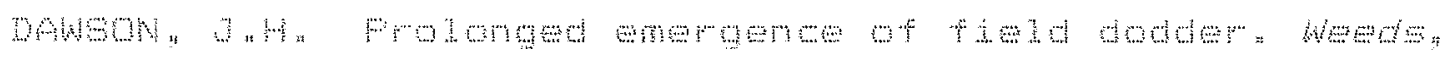

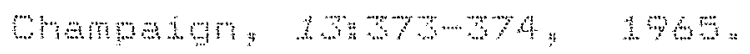

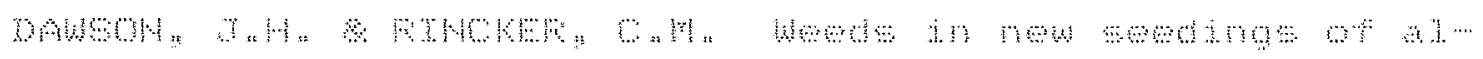

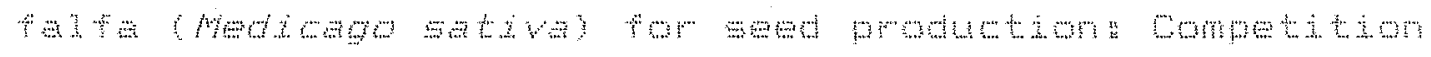

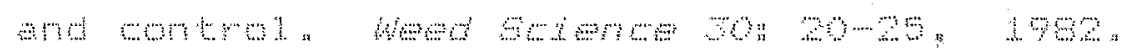

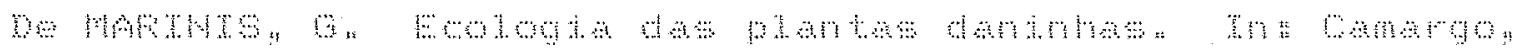

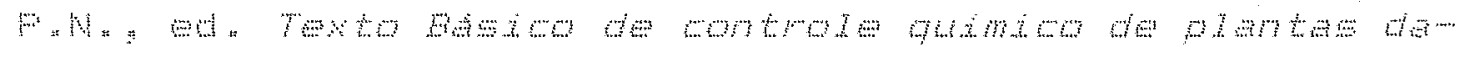
nimhas "

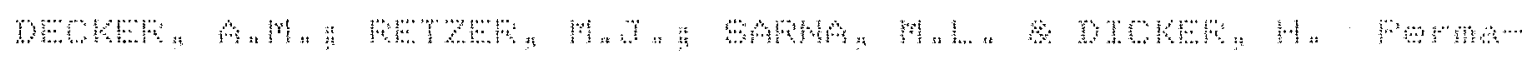

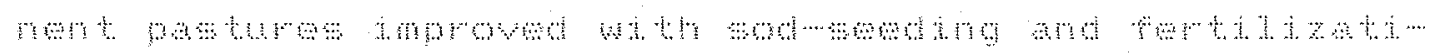

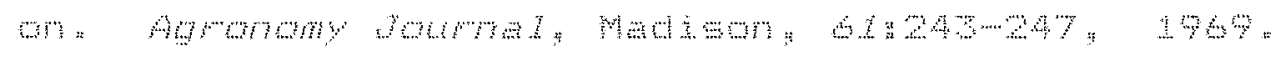

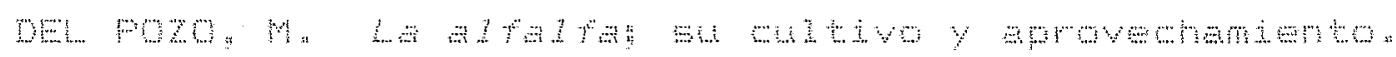

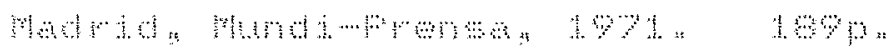

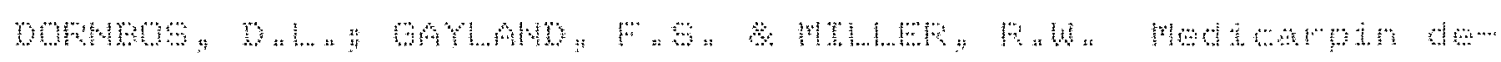

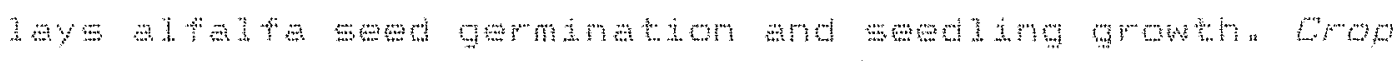

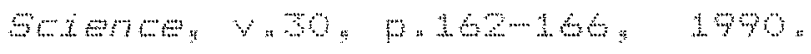




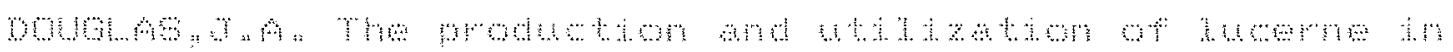

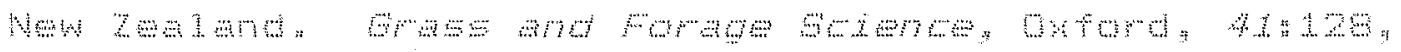
1926

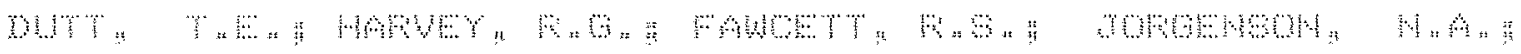

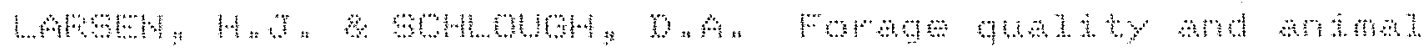

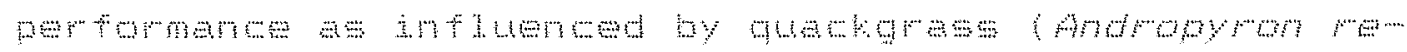

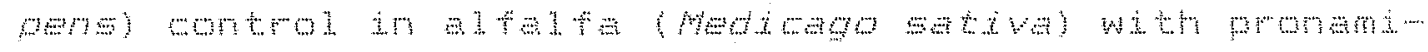

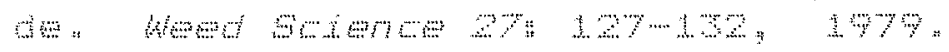

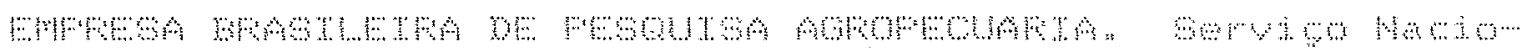

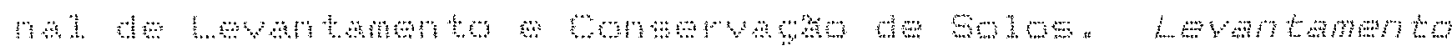

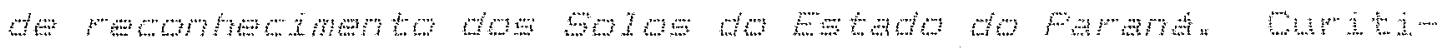

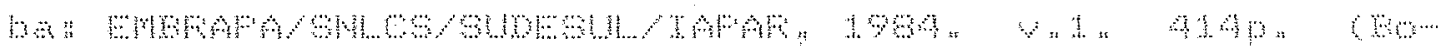
1.

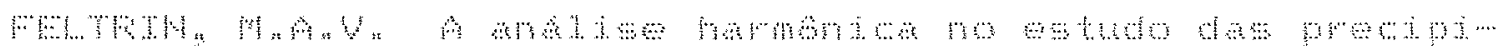

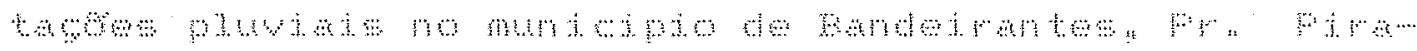
क.

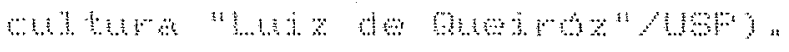

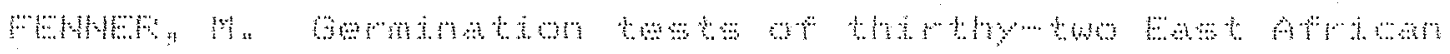

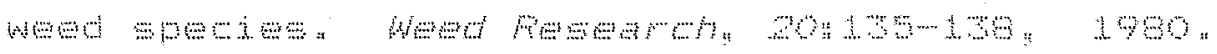




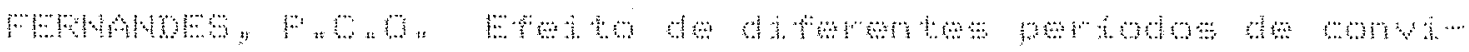

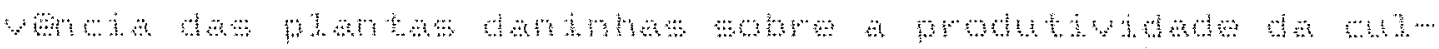

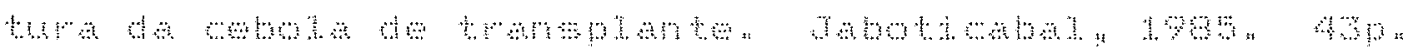

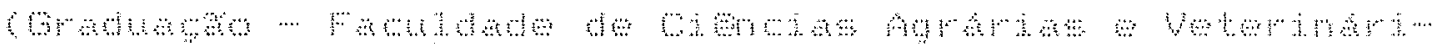
a

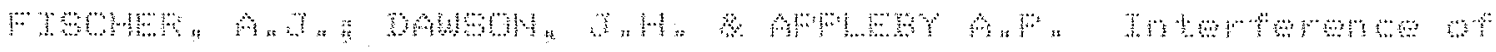

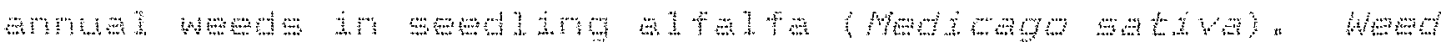

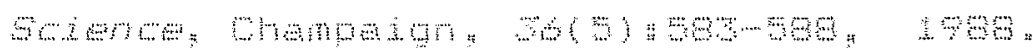

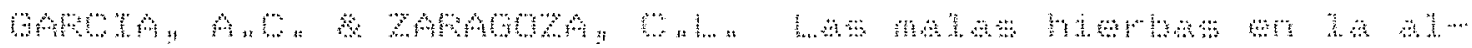

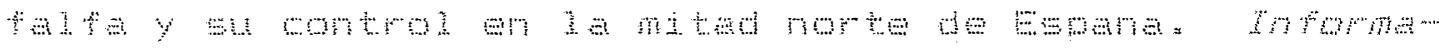

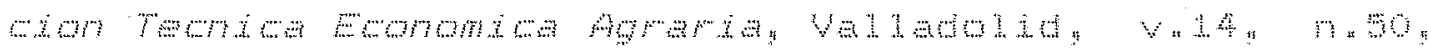
m.

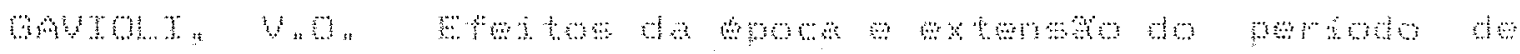

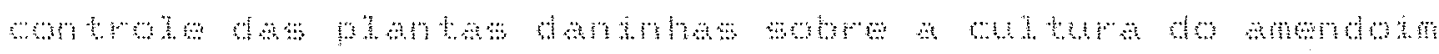

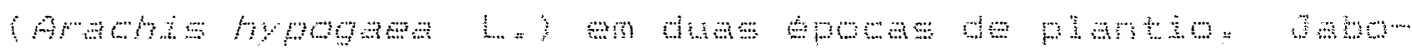

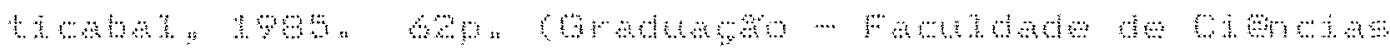

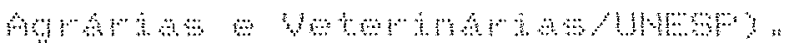

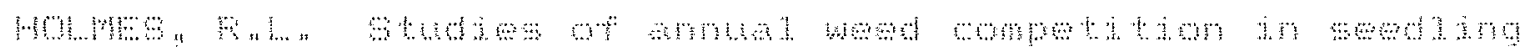

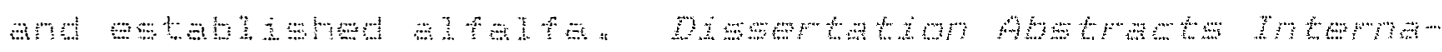

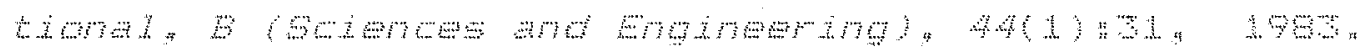




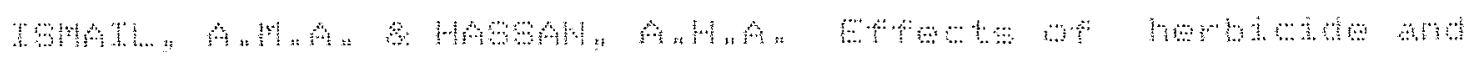

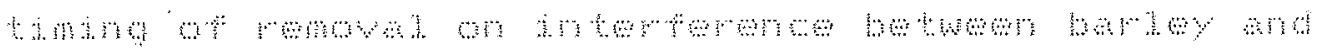

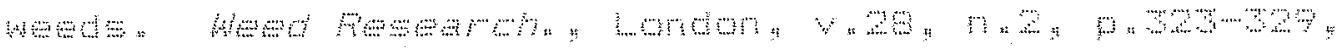
1\%०॥

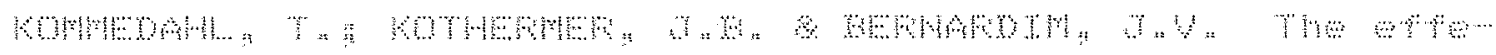

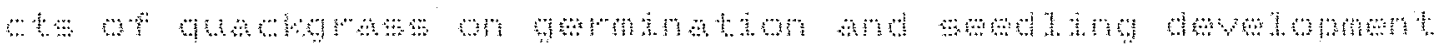

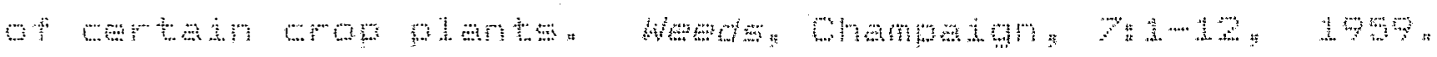

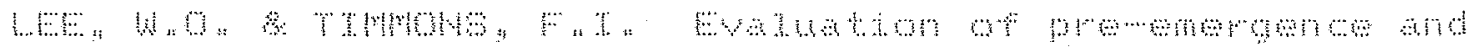

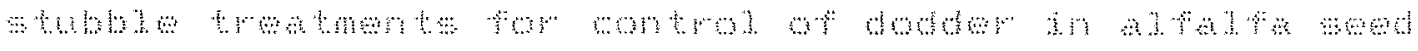

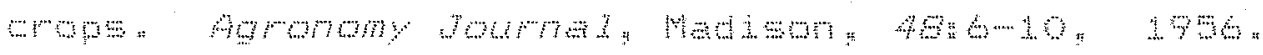

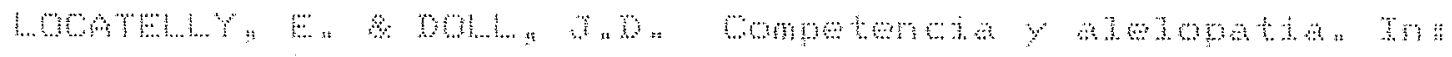

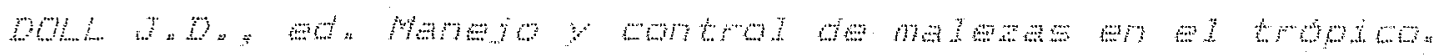

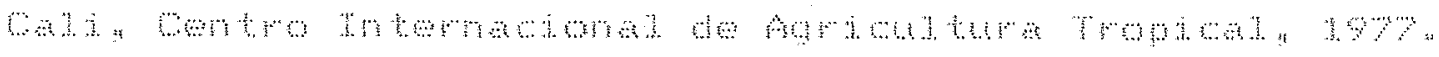

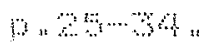

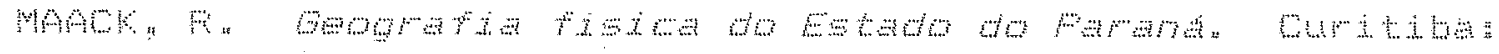

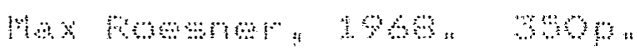

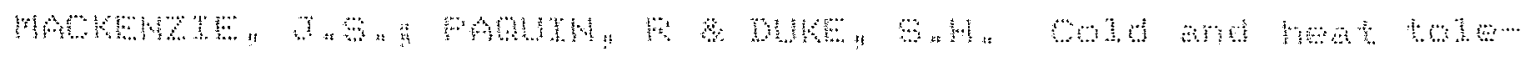

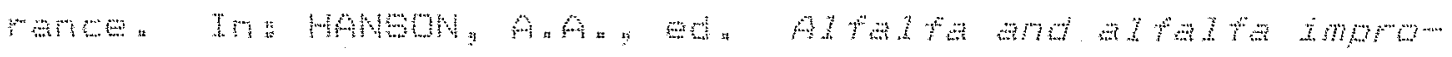

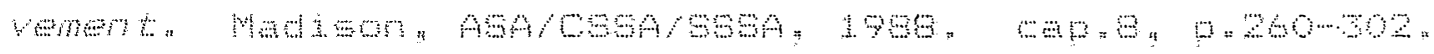




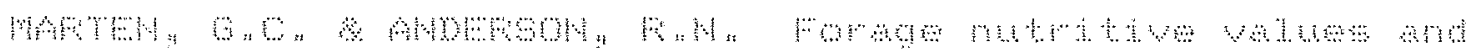

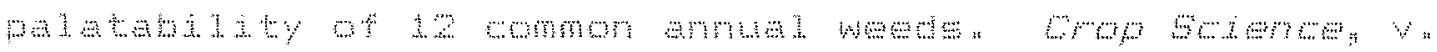
I.

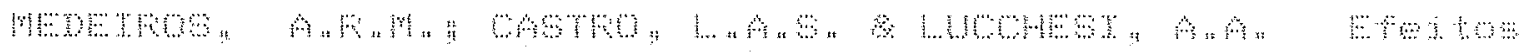

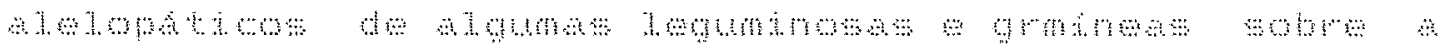

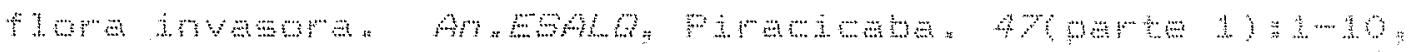
$1 \% \%$

MEMPAD,

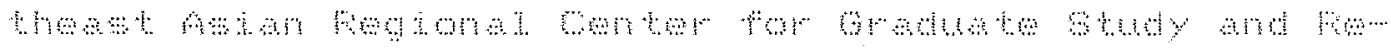
क्w

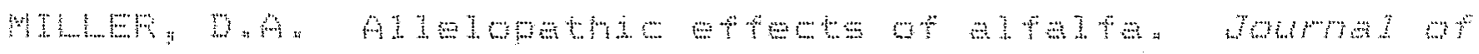

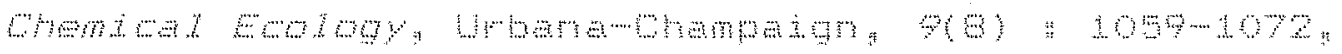
$49 \%$

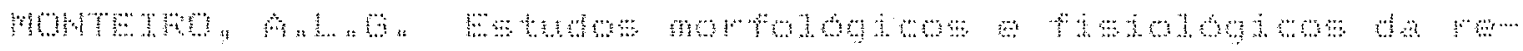

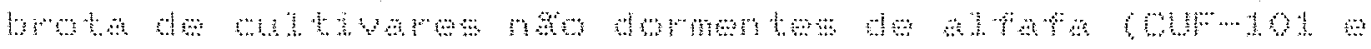

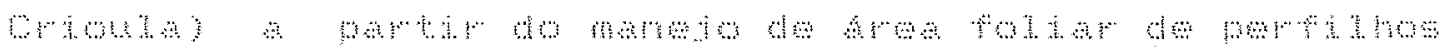
Mан

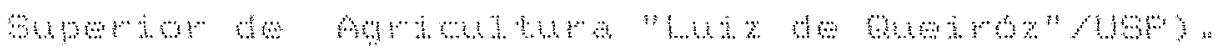

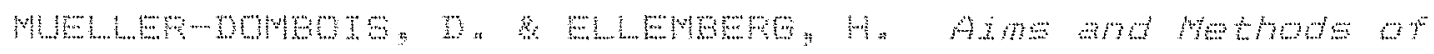

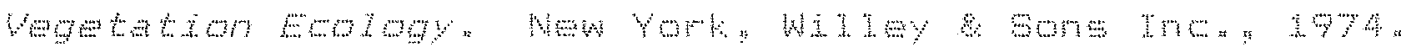
ing 


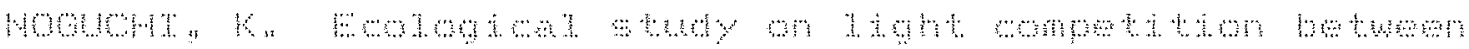

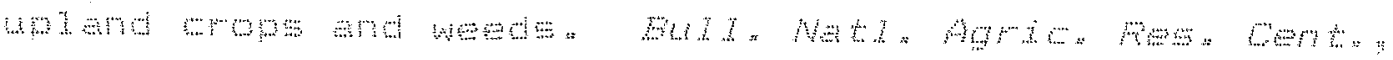

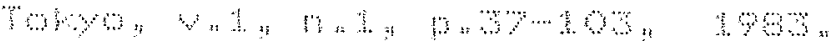

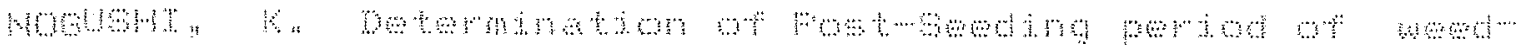

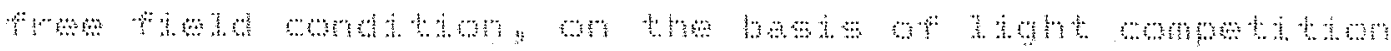

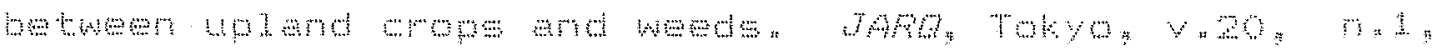
a $13+1 \%: 4 \%$

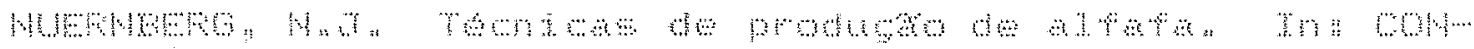

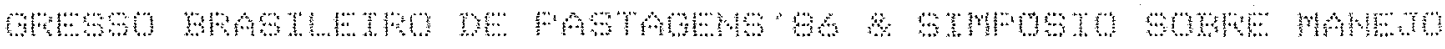

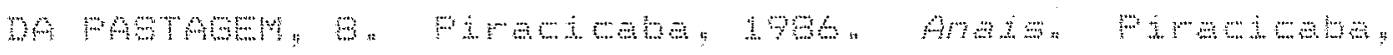

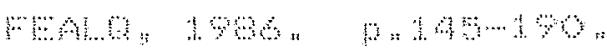

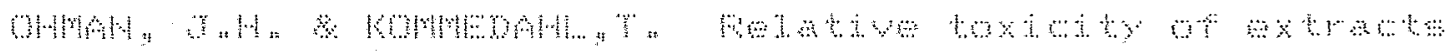

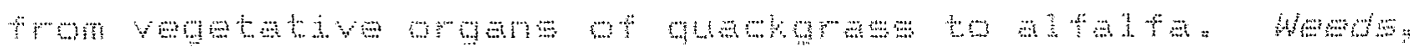
Omampanm "

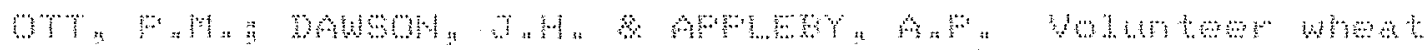

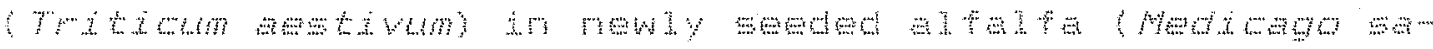
क. 


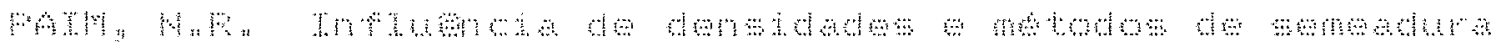

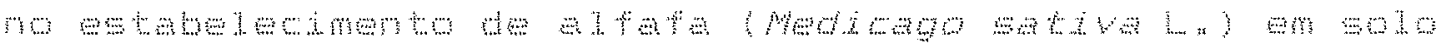
Aक

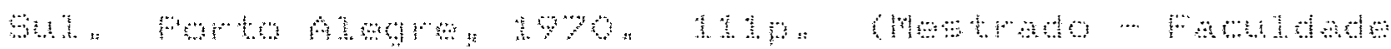
mom

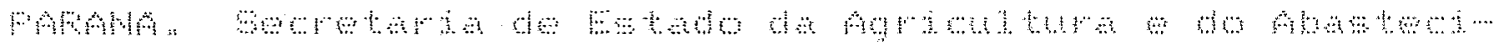

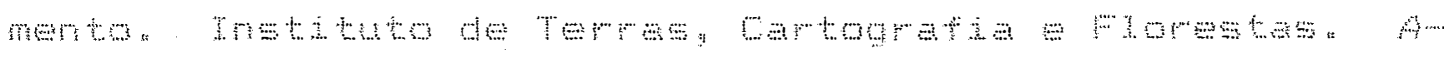
से

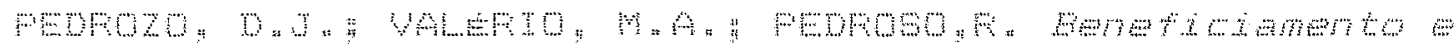

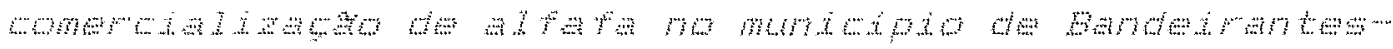

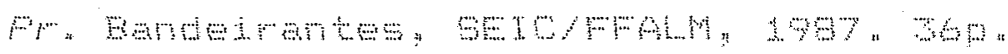

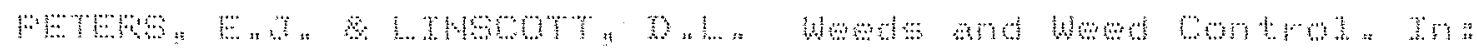

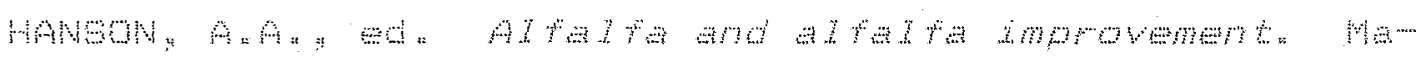

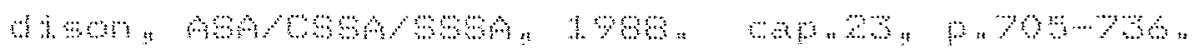

mam Hम

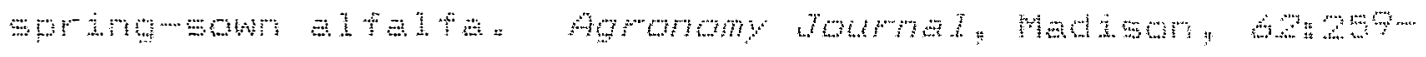

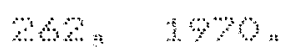




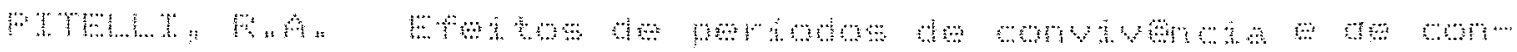

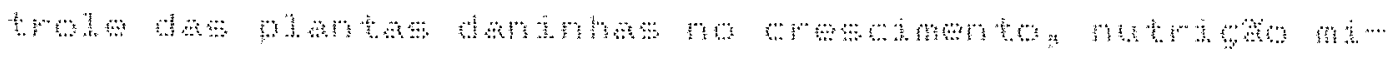

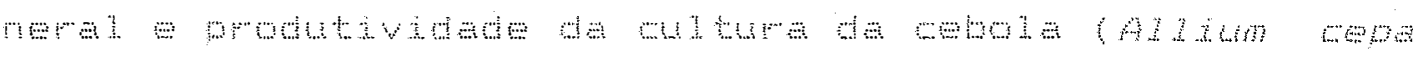

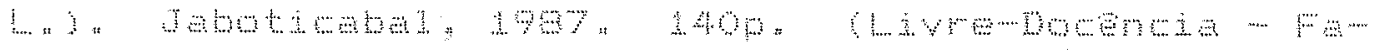

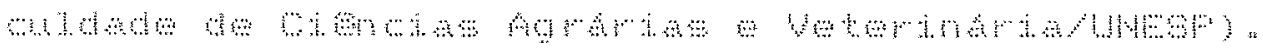

Hพm m: $196 \%$

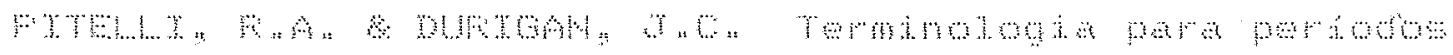

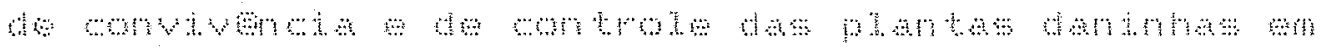

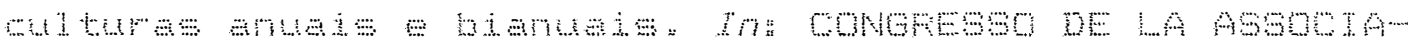

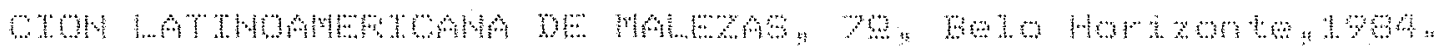
Fin:

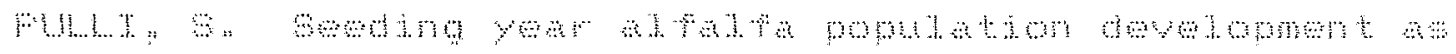

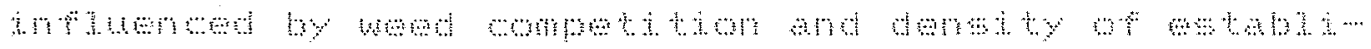

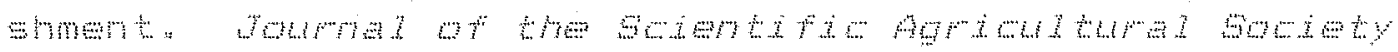

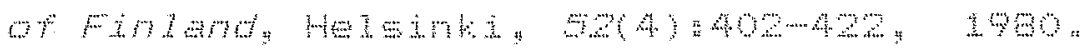

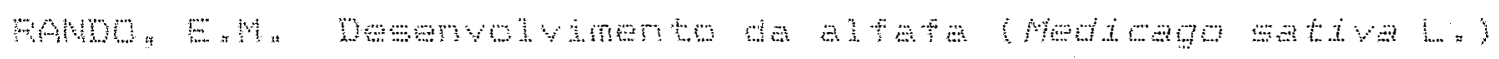

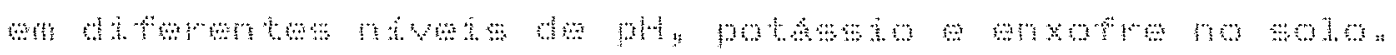

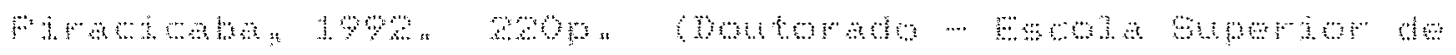
ham 


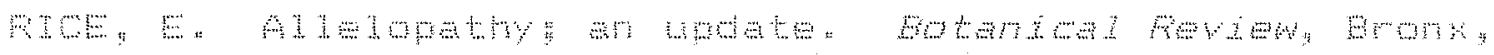

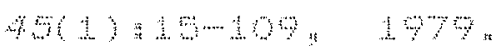

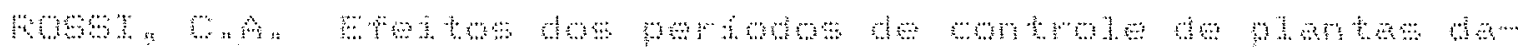

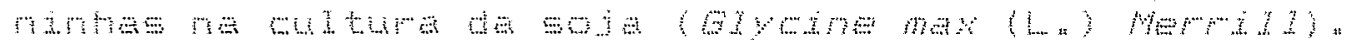

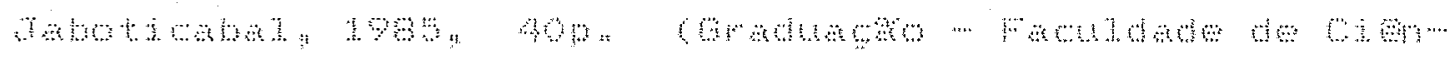

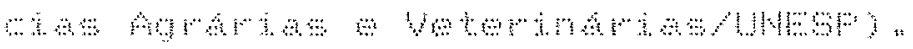

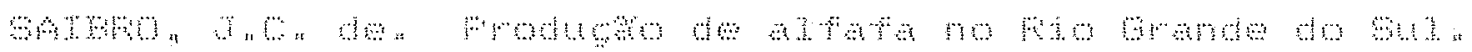

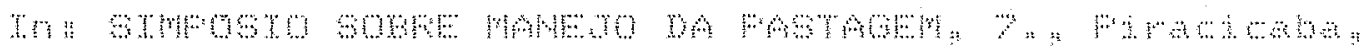

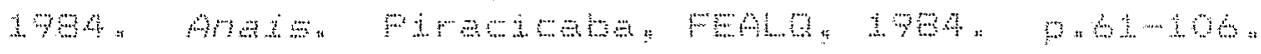

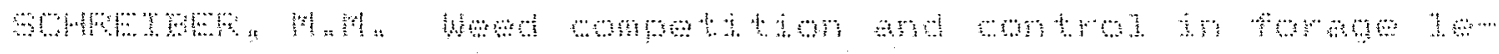

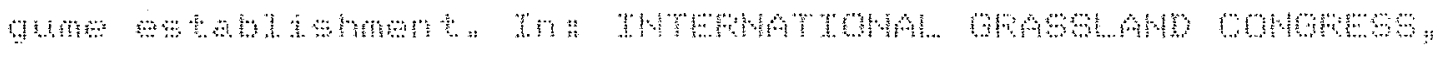

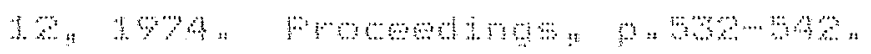

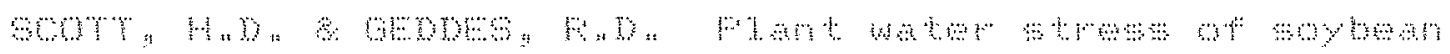
( oy whi : $273 \div 23 \%$ : $19 \%$

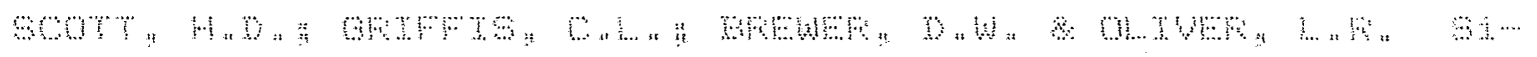

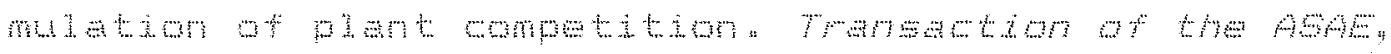

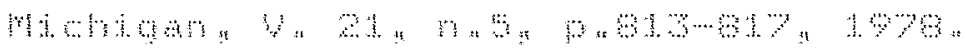




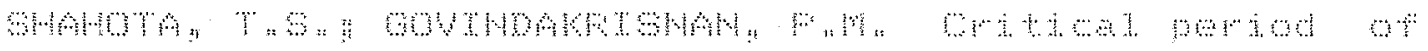

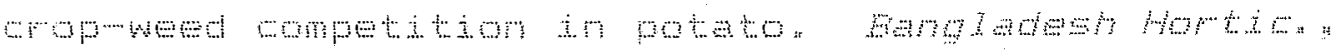

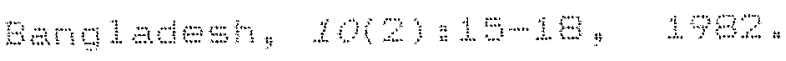

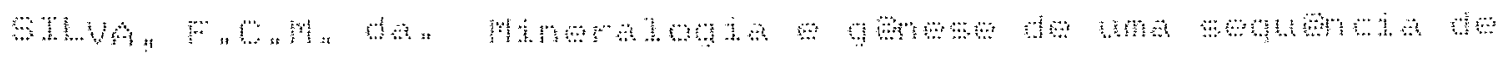

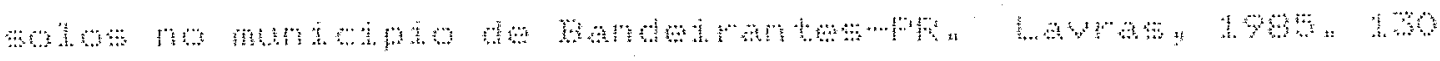

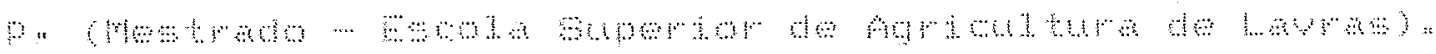

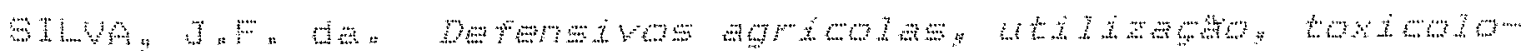

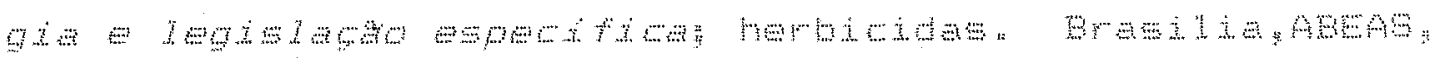
$190 \%, \quad 161 \mathrm{k}$

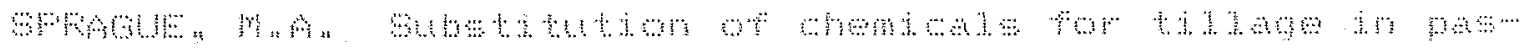

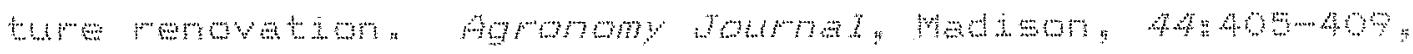
$1 \%$

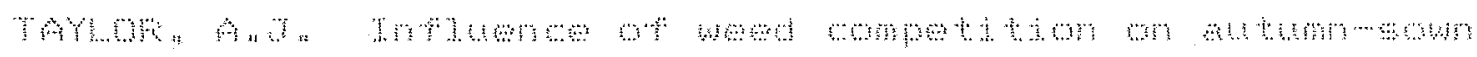

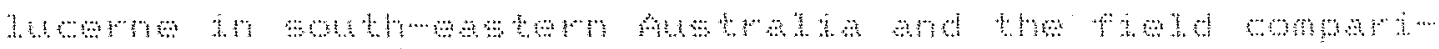

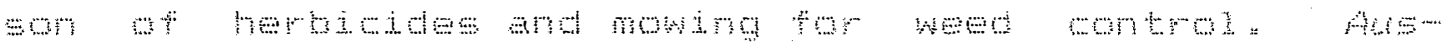

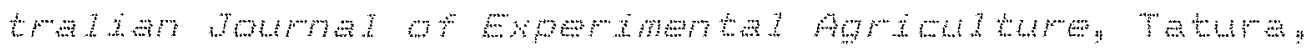

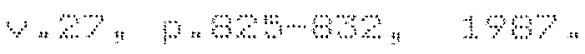

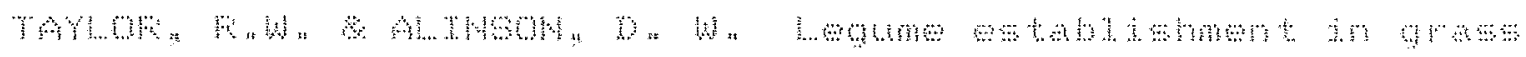

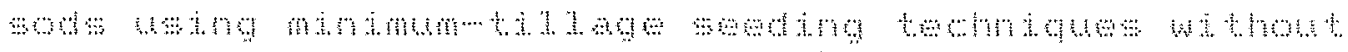

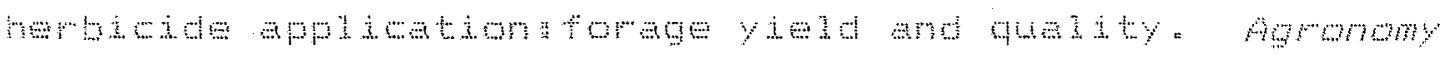
Momman Madsom, 7and 


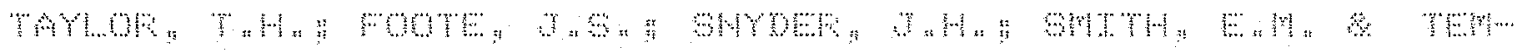

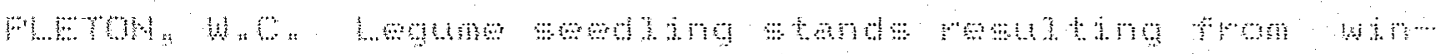

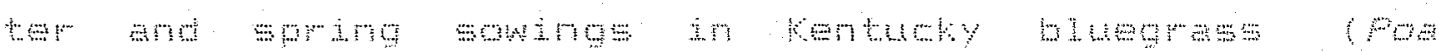
का $19 \%$

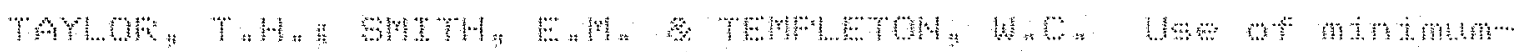

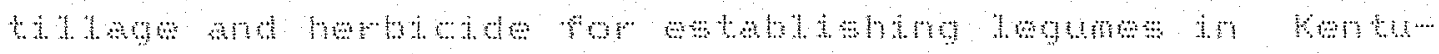

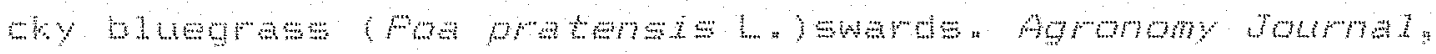
Matison, अ.

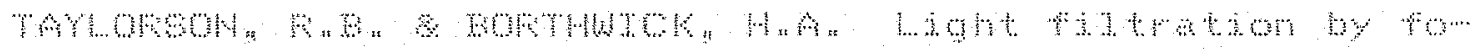

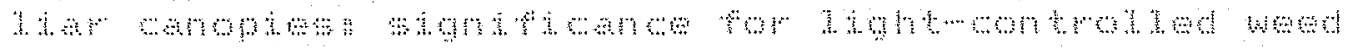

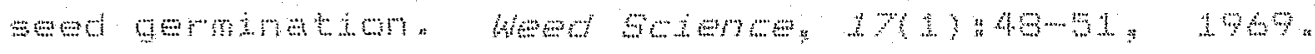

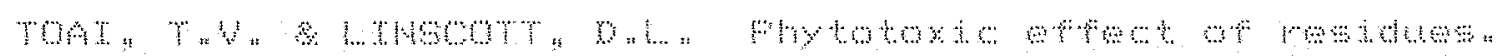

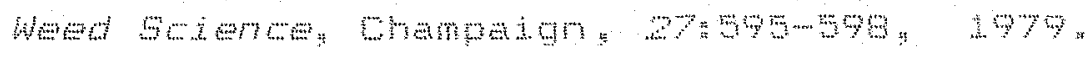

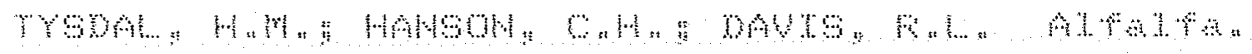

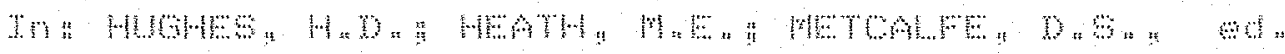

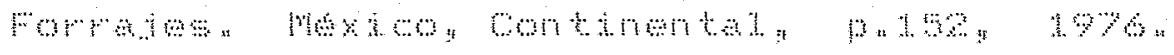

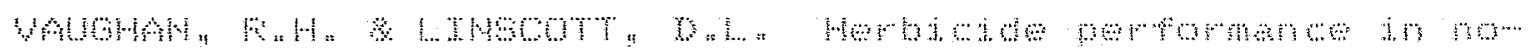

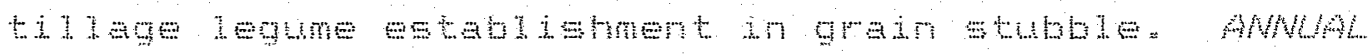

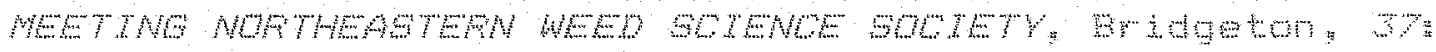
$\mathrm{Am}_{3}, 19 \%$ 


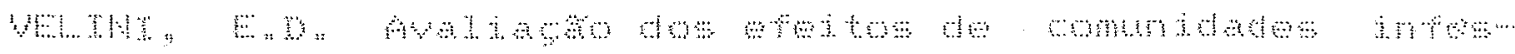

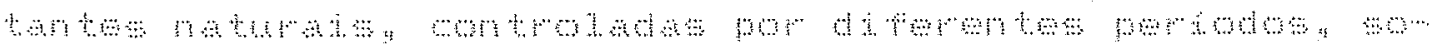

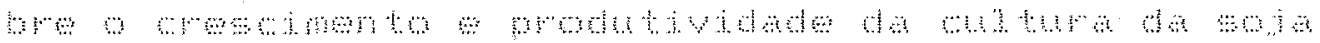

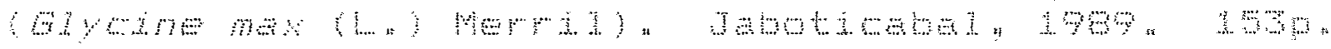

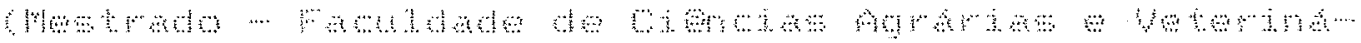
;.

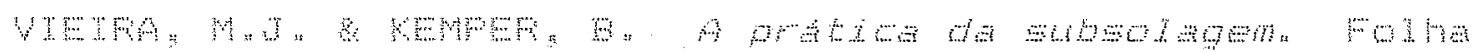
man Futan:

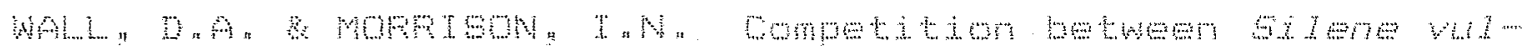

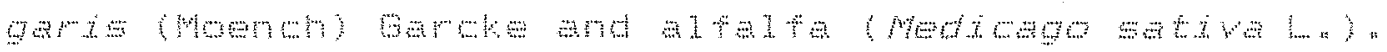

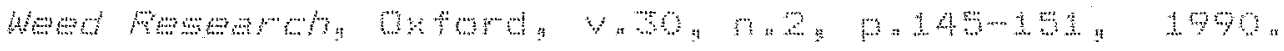

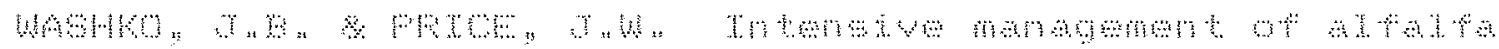

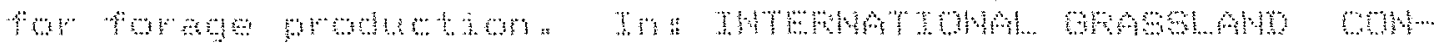

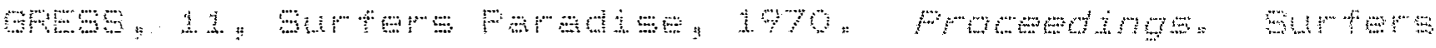

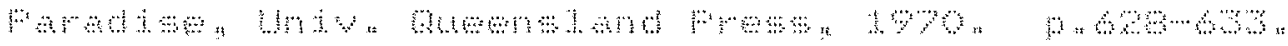

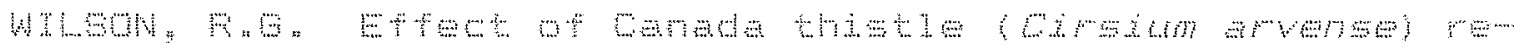
s.

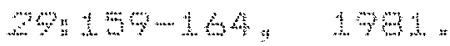

